\title{
Fluoreszenskorrelationsspektroskopie und Rasterkorrelationsmikroskopie molekularer Prozesse in Nervenzellen
}

\author{
Dissertation \\ zur Erlangung des Doktorgrades \\ der Mathematisch-Naturwissenschaftlichen Fakultäten \\ der Georg-August-Universität zu Göttingen
}

vorgelegt von

Arne Gennerich

aus Uslar

Göttingen,

November 2003 
Referent:

Korreferent:

Tag der mündlichen Prüfung:
Prof. Dr. W. Lauterborn

Prof. Dr. Dr. D. Schild

3. November 2003 


\section{Inhaltsverzeichnis}

1 Einleitung 1

2 Grundlagen der Fluoreszenzkorrelationsspektroskopie (FCS) 4

2.1 Theorie der FCS für offene Lösungssysteme . . . . . . . . . . . . . . . . 4

2.1.1 Teilchenstatistik in verdünnten Lösungen . . . . . . . . . . . 5

2.1.2 Korrelation von Konzentrationsfluktuationen . . . . . . . . . . . . 6

2.1.3 Monomolekulares System . . . . . . . . . . . . . . 7

2.1.4 Mischsystem ........................ 9

2.1.5 Triplettzustände . . . . . . . . . . . . . . . . 10

2.1.6 Unkorrelierte Störsignale . . . . . . . . . . . . . . . . . . . . 12

2.2 Prinzipieller Aufbau einer FCS-Apparatur . . . . . . . . . . . . . . . 13

3 Material und Methoden $\quad 15$



3.2 Elektrophysiologie . . . . . . . . . . . . . . . . . 15

3.3 Farbstoffe . . . . . . . . . . . . . . . . . . . 16

3.3.1 Tetramethylrhodamin $(\mathrm{TMR}) \ldots \ldots \ldots \ldots$

3.3 .2 TMR-Dextran . . . . . . . . . . . . . . . . 17

3.3.3 MitoTracker Orange . . . . . . . . . . . . . . . . . . 17

3.4 Antikörperfärbung von $\alpha$-Tubulin . . . . . . . . . . . . . . . . 18

3.5 FCS-Kalibrationsmessungen . . . . . . . . . . . . . . . . . . . . . . 18

3.6 Bildanalysen und Simulationen _. . . . . . . . . . . . . . . . 19 
4 Experimenteller Aufbau: Laserrastermikroskop und FCS-Apparatur 21

4.1 Übersicht . . . . . . . . . . . . . . . . . . . . . . . . . . 21

4.2 Anregungsstrahlengang . . . . . . . . . . . . . . . . . 23

4.3 Detektionsstrahlengang . . . . . . . . . . . . . . . . 25

4.4 Photonendetektion und -verarbeitung . . . . . . . . . . . . 25

4.4 Photodetektor . . . . . . . . . . . . . . . 25

4.4.2 Photon-Counting-Hardware $(\mathrm{PCH}) \ldots \ldots \ldots$

4.5 PCI-Controller . . . . . . . . . . . . . . . . . . . . . 30

4.6 Galvanometer-Scanner und Piezo-Translator . . . . . . . . . . . . . . . . . 31

4.7 DSP-Steuerung . . . . . . . . . . . . . . . . . . . . . . . . . . 32

4.8 Bilderzeugung und -verarbeitung . . . . . . . . . . . . . . . . . . 34

4.9 Echtzeitkorrelationsberechnung . . . . . . . . . . . . . . . . . . 38

5 Passiver Molekültransport in Neuronen $\quad 39$

5.1 Intrazelluläre FCS . . . . . . . . . . . . . . . . . . . . . . . . . . . . . . 39

5.1.1 FCS-Modell für räumlich begrenzte Diffusion . . . . . . . . . . . . . 40

$5.1 .2 \quad$ FCS-Modelle für anisotrope Diffusion . . . . . . . . . . . . . . . . . 41

5.1.3 Berücksichtigung autofluoreszierender Moleküle . . . . . . . . . . . 41

5.2 Bestimmung des Diffusionsraums . . . . . . . . . . . . . . . . . . 42

5.3 Zeitkonstanten dendritischer Diffusion von TMR-Dextran . . . . . . . . . . 46

5.4 Diffusion in Somata . . . . . . . . . . . . . . . . . . . . . . 51

5.5 Detektion autofluoreszierender Partikel . . . . . . . . . . . . . . . 54

5.6 Anisotrope dendritische Diffusion . . . . . . . . . . . . . . 55

5.7 Wechselwirkung zellulärer Elemente mit TMR-Dextran . . . . . . . . . . 60

5.8 Diffusion in dicken Dendriten . . . . . . . . . . . . . . . . . . 60

6 Aktiver Transport von Mitochondrien in Dendriten $\quad 64$

6.1 Lokalisierung und Größenbestimmung fluoreszierender Objekte . . . . . . . 64

6.1.1 Häufig verwendete "Tracking“-Algorithmen . . . . . . . . . . . . . . 64

6.1 .2 Faltungsproduktanalyse (FPA) . . . . . . . . . . 66

6.1.3 Korrelationsanalyse $(\mathrm{KA}) \ldots \ldots \ldots$. . . . . . . . . . 74

6.1.4 Definition: Lokalisationsgenauigkeit und Signal-Rausch-Verhältnis . 82 
6.1.5 Vergleich der Faltungsprodukt- und Korrelationsanalyse . . . . . . . 83

6.2 Hochauflösende Lokalisierung von Ecoli-Bakterien in vitro . . . . . . . . . 91

6.3 Verfolgung von Mitochondrien in vivo . . . . . . . . . . . . . . 95

6.3.1 Visualisierung von Mitochondrien . . . . . . . . . . . . . 95

6.3.2 Trajektorien aktiv transportierter Mitochondrien . . . . . . . . 96

6.3.3 Simulation bewegter Mitochondrien . . . . . . . . . . . . 105

6.3.4 Statistische Analyse der Größenfluktuationen von Mitochondrien . . 111

6.3.5 Interpretation der Messergebnisse . . . . . . . . . . . . . . . . 116

$\begin{array}{lll}7 & \text { Zusammenfassung und Ausblick } & 119\end{array}$

$\begin{array}{ll}\text { A Schaltungsbeschreibung der PCH } & 122\end{array}$

$\begin{array}{ll}\text { Abkürzungsverzeichnis } & 124\end{array}$

$\begin{array}{ll}\text { Literaturverzeichnis } & 125\end{array}$

$\begin{array}{ll}\text { Liste der Veröffentlichungen } & 133\end{array}$ 


\section{Kapitel 1}

\section{Einleitung}

Eine Nervenzelle besteht aus vielen unterschiedlichen Kompartimenten, die sich durch ihre strukturellen Eigenschaften und ihre molekularen Aktivitäten unterscheiden. Der Transport von Molekülen und Organellen zwischen diesen zellulären Regionen - mit Hilfe passiver Diffusion oder molekularer Motoren - ist grundlegend für viele zelluläre Prozesse. Ob ein spezifisches Molekül innerhalb einer Zelle diffundiert oder aktiv transportiert wird, mit welchen Geschwindigkeiten und molekularen Mechanismen der Transport erfolgt und wo in der Zelle unterschiedliche Formen des Transports vorkommen, ist wichtig für das Verständnis der molekularen Prozesse in sowie der Interaktionen zwischen den zellulären Regionen [1]. Die Mobilität von kleinen Molekülen bis hin zu Makromolekülen innerhalb des Zytoplasmas ist von Bedeutung für Stoffwechsel, Wachstum und Fortbewegung einer Zelle. Bislang gibt es keine quantitativen Untersuchungen über submikroskopische passive Transportprozesse von Proteinen in kleinen zytosolischen Kompartimenten von Nervenzellen. Ziel des ersten Teils dieser Arbeit ist deshalb, die intrazelluläre Mobilität eines 10 kDa Dextrans, also eines Moleküls von der Größe eines kleinen Proteins [2], auf einer submikroskopischen Skala zu untersuchen. Es handelt sich um ein mit Tetramethylrhodamin (TMR) markiertes, neutrales und hydrophiles Molekül. Es stehen die Fragen im Mittelpunkt, ob sich die Mobilität des TMR-Dextrans innerhalb der Somata und der Dendriten von kultivierten Neuronen unterscheidet und inwieweit sie von der normalen BRownschen Diffusion in wässriger Lösung abweicht. Die Untersuchungen sollen zeigen, ob und evtl. wie das intrazelluläre Milieu die Diffusion von Molekülen innerhalb verschiedener zellulärer Regionen beeinflusst. Dafür braucht man Messmethoden, die zum einen zelluläre Strukturen visualisieren, zum anderen eine geringe Anzahl von spezifisch markierten Molekülen innerhalb eines kleinen zytosolischen Kompartimentes detektieren sowie schnelle und langsame Prozesse untersuchen und zwischen aktivem Transport und Diffusion unterscheiden können. Die Laserrastermikroskopie (LSM) kombiniert mit der Fluoreszenzkorrelationsspektroskopie (FCS) [1,3] erfüllt diese Anforderungen. Das Ziel ist, ein hochsensitives LSM-Gerät aufbauend auf einer FCS-Apparatur - zu konstruieren und LSM-basierte Methoden und FCS-Algorithmen zu entwickeln, die hochpräzise Messungen von Moleküldynamiken innerhalb von zellulären Kompartimenten ermöglichen. 
Neben der passiven Diffusion von Signalmolekülen und Proteinen spielt der selektive aktive Transport von Zellbestandteilen eine wesentliche Rolle für die Funktion einer Nervenzelle und die Kommunikation zwischen Zellen. Die funktionellen und biochemischen Unterschiede zwischen Axonen und Dendriten von Neuronen sind zum großen Teil eine Folge des selektiven Transports von messenger-RNA (mRNA), Vesikeln und Organellen. Der axonale und dendritische Organellentransport erfolgt entlang von Mikrotubuli und Aktinfilamenten [4-7]. Der mit Abstand größte Teil des axonalen und dendritischen Organellentransports über große Distanzen basiert auf den molekularen Motorproteinen Kinesin und zytoplasmatischem Dynein, die Organellen und Vesikel unter Verbrauch von Adenosin5'-Triphosphat (ATP) entlang von Mikrotubuli „tragen“ [8-10] - Kinesin in Richtung der Synapse und zytoplasmatisches Dynein in Richtung des Zellkörper. Obwohl die Eigenschaften einzelner Motorproteine in vitro eingehend untersucht wurden [11-17], ist nur wenig darüber bekannt, wie Motorproteine in vivo, also in lebenden Zellen, reguliert werden und wie die Koordination der gegenläufigen Motorproteine Kinesin und Dynein abläuft. Viele Organellen wechseln während des Transports anscheinend spontan die Richtung. Es ist nicht bekannt, wie wichtig die Interaktion zwischen den gegenläufigen Motoren bei der Richtungsumkehr ist. Für die koordinierte Aktivität der Motoren spricht, dass Zellen „darauf bedacht sind“, Energie effizient einzusetzen. Aber auch ein „Tauziehen“ (,tug of war") zwischen den gegenläufigen Motoren ist denkbar [18]. Um dieser Fragestellung nachzugehen, muss man aktive Transportprozesse in lebenden Zellen analysieren. Die ersten Forschungsergebnisse zeigen, dass sowohl der Dynein-Transport als auch der Kinesin-Transport vom Protein Dynaktin [19] abhängen und von ihm reguliert werden können [18, 20,21]. Der intrazelluläre bi-direktionale Transport ist somit von „Co-Faktoren" abhängig.

Die meisten gegenwärtigen Forschungsarbeiten basieren auf der Beobachtung mittlerer Bewegungen von Organellen mit Lokalisierungsgenauigkeiten im Bereich der Lichtwellenlänge (siehe z.B., [6,22-24]). Untersuchungen über den submikroskopischen aktiven dendritischen Transport von Organellen in Neuronen, die sowohl Bewegung als auch Form- und Größenveränderungen der Organellen berücksichtigen, gibt es bisher nicht. Der Hauptgrund hierfür ist sicherlich, dass keine Methoden zur Verfügung stehen, mit denen Bewegung, Form und Größe von Organellen in lebenden Zellen mit einer Genauigkeit bis zu wenigen Nanometern untersucht werden können. Ziel des zweiten Teils der Arbeit ist deshalb, experimentelle Methoden und Algorithmen zu entwickeln, mit denen man Größenveränderungen und Bewegungen von Organellen mit einer Genauigkeit bis weit unter der Auflösungsgrenze des Mikroskops analysieren kann. Diese Algorithmen dienen als Grundlage für die Untersuchung des submikroskopischen dendritischen Transports von Mitochondrien in kultivierten Neuronen. Experimente und Simulationen ermöglichen dabei, die Genauigkeit der Algorithmen in Abhängigkeit des Signal-Rausch-Verhältnis (SNR) in den Fluoreszenzbildern quantitativ zu vergleichen. 
Die hier dargestellten Arbeiten haben folgende Ziele:

1. Weiterentwicklung eines FCS-Gerätes zu einer hochsensitiven computergesteuerten Apparatur, die alle Eigenschaften der FCS und der konfokalen Laserrastermikroskopie (CLSM) besitzt.

2. Entwicklung von Algorithmen zur CLSM-basierten Größen- und Formbestimmung von zellulären Kompartimenten.

3. Herleitung eines FCS-Modells für Messungen von Moleküldynamiken in kleinen zytosolischen Kompartimenten.

4. FCS-Messungen in Dendriten und Somata von Neuronen aus dem Bulbus Olfactorius von Xenopus laevis Larven.

5. Herleitung von Computeralgorithmen zur Analyse von Position, Orientierung, Form und Größe von fluoreszierenden Organellen in LSM-Bildern, basierend auf der Faltungsprodukt- (FPA) und Korrelationsanalyse (KA) von Fluoreszenzbildern.

6. Quantitativer Vergleich der Algorithmen mittels Computersimulationen von Fluoreszenzbildern ausgedehnter Objekte.

7. Anwendung der Algorithmen durch hochaufgelöste Lokalisierung sowie Form- und Größenbestimmung von fluoreszierenden Escherichia coli Bakterien in vitro.

8. Untersuchung des submikroskopischen aktiven Transports von Mitochondrien in Dendriten von kultivierten Neuronen. 


\section{Kapitel 2}

\section{Grundlagen der Fluoreszenzkorrelationsspektroskopie (FCS)}

In der Biologie und in der Medizin ist es oft wichtig, einzelne Moleküle zu detektieren (pressewirksame Beispiele sind HIV oder BSE-Proteine) oder ihre Eigenschaften zu untersuchen (z.B. Diffusionskonstanten, Bindungskonstanten, Fluoreszenzverhalten). In der Biophysik gibt es hierfür eine elegante Methode: die Fluoreszenzkorrelationsspektroskopie („Fluorescence Correlation Spectroscopy“, FCS). Sie wurde Anfang der 70er Jahre zur Untersuchung dynamischer Prozesse in biochemischen Systemen eingeführt [25-27]. Basierend auf der Korrelationsanalyse von Intensitätsfluktuationen fluoreszierender Moleküle, angeregt durch eine stationäre Laserlichtquelle, ist es möglich, Aussagen über Transporteigenschaften wie translatorische [25-27] und rotatorische [28-30] Diffusion, den aktiven Transport [31] und den laminaren Fluss [32-34] von Molekülen sowie über chemische Reaktionen [25-27] und intramolekulare Prozesse [35,36] zu erhalten (für Übersichtsarbeiten, siehe [1,37-40]). Nach den ersten FCS-Messungen in offenen Lösungssystemen mit einer Apparatur mit konfokalem Strahlengang [41-43] Anfang der 90er Jahre hat diese Technik schnell an Popularität gewonnen. Durch die Verfügbarkeit von Messvolumina von weniger als einem Femtoliter [3] und die Entwicklung von empfindlichen Photodetektoren ist es möglich, Analysen auf der Ebene einzelner Moleküle durchzuführen.

\subsection{Theorie der FCS für offene Lösungssysteme}

Die FCS basiert auf der Analyse von Intensitätsfluktuationen fluoreszierender Moleküle in Lösungssystemen im thermodynamischen Gleichgewicht. Durch die Beobachtung von Intensitätsfluktuationen werden kleinste stochastische Abweichungen vom Gleichgewicht messbar. Im einfachsten Fall von frei diffundierenden Farbstoffmolekülen sind die Fluk- 
tuationen im Fluoreszenzsignal eine Folge der statistischen Fluktuationen der Anzahl der Moleküle, die in das Beobachtungsvolumen eintreten und es wieder verlassen. Um quantitative Informationen aus dem stochastischen Intensitätssignal zu erhalten, wird das durch einen Laser angeregte Fluoreszenzsignal $I(t)$ einer Korrelationsanalyse unterzogen. Hierzu wird die normierte Autokorrelationsfunktion (AKF)

$$
G(\tau)=\frac{\langle\delta I(t) \delta I(t+\tau)\rangle}{\langle I(t)\rangle^{2}}
$$

der Intensitätsfluktuationen $\delta I(t)$ berechnet. Die Fluktuationen $\delta I(t)$ erfolgen dabei um den zeitlichen Mittelwert $\langle I(t)\rangle$ des gemessenen Fluoreszenzsignals $I(t)$, d.h. $\delta I(t)=I(t)-$ $\langle I(t)\rangle$.

\subsubsection{Teilchenstatistik in verdünnten Lösungen}

Im Fall der BRownschen Molekularbewegung sind die Fluktuationen des Fluoreszenzsignals $\delta I(t)$ bei konstanter Anregungsintensität eine Folge der Konzentrationsfluktuationen $\delta C(\vec{r}, t)=C(\vec{r}, t)-\langle C(\vec{r}, t)\rangle$ der diffundierenden fluoreszierenden Moleküle ( \langle\rangle bezeichnet das Ensemble-Mittel). Für die quantitative Beschreibung der Fluktuationen wird eine verdünnte Lösung im Diffusionsgleichgewicht und im thermodynamischen Gleichgewicht vorausgesetzt, deren Lösungsmoleküle keine Wechselwirkung untereinander haben [44-47]. Die mittlere Konzentration $\langle C\rangle$ der Farbstoffmoleküle ist somit unabhängig von der Zeit $t$ und dem Ort $\vec{r}$. Die Beschreibung des Lösungssystems kann aufgrund der Voraussetzungen analog zu einem idealen Gas erfolgen [45-48].

Die Wahrscheinlichkeit, zu einem festen Zeitpunkt $t$ in einer Lösung mit dem Volumen $V_{0}$ und der Teilchenzahl $N_{0}$ genau $N$ Moleküle in dem Volumenelement $V$ vorzufinden, ist durch die Binominalverteilung gegeben:

$$
p(N)=\left(\begin{array}{c}
N_{0} \\
N
\end{array}\right) q^{N}(1-q)^{N_{0}-N}
$$

$q=V / V_{0}$ bezeichnet hierbei die Wahrscheinlichkeit, ein bestimmtes Molekül im Volumen $V$ vorzufinden. Im Fall eines kleinen Beobachtungsvolumens und großer Teilchenzahlen $N_{0}$ $\left(\rightsquigarrow q \rightarrow 0, N_{0} \rightarrow \infty, N_{0} q=N_{0} V / V_{0} \rightarrow\langle N\rangle\right)$ geht diese Verteilung in die PoIssonVerteilung über [49]:

$$
p(N)=e^{-\langle N\rangle} \frac{\langle N\rangle^{N}}{N !} .
$$

Eine bedeutende Eigenschaft der Poisson-Verteilung ist, dass der Erwartungswert und die Varianz der Zufallsgröße gleich sind, d.h. $\langle N\rangle=\left\langle(\delta N)^{2}\right\rangle$. Für die mittlere Konzentration $\langle C\rangle$ und deren Fluktuationen $\langle\delta C(\vec{r}, t)\rangle$ im Volumen $V$ bedeutet das: $\left\langle\delta C(\vec{r}, t)^{2}\right\rangle=\langle C\rangle / V$. Vollzieht man den Grenzübergang von dem endlichen Beobachtungsvolumen $V$ zu einem 
infinitesimal kleinen Volumenelement $\mathrm{d}^{3} r$ an der Stelle $\vec{r}$, so kann unter Verwendung der DIRACschen $\delta$-Funktion geschrieben werden [26]:

$$
\left\langle\delta C(\vec{r}, t) \delta C\left(\vec{r}^{\prime}, t\right)\right\rangle=\langle C\rangle \delta\left(\vec{r}-\vec{r}^{\prime}\right) .
$$

$\mathrm{Zu}$ einem festen Zeitpunkt $t$ sind die Konzentrationsfluktuationen an verschiedenen Orten $\vec{r}$ und $\vec{r}^{\prime}$ somit unabhängig voneinander. Wie sich in dem nächsten Abschnitt zeigen wird, ist der Ausdruck (2.4) von essentieller Bedeutung für die Theorie der FCS.

\subsubsection{Korrelation von Konzentrationsfluktuationen}

Die im vorigen Abschnitt beschriebenen Konzentrationsfluktuationen sind je nach Größe des Beobachtungsvolumens mehr oder weniger von Bedeutung. Während aus makroskopischer Sicht keine Abweichungen von der mittleren Konzentration zu beobachten sind, werden durch Beschränkung des Beobachtungsvolumens auf Größen, in denen sich im Mittel nur noch wenige Moleküle aufhalten, Konzentrationsfluktuationen messbar. Die größten Fluktuationen erhält man durch die Verwendung von Beobachtungsvolumina, die kleiner als die reziproke Teilchenkonzentration sind ${ }^{1}$. In diesem Abschnitt wird gezeigt, welche Informationen man durch die Korrelationsanalyse der Konzentrationsabweichungen gewinnen kann.

Die Korrelationsfunktion $\phi\left(\vec{r}, \vec{r}^{\prime}, \tau\right)$ der Konzentrationsfluktuationen $\delta C(\vec{r}, t)$ ist definiert durch [26]:

$$
\phi\left(\vec{r}, \vec{r}^{\prime}, \tau\right)=\left\langle\delta C(\vec{r}, t) \delta C\left(\vec{r}^{\prime}, t+\tau\right)\right\rangle .
$$

Da Autokorrelationsfunktionen bezüglich $\tau=0$ symmetrisch sind, genügt es, nur positive $\tau$ zu betrachten. Für die Messungen wird ein stationäres System vorausgesetzt, womit die Mittelwerteigenschaften unabhängig von der Zeit $t$ sind. Daher ist $\phi$ nur von dem Zeitintervall $\tau$ - bezüglich eines willkürlich gewählten Nullpunktes $t=0$ - und nicht von dem absoluten Zeitpunkt $t$ abhängig:

$$
\phi\left(\vec{r}, \vec{r}^{\prime}, \tau\right)=\left\langle\delta C(\vec{r}, 0) \delta C\left(\vec{r}^{\prime}, \tau\right)\right\rangle .
$$

Die Korrelationsfunktion $\phi\left(\vec{r}, \vec{r}^{\prime}, \tau\right)$ beschreibt die Übereinstimmung der Konzentrationsfluktuation $\delta C(\vec{r}, 0)$ am Ort $\vec{r}$ für $\tau=0$ mit derjenigen am Ort $\vec{r}^{\prime}$ nach einem Zeitintervall $\tau>0$, und dies im zeitlichen Mittel über alle $t$ (nach der Ergoden-Hypothese sind Ensemble- und Zeit-Mittel gleich). Vergleicht man nun (2.5) bzw. (2.6) mit dem im vorherigen Abschnitt abgeleiteten Ausdruck (2.4), so sieht man, welche Bedeutung diesem zukommt: Er beschreibt den Wert der Korrelationsfunktion $\phi\left(\vec{r}, \vec{r}^{\prime}, \tau\right)$ für $t=\tau=0$ :

$$
\phi\left(\vec{r}, \vec{r}^{\prime}, 0\right)=\left\langle\delta C(\vec{r}, 0) \delta C\left(\vec{r}^{\prime}, 0\right)\right\rangle=\langle C\rangle \delta\left(\vec{r}-\vec{r}^{\prime}\right) .
$$

\footnotetext{
${ }^{1}$ In der Literatur wird der Kehrwert der Konzentration $V_{\mathrm{T}}:=\langle C\rangle^{-1}=V_{0} / N_{0}=V /\langle N\rangle$ als ,Territorialvolumen“ bzw. „Territorium“ eines einzelnen Moleküls bezeichnet [43]. Eine 10 nM - Lösung mit $6 \cdot 10^{15}$ Teilchen pro Liter hat dementsprechend ein Territorialvolumen eines einzelnen Moleküls von rund $0.17 \mathrm{fl}$.
} 
Der Ausdruck (2.4) besagt, dass es aufgrund der statistischen Unabhängigkeit der Molekülbewegungen - nach Voraussetzung handelt es sich um eine verdünnte Lösung, deren Lösungsmoleküle keine Wechselwirkungen zeigen - für $\tau=0$ keine Korrelation zwischen Konzentrationsfluktuationen an verschiedenen Orten gibt. Unter Einbeziehung der Lösung der Diffusionsgleichung der Moleküle kann mit dieser Bedingung (2.7) die Korrelationsfunktion $\phi\left(\vec{r}, \vec{r}^{\prime}, \tau\right)$ berechnet werden [26]:

$$
\phi\left(\vec{r}, \vec{r}^{\prime}, \tau\right)=\frac{\langle C\rangle}{(4 \pi D \tau)^{3 / 2}} e^{-\frac{\left(\vec{r}-\vec{r}^{\prime}\right)^{2}}{4 D \tau}} .
$$

Es kann somit nur dann zu einer Korrelation zwischen den Konzentrationsfluktuationen an den Orten $\vec{r}$ und $\vec{r}^{\prime}$ im Zeitintervall $\tau$ kommen, wenn aufgrund der Diffusionsbewegung ein Molekül mit einer gewissen Wahrscheinlichkeit in dem betrachteten Zeitintervall $\tau$ vom Ort $\vec{r}$ zum Ort $\vec{r}^{\prime}$ diffundiert ist. Das Resultat der Korrelationsanalyse von Konzentrationsfluktuationen ist also identisch mit der Beschreibung des Diffusionsvorgangs ${ }^{2}$ eines anfänglich am Ort $\vec{r}$ im Volumenelement $\mathrm{d}^{3} r$ lokalisierten Molekülensembles mit der mittleren Konzentration $\langle C\rangle$. Die Amplitude der Korrelationsfunktion $\phi\left(\vec{r}, \vec{r}^{\prime}, \tau\right)$ gibt somit Aufschluss über die mittlere Konzentration $\langle C\rangle$ der Moleküle, während die "Zerfallsrate“, mit der die Korrelationsfunktion für steigendes $\tau$ gegen Null strebt, Aufschluss über die Diffusionskonstante $D$ und damit über die Dynamik der Moleküle gibt.

\subsubsection{Monomolekulares System}

Damit die Korrelationsanalyse der Konzentrationsfluktuationen durchgeführt werden kann, müssen die Konzentrationsabweichungen der zu untersuchenden Molekülspezies „sichtbar" gemacht werden. Hierzu werden die Farbstoffmoleküle (bzw. die mit einem Farbstoff markierten Moleküle) mit einer Laserlichtquelle zum Fluoreszieren angeregt. Die dabei messbaren Fluktuationen im Fluoreszenzsignal $\delta I(t)$ ergeben sich bei konstanter Anregungsintensität durch die Konzentrationsfluktuationen $\delta C(\vec{r}, t)$ der fluoreszierenden Moleküle im Beobachtungsvolumen $V$. Das Fluoreszenzsignal $I(t)$ ist proportional zur Anzahl der fluoreszierenden Moleküle im Beobachtungsvolumen:

$$
I(t)=\int_{V} I_{\mathrm{E}}(\vec{r}) C(\vec{r}, t) \mathrm{d}^{3} r .
$$

$I_{\mathrm{E}}(\vec{r})$ gibt die an dem Ort $\vec{r}$ messbare Emissionsintensität an. Sie lässt sich in Abhängigkeit der Anregungsintensität $I_{\mathrm{A}}(\vec{r})(2.21)$ und der sogenannten „collection efficiency function" $C E F(\vec{r})[50]$ des optischen Systems formulieren:

$$
I_{\mathrm{E}}(\vec{r})=g Q I_{\mathrm{A}}(\vec{r}) C E F(\vec{r}) .
$$

\footnotetext{
${ }^{2}$ Der Diffusionsvorgang ist durch die Wahrscheinlichkeitsdichtefunktion $w\left(\vec{r}, \vec{r}^{\prime}, \tau\right)=$ $(4 \pi D \tau)^{-3 / 2} e^{-\left(\vec{r}-\vec{r}^{\prime}\right)^{2} /(4 D \tau)}$ charakterisiert. Es gilt somit: $\phi\left(\vec{r}, \vec{r}^{\prime}, \tau\right)=\langle C\rangle w\left(\vec{r}, \vec{r}^{\prime}, \tau\right)$.
} 
Dabei bezeichnet $Q$ die Quanteneffizienz des Farbstoffs (bei entsprechender Anregungswellenlänge und -intensität) und $g$ die Effizienz der optischen Komponenten (Linsen, Filter, Spiegel) und der Photodiode. $C E F(\vec{r})$ gibt die ortsabhängige Effizienz der Detektierbarkeit von Fluorezenzphotonen an. Sie kann für das Lochblende-Objektiv-System mit Hilfe semigeometrischer Überlegungen abgeschätzt werden [50]. In einer FCS-Apparatur mit geeigneter Lochblende (Abschnitt 2.2) lässt sich die detektierbare Emissionsintensität durch eine dreidimensionale GAUss-Verteilung approximieren [42]:

$$
I_{\mathrm{E}}(\vec{r})=g Q I_{0} e^{-2 \frac{x^{2}+y^{2}}{r_{x y}^{2}}} e^{-2 \frac{z^{2}}{r_{z}^{2}}}
$$

wobei $r_{x y}$ den $1 / e^{2}$-Radius in lateraler und $r_{z}$ in axialer Richtung bezeichnet.

Für ein monomolekulares System diffundierender Teilchen gilt unter Verwendung der Gleichungen (2.1) und (2.8) bis (2.11) für die Autokorrelationsfunktion $G(\tau)$ folgender Ausdruck [51]:

$$
G(\tau)=\frac{1}{\langle N\rangle} \cdot \frac{1}{1+\frac{\tau}{\tau_{\mathrm{diff}}}} \cdot \frac{1}{\sqrt{1+\frac{\tau}{S^{2} \tau_{\mathrm{diff}}}}} .
$$

$\langle N\rangle$ bezeichnet die mittlere Teilchenzahl pro Detektionsvolumen

$$
V_{\mathrm{D}}=\pi \sqrt{\pi} r_{x y}^{2} r_{z}
$$

Da die detektierbare Emissionsintensität $I_{\mathrm{E}}(\vec{r})$ keine räumlichen Grenzen hat (es gilt $I_{\mathrm{E}}(x, y, z) \rightarrow 0$ für $\left.x, y, z \rightarrow \infty\right)$, beschreibt $V_{\mathrm{D}}$ ein effektiv wirksames Detektionsvolumen. Das Verhältnis der $1 / e^{2}$-Radien $S=r_{z} / r_{x y}$ wird als „Strukturfaktor" bezeichnet. Die Zeitkonstante

$$
\tau_{\text {diff }}=r_{x y}^{2} / 4 D
$$

ist die sogenannte „charakteristische Diffusionszeitkonstante“ des Farbstoffs. Sie entspricht der mittleren Verweildauer eines Moleküls im Detektionsvolumen $V_{\mathrm{D}}$. Für große Strukturfaktoren $S$ gibt diese Zeit die „Halbwertszeit" der AKF $G(\tau)$ an, d.h. $G\left(\tau_{\text {diff }}\right) \simeq G(0) / 2$. Da aufgrund der Poisson-Statistik der Teilchenzahlfluktuationen die Größe der Intensitätsfluktuationen relativ zur mittleren Intensität des Fluoreszenzlichtes abnimmt und damit auch die Amplitude der durch Gleichung (2.1) gegebenen AKF mit steigender Teilchenzahl, ist die normierte AKF reziprok zur mittleren Teilchenzahl $\langle N\rangle$ im Detektionsvolumen $V_{\mathrm{D}}$. Sind die charakteristische Diffusionszeit $\tau_{\text {diff }}$ und die Amplitude $G(0)$ der AKF durch Anpassung der theoretischen AKF (2.12) an die experimentell gemessene AKF bekannt, können die Diffusionskonstante $D$ und die mittlere Konzentration $\langle C\rangle$ der gelösten Farbstoffmoleküle bzw. die mittlere Teilchenzahl $\langle N\rangle$ der Fluorophore im Detektionsvolumen bestimmt werden. Abbildung 2.1 zeigt die AKF einer FCS-Messung innerhalb einer mit Tetramethylrhodamin (TMR) versetzten Lösung zusammen mit dem Ergebnis der Kurvenanpassung des theoretischen AKF-Modells. Das Ergebnis der Kurvenanpassung zeigt die exzellente Übereinstimmung zwischen der experimentellen und der theoretischen AKF [40]. 


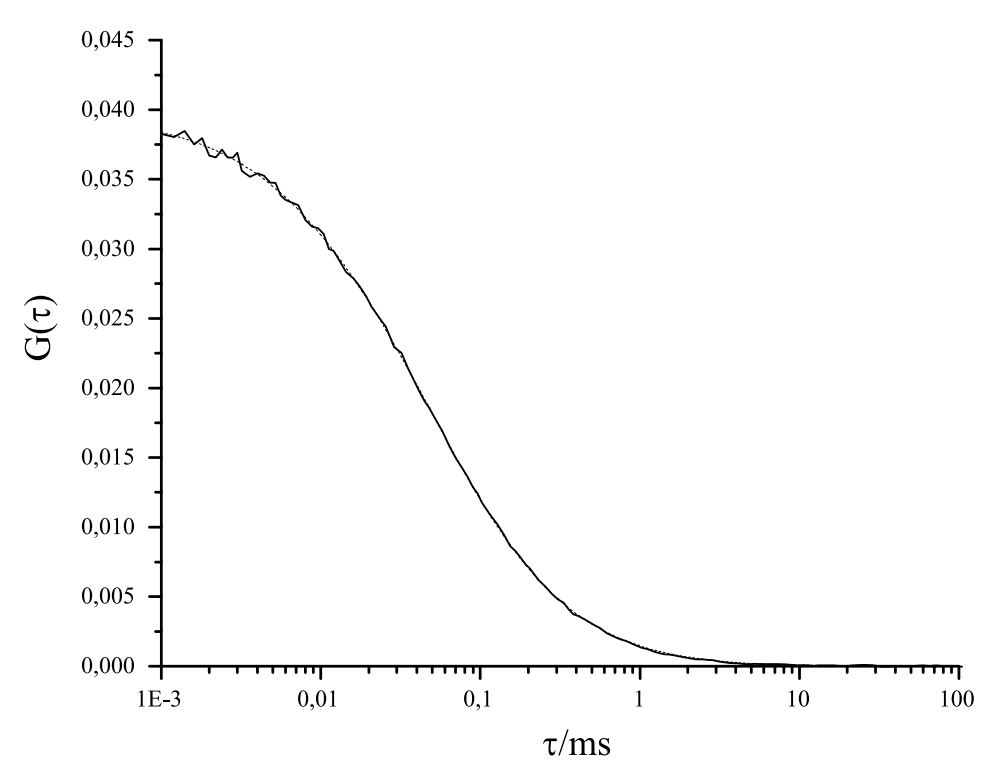

Abb. 2.1: AKF einer FCS-Messung in einer TMR-Lösung (leicht verrauschte Kurve). Ergebnis der Kurvenanpassung mit dem theoretischen AKF-Modell $G(\tau)$ (2.12) (gestrichelte Kurve): $\langle N\rangle=27.21, \tau_{\text {diff }}=49.83 \mu$ s und $S=7.12$ (Anregungsintensität: $I=18.1 \mathrm{~kW} / \mathrm{cm}^{2}$ ).

\subsubsection{Mischsystem}

Die AKF für ein System von $m$ verschiedenen Molekülspezies $j=1 \ldots m$ mit Diffusionskonstanten $D_{j}$ und den Quanteneffizienzen $Q_{j}$ erhält man durch die Erweiterung von (2.12). Da es sich nach Voraussetzung um eine verdünnte Lösung handelt (Abschnitt 2.1.1), sind die Bewegungen der gelösten Moleküle statistisch unabhängig voneinander und die Konzentrationsfluktuationen verschiedener Molekülspezies unkorreliert. Die AKF des Mischsystems $G_{\text {ges }}(\tau)$ ergibt sich dementsprechend aus der Summe der AKFs der jeweiligen Molekülspe$\operatorname{zies} G_{j}(\tau)$ :

$$
\begin{aligned}
G_{\mathrm{ges}}(\tau) & =\frac{\sum_{j=1}^{m} G_{j}(\tau)}{\langle I\rangle^{2}} \\
& =\frac{1}{\left\langle N_{\mathrm{ges}}\right\rangle} \sum_{j=1}^{m} \Phi_{j} \frac{1}{1+\frac{\tau}{\tau_{\mathrm{diff}_{j}}}} \frac{1}{\sqrt{1+\frac{\tau}{S^{2} \tau_{\mathrm{diff}_{j}}}}} .
\end{aligned}
$$

$\left\langle N_{\mathrm{ges}}\right\rangle=\sum_{j=1}^{m}\left\langle N_{j}\right\rangle$ bezeichnet die mittlere Molekülzahl im Detektionsvolumen $V_{\mathrm{D}}$ und $\Phi_{j}$ den fraktionalen Gewichtsfaktor für den $j$-ten Beitrag zur AKF mit dem zugehörigen relativen Molekülanteil $n_{j}=\left\langle N_{j}\right\rangle /\left\langle N_{\text {ges }}\right\rangle \operatorname{mit}\left\langle N_{j}\right\rangle=V_{\mathrm{D}}\left\langle C_{j}\right\rangle[26]$ :

$$
\Phi_{j}=\frac{Q_{j}^{2} n_{j}}{\left(\sum_{j=1}^{m} Q_{j} n_{j}\right)^{2}} .
$$




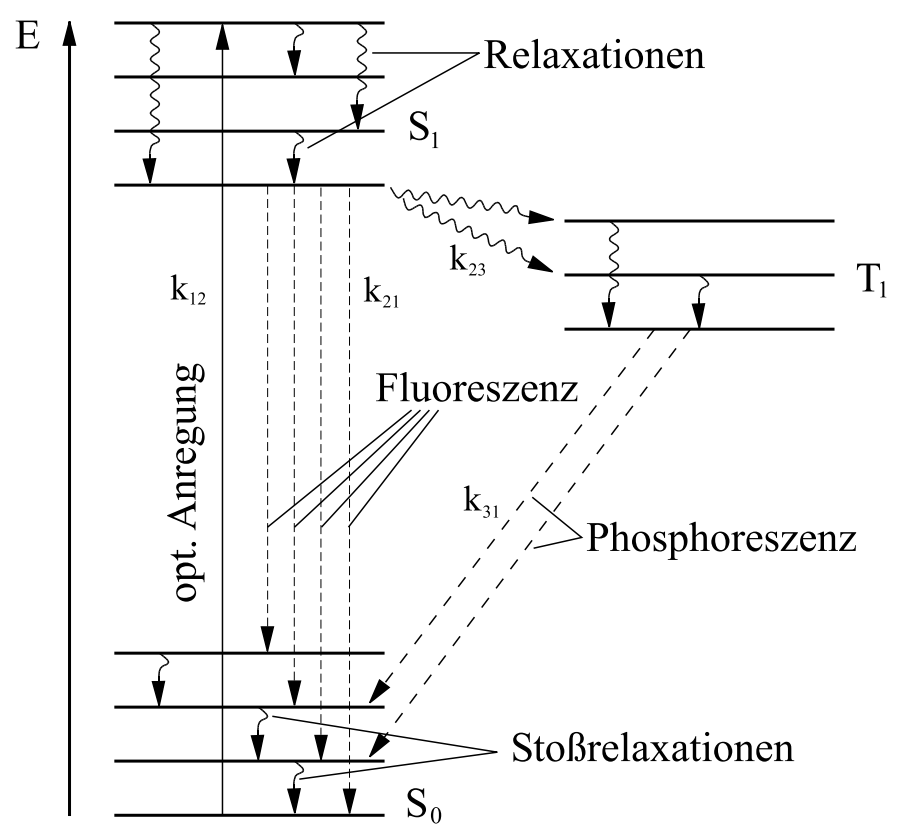

Abb. 2.2: Energiezustandsmodell für Tetramethylrhodamin.

Die Autokorrelationsfunktion $G_{\text {ges }}(\tau)$ ist somit durch die gewichtete Summe der $m$ verschiedenen $G_{j}(\tau)$ gegeben.

\subsubsection{Triplettzustände}

Neben der BRownschen Molekularbewegung können auch intramolekulare Prozesse zu Fluktuationen im Fluoreszenzsignal führen. Diese können einen signifikanten Einfluss auf den Verlauf der AKF haben [35,36]. Im Rahmen dieser Arbeit sind - in Abhängigkeit von der Anregungsintensität - Übergänge der Farbstoffmoleküle in nicht fluoreszierende Triplettzustände zu berücksichtigen. In Abbildung 2.2 sind am Beispiel des verwendeten Farbstoffs Tetramethylrhodamin die möglichen Energiezustände veranschaulicht, die ein Farbstoffmolekül einnehmen kann. Der Laser regt die Farbstoffmoleküle vom Grundzustand $S_{0}$ in viele Rotations- u. Schwingungsenergieniveaus im ersten Singulett-Zustand $S_{1}$ an. Dort relaxieren sie infolge von Stößen mit den Lösungsmolekülen in $\sim 1$ ps in das tiefste Niveau des $S_{1}$-Bandes. Von dort können sie durch Fluoreszenz in viele Rotationsu. Schwingungsenergieniveaus des Grundzustandes übergehen. Da die Absorption von den tieferen besetzten Zuständen startet, die Emission jedoch vom tiefsten Niveau im oberen $S_{1}$-Zustand ausgeht und auf höheren Zuständen im $S_{0}$-Zustand endet, ist das Fluoreszenzspektrum gegenüber dem Absorptionsspektrum „rotverschoben“ (siehe Seite 17, Abb. 3.1 $B)$.

Ist ein Molekül in einem angeregten Zustand $S_{1}$, besteht neben dem fluoreszierenden Übergang auch eine Wahrscheinlichkeit für den Übergang in den Triplettzustand $T_{1}$ 


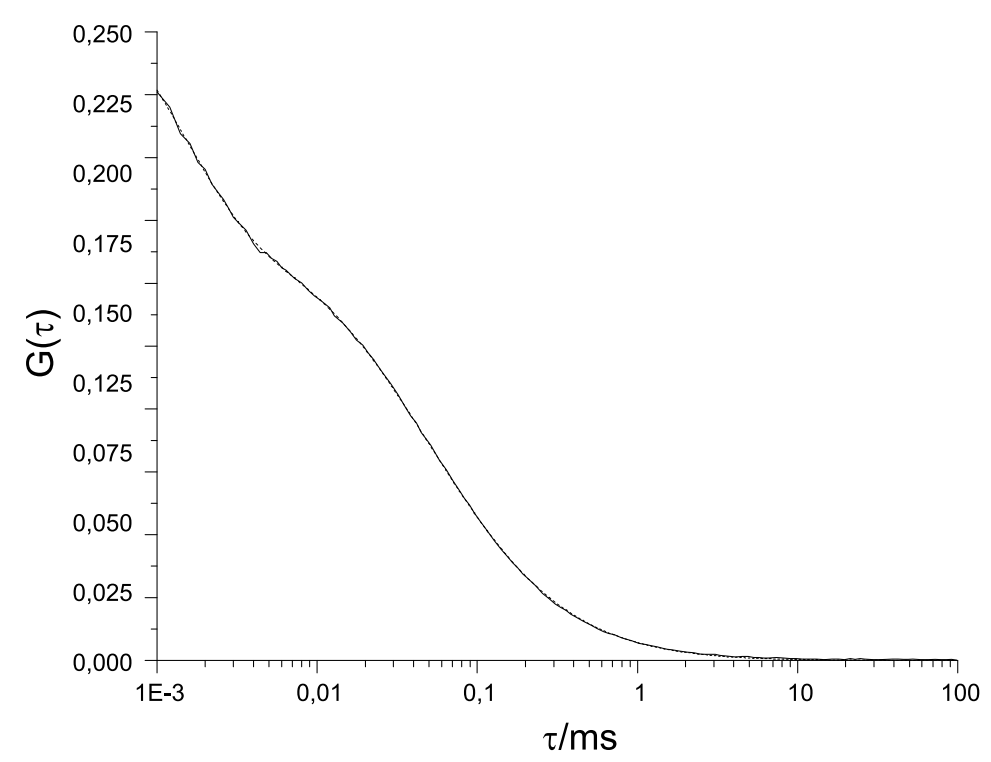

Abb. 2.3: AKF einer FCS-Messung in einer TMR-Lösung mit 40\% Triplettanteil. Ergebnis der Kurvenanpassung mit dem Triplett-korrigierten AKF-Modell (2.18) (von der gemessenen AKF überdeckte gestrichelte Kurve): $\langle N\rangle=5.77, T=0.403, \tau_{T}=1.42 \mu \mathrm{s}$, $\tau_{\text {diff }}=50.29 \mu \mathrm{s}$ und $S=7.31$ (Anregungsintensität: $I=374 \mathrm{~kW} / \mathrm{cm}^{2}$ ).

(„intersystem crossing“). Befindet sich ein Molekül in einem Triplettenergieniveau, so ist es aufgrund der im Vergleich zu den Singulettzuständen langlebigeren Triplettzustände „unsichtbar" (die Relaxation vom Triplettzustand zum Grundzustand $S_{0}$ trägt nicht zur Fluoreszenz $\mathrm{bei}^{3}$ ). Sind Moleküle im Triplettzustand, führt dies zu einer niedrigeren detektierbaren Teichenzahl im Detektionsvolumen. Ist die Zeit, die für das Durchlaufen der Zustände $S_{0}, S_{1}$ und $T_{1}$ benötigt wird, kleiner als die charakteristische Diffusionszeit $\tau_{\text {diff }}$ des Farbstoffs, spiegelt sich der relative Anteil der Farbstoffmoleküle, die sich im Tiplettzustand befinden, mit der entsprechenden Triplettrelaxationszeit in der Autokorrelationsfunktion wider (bei Rhodaminfarbstoffen liegen die charakteristischen Triplett-Relaxationszeiten im Bereich von $0.1-10 \mu \mathrm{s}[35,53])$. Abbildung 2.3 zeigt den Einfluss der Triplettzustände auf den Verlauf der AKF. Der zusätzliche „Tripletthügel“ im AKF-Verlauf ist charakteristisch für die Fluorophore und hängt stark von der Anregungsintensität ab. Für die Berechnung der „Triplett-korrigierten“-AKF werden nur die Übergänge zwischen den Zuständen $S_{0}, S_{1}$ und $T_{1}$ betrachtet. Andere Übergänge können in der betrachteten Zeitskala vernachlässigt werden [35]. Da die photochemische Lebensdauer der Farbstoffmoleküle die der Singulett-Triplett-Übergänge weit übersteigt, erfolgt die Beschreibung der SingulettTriplett-Interaktionen ohne Berücksichtigung der Zerstörung eines Farbstoffmoleküls durch das Laserlicht („photobleaching“). Wendet man dieses Molekülzustandsmodell auf die FCSExperimente an, bei der die Farbstoffmoleküle durch ein Detektionsvolumen mit konstanter

\footnotetext{
${ }^{3}$ Die Phosphoreszenzquantenausbeute des Triplettzustandes ist sehr gering. Daher kann der Triplettzustand als „nicht-lumineszent" bezeichnet werden [52].
} 
Anregungsintensität diffundieren, entstehen die Intensitätsfluktuationen entweder durch die Diffusionsbewegung der Moleküle oder durch die Übergänge in und aus den Triplettzuständen. Unter diesen Voraussetzungen folgt für die Triplett-korrigierte AKF [35]:

$$
G(\tau)=\frac{\left(1+\frac{T e^{-\frac{\tau}{\tau_{\mathrm{T}}}}}{1-T}\right)}{\left\langle N_{\mathrm{ges}}\right\rangle} \sum_{j=1}^{m} \Phi_{j} \frac{1}{1+\frac{\tau}{\tau_{\mathrm{diff}_{j}}}} \frac{1}{\sqrt{1+\frac{\tau}{S^{2} \tau_{\mathrm{diff}_{j}}}}}
$$

$T$ bezeichnet den mittleren relativen Anteil der Moleküle, die sich im Triplett-Zustand befinden, und $\tau_{\mathrm{T}}$ die mittlere Lebensdauer der Triplett-Zustände („average bunching time“ ${ }^{4}$. Für das Zeitintervall $\tau=0$ folgt für $G(\tau)$ :

$$
G(0)=\frac{\left(1+\frac{T}{1-T}\right)}{\left\langle N_{\mathrm{ges}}\right\rangle}=\frac{1}{\left\langle N_{\mathrm{ges}}\right\rangle(1-T)}=\frac{1}{N^{\prime}} .
$$

Dieser Ausdruck zeigt, welchen Einfluss eine Bevölkerung des Triplettzustandes auf die Amplitude der AKF hat. Der in Abbildung 2.3 dargestellte Tripletthügel für kleine $\tau$ entsteht also durch die scheinbar vorhandene, im Vergleich zur Zahl der Moleküle $N_{\text {ges }}$ um den „Triplettanteil“ $T$ verringerte Molekülzahl $N^{\prime}=N_{\text {ges }}(1-T)$.

\subsubsection{Unkorrelierte Störsignale}

In FCS-Experimenten ist das Fluoreszenzsignal $I(t)$ aufgrund von Reflexionen des anregenden Laserstrahls an den optischen Komponenten (Spiegel, Linsen, Filter und Objektträgerglas) und Lichtstreuung durch Unreinheiten auf den Glasoberflächen durch ein stationäres Hintergrundsignal $I_{\mathrm{B}}$ („background intensity“) überlagert. Dieses Signal trägt nicht zur Signalkorrelation bei, vermindert aber die Amplitude der AKF $G(\tau)$ und führt demzufolge zu einer scheinbar höheren Anzahl von Molekülen im Detektionsvolumen [54]. Aus diesem Grund ist es erforderlich, - sofern Konzentrationsbestimmungen durchgeführt werden sollen - die AKF $G(\tau)$ (2.18) mit einem entsprechenden Korrekturfaktor zu versehen [55]:

$$
G(\tau)=\frac{\left(1-\frac{I_{\mathrm{B}}}{I_{\mathrm{ges}}}\right)^{2}}{\left\langle N_{\mathrm{ges}}\right\rangle}\left(1+\frac{T e^{-\frac{\tau}{\tau_{\mathrm{T}}}}}{1-T}\right) \sum_{j=1}^{m} \frac{\Phi_{j}}{1+\frac{\tau}{\tau_{\mathrm{diff}_{j}}}} \frac{1}{\sqrt{1+\frac{\tau}{S^{2} \tau_{\mathrm{diff}_{j}}}}}
$$

$I_{\text {ges }}=\sum_{j=1}^{m}\left\langle I_{j}\right\rangle+I_{\mathrm{B}}$ bezeichnet die gesamte detektierte Intensität einschließlich des Hintergrundsignals $I_{\mathrm{B}}$.

\footnotetext{
${ }^{4}$ Ist die Triplettlebensdauer $\tau_{\mathrm{T} j}$ der verschiedenen Molekülspezies nicht identisch, gibt $\tau_{\mathrm{T}}$ die mittlere Lebensdauer an.
} 


\subsection{Prinzipieller Aufbau einer FCS-Apparatur}

Der Grundaufbau einer FCS-Apparatur besteht aus einem Objektiv mit einem konfokalen Epifluoreszenz- und Detektionsstrahlengang [56-58] (Abb. 2.4). Diese spezielle Anordnung ermöglicht, nur die Objektbereiche abzubilden, die sich in unmittelbarer Umgebung der Brennebene des Objektivs befinden. Hierdurch erreicht man im Gegensatz zur konventionellen Fluoreszenzmikroskopie eine hohe axiale Auflösung. Das Grundprinzip der konfokalen Mikroskopie basiert auf der Verwendung einer Lochblende im Detektionsstrahlengang bei „Epi“"-Beleuchtung5 eines Objekts durch ein Mikroskopobjektiv. Abbildung 2.4 zeigt den prinzipiellen Aufbau einer FCS-Apparatur. Ein kollimierter Laserstrahl mit der Wellenlänge $\lambda_{\text {ex }}$ fällt über einen dichroitischen Spiegel in die Austrittsblende des Objektivs $(\infty$-korrigiert) und wird so zu einem „Brennpunkt" fokussiert. Der so entstehende Brennpunkt ist kein mathematischer Punkt, sondern ein Fokusvolumen $V_{\mathrm{F}}$, das desto kleiner wird, je größer die numerische Apertur des verwendeten Objektivs ist. Da diese nur einen gewissen maximalen Wert annehmen kann, bleibt $V_{\mathrm{F}}$ des Fokus stets endlich, es ist „beugungsbegrenzt". Bei hohen numerischen Aperturen, d.h. etwa 1.2 (Wasserimmersion) oder 1.4 (Ölimmersion) werden Volumina von etwa 1-2 fl erreicht.

Größe und Form des Anregungsvolumens sind durch den Intensitätsverlauf des fokussierten Laserstrahls im Objektraum bestimmt. Für einen kollimierten Laserstrahl mit einer GAussförmigen Intensitätsverteilung in der Rückapertur des Objektivs kann der Intensitätsverlauf im Objektraum in axialer Richtung ( $z$-Koordinate) durch eine LoRENZVerteilung und in lateraler Richtung ( $x y$-Ebene) durch eine GAUss-Verteilung beschrieben werden [59]:

$$
\begin{aligned}
I_{\mathrm{A}}(x, y, z) & =I_{0}(z) e^{-2 \frac{x^{2}+y^{2}}{r^{2}(z)}} \\
r^{2}(z) & =r_{0}^{2}+z^{2}\left(\frac{\lambda_{\mathrm{ex}}}{n \pi r_{0}}\right)^{2}=r_{0}^{2}+z^{2} \tan ^{2} \delta \\
I_{0}(z) & =\frac{r_{0}^{2} I_{0}}{r^{2}(z)},
\end{aligned}
$$

wobei $I_{0}$ die maximale Anregungsintensität im Zentrum der schmalsten Stelle des fokussierten Lasertstrahls bezeichnet. Der Radius $r_{0}$ ist näherungsweise durch den Ausdruck

$$
r_{0} \approx \frac{\mathrm{f} \lambda_{\mathrm{ex}}}{n \pi \mathrm{R}}=\frac{\lambda_{\mathrm{ex}}}{n \pi \tan \delta}
$$

gegeben ${ }^{6}$. Hierbei bezeichnet $n$ den Brechungsindex des Mediums unter dem Objektiv, f die Objektivbrennweite und $\delta$ den Winkel, unter dem der Laserstrahl fokussiert wird.

\footnotetext{
${ }^{5}$ Axiale Auflichtbeleutung (engl. epi-illumination); hierbei erfolgt nicht nur die Betrachtung des Objekts sondern auch die Beleuchtung durch das Objektiv.

${ }^{6}$ Die Güte dieser Approximation hängt von der Bedingung $\mathrm{f} \gg \mathrm{R}$ ab. Für $\mathrm{f} / \mathrm{R} \approx 1$ liefert sie immer noch grobe Richtwerte; da der „Brennpunktradius“ $r_{0}$ gegenüber dem Radius des einfallenden Laserstrahls $\mathrm{R}$ vernachlässigt werden kann, gilt näherungsweise die Beziehung $\tan \delta=\mathrm{R} / \mathrm{f}$ ) [59-61].
} 


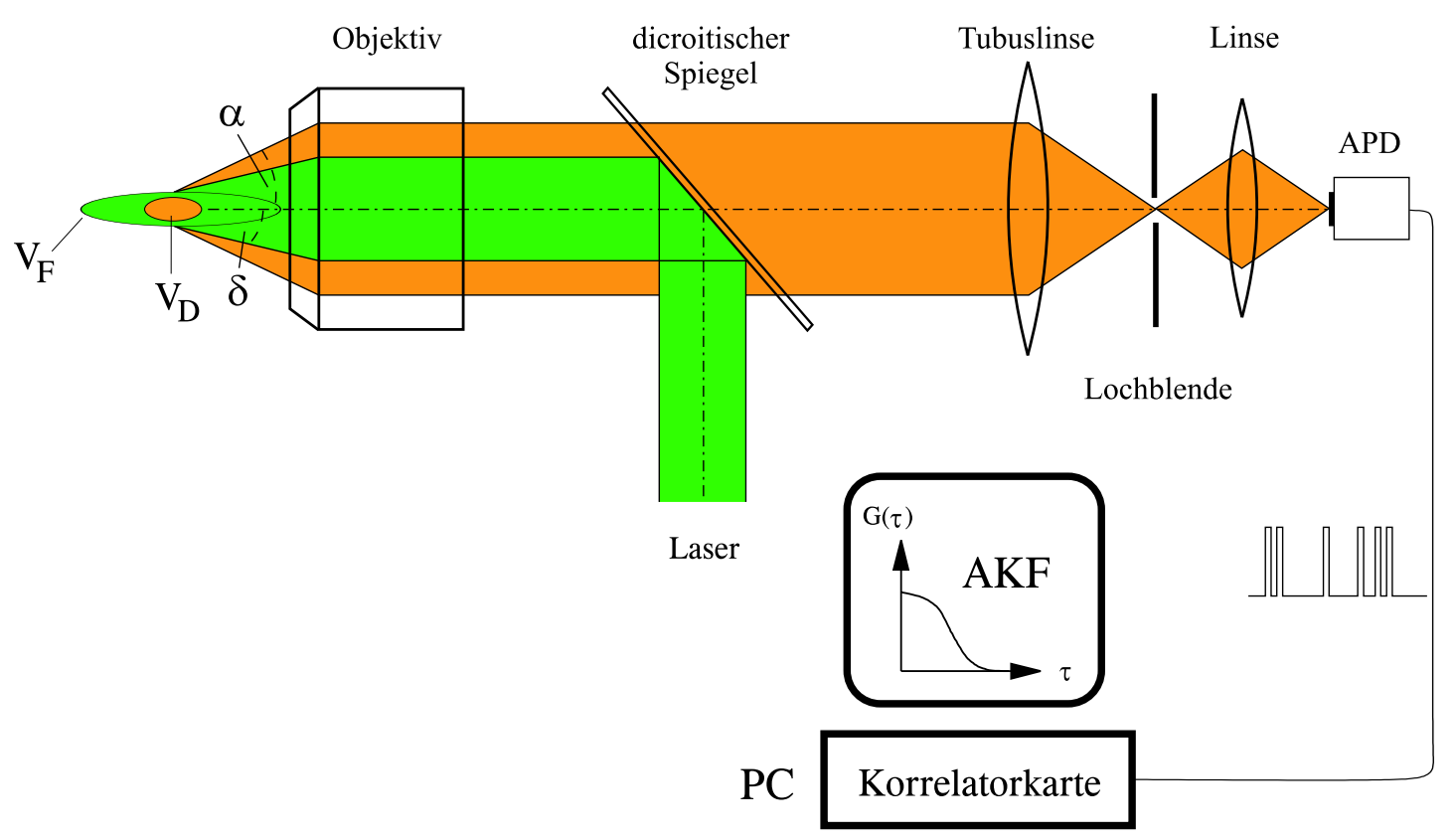

Abb. 2.4: Prinzipieller Aufbau einer FCS-Apparatur.

Im Gegensatz zur konventionellen konfokalen Mikroskopie wird die Rückapertur des Objektivs in dem FCS-Aufbau nicht voll ausgeleuchtet. Daher entstehen keine zusätzlichen beugungsbedingten "AIRY-Ringe" in der Objektebene [62]. Positioniert man das entstehende Fokusvolumen in einer Farbstofflösung, dann werden nur diejenigen Farbstoffmoleküle zum Fluoreszieren angeregt, die gerade durch das Fokusvolumen diffundieren. Das auf diese Weise erzeugte Emissionslicht wird zum Teil vom Objektiv „eingesammelt" und, nachdem es den dichroitischen Spiegel passiert hat, mit der Tubuslinse in die Zwischenbildebene abgebildet. Der maximale Winkel $\alpha$, unter dem das Fluoreszenzlicht noch in das Objektiv gelangen kann, ist durch die numerische Apertur NA $=n \sin \alpha$ des Objektivs gegeben. Durch die Positionierung einer Lochblende in der Zwischenbildebene (oder einer zu ihr konjugierten Ebene) gelangen nur diejenigen Photonen durch die Lochblende, die aus der unmittelbaren Umgebung der Brennebene stammen. Der in die Objektebene projizierte Lochblendenradius $s_{0}=r_{\mathrm{L}} / V\left(r_{\mathrm{L}}\right.$ physikalischer Lochblendenradius, $V$ optische Vergrößerung des Systems) sollte mit dem Radius $r_{0}$ (2.24) des Fokusvolumens übereinstimmen. Unter dieser Voraussetzung kann durch die Wirkung der Lochblende die am Ort $\vec{r}$ im Objektraum messbare Emissionsintensitätsverteilung $I_{\mathrm{E}}(\vec{r})$ (Abschnitt 2.1.3) durch eine dreidimensionale Gauss-Verteilung approximiert werden [42]. Hierdurch ensteht ein Detektionsvolumen $V_{\mathrm{D}}$ von weniger als einem Femtoliter [3]. Die Lochblende wird anschließend 1:1 auf den Photodetektor (Avalanchephotodiode, APD) abgebildet. Die Photodiode detektiert die eintreffenden Photonen und generiert für die detektierten Emissionsphotonen Spannungspulse. Ein im PC integrierter Hardwarekorrelator (Abschnitt 4.9) registriert diese Pulse und berechnet „on-line“ die AKF des Signals. 


\section{Kapitel 3}

\section{Material und Methoden}

\section{$3.1 \quad$ Zellkultur}

Für die FCS-Messungen wurden kultivierte Mitralzellen aus dem Bulbus olfactorius von Larven des südafrikanischen Krallenfrosches Xenopus laevis verwendet [63,64]. Im Gegensatz zu Säugetier-Präparaten hat die Amphibienkultur den Vorteil, dass man die Kultivierung und die Messungen bei Zimmertemperatur durchführen kann. Die Zellen wachsen in einem Tropfen Medium (ca. $50 \mu \mathrm{l}$ ) aus 70\% Leibovitz-Medium L15, $10 \%$ Pferdeserum und $50 \mu \mathrm{g} / \mathrm{ml}$ Gentamycin auf einem in der Kulturschale eingearbeiteten, zuvor mit PolyLysin $(50 \mu \mathrm{g} / \mathrm{ml})$ und Laminin $(20 \mu \mathrm{g} / \mathrm{ml})$ beschichteten Objektträgerglas auf. Nach zwölf Stunden wird das Medium durch $100 \mu$ l des endgültigen Kulturmediums (70\% L15, 5\% Pferdeserum, $50 \mu \mathrm{g} / \mathrm{ml}$ Gentamycin) ersetzt [63]. Die Messungen können dann nach zwei bis drei weiteren Tagen an den so kultivierten Neuronen durchgeführt werden. Die Kultur besteht aus unterschiedlichen Zelltypen: Der Anteil von Mitralzellen und Interneuronen liegt bei etwa $20 \%$ bzw. $70 \%$, der von Gliazellen bei ca. $10 \%$.

\subsection{Elektrophysiologie}

Um die kultivierten Neurone mit dem hydrophilen 10 kDa TMR-Dextran zu befüllen, wurde die Patch-Clamp-Technik angewendet [65]. In der Whole-Cell-Konfiguration kann so die intrazelluläre Ionenzusammensetzung kontrolliert, ein Farbstoff injiziert und Ströme über die Zellmembran gemessen werden. Für die Patch-Clamp-Ableitungen werden Glaskapillaren aus Borosilikatglas (Hilgenberg, Malsfeld) mit einem Zwei-Schritt-Pipettenzieher (Narishige, Japan) gezogen und mit einer Mikroforge (Heizdraht) poliert. Bei entsprechender Einstellung des Pipettenziehers erhält man Öffnungsdurchmesser von $\sim 1 \mu \mathrm{m}$. Eine mit der Pipettenlösung befüllte Glaskapillare wird an einem oberhalb der Objektebene angebrachten Pipettenhalter befestigt. Die hergestellten Pipetten haben bei einer KClPipettenlösung und einer NaCl-Ringer-Lösung einen Widerstand von $8 \mathrm{M} \Omega$. Eine Elek- 
trode, die im Pipettenhalter befestigt und mit dem Patch-Clamp-Vorverstärker verbunden ist, taucht hierbei in die Pipettenlösung ein. Die Masse des Patch-Clamp-Verstärkers wird über eine $\mathrm{AgCl} / \mathrm{Cl}^{-}$-Elektrode mit der Badlösung (extrazelluläre Lösung) verbunden. Die Kulturzellen werden während der Messung über einen Zulauf mit der Badlösung überströmt. Zum Lösungsaustausch ist gegenüber dem Zulauf eine pumpbetriebene Absaugvorrichtung angebracht. Die Strömungsgeschwindigkeit kann reguliert werden, indem man die Höhendifferenz zwischen Vorratsbehälter und Objektebene verstellt. Bevor die Pipette in die Badlösung eintritt, wird über ein Schlauchsystem Überdruck in der Pipette erzeugt. Das verhindert, dass Badlösung in die Pipettenöffnung einströmt. Mit Hilfe von Mikromanipulatoren wird unter visueller Kontrolle (CCD-Kamera, Abb. 4.1) die Pipettenspitze in einigen Mikrometern Entfernung von der Zellmembran positioniert (Grobeinstellung). Anschließend wird die Pipettenspitze mit Piezoelementen auf die Zellmembran aufgesetzt (Feineinstellung). Während des Aufsetzens wird der Überdruck entfernt und damit ein Membranstück an die Pipettenöffnung angesaugt. Die Zellmembran schmiegt sich dabei so an das Pipettenglas, dass zwischen Pipette und Bad ein Widerstand von einigen Gigaohm (2G $\Omega-10$ G $\Omega$ ) entsteht („Sealwiderstand“). Durch einen leichten Unterdruck in der Pipette lässt sich nun ein Loch in die Membran reißen, so dass eine mechanische und elektrische Verbindung zum Zellinneren entsteht. Die intrazelluläre Ionenzusammensetzung wird dann im Wesentlichen durch die Pipettenlösung bestimmt. Für die FCS-Messungen wird anschließend die Spannung über der Zellmembran mit dem Patch-Clamp-Verstärker auf das Ruhepotenzial $(-80 \mathrm{mV})$ der Zelle eingestellt und konstant gehalten (Voltage-ClampBetriebsart). Über ein am Patch-Clamp-Verstärker angeschlossenes Oszilloskop kann dann der Regelstrom, der dem Membranstrom entspricht, überwacht werden. Durch Umschalten in die Current-Clamp-Betriebsart ist es möglich, die Membranspannung zu messen und Informationen über den Sealwiderstand zu erhalten. Dieser wird während der Messung kontinuierlich kontrolliert, um die Güte der Verbindung zwischen Pipette und Zellmembran zu überwachen. Die Zusammensetzung der Badlösung entspricht (in mM): $\mathrm{NaCl} 102, \mathrm{KCl} 2$, $\mathrm{MgCl}_{2}$ 2, $\mathrm{CaCl}_{2}$ 2, Glukose 20, HEPES 10, 240 mOsm, pH 7.8, und die der Pipettenlösung: $\mathrm{NaCl}$ 2, KCl 103, $\mathrm{MgCl}_{2}$ 3, EGTA 1, HEPES 10, $\mathrm{K}_{2}$-ATP 1, $\mathrm{Na}_{2}$-GTP 0.01, 220 mOsm, $\mathrm{pH} 7.8$.

\subsection{Farbstoffe}

\subsubsection{Tetramethylrhodamin (TMR)}

Für die Bestimmung des Detektionsvolumens $V_{\mathrm{D}}$ der FCS-Apparatur wird der Farbstoff Tetramethylrhodamin (TMR, Sigma-Aldrich Chemie, Deisenhofen) verwendet. TMR (Abb. 3.1) ist ein Rhodaminderivat und hat in wässriger Lösung eine Quantenausbeute von etwa $15 \%$ [66]. Das Maximum der Absorption liegt bei der Wellenlänge $\lambda_{\text {abs }}=555 \mathrm{~nm}$, das der Emission bei $\lambda_{\mathrm{em}}=580 \mathrm{~nm}$. Abbildung $3.1 B$ zeigt das Absorptions- und Emissionsspektrum von TMR. Tetramethylrhodamin ist vor allem wegen der spektralen Eigenschaften 
<smiles>CN(C)c1ccc2c(-c3ccccc3C(=O)O)c3ccc(=[N+](C)C)cc-3oc2c1</smiles>

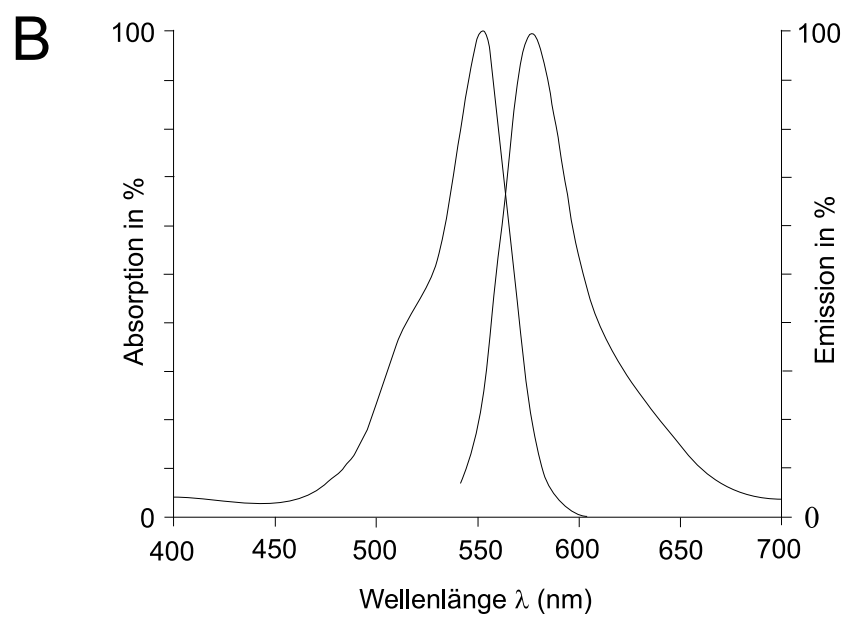

Abb. 3.1: Strukturformel und Absorptions- und Emissionsspektrum von TMR [67]. (A) Strukturformel von TMR. (B) Absorptions- und Emissionsspektrum von TMR in wässriger Lösung (pH 7.0).

(passend zu der Anregungswellenlänge des Lasers von $\lambda_{\text {ex }}=543.5 \mathrm{~nm}$ ), der in $\mathrm{H}_{2} \mathrm{O}$ bekannten Diffusionskonstante von $D_{\text {TMR }}=2.8 \cdot 10^{-6} \mathrm{~cm}^{2} \mathrm{~s}^{-1}$ [42] und hoher Photostabilität ein besonders geeigneter Farbstoff für die FCS-Kalibrationsmessungen.

\subsubsection{TMR-Dextran}

Für die intrazellulären FCS-Messungen wird ein neutrales, hydrophiles 10 kDa TMRDextran $^{1}$ (D-1816, Molecular Probes, Leiden, Niederlande) verwendet ${ }^{2}$. Die zu untersuchenden Neurone werden unter Anwendung der Patch-Clamp-Technik mit dem Dextran befüllt. Das TMR-Dextran gibt man hierzu in die Pipettenlösung. Um eine Osmolaritätsveränderung durch die Farbstoffmoleküle zu verhindern, wird Farbstofflösung mit einem Volumen von maximal 1/100 des Volumens der Pipettenlösung zugegeben.

\subsubsection{MitoTracker Orange}

Für die Untersuchungen des in vivo - Transports von Mitochondrien werden die Zellkulturen vor Beginn der Messungen für ca. eine Minute in 10-50 nM „MitoTracker“ (MitoTracker Orange CMTRos, M-7510, Molecular Probes, Leiden, Niederlande) inkubiert. Der Farbstoff wird hierzu in der Badflüssigkeit gelöst. Die LSM-Messungen erfolgen nach Austausch der Farbstofflösung gegen die farbstofffreie Badflüssigkeit (Abschnitt 3.2). MitoTracker ist ein lipophiler kationischer Farbstoff und ein Derivat des Farbstoffs Tetramethylrosamin.

\footnotetext{
${ }^{1} 1$ Dalton $=1.66018 \cdot 10^{-24} \mathrm{~g}$.

${ }^{2}$ Ein Molekül Dextran trägt im Durchschnitt zwei TMR-Moleküle [67].
} 
Sein Absorptionsmaximum liegt bei der Wellenlänge $\lambda_{\text {abs }}=551 \mathrm{~nm}$, das der Emission bei $\lambda_{\mathrm{em}}=576 \mathrm{~nm}$. Fluoreszierende lipophile kationische Farbstoffe wie Rhodamin 123, Tetramethylrosamin und X-Rosamin diffundieren in eukariotische Zellen und reichern sich in Mitochondrien an. Der Grund hierfür ist das stark negative Membranpotenzial der Mitochondrien. Berechnungen ergeben, dass der Farbstoff im elektrochemischen Gleichgewicht in Mitochondrien 1000- bis 10000-fach höher konzentriert ist als im Zytoplasma der Zelle [68-70].

\subsection{Antikörperfärbung von $\alpha$-Tubulin}

Der Nachweis von Mikrotubuli ${ }^{3}$ (MTs) innerhalb der kultivierten Neurone erfolgt in dieser Arbeit durch immunozytochemische Färbung mit einem monoklonalen Antikörper gegen $\alpha$-Tubulin (T-6793, Sigma-Aldrich Chemie, Deisenhofen). Die Zellkultur wird hierzu für ein bis zwei Stunden bei Raumtemperatur mit 4\% Paraformaldehyd (PFA) in einer 0.1 M Phosphat-Puffer-Lösung (PB; Zusammensetzung in mM: $\mathrm{Na}_{2} \mathrm{HP}_{4}$ 81, $\mathrm{NaH}_{2} \mathrm{PO}_{4}$ 19, pH 7.4) fixiert. Anschließend wird die Zellkultur dreimal für je 20 Minuten mit frischer Pufferlösung überspült. Die Blockierung der noch freien Bindungsstellen erfolgt für eine Stunde mit $0.25 \%$ Rinderserum Albumin (BSA), 10\% Mausserum (NMS), 0.25\% Triton X-100 (TX) in PB. Dann wird die Zellkultur für zwei bis drei Stunden bei Raumtemperatur mit dem primären Antikörper inkubiert (gelöst in Blockierungsflüssigkeit, Verdünnungsfaktor 1/1000). Hiernach wird die Zellkultur nochmals dreimal für je 20 Minuten mit PB überspült. Nun erfolgt eine ein- bis zweistündige Inkubation mit dem sekundären Antikörper (Alexa Fluor 488 goat anti-mouse IgG, A-11001, Molecular Probes, Leiden, Niederlande). Dieser wird hierzu in PB gelöst $(10 \mu \mathrm{g} / \mathrm{ml})$. Vor Beginn der LSM-Messungen wird die Kultur erneut dreimal für je 20 Minuten in frischer Pufferlösung gereinigt.

\subsection{FCS-Kalibrationsmessungen}

Die Bestimmung des Detektionsvolumens $V_{\mathrm{D}}=\pi \sqrt{\pi} r_{x y}^{2} r_{z}$ der FCS-Apparatur erfolgt durch FCS-Messungen mit dem Farbstoff TMR (Abschnitt 3.3.1). Mit Hilfe der bekannten Diffusionskonstante $D_{\mathrm{TMR}}=2.8 \cdot 10^{-6} \mathrm{~cm}^{2} / \mathrm{s}$ [42] und den beiden Kurvenanpassungsparametern $\tau_{\text {diff }}=r_{x y}^{2} / 4 D$ und $S=r_{z} / r_{x y}$ werden nach jedem Apparaturabgleich die beiden $1 / e^{2}$ Radien $r_{x y}$ und $r_{z}$ erneut bestimmt. Die Messungen erfolgen in einem Tropfen TMR-Lösung mit einer Konzentration zwischen $10 \mathrm{nM}$ und $200 \mathrm{nM}$. Die Auswertung der AKF-Daten wird - da es sich um einen im Vergleich zum Detektionsvolumen $V_{\mathrm{D}}$ unendlich ausgedehnten TMR-Lösungstropfen handelt - mit dem Standard-AKF-Modell (2.18) durchgeführt. Die

\footnotetext{
${ }^{3}$ Mikrotubuli entstehen durch die Polymerisierung von $\alpha$ - und $\beta$-Tubulin [2]. Ihre Eigenschaften werden durch eine Reihe von Mikrotubuli-assoziierten Proteinen (MAPs) beeinflusst, die an die Oberfläche der Mikrotubuli binden.
} 
charakteristische Diffusionszeitkonstante $\tau_{\text {diff }}$ des Farbstoffs TMR, lag - je nach Justierung der Lochblende - in einem Bereich von

$$
46 \mu \mathrm{s} \leq \tau_{\text {diff }} \leq 56 \mu \mathrm{s}
$$

Für den $1 / e^{2}$-Radius $r_{x y}$ folgt daraus:

$$
0.23 \mu \mathrm{m} \leq r_{x y} \leq 0.25 \mu \mathrm{m}
$$

Für den Strukturparameter $S$ ergeben die Kurvenanpassungen einen Wertebereich von:

$$
6.95 \leq S \leq 7.5
$$

hieraus folgt für den axialen $1 / e^{2}$-Radius $r_{z}$ :

$$
1.6 \mu \mathrm{m} \leq r_{z} \leq 1.8 \mu \mathrm{m}
$$

Aus den Wertebereichen der Radien $r_{x y}$ und $r_{z}$ resultiert für das Detektionsvolumen $V_{\mathrm{D}}$ :

$$
0.45 \mathrm{fl} \leq V_{\mathrm{D}} \leq 0.65 \mathrm{fl} .
$$

\subsection{Bildanalysen und Simulationen}

Sämtliche Bildanalysen sowie Simulationen von Fluoreszenzbildern erfolgen in dieser Arbeit mit der Software IDL (Research Systems, Boulder, CO, USA) auf einem Pentium PC mit Linux-Betriebssystem. Die entwickelten mathematischen Modelle zur Faltungsproduktund Korrelations-Bildanalyse (Abschnitt 6.1.2 und 6.1.3) werden hierzu in die Software implementiert. IDL ist eine Matrizen-basierte Computersprache und ermöglicht komplexe Datenanalysen mit vordefinierten und benutzerdefinierten Funktionen. Es stehen unter anderem Kurvenanpassungsalgorithmen, Routinen zur numerischen Berechnung von Mehrfachintegralen und vielfältige Datenvisualisierungsmöglichkeiten zur Verfügung.

Die Simulation von Fluoreszenzbildern von ausgedehnten theoretischen Objekten erfolgt in zwei Schritten. Als erstes wird ein rauschfreies Bild mit der theoretischen Intensitätsverteilung $\mathcal{I}_{\text {obj }}(x, y)$ (Abschnitt 6.1.2) des Objektes berechnet (die Intensität ist dabei durch die mittlere Anzahl der Photonen pro Pixel gegeben). Im zweiten Schritt wird Rauschen addiert. Für die Simulation von Poisson-Rauschen (Abschnitt 6.1.5) auf einer theoretischen Intensitätsverteilung sind entsprechende IDL-Routinen implementiert. Hierbei wird jedem Bildpixel mit den Koordinaten $\left(x_{i}, y_{i}\right)$ eine Zufallszahl aus einer Poisson-Verteilung mit Mittelwert $\mathcal{I}_{\text {obj }}\left(x_{i}, y_{i}\right)$ und Standardabweichung $\sqrt{\mathcal{I}_{\text {obj }}\left(x_{i}, y_{i}\right)}$ zugeordnet [71], wobei $\mathcal{I}_{\mathrm{obj}}\left(x_{i}, y_{i}\right)$ der Intensitätswert des jeweiligen Pixels ist.

Die Simulation von Bildsequenzen stationärer und bewegter fluoreszierender Mitochondrien erfolgt dagegen unter Berücksichtigung der speziellen Photonenstatistik des totzeitbehafteten Photonen-Detektionssystems (Abschnitt 4.4.1, Abbildung 4.2 B). Im ersten Schritt 
wird auch hier mit der Intensitätsverteilung $\mathcal{I}_{\text {obj }}(x, y)$ (einschließlich einer Hintergrundkonstante $I_{B}$ ) ein rauschfreies theoretisches Bild des Objektes erzeugt. Die Größenparameter des Objektes und die Hintergrundkonstante stammen dabei aus der Faltungsproduktanalyse der experimentellen LSM-Bilder. Die Parameter sind die Mittelwerte sämtlicher gemessener Werte der Bildsequenz. Handelt es sich um die Bildsequenz eines bewegten Objektes, wird die Objektposition von Bild zu Bild entsprechend der vorgegebenen Trajektorie verändert. Anschließend wird jedem Bildpixel mit einer Zählrate oberhalb von $1.5 \cdot 10^{6} \mathrm{~s}^{-1}$ eine Pseudo-Zufallszahl $n$ aus einer Gauss-Verteilung mit dem Mittelwert $\mathcal{I}=\mathcal{I}_{\text {obj }}\left(x_{i}, y_{j}\right)$ und der Standardabweichung $\sigma(\mathcal{I})$ zugeordnet. Die Standardabweichung ergibt sich dabei aus der Varianz (Abschnitt 4.4.1)

$$
\begin{aligned}
\sigma^{2}[\mathcal{I}]= & t_{p} \cdot\left[1.04892\left(\mathcal{I} / t_{p}\right)-0.05101\left(\mathcal{I} / t_{p}\right)^{2}-0.00158\left(\mathcal{I} / t_{p}\right)^{3}\right. \\
& \left.+0.00008\left(\mathcal{I} / t_{p}\right)^{4}\right],
\end{aligned}
$$

wobei $t_{p}$ die Pixelverweildauer in $\mu$ s bezeichnet $\left(\mathcal{I} / t_{p}\right.$ ist die mittlere Photonenanzahl in $\left.10^{6} \mathrm{~s}^{-1}\right)$. Die Erzeugung der Zahl $n$ erfolgt durch die Generierung einer Zufallszahl $u$ aus einer Normalverteilung mit einer Standardabweichung von 1 und einem Mittelwert von 0 sowie der Skalierung

$$
n^{\prime}(\mathcal{I})=\mathcal{I}+\sigma(\mathcal{I}) \cdot u
$$

und der anschließenden Rundung auf einen ganzzahligen Wert $n$ (negative Zahlen werden durch eine Null ersetzt). Den Bildpixeln mit einer Zählrate unterhalb von $1.5 \cdot 10^{6} \mathrm{~s}^{-1}$ (siehe Abbildung 4.2) wird mit den Standardalgorithmen eine Zufallszahl aus einer PoissonVerteilung zugeordnet (s.o.). Die daraus resultierenden simulierten Bilder weisen die gleiche Rauschcharakteristik auf wie die zugrundeliegenden experimentellen LSM-Bilder von fluoreszierenden Mitochondrien. 


\section{Kapitel 4}

\section{Experimenteller Aufbau: Laserrastermikroskop und FCS-Apparatur}

Im Rahmen dieser Arbeit wurde eine bereits im Labor vorhandene FCS-Apparatur [3] zu einem kombinierten Laserrastermikroskop (LSM) und FCS-Gerät (FCLSM) weiterentwickelt. Durch die Kombination der beiden optischen Methoden ist es jetzt möglich, in schneller zeitlicher Abfolge FCS- und LSM-Messungen an einer Zellprobe durchzuführen. Ein weiterer Vorteil mit großem praktischen Nutzen - neben der Zusammenführung beider Methoden in einem Gerät - ist die freie Positionierbarkeit des konfokalen Detektionsvolumens: Dadurch können zum Beispiel Konzentrationen und Diffusionseigenschaften von Molekülen an beliebigen Stellen im Zytoplasma eines Neurons gemessen und im Anschluss an den FCS-Messungen Zellkompartimente mit hoher Genauigkeit abgetastet werden, um so Informationen über den für die Farbstoffmoleküle zur Verfügung stehenden Raum zu erhalten. Durch die Verwendung einer Avalanchephotodiode als Photodetektor zeichnet sich das LSM - im Vergleich zu den herkömmlichen Mikroskopen mit Photomultiplier - durch eine hohe Photonendetektionseffizienz und eine äußerst niedrige Dunkelzählrate aus. Hierdurch wird der Anteil des Photodetektors am Hintergrundrauschen in den LSM-Bildern vernachlässigbar.

\section{1 Übersicht}

Das Grundelement des optischen Aufbaus besteht aus einem inversen Mikroskop (Axiovert 35, Carl Zeiss, Oberkochen) mit einem Wasserimmersionsobjektiv (C-Apochromat 40/1.2W). Abbildung 4.1 zeigt eine Übersicht des experimentellen Aufbaus. Dieser besteht aus einem Anregungsstrahlengang (einschließlich des Lasers und der GalvanometerScanner), dem Detektionsstrahlengang (einschließlich des Photodetektors), einer Hardware 


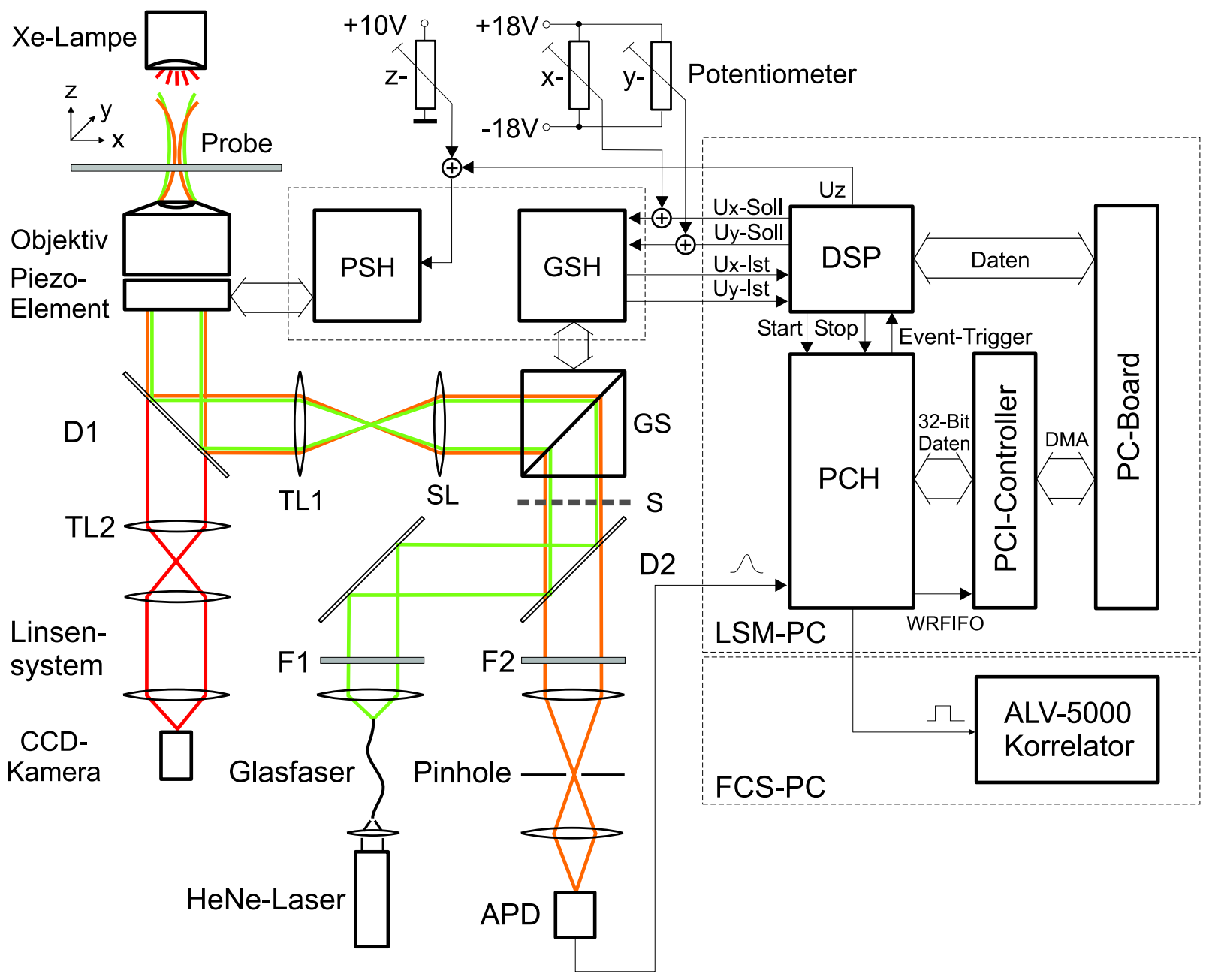

Abb. 4.1: Übersichtsplan des kombinierten Laserrastermikroskops und FCS-Aufbaus (Anregungs- und Detektionsstrahlengang, Computer-gesteuertes Photonendetektions- und Scan-System und assoziierte Komponenten; TL: Tubuslinse, SL: Scanlinse, D: dichroitischer Spiegel, F: Filter, S: Shutter, PSH: Piezo-Steuerungs-Hardware (PI-Regelkreis), GSH: Galvanometer-Steuerungs-Hardware (PID-Regelkreis), GS: Galvanometer-Scanner, PCH: Photon-Counting-Hardware).

zur Verarbeitung der Photodiodensignale sowie einem Computersystem (LSM- und FCSPC) ${ }^{1}$. Die Galvanometer-Scanner werden durch einen digitalen Signalprozessor (DSP) angesteuert. Die DSP-Initialisierung und Prozessüberwachung sowie die Verarbeitung der Photonendaten und die Berechnung der LSM-Bilder erfolgt über eine in $\mathrm{C}++$ program-

\footnotetext{
${ }^{1}$ Der Patch-Clamp-Aufbau (Abschnitt 3.2) mit den zugehörigen Geräten ist zugunsten der Übersichtlichkeit nicht dargestellt. Es besteht aus einem Pipettenhalter mit Mikro- und Piezotranslatoren, einem Patch-Clamp-Verstärker, Oszilloskop, einem PC mit Pulsprogramm und DA-Wandler-Karte sowie einem mehrspurigen digitalen Aufzeichnungsgerät (für technische Details siehe [72]).
} 
mierte Software (IPS, „Image-Processing-Software“, Abschnitt 4.8). Für die Detektion und Verarbeitung der Photodioden-Spannungspulse wurde im Rahmen dieser Arbeit eine spezielle Photon-Counting-Hardware (PCH) entwickelt (Abschnitt 4.4.2). Sie sendet die Photonendaten an einen PCI-Controller im LSM-PC. Um einen Echtzeit-Datentransfer zwischen PCI-Controller und LSM-PC zu ermöglichen, wurde das RT-Linux-Betriebssytem („RealTime Linux“) gewählt. Die detektierten Photodioden-Spannungspulse werden zusätzlich an dem im FCS-PC integrierten Hardwarekorrelator (Abschnitt 4.9) gesendet. Hierdurch kann beliebig zwischen LSM- und FCS-Messungen gewechselt werden.

In den folgenden Abschnitten werden die wichtigsten Elemente und Funktionseinheiten des kombinierten LSM- und FCS-Aufbaus erläutert und beschrieben.

\subsection{Anregungsstrahlengang}

Der Anregungsstrahlengang wurde in Hinsicht auf ein Strahlprofil hoher Güte und eine optimale Ausleuchtung der Rückapertur des Objektivs konzipiert. Die Wellenlänge des verwendeten Dauerstrichlasers von $\lambda_{\mathrm{ex}}=543.5 \mathrm{~nm}$ erlaubt eine effiziente Anregung der verwendeten Farbstoffe TMR und MitoTracker (Abschnitt 3.3.1 und 3.3.3). Die wichtigsten Komponenten lassen sich wie folgt zusammenfassen:

- HeNe-Laser cw, $\lambda_{\mathrm{ex}}=543.5 \mathrm{~nm}, P=2.2 \mathrm{~mW}$ (LK 54015, Laser Graphics, Dieburg)

- Monomode-Glasfaser Kerndurchmesser $3.5 \mu \mathrm{m}$, Anschliffwinkel $3^{\circ}$ (QSMJ3AF3AF-488-3.5/125-3-5, LINOS Photonics, Göttingen)

- Fassungsrevolver 5 fach mit Neutralfiltern verschiedenen Transmissionsgrades (F1) (065063, LINOS Photonics)

- Dichroitischer Spiegel (D2) R $(\lambda=450 \mathrm{~nm}-520 \mathrm{~nm}) \geq 99 \%$, T $(\lambda=557 \mathrm{~nm}-$ $750 \mathrm{~nm}) \geq 85 \%$ (BSP-25-560, DELTA Light \& Optics, Dänemark)

- Galvanometer-Sanner (Abschnitt 4.6)

- Scanlinse (SL) Bikonvexlinse aus BK7 mit Breitbandentspiegelung, $\mathrm{R}$ ( $\lambda=450 \mathrm{~nm}-$ $700 \mathrm{~nm})<0.3 \%, \mathrm{f}_{\mathrm{s}}=40 \mathrm{~mm} \pm 2 \%, \varnothing=31.5 \mathrm{~mm}$ (063012322, LINOS Photonics)

- Tubuslinse (TL1) $\mathrm{f}_{\mathrm{T}}=163.5 \mathrm{~mm}$ (Carl Zeiss, Oberkochen)

- Dichroitischer Spiegel (D1) R $(\lambda=530 \mathrm{~nm}-675 \mathrm{~nm}) \geq 90 \%$, T $(\lambda>690 \mathrm{~nm})$ $\simeq 90 \%$ (BSP690 DELTA Light Optics, Dänemark)

Die Verwendung eines Monomode-Glasfaserkabels sorgt für eine effiziente Raumfilterung und macht eine zusätzliche Filterung des Laserlichtes überflüssig. Die Laserleistung 
kann durch die Auswahl verschiedener Neutralfilter reguliert werden, um so FCS- und LSMMessungen bei unterschiedlichen Lichtintensitäten durchführen zu können. Das Laserlicht wird vor dem Eintritt in die Galvanometer-Einheit zu einem Strahl mit einem Durchmesser von $d=2 \mathrm{~mm}$ kollimiert. Um eine einfache Beziehung zwischen dem Drehwinkel eines Scanspiegels und der Ortsverschiebung in der Objektebene zu ermöglichen, muss die Drehebene des Laserstrahls in der Rückapertur des Objektivs liegen. Das verhindert auch einen Intensitätsverlust durch das „Herauslaufen“ des Laserstrahls aus der Rückapertur. Die Scanning-Einheit ist so positioniert, dass sich die zur Rückapertur konjugierte Drehebene („conjugate telecentric plane“) zwischen den beiden Scan-Spiegeln befindet [73]. Die Auslenkung eines Scanspiegels um den Winkel $\alpha^{\prime}$ transformiert sich zu der Ortsauslenkung $\Delta x=\mathrm{f}_{\mathrm{S}} \cdot \tan 2 \alpha^{\prime} / \mathrm{V}$ in der Objektebene und $\Delta x^{\prime}=\mathrm{f}_{\mathrm{S}} \cdot \tan 2 \alpha^{\prime}$ in der Zwischenbildebene (gleiches gilt für die y-Auslenkung). Mit einer maximalen Auslenkung von $\pm 2.3^{\circ}$, einer Vergrößerung von $V=40$ und einer Brennweite von $\mathrm{f}_{\mathrm{S}}=40 \mathrm{~mm}$ ergibt sich im quasistatischen Betrieb ein abfahrbares Objektfeld von $\sim 160 \mu \mathrm{m} \times 160 \mu \mathrm{m}$ (im LSM-Betrieb wird ein Objektfeld von $90 \mu \mathrm{m} \times 90 \mu \mathrm{m}$ ausgenutzt, Abschnitt 4.7). Die Auswertung mit einem in der Objektebene platzierten Mikrometermaß (Zeiss, Göttingen) ergibt die Beziehungen $1 \mathrm{~V} \hat{=} 4.456 \mu \mathrm{m}$ (x-Achse) und $1 \mathrm{~V} \hat{=} 4.545 \mu \mathrm{m}$ (y-Achse). Der Abstand zwischen der konjugierten Drehebene und der vorderen Brennebene der Scanlinse beträgt $43 \mathrm{~mm}$. Um möglichst wenig Fluoreszenzlicht durch Reflexionen an den Linsengrenzflächen zu verlieren, wurde anstelle eines Linsensystems eine hochvergütete Scanlinse mit einem Durchmesser von $31.5 \mathrm{~mm}$ ausgewählt. Da der Laserstrahl im Abstand von $43 \mathrm{~mm}$ von den Scanspiegeln nur um maximal $\Delta x^{\prime}=43 \mathrm{~mm} \cdot \tan 4.6^{\circ}=3.5 \mathrm{~mm}$ von der optischen Achse ausgelenkt wird, sind die Fehler aufgrund sphärischer Aberration minimal. Durch die Anordnung der Scan- und der Tubuslinse wird der Laserstrahl auf den Durchmesser $D=8.23 \mathrm{~mm}$ $\left(D=d \cdot \mathrm{f}_{\mathrm{T}} / \mathrm{f}_{\mathrm{S}}\right)$ aufgeweitet. Anschließend wird der kollimierte Laserstrahl über einen weiteren dichroitischen Spiegel (D1), der sich in dem Reflektorschieber des Mikroskops befindet, in die Rückapertur des Objektivs abgelenkt. Der Durchmesser der Rückapertur beträgt $9 \mathrm{~mm}$. Dadurch füllt der einfallende Laserstrahl die Objektivrückapertur optimal aus. Eine weitere Aufweitung des Laserstrahls würde zu einer zunehmenden Überleuchtung der Rückapertur führen und deshalb auch zu einer Zunahme an ungewollten Beugungserscheinungen. Der dichroitische Spiegel im Mikroskop reflektiert die für die FCS-Messungen relevanten Wellenlängen, also die Anregungswellenlänge von $\lambda_{\mathrm{ex}}=543.5 \mathrm{~nm}$ und die Emissionswellenlängen $550 \mathrm{~nm}-670 \mathrm{~nm}$ (siehe Abbildung $3.1 \mathrm{~B}$ ), und transmittiert die Wellenlängen oberhalb von $\lambda=690 \mathrm{~nm}$ mit $\sim 90 \%$. Mit Hilfe der Durchlichtbeleuchtung (Xenon-Lampe, Carl Zeiss, Göttingen; Abb. 4.1) und einer zweiten im Mikroskop integrierten Tubuslinse können so Objektstrukturen auf die CCD-Kamera - die im roten Spektralband sehr empfindlich ist - (CF4, Kappa, Gleichen) abgebildet werden, ohne den Reflektorschieber während des Experiments umzustellen. 


\subsection{Detektionsstrahlengang}

Das vom Objektiv eingesammelte Fluoreszenzlicht gelangt über den dichroitischen Spiegel (D1) im Reflektorschieber zur Tubuslinse und wird in die Zwischenbildebene fokussiert. Die nachstehende Scanlinse kollimiert das Emissionslicht wieder zu einem parallelen Lichtstrahl, der dann über die Scanspiegel zum zweiten dichroitischen Spiegel (D2) gelangt (Abbildung 4.1). Dieser trennt das Emissionslicht von störendem Reflexions- und Streulicht mit der Anregungswellenlänge $\lambda_{\mathrm{ex}}=543.5 \mathrm{~nm}$. Da der dichroitische Spiegel noch $1 \%$ des reflektierten Anregungslichtes durchlässt, muss ein zusätzlicher Bandpassfilter integriert werden. Der Anteil an Reflexionslicht ist durch das Objektträgerglas, auf dem sich die Kulturzellen befinden, besonders hoch. Der hinter dem dichroitischen Spiegel platzierte Sperrfilter (F2) (HQ 582/50, AF Analysetechnik, Pfrondorf) blockt die Wellenlängen zwischen $485 \mathrm{~nm}$ und $545 \mathrm{~nm}$ mit OD6 (das Verhältnis der Anzahl von transmittierten zu eintreffenden Photonen beträgt $10^{-6}$ ) sowie die Wellenlängen $610 \mathrm{~nm}-700 \mathrm{~nm}$ mit mindestens OD4. Zusätzlich reduziert sich die Detektion von längerwelligem Raman-Streulicht, das durch die Streuung des Anregungslichtes im Lösungsmittel entsteht. Nachdem das Emissionslicht den dichroitischen Spiegel und den Sperrfilter passiert hat, wird es durch eine Linse $(R<0.3 \%$ für $\lambda=450 \mathrm{~nm}-700 \mathrm{~nm}, 063854322$, LINOS Photonics, Göttingen) mit der Brennweite $\mathrm{f}_{\mathrm{L}}=100 \mathrm{~mm}$ fokussiert (Abbildung 4.1). In der Brennebene, die zur Zwischenbildebene konjugiert ist, befindet sich eine Lochblende (reflexfrei, 040198, LINOS Photonics, Göttingen) mit dem Durchmesser von $d_{\mathrm{L}}=2 r_{\mathrm{L}}=50 \mu \mathrm{m}$. Die Lochblende befindet sich in einem xy-Messverschieber (065070, LINOS Photonics, Göttingen), der eine Justierung der Lochblende in der Ebene orthogonal zur optischen Achse ermöglicht. Der Lochblendenradius ist so gewählt, dass die Fluoreszenzphotonen, die aus dem Bereich der schmalsten Stelle des Fokus' mit dem Durchmesser $d_{x y}=2 r_{x y} \simeq 0.48 \mu \mathrm{m}$ (Abschnitt 3.5) emittiert wurden, ungehindert durch die Lochblende gelangen. Bildet man die Lochblende mit dem Radius $r_{\mathrm{L}}$ in die Objektebene ab, ergibt sich der Radius $s_{0}=0.25 \mu \mathrm{m}\left(s_{0}=\mathrm{f}_{\mathrm{S}} / \mathrm{f}_{\mathrm{L}} \cdot r_{\mathrm{L}} / V\right)$. Die Lochblende ist maßgeblich an der Entstehung des 3D-GAussförmigen Detektionsvolumens beteiligt [42,50] (Abschnitt 2.2). Die Emissionsphotonen, die die Lochblende passieren, gelangen dann über eine weitere Linse ( $\mathrm{f}=10 \mathrm{~mm}, R<0.3 \%$ für $\lambda=450 \mathrm{~nm}-700 \mathrm{~nm}$, 063019322, LINOS Photonics, Göttingen) zu dem Photodetektor.

\subsection{Photonendetektion und -verarbeitung}

\subsubsection{Photodetektor}

Die Detektion der Emissionsphotonen erfolgt durch ein sogenanntes „Single-photon counting module" (SPCM-AQ-141, EG\&G Optoelectronics, Dumberry, Kanada), dessen Kern aus einer temperaturstabilisierten Avalanchephotodiode (APD, ,avalanche photodiode“) besteht $[74,75]$. Der gewählte Photodetektor hat eine geringe Totzeit $(<32 \mathrm{~ns})$, eine niedrige Dunkelzählrate $\left(100 \mathrm{~s}^{-1}\right)$ und eine hohe Gesamteffizienz. Die niedrige Totzeit wird 



Abb. 4.2: Zur Photonendetektion mit totzeitbehafteter APD. (A) Relative Standardabweichung der gemessenen mittleren Zählrate $\langle N\rangle$ des Detektionssystems, $r=\sqrt{\left\langle\delta N^{2}\right\rangle} /\langle N\rangle$ (berechnet mit dem Kurvenanpassungsergebnis aus Abbildung B; durchgezogene Kurve) und der totzeitkorrigierten und PoIsson-verteilten Zählrate $\left\langle N^{\prime}\right\rangle$ [76], $r^{\prime}=$ $\sqrt{\left\langle\delta N^{\prime 2}\right\rangle} /\left\langle N^{\prime}\right\rangle=\sqrt{\left\langle N^{\prime}\right\rangle} /\left\langle N^{\prime}\right\rangle=1 /\left\langle N^{\prime}\right\rangle$ (gestrichelte Kurve), aufgetragen über der mittleren Zählrate $\langle N\rangle$. Die Umrechnung von $\left\langle N^{\prime}\right\rangle$ in $\langle N\rangle$ ergibt sich aus dem eingefügten Graphen. Er zeigt die mittlere Zählrate $\langle N\rangle$ am Signalausgang der verwendeten APD in Abhängigkeit der totzeitkorrigierten Photonenrate $\left\langle N^{\prime}\right\rangle$ (Datenpunkte, EG\&G Optoelectronics, Kanada). Die durchgezogene Kurve zeigt das Ergebnis der Kurvenanpassung mit der Funktion $\langle N\rangle=\left\langle N^{\prime}\right\rangle t /\left(1+\left\langle N^{\prime}\right\rangle \tau\right)[76]$ mit $t=0.64661 \mu$ s und $\tau=0.03105 \mu \mathrm{s}\left(\left\langle N^{\prime}\right\rangle\right.$ in $\left.10^{6} \mathrm{~s}^{-1}\right)$. Die Zeitkonstante $\tau=31.05$ ns entspricht der mittleren Totzeit der APD. (B) Varianz $\left\langle\delta N^{2}\right\rangle$ der Photonenzählrate in Abhängigkeit der mittleren Zählrate $\langle N\rangle$, gemessen mit der Photon-Counting-Hardware (Abschnitt 4.4.2), d.h. nach Einbettung der APD-Pulse in einen $20 \mathrm{MHz}$-Bitstream. Die Datenpunkte entsprechen den experimentell bestimmten Werten, die durchgezogene Kurve zeigt das Ergebnis der Kurvenanpassung mit einem Polynom vierten Grades: $\left\langle\delta N^{2}\right\rangle=\sigma^{2}(N)=1.04892 N-0.05101 N^{2}-0.00158 N^{3}+0.00008 N^{4}$ $\left(N\right.$ in $\left.10^{6} s^{-1}\right)$. Die gestrichelte Gerade beschreibt die Varianz der Zählrate für einen Photodetektor mit PoISson-Statistik: $\left\langle\delta N^{2}\right\rangle=\langle N\rangle$. Für die Messungen wurde ein Tropfen einer $1 \mathrm{mM}$ TMR-Lösung auf ein Objektträgerglas aufgebracht. Der Laserfokus $\left(I=374 \mathrm{~kW} / \mathrm{cm}^{2}\right)$ wurde mit Hilfe des z-Piezoelementes entlang der optischen Achse Schritt für Schritt ausgehend von einer Postition innerhalb des $160 \mu \mathrm{m}$ dicken Objektträgerglases - in die Farbstofflösung bewegt.

durch aktives Löschen („quenchen“) des Lawinenstromes nach einem Photonenereignis („avalanche initiation“) erreicht [77,78]. Hierdurch ist eine Gesamteffizienz von 60-80\% möglich, wenn das Licht in einem Bereich $<100 \mu \mathrm{m}$ auf die aktive Detektoroberfläche fokussiert wird. Da die $50 \mu \mathrm{m}$-Lochblende 1:1 auf die Detektoroberfläche abgebildet wird (Abschnitt 4.3), ist hier ein Optimum erreicht. Die Maximalzählrate liegt für dieses Modul bei $\sim 18 \cdot 10^{6} \mathrm{~s}^{-1}$. Der Detektor kann über Mikromanipulatoren radial zur optischen Achse 

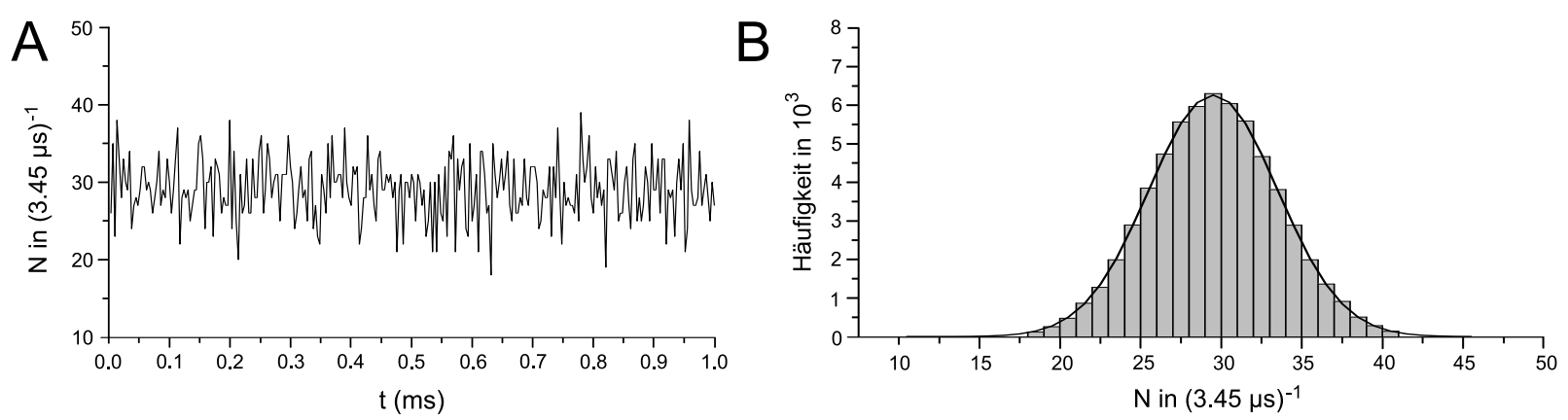

Abb. 4.3: Zur Statistik der Photonendetektion. (A) Intensitätssignal einer $1 \mathrm{mM}$ TMRLösung (Messung zum Experiment aus Abbildung 4.2 B). Gezeigt ist ein Ausschnitt von einer Millisekunde einer 0.22 Sekunden dauernden Messung. Das mittlere Fluoreszenzsignal entspricht einer Zählrate von $8.41 \cdot 10^{6} \mathrm{~s}^{-1}$. (B) Häufigkeitsverteilung der Photonenzählraten. Das Histogramm (sämtliche Zählraten der 0.22 Sekunden dauernden Messung) lässt sich durch eine Gauss-Verteilung mit dem Mittelwert $\langle N\rangle=29.03$ und der Standardabweichung $\sigma=3.99$ beschreiben.

justiert werden, so dass die Lochblende ins Zentrum der aktiven Detektoroberfläche abgebildet wird. Die Photonenereignisse werden durch Spannungspulse mit einer Amplitude von $\sim 2 \mathrm{~V}$ und einer Pulsdauer von $\sim 9$ ns angezeigt. Das Ausgangssignal der APD ist zur weiteren Verarbeitung mit der Photon-Counting-Hardware (PCH) des Detektionssystems verbunden (Abschnitt 4.4.2).

Durch die niedrige Dunkelzählrate der APD von 100 Photonen pro Sekunde ist ein Minimum an Hintergrundrauschen in den Fluoreszenzbildern gewährleistet. Bei einer mittleren Pixelverweildauer von $4 \mu$ s entspricht dies einem Photonenpuls pro 2500 Pixel. Dieser Beitrag kann somit vernachlässigt werden. Auf der anderen Seite begrenzt die Totzeit des Detektors die detektierbare Zählrate [76]. Der eingefügte Graph in Abbildung 4.2 A zeigt die mittlere Zählrate $\langle N\rangle$ der APD in Abhängigkeit der „totzeitkorrigierten“ Zählrate $\left\langle N^{\prime}\right\rangle[79]$. Die Anzahl der eintreffenden Photonen wird demnach bei steigender Lichtintensität zunehmend unterschätzt. Zudem hat die Detektortotzeit einen Einfluss auf die Statistik des detektierten Signals: Die relative Standardabweichung der mittleren Zählrate $\langle N\rangle$, gemessen mit dem Detektionssystem, vergrößert sich in dem für die Detektion relevanten Bereich von $\langle N\rangle<15 \cdot 10^{6} \mathrm{~s}^{-1}$ im Vergleich zu der relativen Standardabweichung der höheren und PoIsson-verteilten Zählrate $\left\langle N^{\prime}\right\rangle$ des totzeitkorrigierten Photodetektors (Abbildung $4.2 \mathrm{~A}$ ). Die relative Standardabweichung $r^{\prime}=1 /\left\langle N^{\prime}\right\rangle$ der korrigierten Zählrate $\left\langle N^{\prime}\right\rangle$ ist zum Vergleich über die mittlere detektierte Zählrate $\langle N\rangle$ aufgetragen. Die Umrechnungswerte sind von der Firma EG\&G Optoelectronics (Dumberry, Kanada) zur Verfügung gestellt. Hierbei wird vorausgesetzt, dass die Zählrate am Ausgang der APD durch Einbettung in den $20 \mathrm{MHz}$-Bitstream der PCH nicht verändert wird. Die größere relative Standardabweichung $r$ der totzeitbehafteten APD führt somit zu einem kleineren SNR der Bilder (Abschnitt 6.1.4). Die im Rahmen dieser Arbeit bestimmten Lokalisierungsgenauigkeiten des LSM - definiert durch die Standardabweichung einer Messgröße - 
stellen somit obere Grenzen dar. Weiterhin verändert sich die Varianz $\left\langle\delta N^{2}\right\rangle$ des Signals nicht-linear mit der mittleren detektierten Rate $\langle N\rangle$ (Abbildung $4.2 \mathrm{~B}$ ). Zudem lässt sich die Verteilung der Zählrate durch eine Gauss-Verteilung beschreiben [76] (Abbildung 4.3 B) - im Gegensatz zu anderen Detektorsystemen, wie z.B. einem Photomultiplier, bei dem das detektierte Signal in guter Näherung durch eine Poisson-Statistik mit $\left\langle\delta N^{2}\right\rangle=\langle N\rangle$ beschrieben werden kann. Photomultiplier- und CCD-basierte Detektionssysteme weisen dagegen ein nicht vernachlässigbares Hintergrundsignal in den Fluoreszenzbildern auf, was besonders im Fall von kleinen Fluoreszenzsignalen zu einem ungünstigeren SNR führt.

\subsubsection{Photon-Counting-Hardware $(\mathrm{PCH})$}

Die Detektion und Aufbereitung der Photodiodenspannungspulse (Abschnitt 4.4.1) erfolgt durch eine Photon-Counting-Hardware (PCH, Abb. 4.4), die speziell für dieses Projekt entwickelt wurde. Sie befindet sich auf einer Zusatzplatine direkt auf dem PCI-ControllerBoard (Abschnitt 4.5) im LSM-PC. Zur weiteren Verarbeitung wandelt sie die von der APD generierten Spannungspulse in einen $20 \mathrm{MHz}$ „Bitstream“ (TTL-Signal) um und sendet diesen nach einer Seriell-Parallel-Wandlung durch ein mit $20 \mathrm{MHz}$ getaktetes Schieberegister in Form von 32-Bit-Worten an den PCI-Controller. Ein Bit ist hierbei auf „1" gesetzt, wenn in dem entsprechenden Zeitintervall von 50 ns ein Photodioden-Spannungspuls detektiert wurde, andernfalls ist es auf „0" gesetzt ${ }^{2}$. Die Taktfrequenz der Elektronik ist mit $20 \mathrm{MHz}$ $(T=50 \mathrm{~ns})$ optimal auf die Maximalzählrate der APD von $18 \cdot 10^{6} \mathrm{~s}^{-1}$ abgestimmt. Die $32-$ Bit-Worte werden im Takt von $1.6 \mu \mathrm{s}(32 \times 50 \mathrm{~ns})$ in den FIFO-Speicher des PCI-Controllers gesendet. Für den Speicherzugriff generiert die Elektronik ein Schreib-Signal (WRFIFO\#, Abb. 4.4).

Die PCH verfügt insgesamt über sechs TTL-Anschlüsse. Neben dem Eingang für das Photodiodensignal (J1) und dem WRFIFO-Signalausgang (J3) gibt es jeweils einen weiteren Eingang zum externen Starten (J5) und zum Stoppen (J4) des Photon-CountingProzesses durch den DSP, einen zusätzlichen Photodiodensignalausgang für die Korrelatorkarte im FCS-PC (J2) und einen 100 kHz Taktausgang zur Synchronisation der DSP-Karte (J6) („Event-Trigger“, Abschnitt 4.7) (eine detaillierte Beschreibung der Hardware ist im Anhang A zu finden).

Die Abarbeitung des DSP-Programms - ein Durchlauf wird als „Event" bezeichnet erfolgt zyklisch (Abschnitt 4.7). Für die Steuerung der Events stehen dem DSP ein interner Zeitgeber sowie eine externe Triggerleitung zur Verfügung. Damit eine Synchronisation

\footnotetext{
${ }^{2}$ Das hier dargestellte Abspeichern des gesamten Bitstreams, bestehend aus einer Abfolge von Einsen und Nullen, ist nicht besonders effizient, wenn es sich um kleine Photocountraten handelt. Es empfiehlt sich vielmehr, nur die Zeitpunkte der Photocounts abzuspeichern [80]. Aus diesem Grund wurde vorab eine entprechende Hardware gebaut, die die Zeitpunkte der Photonendetektion asynchron dem PCI-Controller übergibt. Es hat sich aber gezeigt, dass der PCI-Controller (entgegen der Spezifikation) nicht im schnellen asynchronen Speicherzugriffsbetrieb ( $\mathrm{f}>10 \mathrm{MHz}$ ) eingesetzt werden kann. Im Fall der hier beschriebenen PCH konnte das Problem durch die Reduzierung der maximalen Speicherzugriffsfrequenz auf $625 \mathrm{kHz}$ $(T=1.6 \mu \mathrm{s})$ umgangen werden.
} 


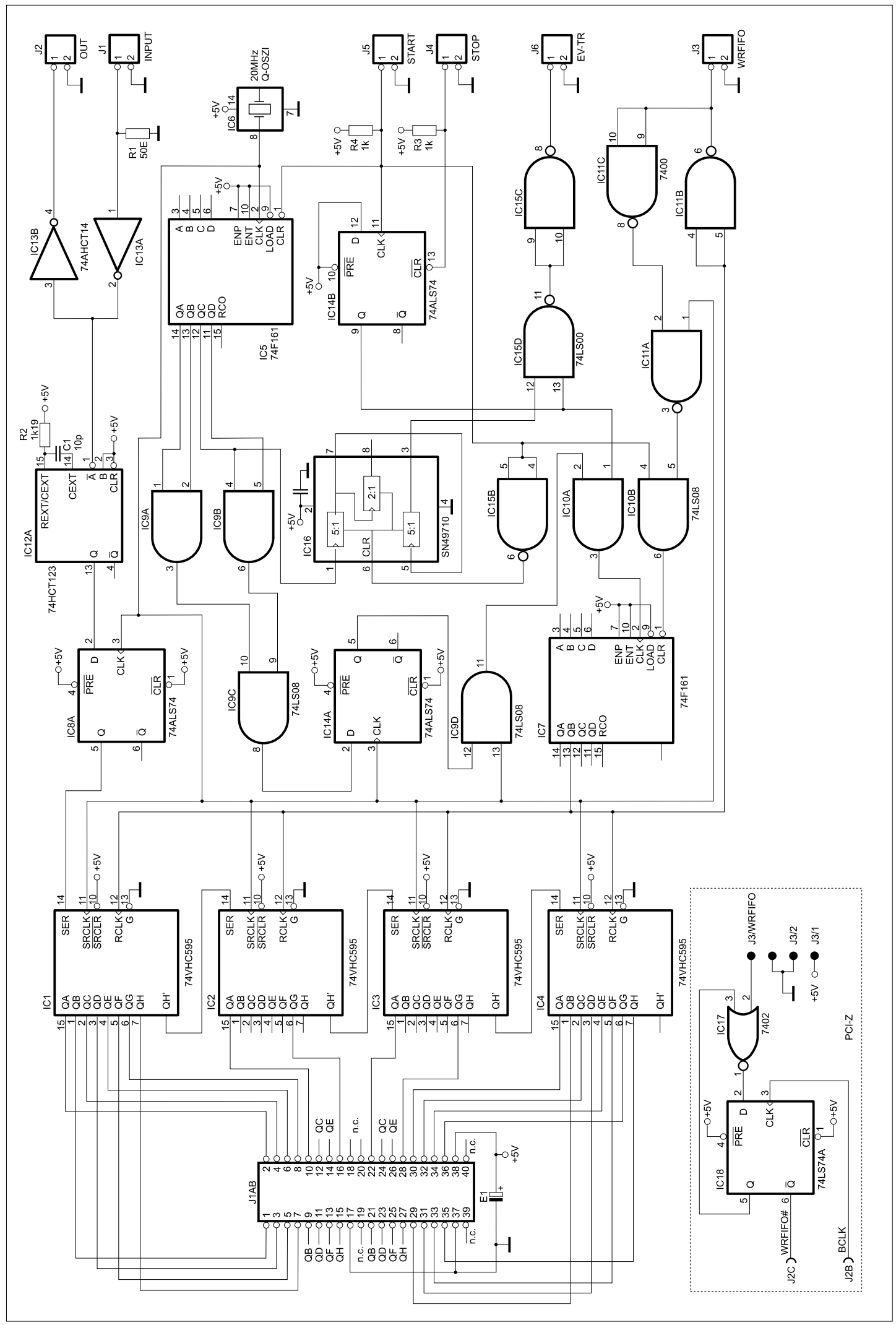

Abb. 4.4: Schaltplan der Photon-Counting-Hardware. 
zwischen der Ansteuerung der Galvanometer-Einheit durch den DSP und des PhotonCounting-Prozesses der PCH gewährleistet ist, wird das Event-Triggersignal durch die PCH generiert (J6). Bevor die PCH mit dem Einlesen der Photocounts und der Generierung des DSP-Triggersignals beginnen kann, wird im DSP ein „Initialisierungs-Programm“ durchlaufen. Dieser Programmteil wird nur einmal zu Beginn einer Messung abgearbeitet. In diesem Abschnitt stehen die DSP-Befehle, die das Startsignal für die PCH generieren. Der DSP wartet nach Ausführung der Initialisierungsbefehle auf das externe Event-Triggersignal der PCH. Das Einlesen der Photocounts und die Ansteuerung der GalvanometerScanner erfolgt somit in einem festen Zeitraster.

\subsection{PCI-Controller}

Der Transfer der Photocount-Daten von der PCH (20 MHz-Bitstream, Abschnitt 4.4.2) in den Arbeitsspeicher des LSM-PC erfolgt durch ein PCI-Controller-Interface (PCI-Proto LAB, H+K Messsysteme GmbH, Berlin). Den Kern der Schnittstelle bildet ein PCIController (S5933 PCI Matchmaker, AMCC, San Diego, CA, USA). Die PCI-ControllerKarte ist mit dem PCI-Bus des LSM-PC verbunden. Für den Datentransfer besitzt der PCI-Controller einen internen FIFO-Speicher (acht 32-Bit Worte). Dieser wird während des Photon-Counting-Prozesses durch die PCH beschrieben. Die Weiterleitung der zwischengespeicherten Daten erfolgt im DMA-Betrieb. Sobald die PCH vier Worte im FIFOSpeicher abgelegt hat, sendet der PCI-Controller sie mit einer Taktrate von $33 \mathrm{MHz}$ in den Arbeitsspeicher des LSM-PCs (Real-Time-Linux-Betriebssytem, Abschnitt 4.8). Für den PCI-Controller ist ein 1 GByte großer Bereich des Arbeitsspeichers reserviert. So können die Daten einer 6.67 Minuten $\left(8 \times 10^{9} \times 50 \mathrm{~ns}\right)$ dauernden Messung im Arbeitsspeicher des PCs abgelegt werden. Die Zeiten von typischen LSM-Messungen liegen im Sekundenbereich; so ist ein problemloser Betrieb gewährleistet. Da der Speicherbereich auch für die LSM-Software „sichtbar“ ist (Abschnitt 4.8), können Daten während des DMA-Zugriffs des PCI-Controllers aus dem Speicher gelesen und verarbeitet werden. Somit kann die LSMSoftware während einer Messung die Photonen-Daten in komprimierter Form - durch die Berechnung der Zeitpunkte der Photocounts - in einem Speicherbereich der Festplatte ablegen. Der PCI-Controller kann auf diese Weise den Speicher ohne Unterbrechnung zyklisch beschreiben.

Der Controller kann insgesamt 64 MByte Daten ohne Unterbrechung in den Arbeitsspeicher des PCs senden. Danach setzt der LSM-PC in Echtzeit ${ }^{3}$ (Interrupt-gesteuert) das Transfer-Count-Register im PCI-Controller zurück und den Adresszeiger um 64 MByte weiter. Dieser Vorgang benötigt weniger als $5 \mu \mathrm{s}$. Während der Abarbeitung des Interrupts kann die PCH im Takt von $1.6 \mu$ s (Anhang A) weitere vier Worte in den FIFO-Speicher

\footnotetext{
${ }^{3}$ Ein „Echtzeit“-Betriebssystem ist dadurch definiert, dass es innerhalb einer vorgegebenen Zeitspanne unter allen erdenklichen Betriebszuständen auf Ereignisse reagiert. Dies ist aber kein Kriterium dafür, ob ein System besonders schnell ist.
} 
des PCI-Controllers ablegen. Dies entspricht einer Zeit von $6.4 \mu \mathrm{s}$. Somit ist sichergestellt, dass keine Daten verloren gehen.

\subsection{Galvanometer-Scanner und Piezo-Translator}

Die Positionierung des Detektionsvolumens im Objektraum wird durch GalvanometerScanner ( $x y$-Ebene) und einem Piezoelement ( $z$-Achse) realisiert. Die Ansteuerung der Galvanometer-Scanner und des Piezoelementes kann entweder im „Handbetrieb“, d.h. mit Hilfe der $x$-, $y$ - u. $z$-Potentiometer (Abb. 4.1), oder DSP-gesteuert unter Anwendung der LSM-Software (Abschnitt 4.8) erfolgen. Auf diese Weise ist es möglich, Zellmembranen und zytosolische Kompartimente im Scanbetrieb („Rasterscan“) abzufahren oder im quasistatischen Betrieb eine beliebige Platzierung des Detektionsvolumens innerhalb der Neurone vorzunehmen.

Die Scanning-Einheit besteht aus zwei in einem gusseisernen Winkel befestigten Galvanometer-Scannern (G120DT, GSI Lumonics, Unterschleißheim) und einer Steuerungs-Hardware (AE1000 Controller Boards, GSI Lumonics). Der eintretende und der austretende Laserstrahl bilden in Ruhestellung (beide Eingangssignale auf $0 \mathrm{~V}$ ) einen Winkel von $90^{\circ}$, wobei der austretende Laserstrahl im Vergleich zum einfallenden um $6.78 \mathrm{~mm}$ höhenversetzt ist. Die Scanspiegel (E10-082694/E10-082714, GSI Lumonics) haben eine Silberbeschichtung mit einem Reflexionsvermögen von $\mathrm{R}>96 \%$ für $\lambda=450 \mathrm{~nm}-700 \mathrm{~nm}$. Die Auslenkung der Galvanometer-Spiegel ist im quasi-statischen Betrieb proportional zur angelegten Eingangsspannung. Die Steuerungs-Hardware ist so abgeglichen, dass bei einer maximalen Eingangsspannung von $\pm 18 \mathrm{~V}$ eine Winkelauslenkung von $\pm 2.3^{\circ}$ erfolgt. Da die Spiegelauslenkung im Fall einer dynamischen Ansteuerung (LSM-Betrieb) eine Funktion der Eingangsspannung und deren Frequenz ist, muss man die Spiegelposition in Abhängigkeit des angelegten Eingangssignals messen. Die Steuerungs-Hardware (PID-Regelkreise) stellt zu diesem Zweck für jeden Galvanometer-Scanner ein Positionssignal zur Verfügung. Es ist proportional zur Auslenkung des Spiegels und gibt die tatsächliche momentane Position des Spiegels wider. Im LSM-Betrieb generiert der DSP die Eingangsspannungen der Galvanometer-Scanner und misst gleichzeitig die Positionssignale (Abschnitt 4.7).

Die axiale Positionierung des Laserfokus' im Objektraum erfolgt durch den z-Trieb des Mikroskops (Grobeinstellung) und durch ein Piezo-Translator (P-721.10, PIFOC Mikroskop Fokussierung, Physik Instrumente, Waldbronn), der zwischen dem Objektivrevolver und dem Objektiv angebracht ist. Über einen Regelverstärker (E-610.L0, LVPZTVerstärker/Servo-Controller, Physik Instrumente) ist es möglich, das Objektiv in einem Bereich von $100 \mu \mathrm{m}$ entlang der optischen Achse mit einer Genauigkeit von $10 \mathrm{~nm}$ zu positionieren (Feineinstellung). Der Regelkreises wird mit einer Spannung zwischen 0 und $10 \mathrm{~V}$ angesteuert. Die axiale Position $z$ des Detektionsvolumens, bezogen auf den Nullpunkt $\left(U_{z}=0 \mathrm{~V}\right)$, ergibt sich aus der Beziehung $z=10 \mu \mathrm{m} \cdot U_{z} / \mathrm{V}$. Die Steuerung des Piezoelements kann wahlweise im Handbetrieb mit Hilfe des z-Potentiometers (Abb. 4.1) oder mit der LSM-Software (Abschnitt 4.8) erfolgen. 


\subsection{DSP-Steuerung}

Die Generierung der Galvanometer- und Piezo-Eingangsspannungen (Abb. 4.1), die Überwachung der Spiegel-Positionssignale sowie das Starten und das Stoppen der PCH (Abschnitt 4.4.2) erfolgt durch einen $40 \mathrm{MHz}$ SHARC-DSP (Floatingpoint-Signalprozessor, ADSP21062, AnalogDevices, Norwood, MA, USA), der auf einer PC-Erweiterungskarte (ADwin-9, Jäger Messtechnik GmbH, Lorch) integriert ist. Die Karte besitzt zwei 12-Bit Analog-Digital-Converter (ADCs), vier 12-Bit Digital-Analog-Converter (DACs), 16 digitale Ein- und Ausgänge, einen Triggereingang sowie einen lokalen 32 MByte Daten-Speicher. Die ADCs und DACs sind auf einen Eingangs- und Ausgangsspannungsbereich von $\pm 10 \mathrm{~V}$ eingestellt. Bei quasi-statischer Ansteuerung der Galvanometer kann somit ein Objektfeld von $\sim 90 \mu \mathrm{m} \times 90 \mu \mathrm{m}$ abgefahren werden (Abschnitt 4.6). Die Galvanometer-Scanner werden mit einem „Sägezahn“-Spannungsverlauf angesteuert (Seite 37, Abb. 4.7). Während das Detektionsvolumen in der Objektebene linear von der linken zur rechten Seite bewegt wird (Ansteuerung durch DAC1), liegt am Eingang für die y-Ablenkung ein konstanter Spannungswert (DAC2). Ist das Zeilenende erreicht, wird das Detektionsvolumen während des Zeilenrücklaufs um den voreingestellten Wert entlang der y-Achse weiterbewegt. Auf diese Weise wird das Bild Zeile für Zeile abgefahren. Während des letzten Zeilenrücklaufs wird die Steuerspannung für die y-Ablenkung wieder auf die erste Zeile eingestellt.

Die Programmierung des DSP erfolgt mit Hilfe eines Echtzeit-Entwicklungstools (ADbasic, Jäger Messtechnik GmbH, Lorch). ADbasic ist ein Compiler mit BASIC-Syntax. Er bietet erweiterte Funktionen für den Zugriff auf die analogen und die digitalen Einund Ausgänge, Funktionen zur Prozesssteuerung sowie Datenaustausch mit dem LSMPC [81]. Der DSP-Prozess, d.h. die Generierung der Steuerspannungen und das Abtasten der Galvanometer-Positionssignale, läuft unabhängig vom Zustand des LSM-PC ab. Der LSM-PC kann jedoch jederzeit auf das ADwin-System zugreifen, um Daten auszutauschen oder um ein neues Programm auf das ADwin-System zu laden. Der Datenaustausch zwischen dem DSP-Prozess und der LSM-Software (Abschnitt 4.8) erfolgt über globale Variablen und Arrays. Diese können sowohl vom DSP als auch von der Image-ProcessingSoftware des LSM-PC (IPS, Abschnitt 4.8) beschrieben und gelesen werden. Die Kommunikation zwischen der IPS und dem ADwin-System wird durch Software-Routinen, die ADbasic für eigene C-Programme bereitstellt, ermöglicht. Diese sind in der IPS eingebunden. Nach Start der IPS wird der ADwin-Treiber auf das ADwin-System geladen [81]. Dieser ermöglicht die Kommunikation zwischen dem PC und der ADwin-Karte. Durch das Laden des Treibers werden Prozesse auf dem ADwin-System gelöscht und alle globalen Variablen auf den Wert „0“ gesetzt. Anschließend wird das DSP-Programm auf das ADwin-System geladen. Der DSP-Prozess wird gestartet, sobald die IPS das Startsignal gibt. Nach der Festlegung der Scan-Region, der Anzahl der zu erzeugenden LSM-Bilder, der Pixelgröße (in nm) und der Scanzeit pro Bild oder Pixel berechnet die IPS sämtliche Parameter und 12-Bit Sample-Spannungswerte, die der DSP für die Generierung der Galvanometer-Spannungen benötigt. Die Berechnung der 12-Bit Sample-Werte für DAC1 (sämtliche Werte für eine Zeilenablenkung) erfolgt unter Berücksichtigung der voreinge- 
stellten Sample-Rate der Zeilen-Ablenkspannung (Abschnitt 4.8) und der vereinfachten Annahme einer quasi-statischen Auslenkung der Spiegel. Die tatsächliche Spiegelauslenkung wird während des Scan-Vorgangs durch den DSP gemessen und der LSM-Software mitgeteilt. Die IPS speichert die berechneten Sample-Werte in zwei globale Arrays ab. Der DSP kann auf sie zugreifen und so die nötigen Signale erzeugen. Die Umrechnung der ADCund DAC-Registerwerte in die entsprechende Spannung ist durch den Ausdruck

$$
\mathrm{U}=(\text { Digit }-2048) \cdot \frac{20 \mathrm{~V}}{4096}
$$

gegeben. Der Registerwert „0“ ergibt den Spannungswert -10 V und der Wert 4095 die maximale Spannung von 9.99512 V. Ein „Digit“ entspricht einem Spannungswert von 4.88 $\mathrm{mV}$.

Um eine möglichst hohe Zeitauflösung für die LSM-Aufnahmen zu erreichen, wird das Galvanometer-System für die Zeilen-Ablenkung mit einer Signalgrundfrequenz bis in den Bereich seiner Grenzfrequenz hinein betrieben $\left(f_{\mathrm{g}} \sim 2 \mathrm{kHz}\right)$. Die maximale Frequenz der Zeilenablenkungsspannung ist in der IPS auf $1 \mathrm{kHz}$ festgelegt. Bei dieser Frequenz folgt der Galvanometer-Scanner dem anfänglich scharfen Sägezahnverlauf nicht mehr vollständig, verläuft aber in einem Bereich von 80\% der Maximalamplitude linear (Seite 37, Abb. 4.7). Die maximale Abweichung von einer Geraden ist im Bereich von $\pm 0.8 \cdot U_{\max }$ kleiner $1 \%$. Die IPS berechnet die LSM-Bilder nur für den Bereich des Objektfeldes, der linear, d.h. mit einer konstanten Verweildauer pro Pixel („pixel dwell time“), abgefahren wird (Abb. 4.7). Da die y-Ablenkung Schrittweise nach jedem Zeilen-Scan erfolgt, d.h. mit einem minimalen Abstand von 1 Millisekunde, kann die y-Ablenkung als quasi-statisch betrachtet werden (die Konvertierungszeit der DACs beträgt $\sim 10 \mu \mathrm{s}$ ). Wird der Registerwert von DAC2 um ein Digit verändert, bewegt sich der Laserfokus in der Objektebene um $22 \mathrm{~nm}$ weiter (1 V厃̂ $4.545 \mu \mathrm{m}$, Abschnitt 4.2), dem kleinstmöglichen Zeilenabstand. Nachdem die ScanParameter und Sample-Werte berechnet und in den globalen Variablen und Arrays abgelegt sind, startet die IPS den DSP-Prozess (Abschnitt 4.8).

Ein ADbasic-Programm besteht aus den drei Abschnitten EVENT, INIT und FINISH sowie einem Abschnitt zur Variablendeklaration [81]. Der INIT-Abschnitt wird direkt nach dem Start des ADbasic-Prozesses einmal durchlaufen. In diesem Abschnitt werden die Datenregister der DACs (Ausgangsspannungen $U_{x}, U_{y}$ und $U_{z}$ ) mit den Datenworten für die ersten zu generierenden Spannungswerte initialisiert. Der 12-Bit Sample-Wert für $U_{z}$ (DAC3) wird von der IPS in einer globalen Variablen abgelegt. Dieser Wert kann während einer Messung durch die IPS geändert werden. Anschließend generiert der DSP das Startsignal für die PCH. Hierzu erzeugt er für für $\sim 1 \mu$ s einen $0 \mathrm{~V}$-Pegel an dem Signaleingang (J5) der PCH (Abschnitt 4.4.2).

Dem INIT-Abschnitt folgt der EVENT-Programmteil. Der EVENT-Abschnitt wird einmal ausgeführt, wenn ein Impuls vom externen Triggereingang eintrifft. Um eine Synchronisation zwischen der PCH und der Galvanometer-Ansteuerung durch den DSP zu erreichen, wird das EVENT-Tiggersignal durch die PCH generiert (Abschnitt 4.4.2). Nachdem der 
DSP die PCH gestartet hat, wartet er auf das Eintreffen des ersten Impulses. Die PCH generiert ein $100 \mathrm{kHz}$-Triggersignal. Somit wird der EVENT-Abschnitt im Abstand von $10 \mu \mathrm{s}$ einmal ausgeführt. Die Ausführung sämtlicher Befehle in diesem Abschnitt benötigt $\sim 6 \mu$ s. Der erste Befehl startet gleichzeitig die DA-Wandlung der vorab initialisierten DACs. Danach wird der AD-Wandler gestartet. Der Eingang des ADC ist mit dem Positionssignal (Zeilen-Ablenkung) der Galvanometer-Steuerungshardware verbunden (Abschnitt 4.6). Die Positionssignale der y-Ablenkung und des Piezo-Translators werden aufgrund der quasistatischen Ansteuerung nicht überwacht. Nach Start der Wandlung der DACs und des ADC werden die Datenregister der DACs mit den 12-Bit Sample-Worten für die im nächsten „Event" auszugebenen Spannungswerte initialisiert. Nach Beendigung der AD-Wandlung (zeigt ein internes Bit an) wird der gemessene Spannungswert ausgewertet, um die Phasenverschiebung zwischen dem generierten Steuersignal und dem Positionssignal zu berechnen. Sie ergibt sich, wenn man die Zeitpunkte der Nulldurchgänge beider Signale vergleicht. Zudem berechnet der DSP den maximalen Amplitudenbereich, innerhalb dessen die tatsächliche Spiegelauslenkung linear verläuft (max. 1\% Abweichung vom Verlauf einer Geraden). Beide Werte werden vom DSP in globale Variablen abgelegt.

Der Zugriff auf die globalen Daten-Arrays mit den 12-Bit Sample-Werten für DAC1 und DAC2 erfolgt über deklarierte Zählvariablen. Der DSP inkrementiert die Zählvariablen beim Eintritt in den EVENT-Abschnitt unter Berücksichtigung der vorgegebenen SampleRate der Zeilenablenkspannung. Die Dauer eines Spannungs-Samples (DAC1) wird vor Beginn der Messung von der IPS berechnet und in einer globalen Variablen abgespeichert (Abschnitt 4.8). Sie beträgt ein ganzzahliges Vielfaches des EVENT-Taktes. Ist sie z.B. auf den Wert „2“ gesetzt, wird der Registerwert von DAC1 nach jedem zweiten „Event“, d.h. alle $20 \mu \mathrm{s}$, neu gesetzt. Die Zählvariablen werden nach der Generierung einer Zeilenablenkung (DAC1-Register-Zählvariable) bzw. nach einer vollständigen y-Ablenkung (DAC2-RegisterZählvariable) zurückgesetzt. Ist ein Bild abgetastet, wird der „Bildindex“ erhöht. Da das Positionssignal dem generierten Signal nacheilt, wird der EVENT-Abschnitt nach der Generierung sämtlicher Bilder noch so häufig durchlaufen (ohne neue Spannungen auszugeben), bis die der Phasenverschiebung entsprechende Zeit - ein Vielfaches von $10 \mu$ s - überbrückt ist. Daraufhin beendet der DSP den Prozess und durchläuft den FINISH-Abschnitt. Dieser wird nach der Beendigung des DSP-Prozesses einmal ausgeführt. In diesem Teil stoppt der DSP die PCH und teilt der IPS das Ende des Scan-Vorgangs mit.

\subsection{Bilderzeugung und -verarbeitung}

Die Steuerung des Laserrastermikroskops erfolgt durch die im Rahmen dieser Arbeit entwickelten „Image-Processing-Software“ (IPS). Sie erlaubt die Steuerung des gesamten Messprozesses - von der Auswahl der Scan-Region, der Pixelauflösung, der Anzahl der gewünschten Bilder, der Scan-Zeit pro Bild oder Pixel und dem Starten und Stoppen des DSP-Prozesses sowie der DSP-Initialisierung (Abschnitt 4.7) bis hin zur Erzeugung von 

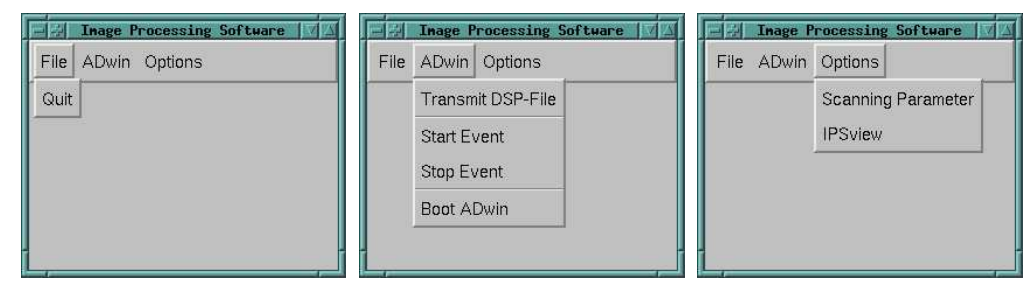

Abb. 4.5: Grafische Benutzeroberfläche der IPS (Hauptmenü).

animierten Bildsequenzen. Für die weitere Verarbeitung lassen sich die erzeugten LSMBilder im ASCII- und BMP-Format abspeichern.

Die IPS wird über eine unter dem RT-Linux Betriebssystem laufende grafische Benutzeroberfläche bedient (Abb. 4.5 und 4.6). Die Software ist in der Sprache C++ programmiert. Die grafischen Fenster und Schaltelemente wurden mit Hilfe der QT-Bibliothek (Trolltech, Oslo, Norwegen) erstellt. Für die Kommunikation mit dem ADwin-System sind C-Funktionen eingebunden, die von der DSP-Entwicklungsumgebung ADbasic (Abschnitt 4.7) für eigene Programme bereitgestellt werden. Abbildung 4.5 zeigt die Übersicht des IPSHauptmenüs. Das grafische Fenster erscheint nach dem Start des Programms auf dem Monitor des LSM-PCs. Die Steuerung der verschiedenen Funktionen erfolgt über eine Menüleiste. Über das „Pull-Down“-Menü $A D$ win können der ADwin-Treiber (Boot $A D$ win) und das DSP-Programm (Transmit DSP-File) auf das ADwin-System geladen und der DSPProzess gestartet und gestoppt werden (Abschnitt 4.7). Die grafische Benutzeroberfläche zur Editierung der LSM-Parameter (Abb. 4.6) wird über das Schaltelement Scanning Parameter aufgerufen. Die Größe der Scan-Region wird durch die Eingabe der Breite und der Höhe des Scan-Feldes in Vielfachen von 88 nm-Pixeln festgelegt (Frame Size). Die Bestimmung der Scan-Region erfolgt unter der Annahme einer quasi-statischen Auslenkung der Scan-Spiegel (Abschnitt 4.7). Die tatsächliche Spiegelauslenkung wird während des ScanVorgangs vom DSP berechnet und der IPS mitgeteilt. Die Scan-Region kann, wenn ihr Zentrum auf der optischen Achse liegt $\left(x_{0}=0\right.$ und $\left.y_{0}=0\right)$, auf einen maximalen Bereich von $1024 \times 1024$ Pixel eingestellt werden. Die Verschiebung des Laserfokus' um ein $88 \mathrm{~nm}-$ Pixel entspricht einer Steuerspannungsänderung von $19.521718 \mathrm{mV}$. Somit ergibt sich für einen Zeilen-Scan mit einer maximalen Auslenkung von \pm 512 Pixel ein Steuerspannungsbereich von $\pm 9.99512 \mathrm{~V}$. Dies ist gleichzeitig der maximale Ausgangsspannungsbereich der DACs (Abschnitt 4.7). Bei einer quasi-statischen Ansteuerung der Galvanometerscanner kann somit eine Scan-Region von $90 \mu \mathrm{m} \times 90 \mu \mathrm{m}$ abgefahren werden.

Die „Pixelauflösung“ der zu erzeugenden LSM-Bilder wird durch den vertikalen Abstand der Zeilen-Scans festgelegt. Es kann zwischen einem Zeilenabstand von $22 \mathrm{~nm}, 44 \mathrm{~nm}$, $88 \mathrm{~nm}$ und $176 \mathrm{~nm}$ gewählt werden (Pixel Resolution). Zudem lassen sich das Zentrum der Scan-Region (Frame Center), die Anzahl der zu erzeugenden LSM-Bilder (Frame Number), die Position des Laserfokus' entlang der optischen Achse (Z Setting) sowie die Scan-Zeit pro Bild oder Pixel (Scan Time) festlegen. Sind alle Parameter bestimmt, kann die Initialisie- 


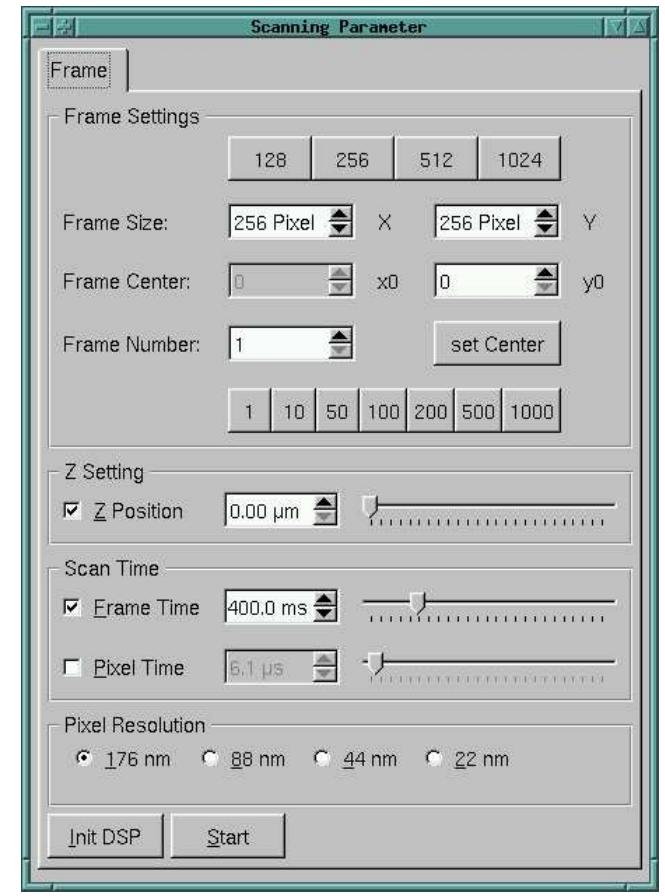

Abb. 4.6: Grafische Benutzeroberfläche der IPS („Scanning Parameter“)

rung des DSP beginnen. Durch die Betätigung des Schaltelementes Init DSP wird die IPS veranlasst, sämtliche für den DSP erforderlichen Parameter zu berechnen und in die globalen Variablen und Arrays des ADwin-Systems abzulegen (Abschnitt 4.7). Hierzu gehören die 12-Bit Sample-Spannungswerte für DAC1 (Registerwerte für eine Zeilenablenkung mit einem Sägezahn-Spannungsverlauf, Abb. 4.7), die Anzahl der 12-Bit Worte sowie die Dauer $\mathrm{T}_{\mathrm{a}}$ pro Sample-Wert (in einem ganzzahligen Vielfachen des DSP-EVENT-Taktes von $10 \mu \mathrm{s}$ ), die 12-Bit Sample-Werte für DAC2 (Registerwerte für eine y-Ablenkung) und deren Anzahl sowie die Anzahl der zu erzeugenden LSM-Bilder. Nach der Initialisierung des ADwin-Systems wird durch die Betätigung des Schaltelementes Start der DSP-Prozess in Gang gesetzt. Der DSP startet dann den Photon-Counting-Prozess der PCH (Abschnitt 4.4.2) und generiert die Steuerspannungen für die Galvanometer-Scanner und das Piezoelement (Abb. 4.1). Gleichzeitig überwacht er das Positionssignal $U_{\text {x-Ist }}$ des ZeilenablenkungsGalvanometers, bestimmt daraus den tatsächlichen Spannungsbereich $\pm \mathrm{A}_{\max }$, innerhalb dessen die Spiegelauslenkung linear verläuft (Abb. 4.7), berechnet die Phasenverschiebung $\Delta \mathrm{T}$ zwischen dem Galvanometer-Eingangssignal $U_{\mathrm{x} \text {-Soll }}$ und dem Positionssignal und teilt diese Daten der IPS mit.

Während des Scan-Prozesses werden die von der APD generierten Photocounts mit Hilfe der PCH und des PCI-Controllers in den Arbeitsspeicher des LSM-PCs übertragen (Abschnitt 4.4.2 und 4.5). Nach Ende der Messung berechnet die IPS aus den Photonendaten die LSM-Bilder und stellt sie in einer Bildsequenz auf dem Monitor dar. Für die Berechnung der Bilder wird die Tatsache ausgenutzt, dass die Spiegelauslenkungen 


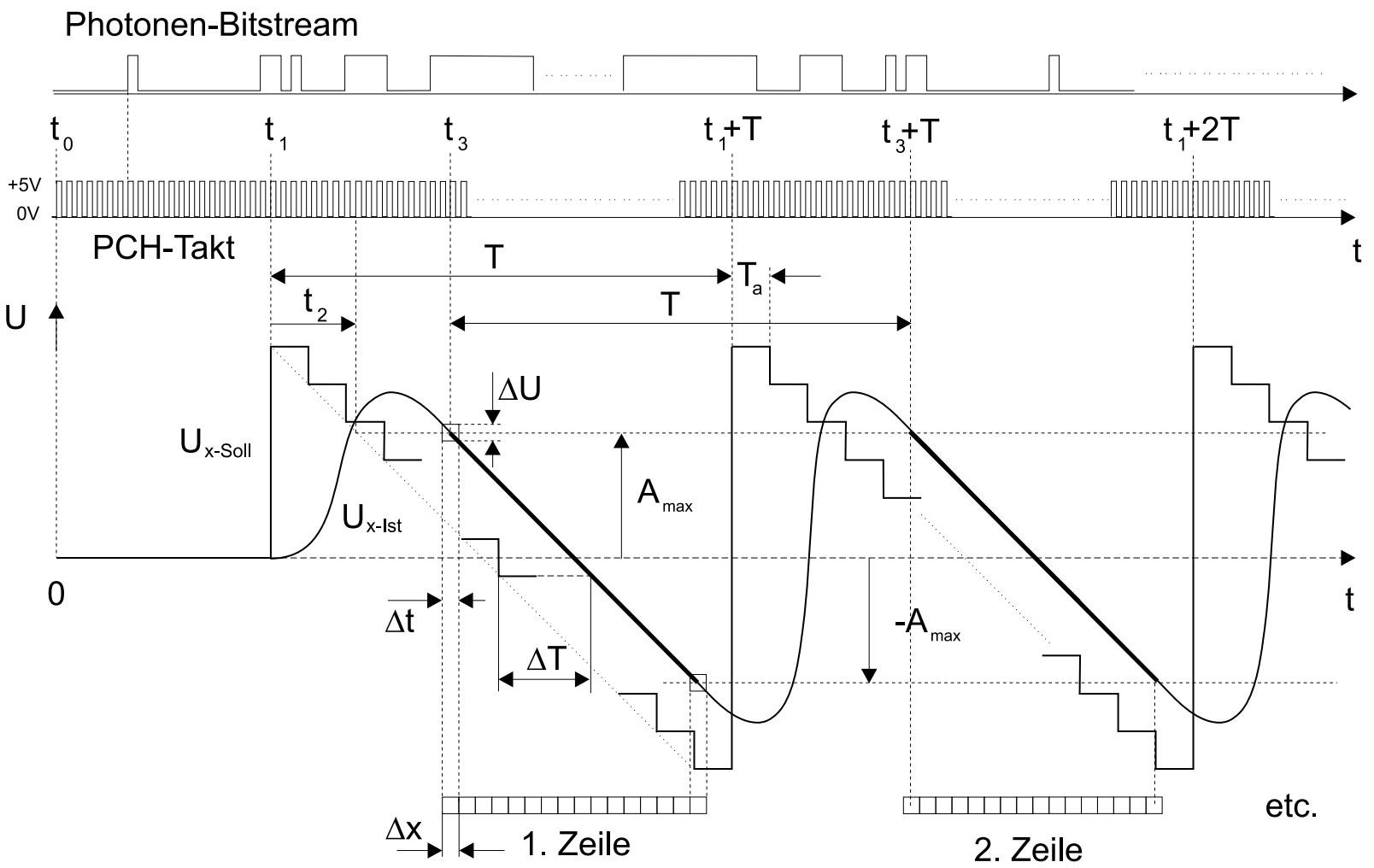

Abb. 4.7: Schematische Darstellung des Galvanometer-Eingangssignals $U_{x-\text { soll }}$ (Zeilenablenkung) und des tatsächlichen Positionssignals $U_{\text {x-st }}$ zusammen mit dem Photonen-Bitstream und dem $20 \mathrm{MHz}-\mathrm{PCH}$-Takt.

der Galvanometer-Scanner im eingeschwungenen Zustand periodisch verlaufen. Die Frequenzen, mit denen die Auslenkungen erfolgen, entsprechen den bekannten Frequenzen der Galvanometer-Eingangssignale $U_{\mathrm{x} \text {-Soll }}$ und $U_{\mathrm{y} \text {-Soll }}$. Wegen der Synchronisation der PCH mit dem ADwin-System (Abschnitt 4.7) erfolgt der Photon-Counting-Prozess und die Signalgenerierung des DSP in einem festen Zeitraster (Abb. 4.7). Damit die gesetzten Bits aus dem Photonen-Bitstream direkt den Bildpixeln zugeordnet werden können, berechnet die IPS den Startzeitpunkt $t_{3}$ der ersten Zeile sowie das Pixel-Zeitintervall $\Delta t$. Zusammen mit der bekannten Periodendauer $T$, der Anzahl der Pixel pro Zeile und der Anzahl der Zeilen pro Bild lassen sich dann die Photonencounts direkt in die zugehörigen Pixel sämtlicher Bilder einfügen. Hierzu bestimmt die IPS mit Hilfe der DAC1-Sample-Werte $\left(U_{\mathrm{x} \text {-Soll }}\right)$ und der Sample-Dauer $T_{a}$ eine Gerade, die tangential dem Treppenstufenverlauf von $U_{\text {x-Soll }}$ folgt, und berechnet damit den Zeitpunkt $t_{2}$, wenn die Gerade den Amplitudenwert $A_{\max }$ erreicht (Abb. 4.7). Zusammen mit der Phasenverschiebung $\Delta T$ und dem experimentell bestimmten zeitlichen Versatz $t_{1}$ zwischen dem ersten PCH-Takt und dem ersten gewandelten Spannungs-Sample kann schließlich der Zeitpunkt $t_{3}$ des Zeilenanfangs bestimmt werden (Abb. 4.7). Der Intensitätswert des ersten Pixels der ersten Zeile ergibt sich dann aus der Summe aller Photocounts im Intervall $t_{3}-\Delta t / 2 \leq t<t_{3}+\Delta t / 2$. 
Das einem Pixel entsprechende Zeitintervall $\Delta t$ folgt aus dem Spannungswert $\Delta U$ und der vorab berechneten Geradengleichung. Der Wert von $\Delta U$ ist hierbei durch die vorgegebene Pixelauflösung $\Delta x$ festgelegt $(1 \mathrm{~V} \hat{=} 4.456 \mu \mathrm{m})$. Damit nicht die Intensitätswerte für alle Pixel nacheinander berechnet werden müssen, durchläuft die IPS stattdessen die im Arbeitsspeicher abgelegten 32-Bit-Worte des Photonen-Bitstreams und ordnet die gesetzten Bits direkt den entsprechenen Pixeln zu. Diese Vorgehensweise ist effizienter, da einem Großteil der Pixel keine Photocounts zugeordnet werden. Auf diese Weise ist ein schneller Bildaufbau möglich. Die LSM-Bilder werden nacheinander berechnet und als Bildsequenz dargestellt. Anschließend werden automatisch sämtliche Parameter (Anzahl der Pixel pro Zeile, Pixelauflösung, Anzahl der Zeilen pro Bild, Bildanzahl und Scan-Zeit pro Bild und Pixel) sowie die Pixel-Intensitätsdaten in einem ASCII-File abgespeichert (*.ips; „ImageProcessing-Software"“-Files). Durch die Betätigung des Schaltelementes IPSview (Abb. 4.5) erscheint ein Benutzerfenster mit einer Liste der abgespeicherten IPS-Daten-Files. Die Daten einer Messung können dann erneut in den Arbeitsspeicher geladen und als Bildsequenz dargestellt werden.

\subsection{Echtzeitkorrelationsberechnung}

Das Ausgangssignal des Photodetektors (Abschnitt 4.4.1) ist über die PCH (Abschnitt 4.4.2) mit einer Korrelatorkarte (ALV-5000/E, ALV-Laser Vertriebsgesellschaft, Langen) verbunden. Diese befindet sich im FCS-Analyse-Computer (FCS-PC, Abb. 4.1). Der Karte stehen für die Berechnung der AKF 288 Kanäle mit jeweils 64 Bit Auflösung zur Verfügung. Sie sind in einem Zeitbereich von $200 \mathrm{~ns}$ bis zu einigen Stunden abschnittsweise logarithmisch angeordnet [82]. Jeder Kanal hat eine individuelle „Sampling-Zeit“ $T_{s}$. Diese spezielle Anordnung ermöglicht - trotz der geringen Kanalanzahl - die Abdeckung eines weiten Verzögerungszeitbereichs, ohne viele Informationen zu verlieren. Die Multiplikation und die Aufsummierung der Daten läuft für viele verschiedene Verzögerungszeiten parallel. Die AKF wird nach dem folgenden Algorithmus berechnet: 1. Zählen der Photoelektronenpulse innerhalb der Sampling-Zeitintervalle der Breite $T_{s} ; 2$. Verzögerung der „Samples" um ein ganzzahliges Vielfaches $n$ der Sample-Zeit $T_{s}: \tau=n \cdot T_{s} ; 3$. Multiplikation der verzögerten mit den unverzögerten Sample-Daten; 4. Aufsummierung aller Produkte (siehe auch [83]). Gleichzeitig wird die AKF über ein internes Schema normiert. Wenige Millisekunden nach dem Start der Analyse erscheint auf dem Monitor eine Korrelationsfunktion, deren Verlauf sich durch die ständige Datenaufnahme und Mittelwertbildung nach und nach glättet. Zusätzlich zur AKF ist in einem zweiten Fenster die über kurze Zeitabschnitte gemittelte Photonenzählrate aufgetragen (in kHz). Der Zeitabschnitt, in dem Photoelektronenpulse für die Mittelwertbildung gezählt werden, ist einige Millisekunden lang und hängt von der voreingestellten Messzeit ab. Die relativ hohen Photonenzählraten $\left(>10 \cdot 10^{3} \mathrm{~s}^{-1}\right.$, Abschnitt 5) verhindern jedoch die Auswertung von Einzelphotonenereignissen. 


\section{Kapitel 5}

\section{Passiver Molekültransport in Neuronen}

Ein wesentlicher Teil zellulärer Prozesse basiert auf der Diffusion von kleinen Signalmolekülen bis hin zu großen Makromolekülen. Die Diffusion eines Makromoleküls innerhalb einer Zelle wird durch eine hohe Konzentration von zellulären Proteinen behindert (typischerweise 20-30 vol\%). Zelluläre Proteine kommen in verschiedenster Form und Größe vor. Aktinfilamente und Mikrotubuli können z.B. Längen von einigen Mikrometern erreichen. Um dynamische zelluläre Prozesse zu verstehen, ist es erforderlich, das Verständnis der Diffusion von Makromolekülen in den beengten und überfüllten intrazellulären Kompartimenten zu verbessern.

In diesem Teil der Arbeit wird die Dynamik eines mit Farbstoff markierten hydrophilen $10 \mathrm{kDa}$ Dextrans (TMR-Dextran) innerhalb von Somata und Dendriten kultivierter Neurone untersucht, also eines Moleküls von der Größe eines kleinen Proteins. Für diese Untersuchungen braucht man eine Messmethode, die eine geringe Anzahl von Dextranmolekülen innerhalb eines kleinen zytosolischen Kompartimentes detektieren sowie schnelle und langsame Prozesse untersuchen und zwischen aktivem Transport und Diffusion unterscheiden kann. Die Fluoreszenzkorrelationsspektroskopie (FCS) ist eine Methode, die diese Anforderungen erfüllt [3,25-27]. Es werden experimentelle LSM-basierte Methoden und FCS-Algorithmen entwickelt, die es ermöglichen, hochpräzise Messungen von Moleküldynamiken innerhalb von Dendriten von Neuronen durchzuführen.

\subsection{Intrazelluläre FCS}

Nach den ersten FCS-Messungen in offenen Lösungssystemen Anfang der 90er Jahre mit einer FCS-Apparatur mit konfokalem Strahlengang [41-43] hat die FCS schnell an Popularität gewonnen. Bald darauf erschienen die ersten Arbeiten über intrazelluläre FCSAnwendungen. Es folgten Untersuchungen der Diffusion [84-88] und des aktiven Trans- 
ports [31] von fluoreszierenden Molekülen innerhalb verschiedener Zelltypen, und zwar unter Anwendung von Diffusionsmodellen für räumlich uneingeschränkte Systeme. Die Anwendung der Standard-FCS-Modelle für räumlich uneingeschränkte Lösungssysteme (Abschnitt 2.1) ist gerechtfertigt, solange die räumliche Ausdehnung des konfokalen Detektionsvolumens gegenüber der des Zellkompartimentes klein ist. Im Zuge dieser Arbeit werden FCS-Messungen innerhalb von Dendriten kultivierter Neurone durchgeführt, deren räumliche Ausdehnung in der gleichen Größenordnung liegt wie die des Detektionsvolumens. Um die Messdaten richtig interpretieren zu können, muss die Plasmamembran als Diffusionsgrenze in das Diffusionsmodell einbezogen werden [3].

\subsubsection{FCS-Modell für räumlich begrenzte Diffusion}

Bei FCS-Messungen innerhalb eines Dendriten, dessen Breite und Höhe in der gleichen Größenordnung sind wie die $1 / e^{2}$-Radien $r_{x y}$ und $r_{z}$ des Detektionsvolumens $V_{D}$ (oder kleiner), muss die räumlich begrenzte Diffusion der Moleküle berücksichtigt werden. Ist die Höhe $d_{z}$ des Diffusionsraumes ausreichend klein, d.h. $d_{z} / r_{z} \leq 0.83$ [3], kann die Diffusion in z-Richtung, d.h. entlang der optischen Achse, vernachlässigt werden. Die Durchmesser der untersuchten Dendriten liegen im Bereich von $1 \mu \mathrm{m}$ und darunter. Der $1 / e^{2}$-Radius des Detektionsvolumens in axialer Richtung beträgt $r_{z}=1.7 \mu \mathrm{m}$ (Abschnitt 3.5). Damit gilt für die Messungen $Z=d_{z} / r_{z}<0.59$. Unter diesen Bedingungen kann die AKF für Brownsche Diffusion in Dendriten durch folgenden Ausdruck beschrieben werden [3]:

$$
G(\tau)=\frac{1}{\left\langle N_{\mathrm{ges}}\right\rangle}\left(1+\frac{T e^{-\tau / \tau_{T}}}{1-T}\right) \sum_{j=1}^{m} \Phi_{j} \cdot g_{x}^{j}(\tau) \cdot \bar{g}_{y^{*}}^{j}(\tau)
$$

Hierbei erfolgt die Summation über $m$ Standard-AKF-Terme für die Diffusion entlang des Dendriten, d.h. der $x$-Achse,

$$
g_{x}^{j}(\tau)=\left(1+\tau / \tau_{\text {diff }_{j}}\right)^{-1 / 2}
$$

und $m$ Terme $\bar{g}_{y^{*}}^{j}(\tau)$ für räumlich begrenzte Diffusion orthogonal zur Achse des Dendriten, d.h. der $y$-Achse,

$$
\bar{g}_{y^{*}}^{j}(\tau)=\frac{\sqrt{\pi}}{Y}\left[1+\left(\frac{Y}{\sqrt{\pi}} \cdot \frac{\operatorname{erf}(Y)}{\operatorname{erf}^{2}(Y / \sqrt{2})}-1\right) \cdot \frac{\exp \left[-k(Y)(\pi / Y)^{2} \tau / \tau_{\text {diff }_{j}}\right]}{\sqrt{1+\tau / \tau_{\text {diff }_{j}}}}\right],
$$

mit

$$
k(Y)=0.689+0.34 \exp \left[-0.37(Y-0.5)^{2}\right] .
$$

Der Parameter $Y$ entspricht dem Verhältnis der Breite $d_{y}$ des Dendriten zum $1 / e^{2}$-Radius $r_{x y}$ des „offenen“ Detektionsvolumens $V_{D}$, d.h. $Y=d_{y} / r_{x y}$.

Damit die Molekülkonzentration $\langle C\rangle$ aus der mittleren detektierten Teilchenzahl $\left\langle N_{\text {ges }}\right\rangle$ bestimmt werden kann, muss das tatsächliche, durch die Grenzen der Plasmamembran 
gegebene Volumen $V_{D}^{*}$ bekannt sein. Im Fall der räumlichen Einschränkung entlang der $y$ und $z$-Achse ist das tatsächliche Volumen $V_{D}^{*}$ gegeben durch [3]

$$
V_{D}^{*}=\pi^{3 / 2} r_{x y}^{2} r_{z} \cdot \frac{[\operatorname{erf}(Y / \sqrt{2})]^{2}}{\operatorname{erf}(Y)} \cdot \frac{[\operatorname{erf}(Z / \sqrt{2})]^{2}}{\operatorname{erf}(Z)}
$$

\subsubsection{FCS-Modelle für anisotrope Diffusion}

Lässt sich die Diffusion entlang und orthogonal zur Achse des Dendriten durch verschiedene Diffusionskonstanten charakterisieren, d.h. $D_{x}=D_{\|}$und $D_{y}=D_{z}=D_{\perp}$, dann folgt für die AKF einer molekularen Spezies

$$
\begin{aligned}
G(\tau)= & \frac{1}{\langle N\rangle}\left(1+\frac{T e^{-\tau / \tau_{T}}}{1-T}\right) \cdot \frac{1}{\sqrt{1+\tau / \tau_{\text {diff }}}} \\
& \cdot \frac{1}{\sqrt{1+\tau / \tau_{\text {diff }}}} \cdot \frac{1}{\sqrt{1+\tau / S^{2} \tau_{\text {diff }}}},
\end{aligned}
$$

mit $\tau_{\text {diff }}=r_{x y}^{2} / 4 D_{\|}$und $\tau_{\text {diff }}=r_{x y}^{2} / 4 D_{\perp}$. Ist die Diffusion orthogonal zum Dendriten vernachlässigbar $(Y \leq 0.83$ und $Z \leq 0.83$ ), reduziert sich die AKF auf den Ausdruck

$$
G(\tau)=\frac{1}{\langle N\rangle}\left(1+\frac{T e^{-\tau / \tau_{T}}}{1-T}\right) \cdot \frac{1}{\sqrt{1+\tau / \tau_{\text {diff }}}} .
$$

Die AKF (5.1) für räumlich begrenzte Diffusion einer Spezies lässt sich dann für den Fall der anisotropen Diffusion wie folgt schreiben:

$$
G(\tau)=\frac{1}{\langle N\rangle}\left(1+\frac{T e^{-\tau / \tau_{T}}}{1-T}\right) \cdot g_{x}(\tau) \cdot \bar{g}_{y^{*}}(\tau),
$$

mit

$$
g_{x}(\tau)=\left(1+\tau / \tau_{\text {diff||}}\right)^{-1 / 2}
$$

und

$$
\bar{g}_{y^{*}}(\tau)=\frac{\sqrt{\pi}}{Y}\left[1+\left(\frac{Y}{\sqrt{\pi}} \cdot \frac{\operatorname{erf}(Y)}{\operatorname{erf}^{2}(Y / \sqrt{2})}-1\right) \cdot \frac{\exp \left[-k(Y)(\pi / Y)^{2} \tau / \tau_{\text {diff }_{\perp}}\right]}{\sqrt{1+\tau / \tau_{\text {diff }}}}\right] .
$$

\subsubsection{Berücksichtigung autofluoreszierender Moleküle}

Autofluoreszierende Biomoleküle können einen großen Einfluss auf intrazelluläre FCSMessungen haben $[86,89]$. Bewegt sich ein autofluoreszierendes Molekül durch das konfokale Detektionsvolumen, kann dies zu einem detektierbaren Intensitätsspike führen und einen 
„transienten“AKF-Beitrag hervorrufen. Die lineare Translation eines autofluoreszierenden Moleküls durch das Detektionsvolumen ist ein deterministischer Prozess. Die der Translation folgende Intensitätsänderung $\delta I(t)$ ist durch das Faltungsprodukt zwischen der detektierbaren Emissionsintensitätsverteilung $I_{E}(\vec{r})$ (2.11) und der Objekt-Funktion des fluoreszierenden Moleküls gegeben. Die Objektfunktion eines kleinen Moleküls $\left(d \ll r_{x y}\right)$ kann durch eine DiRAC $\delta$-Funktion angenähert werden. Bewegt sich das Molekül entlang der $x$-Achse, folgt für die Intensitätsveränderung

$$
\delta I(t) \sim \exp \left(-2 \frac{v^{2} t^{2}}{r_{x y}^{2}}\right),
$$

wobei das Molekül das Zentrum des Detektionsvolumens zum Zeitpunkt $t=0$ mit der Geschwindigkeit $v$ durchquert. Dieser Intensitätsspike führt während einer FCS-Messung $\mathrm{zu}$ einer transienten AKF-Komponente, proportional $\mathrm{zu}^{1}$

$$
g_{\mathrm{STE}}(\tau)=e^{-\left(\frac{\tau}{\tau_{t}}\right)^{2}} .
$$

Hierbei bezeichnet $\tau_{t}=r_{x y} / v$ die „charakteristische“ Translationszeit. Aufgrund der zeitlichen AKF-Mittelung (Abschnitt 4.9) verschwindet dieser zusätzliche Anteil allmählich. Denselben Ausdruck (5.12) berechneten Magde et al. [33] für den stationären stochastischen Prozess der gleichförmigen linearen Bewegung von fluoreszierenden Partikeln.

\subsection{Bestimmung des Diffusionsraums}

Für eine quantitative Auswertung von intrazellulären FCS-Daten ist es erforderlich, Kenntnisse über den für die Moleküle zur Verfügung stehenden Diffusionsraum zu haben. Zum einen kann die Molekülkonzentration nur dann von der mittleren Teilchenzahl $\langle N\rangle$ im Detektionsvolumen bestimmt werden, wenn das Detektionsvolumen bekannt ist. In Dendriten ist dieses Volumen durch die Grenzen der Plasmamembran gegeben, die daher bestimmt werden müssen. Zum anderen ist der Durchmesser des Dendriten ein Parameter im AKF-Modell (5.1) für räumlich begrenzte Diffusion. Eine unabhängige Bestimmung des Durchmessers kann daher das entsprechende Ergebnis der AKF-Analyse bestätigen.

In dieser Arbeit werden - abhängig von der intrazellulären Farbstoffkonzentration zwei verschiedene Methoden verwendet, um das Querschnittsprofil und den Durchmesser eines Dendriten zu bestimmen. Die erste besteht in der Färbung der Plasmamembran: Die Zellkultur wird nach der FCS-Messung für ca. 3 Minuten in $20 \mu \mathrm{M}$ di-8-ANNEPS (Molecular Probes, Leiden, Niederlande) inkubiert. Hierzu wird der Membranfarbstoff in der Badflüssigkeit gelöst. Anschließend wird die Zellkultur für einige Minuten mit der farbstofffreien Badlösung überspült. Danach wird das konfokale Detektionsvolumen durch das Zentrum des Dendriten gesteuert, und zwar orthogonal zu dessen Achse. Abbildung 5.1 zeigt die Resultate zweier Linien-Scans durch einen dünnen und einen dicken Dendriten. Der Durchmesser des Dendriten ergibt sich aus der Analyse des Faltungsproduktes

\footnotetext{
${ }^{1}$ Die Abkürzung „STE“ steht für die englische Bezeichnung „single transition event“ [89].
} 

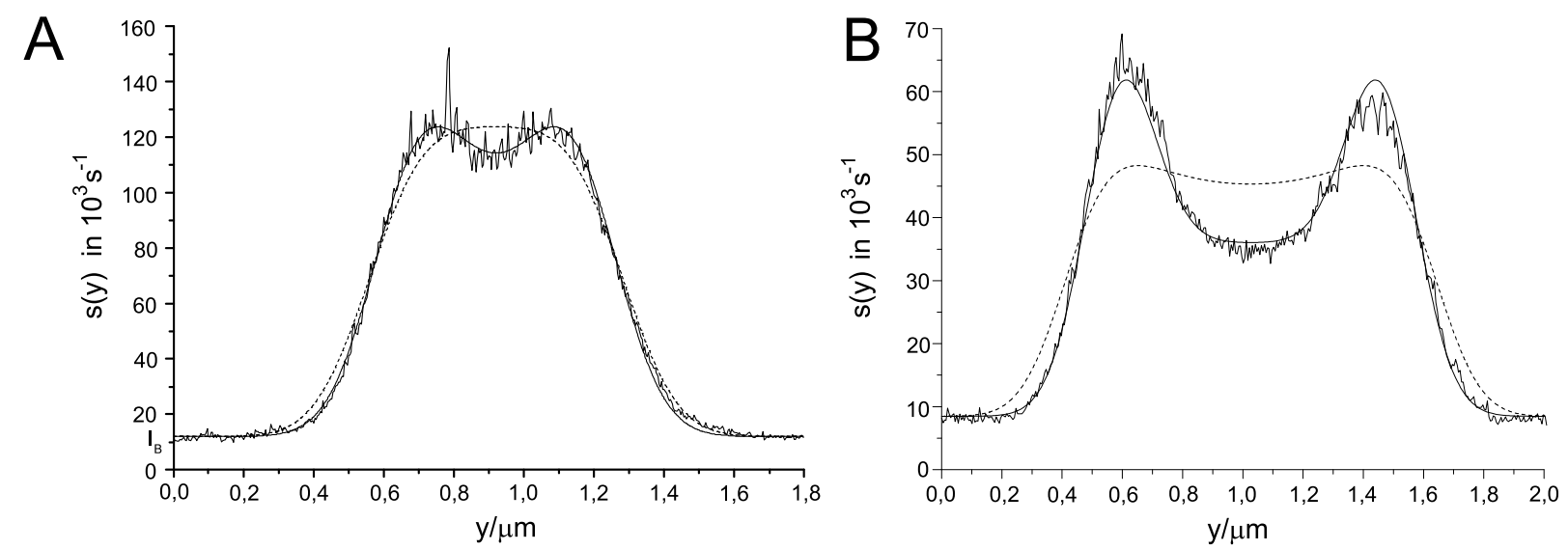

Abb. 5.1: Scan-Profile von mit di-8-ANNEPS gefärbten Dendriten kultivierter Neurone. (A) Linien-Scan (verrauschte Kurve) durch einen dünnen Dendriten; Scan-Geschwindigkeit: $32 \mathrm{~nm} / \mathrm{s}$. Ergebnis der Kurvenanpassung unter Annahme eines Rechteckprofils (Gl. 5.17, durchgezogene glatte Kurve) und eines Kreisprofils (Gl. 5.16, gestrichelte Kurve): $d_{y}=$ $0.51 \mu \mathrm{m}, d_{z}=0.35 \mu \mathrm{m}, \alpha_{\text {rect }}=47.52 \cdot 10^{3} \mathrm{~s}^{-1}, d=0.72 \mu \mathrm{m}, \alpha_{\text {circ }}=60.5 \cdot 10^{3} \mathrm{~s}^{-1}$ und $y_{0}=0.92 \mu \mathrm{m}$ (fixierte Parameter: $r_{x y}=0.25 \mu \mathrm{m}, r_{z}=1.73 \mu \mathrm{m}$ und $I_{B}=12 \cdot 10^{3} \mathrm{~s}^{-1}$ ). Summe der Gaussschen Fehlerquadrate: $\chi_{\text {circ }}^{2}=29.95$ und $\chi_{\text {rect }}^{2}=11.57$. (B) Linien-Scan (verrauschte Kurve) durch einen dicken Dendriten; Scan-Geschwindigkeit: $32 \mathrm{~nm} / \mathrm{s}$. Die glatte Kurve zeigt das theoretische Profil $s_{\text {rect }}(y)$ (5.17) für einen rechteckigen Querschnitt. Ergebnis der Kurvenanpassung: $\alpha=15.31 \cdot 10^{3} \mathrm{~s}^{-1}, d_{y}=0.895 \mu \mathrm{m}, d_{z}=0.76 \mu \mathrm{m}, y_{0}=$ $1.03 \mu \mathrm{m}$ und $I_{B}=8.46 \cdot 10^{3} \mathrm{~s}^{-1}$ (fixierte Parameter: $r_{x y}=0.236 \mu \mathrm{m}, r_{z}=1.652 \mu \mathrm{m}$ ). Ergebnis der Kurvenanpassung mit dem theoretischen Modell $s_{\text {circ }}(y)$ (5.16) für ein Profil mit Kreisquerschnitt: $\alpha=23.97 \cdot 10^{3} \mathrm{~s}^{-1}$ und $d=1.22 \mu \mathrm{m}$ (fixierte Parameter: $r_{x y}=$ $0.236 \mu \mathrm{m}, r_{z}=1.652 \mu \mathrm{m}, y_{0}=1.03 \mu \mathrm{m}$ und $\left.I_{B}=8.46 \cdot 10^{3} \mathrm{~s}^{-1}\right)$.

zwischen der detektierbaren Emissionsintensitätsverteilung $I_{E}(\vec{r})(2.11)$ des Detektionsvolumens und der Objektfunktion $\chi(x, y, z)$ des Dendriten. $\chi(x, y, z)$ liefert den Wert " 1 " für alle Orte auf der Plasmamembran des Dendriten und den Wert „0“ für alle anderen Orte. Wegen der hohen Konzentration des Membranfarbstoffs kann der zytosolische Fluoreszenzbeitrag vernachlässigt werden. Die Auswertung des Scan-Profils gibt Aufschluss über den Querschnitt und den Durchmesser des Dendriten. Die Objektfunktionen für einen Dendriten mit Kreis- oder Rechteckquerschnitt und der Fortpflanzungsrichtung entlang der $x$-Achse sind durch folgende Ausdrücke gegeben:

$$
\begin{aligned}
\chi_{\text {circ }}(y, z)= & \int_{y_{0}-d / 2}^{y_{0}+d / 2} \mathrm{~d} y^{\prime \prime} \delta\left(y^{\prime \prime}-y\right)\left[\delta\left(z-\sqrt{d^{2} / 4-\left(y^{\prime \prime}-y_{0}\right)^{2}}\right)\right. \\
& \left.+\delta\left(z+\sqrt{d^{2} / 4-\left(y^{\prime \prime}-y_{0}\right)^{2}}\right)\right]
\end{aligned}
$$


und

$$
\begin{aligned}
\chi_{\text {rect }}(y, z)= & \int_{y_{0}-d_{y} / 2}^{y_{0}+d_{y} / 2} \mathrm{~d} y^{\prime \prime} \delta\left(y^{\prime \prime}-y\right)\left[\delta\left(z-\frac{d_{z}}{2}\right)+\delta\left(z+\frac{d_{z}}{2}\right)\right] \\
& +\int_{-d_{z} / 2}^{d_{z} / 2} \mathrm{~d} z^{\prime \prime} \delta\left(z^{\prime \prime}-z\right)\left[\delta\left(y-y_{0}+\frac{d_{y}}{2}\right)+\delta\left(y-y_{0}-\frac{d_{y}}{2}\right)\right],
\end{aligned}
$$

wobei das Zentrum des Querschnitts durch die Koordinaten $y=y_{0}$ und $z=0$ gegeben ist. Der Kreisquerschnitt ist durch den Durchmesser $d$ und das Rechteckprofil durch die Breite $d_{y}$ und die Höhe $d_{z}$ definiert. Die Parameter $d, d_{y}$ und $d_{z}$ variieren bei einem Dendriten langsam entlang dessen Achse.

Das Faltungsprodukt zwischen der Objektfunktion und der detektierbaren Emissionsintensitätsverteilung $I_{E}(\vec{r})$ ergibt das theoretische Scan-Profil. Für einen Linien-Scan entlang der $y$-Achse (orthogonal zur Achse des Dendriten) gilt

$$
s(y)=\left\langle C_{S}\right\rangle \int_{-\infty}^{+\infty} \mathrm{d} x^{\prime} \int_{-\infty}^{+\infty} \mathrm{d} y^{\prime} \int_{-\infty}^{+\infty} \mathrm{d} z^{\prime} \xi\left(x^{\prime}, y^{\prime}, z^{\prime}\right) \cdot I_{E}\left(x^{\prime}, y-y^{\prime}, z^{\prime}\right),
$$

unter Verwendung der mittleren Anzahl der Farbstoffmoleküle pro Flächenelement $\left\langle C_{S}\right\rangle$. Für die Faltungsprodukte folgt weiter

$$
\begin{aligned}
s_{\text {circ }}(y)= & \alpha \cdot\left(1-S^{-2}\right)^{-1 / 2} \cdot \exp \left\{-2\left[\frac{d^{2} / 4-y_{0}^{2}}{r_{z}^{2}}+\frac{y^{2}}{r_{x y}^{2}}-\frac{\left(y S^{2}-y_{0}\right)^{2}}{r_{z}^{2}\left(S^{2}-1\right)}\right]\right\} \\
& \cdot\left\{\operatorname{erf}\left[\frac{\sqrt{2\left(S^{2}-1\right)}}{r_{z}}\left(y_{0}+\frac{d}{2}-\frac{y S^{2}-y_{0}}{S^{2}-1}\right)\right]\right. \\
& \left.-\operatorname{erf}\left[\frac{\sqrt{2\left(S^{2}-1\right)}}{r_{z}}\left(y_{0}-\frac{d}{2}-\frac{y S^{2}-y_{0}}{S^{2}-1}\right)\right]\right\},
\end{aligned}
$$

und

$$
\begin{aligned}
s_{\text {rect }}(y)= & \alpha \cdot\left[\operatorname { e x p } ( - \frac { d _ { z } ^ { 2 } } { 2 r _ { z } ^ { 2 } } ) \left\{\operatorname{erf}\left(\sqrt{2} \frac{y-y_{0}+d_{y} / 2}{r_{x y}}\right)\right.\right. \\
& \left.-\operatorname{erf}\left(\sqrt{2} \frac{y-y_{0}-d_{y} / 2}{r_{x y}}\right)\right\}+S \cdot \operatorname{erf}\left(\frac{d_{z}}{\sqrt{2} r_{z}}\right) \\
& \left.\cdot\left\{\exp \left(-2 \frac{\left(y-y_{0}+d_{y} / 2\right)^{2}}{r_{x y}^{2}}\right)+\exp \left(-2 \frac{\left(y-y_{0}-d_{y} / 2\right)^{2}}{r_{x y}^{2}}\right)\right\}\right],
\end{aligned}
$$

mit

$$
\alpha=g Q I_{0}\left\langle C_{S}\right\rangle \frac{\pi}{2} r_{x y}^{2}, S=\frac{r_{z}}{r_{x y}} .
$$

Die Ergebnisse der Kurvenanpassungen beider Faltungsfunktionen $s_{\text {circ }}(y)$ und $s_{\text {rect }}(y)$ an die experimentellen Scan-Profile aus Abbildung 5.1 zeigen, dass die Querschnitte der Dendriten in beiden Fällen am besten durch ein Rechteckprofil angenähert werden können. Das 
Kriterium ist hierbei die Summe der Gaussschen Fehlerquadrate. Zwei Gründe sind naheliegend: Zum einen beobachtet man häufig eine rechteckige Verformung der Dendritenunterseite durch Adhäsion zwischen der Plasmamembran des Dendriten und der Oberfläche des Objektträgerglases. Zum anderen haben Dendriten häufig unterschiedliche Breiten und Höhen. Deshalb lässt sich der Dendritenquerschnitt meistens nicht als Kreisquerschnitt mit konstantem Radius beschreiben.

Analog ergibt sich für einen $z$-Scan unter Annahme eines Rechteckprofils

$$
\begin{aligned}
s_{\text {rect }}(z)= & \alpha \cdot\left[S \cdot \operatorname { e x p } ( - \frac { d _ { y } ^ { 2 } } { 2 r _ { x y } ^ { 2 } } ) \left\{\operatorname{erf}\left(\sqrt{2} \frac{z-z_{0}+d_{z} / 2}{r_{z}}\right)\right.\right. \\
& \left.-\operatorname{erf}\left(\sqrt{2} \frac{z-z_{0}-d_{z} / 2}{r_{z}}\right)\right\}+\operatorname{erf}\left(\frac{d_{y}}{\sqrt{2} r_{x y}}\right) \\
& \left.\cdot\left\{\exp \left(-2 \frac{\left(z-z_{0}+d_{z} / 2\right)^{2}}{r_{z}^{2}}\right)+\exp \left(-2 \frac{\left(z-z_{0}-d_{z} / 2\right)^{2}}{r_{z}^{2}}\right)\right\}\right] .
\end{aligned}
$$

Die zweite Methode, den Querschnitt und den Durchmesser eines Dendriten zu bestimmen, besteht in der Auswertung des Scan-Profils eines Dendriten, der homogen mit hydrophilem Farbstoff gefüllt ist. Diese Methode ist anwendbar, wenn die Emissionsintensität hoch genug ist, um ein glattes Linien-Scan-Profil zu erhalten, und wenn FCS-Messungen an mehreren Zellen in einer Kultur durchgeführt werden sollen. Das theoretische Scan-Profil für einen Dendriten mit Kreisquerschnitt folgt aus dem Faltungsprodukt

$$
s_{\text {circ }}^{\prime}(y)=\langle C\rangle \int_{-\infty}^{+\infty} \mathrm{d} x^{\prime} \int_{0}^{+\infty} \mathrm{d} r \int_{0}^{2 \pi} \mathrm{d} \varphi r \xi_{\text {circ }}(r) \cdot I_{E}\left(x^{\prime}, y-r \cos \varphi, r \sin \varphi\right),
$$

zwischen der detektierbaren Emissionsintensitätsverteilung $I_{E}(\vec{r})$ und der entsprechenden Objektfunktion in der $y z$-Ebene

$$
\chi_{\text {circ }}(r)=\Theta(R-r)=\left\{\begin{array}{l}
1 \text { für } r \leq R \\
0 \text { sonst, }
\end{array}\right.
$$

mit den Zylinderkoordinaten $x^{\prime}, y^{\prime}=r \cos \varphi$ und $z^{\prime}=r \sin \varphi$. Die Fortpflanzungsrichtung des Dendriten verläuft hierbei entlang der $x$-Achse. $\langle C\rangle$ bezeichnet die mittlere Farbstoffkonzentration innerhalb des Dendriten. Für das theoretische Scan-Profil folgt dann

$$
\begin{aligned}
s_{\text {circ }}^{\prime}(y)= & \vartheta \exp \left[-2\left(y-y_{0}\right)^{2} / r_{x y}^{2}\right] \int_{0}^{R} \mathrm{~d} r \int_{0}^{2 \pi} \mathrm{d} \varphi r \\
& \cdot \exp \left[-2\left\{r^{2} \cos ^{2} \varphi-2\left(y-y_{0}\right) r \cos \varphi+r^{2} \sin ^{2} \varphi / S^{2}\right\} / r_{x y}^{2}\right],
\end{aligned}
$$

mit

$$
\vartheta=\langle C\rangle g Q I_{o} \pi^{1 / 2} r_{x y}
$$

Das Zentrum des Dendritenquerschnitts ist durch die Koordinaten $y=y_{0}$ und $z=0$ gegeben. 
Für das theoretische Scan-Profil $s_{\text {rect }}^{\prime}(y)$ eines mit Farbstoff gefüllten „rechteckigen" Dendriten folgt mit der Objektfunktion

$$
\begin{aligned}
\chi_{\mathrm{rect}}(y, z)= & {\left[\varepsilon\left(y-y_{0}+d_{y} / 2\right)-\varepsilon\left(y-y_{0}-d_{y} / 2\right)\right] } \\
& \cdot\left[\varepsilon\left(z+d_{z} / 2\right)-\varepsilon\left(z-d_{z} / 2\right)\right],
\end{aligned}
$$

unter Verwendung der Sprungfunktion

$$
\begin{gathered}
\varepsilon\left(y-y_{0}\right)=\left\{\begin{array}{l}
1 \text { für } y \geq y_{0} \\
0 \text { sonst }
\end{array}\right. \\
s_{\text {rect }}^{\prime}(y)=\beta \cdot\left[\operatorname{erf}\left(\sqrt{2} \frac{y-y_{0}+d_{y} / 2}{r_{x y}}\right)-\operatorname{erf}\left(\sqrt{2} \frac{y-y_{0}-d_{y} / 2}{r_{x y}}\right)\right],
\end{gathered}
$$

mit

$$
\beta=g Q I_{0}\langle C\rangle r_{x y}^{2} r_{z} \frac{\pi^{3 / 2}}{2^{5 / 2}} \operatorname{erf}\left(\frac{d_{z}}{\sqrt{2} r_{z}}\right) .
$$

Für einen Raster-Scan entlang der optischen Achse folgt analog

$$
s_{\text {rect }}^{\prime}(z)=\gamma \cdot\left[\operatorname{erf}\left(\sqrt{2} \frac{z-z_{0}+d_{z} / 2}{r_{z}}\right)-\operatorname{erf}\left(\sqrt{2} \frac{z-z_{0}-d_{z} / 2}{r_{z}}\right)\right],
$$

mit

$$
\gamma=g Q I_{0}\langle C\rangle r_{x y}^{2} r_{z} \frac{\pi^{3 / 2}}{2^{5 / 2}} \operatorname{erf}\left(\frac{d_{y}}{\sqrt{2} r_{x y}}\right)
$$

Abbildung 5.2 zeigt einen Linien-Scan entlang der $y$-Achse durch das Zentrum eines mit Farbstoff gefüllten Dendriten. Das Ergebnis der Kurvenanpassung mit dem theoretischen Scan-Profil $s_{\text {circ }}^{\prime}(y)$ (5.21) macht deutlich, dass der Querschnitt des Dendriten am besten durch ein Kreisprofil beschrieben werden kann. Die Anpassung des theoretischen Scan-Profils $s_{\text {rect }}^{\prime}(y)$ (5.24) für einen Dendriten mit rechteckigem Querschnitt führt bei diesem Beispiel zu einem schlechteren Ergebnis - wahrscheinlich durch die geringe Adhäsion zwischen der dendritischen Plasmamembran und der Glasoberfläche.

\subsection{Zeitkonstanten dendritischer Diffusion von TMR- Dextran}

Der folgende Abschnitt stellt die Ergebnisse der FCS-Messungen innerhalb von Dendriten kultivierter Neurone aus dem Bulbus olfactorius von Xenopus laevis Kaulquappen dar. Vor Beginn der Messungen werden die Neurone mit Hilfe der Patch-Clamp-Technik (Abschnitt 3.2) mit $10 \mathrm{kDa}$ TMR-Dextran gefüllt. Abbildung 5.3 zeigt eine Serie von AKFs, die innerhalb desselben dendritischen Kompartiments gemessen wurden. Die Messungen zeigen 


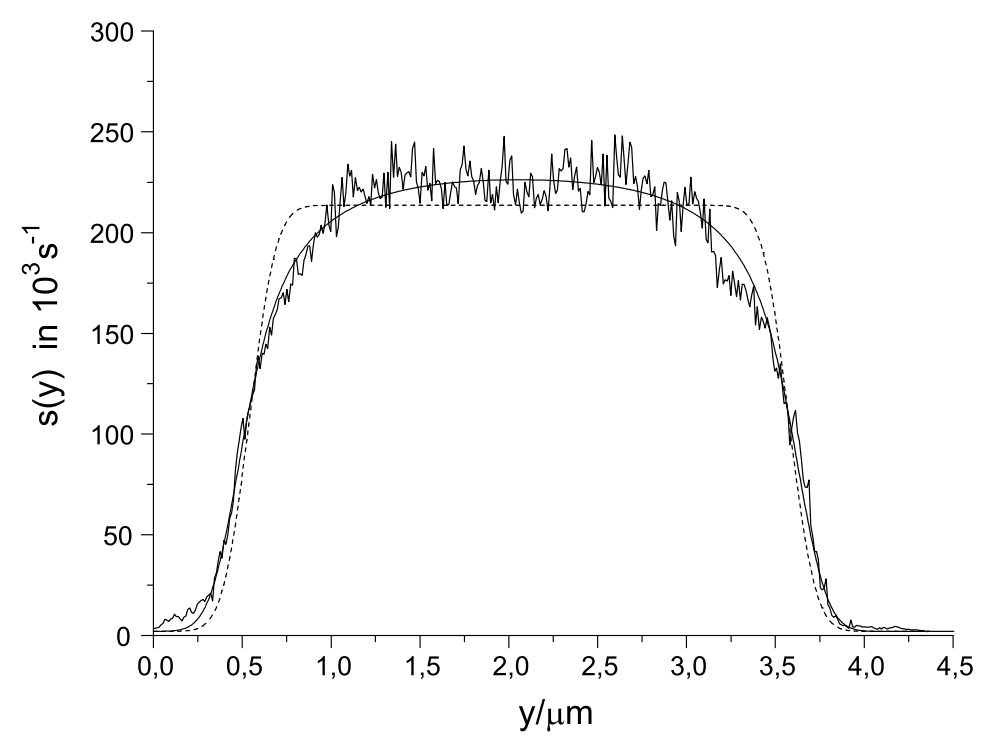

Abb. 5.2: Linien-Scan (verrauschte Kurve) durch einen mit $10 \mathrm{kDa}$ TMR-Dextran gefüllten, dicken Dendriten. Scan-Geschwindigkeit: $38 \mathrm{~nm} / \mathrm{s}$. Ergebnis der Kurvenanpassung des theoretischen Scan-Profils $s_{\text {circ }}^{\prime}(y)$ (5.21) (durchgezogene glatte Kurve): $\vartheta=384.71$. $10^{3} \mathrm{~s}^{-1} \mu \mathrm{m}^{-2}, R=1.636 \mu \mathrm{m}$ und $y_{0}=2.053 \mu \mathrm{m}$. Ergebnis der Kurvenanpassung des Scan-Profils $s_{\text {rect }}^{\prime}(y)$ (5.24) (gestrichelte Kurve): $\beta=105.5 \cdot 10^{3} \mathrm{~s}^{-1}, d_{y}=3.035 \mu \mathrm{m}$ und $y_{0}=2.058 \mu \mathrm{m}$ (fixierte Parameter: $r_{x y}=0.236 \mu \mathrm{m}, S=7$ und $I_{B}=2.2 \cdot 10^{3} \mathrm{~s}^{-1}$ ).



Abb. 5.3: AKFs von FCS-Messungen in einem mit $10 \mathrm{kDa}$ TMR-Dextran gefüllten Dendriten (das zugehörige Scan-Profil ist in Abb. 5.1 B gezeigt). Die Dauer einer Messung und der zeitliche Abstand zwischen zwei Messungen betrugen je 10 Sekunden. Die Messungen wurden nach dem Erreichen des Diffusionsgleichgewichtes ausgeführt. Die Anregungsintensität betrug - wie auch für alle anderen Messungen in Abschnitt $5-I=3.14 \mathrm{~kW} / \mathrm{cm}^{2}$. 

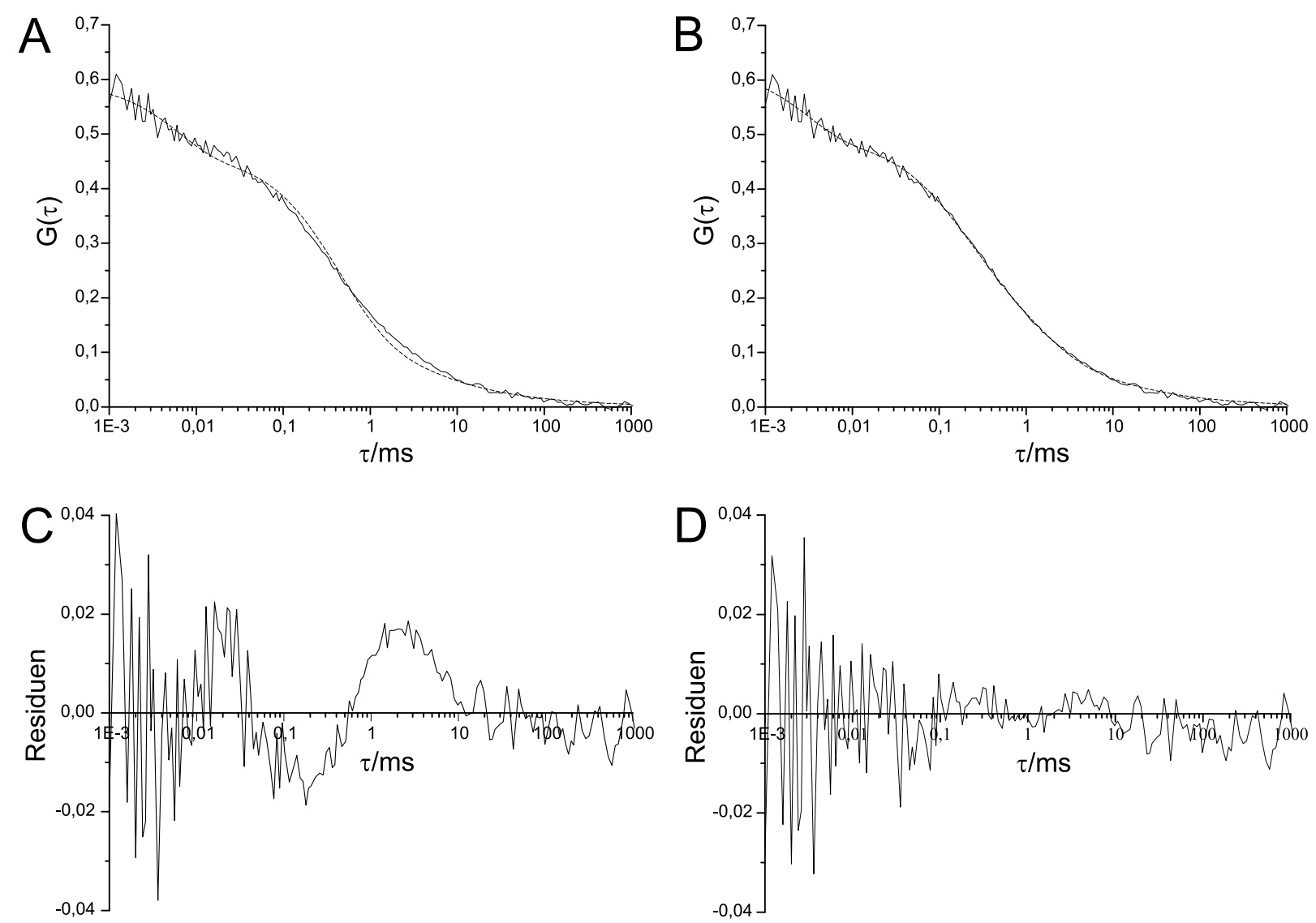

Abb. 5.4: AKF einer FCS-Messung in einem mit TMR-Dextran gefüllten Dendriten (identisch zu der untersten $A K F$ in Abb. 5.3). (A) Ergebnis der Kurvenanpassung mit einem 1-Komponenten-Modell (Gl. 5.1, $m=1$, gestrichelte Kurve): $\langle N\rangle=2.164, T=0.223$, $\tau_{T}=6.05 \mu \mathrm{s}$ und $\tau_{\text {diff }}=0.515 \mathrm{~ms}$ (fixierter Parameter: $Y=3.79$, Ergebnis der Auswertung des zugehörigen Scan-Profils, siehe Abb. 5.1 B). (B) Ergebnis der Auswertung mit einem 2-Komponenten-Modell (Gl. 5.1, $m=2$, gestrichelte Kurve): $\left\langle N_{\text {ges }}\right\rangle=2.028$, $T=0.208, \tau_{T}=3.01 \mu \mathrm{s}, \Phi_{1}=0.598$ und $\tau_{\text {diff }}=0.185 \mathrm{~ms}$ und $\tau_{\text {diff }}=1.422 \mathrm{~ms}$ (fixierter Parameter: $Y=3.79)$. (C) Differenz zwischen der experimentellen und theoretischen Kurve in A. (D) Differenzkurve für B. Die Farbstoffkonzentration innerhalb des Dendriten betrug $\langle C\rangle=25 \mathrm{nM}$ (berechnet mittels: $\langle C\rangle=\left\langle N_{\text {ges }}\right\rangle / V_{D}^{*} N_{A}, N_{A}=6.02 \times 10^{23} \mathrm{Mol}^{-1}$ und $V_{D}^{*}=0.133 \mathrm{fl}$ mit $V_{D}^{*}=\pi^{3 / 2} r_{x y}^{2} r_{z}[\operatorname{erf}(Y / \sqrt{2})]^{2} / \operatorname{erf}(Y) \times[\operatorname{erf}(Z / \sqrt{2})]^{2} / \operatorname{erf}(Z)$ und $\left.Z=d_{z} / r_{z}=0.461\right)$.

starke Abweichungen für größere Zeiten $\tau$. In erster Näherung lassen sie sich durch ein AKF-Modell für eine monomolekulare Spezies beschreiben (Gl. 5.1, $m=1$, Abb. 5.4 A). Das Ergebnis der Kurvenanpassung ist aber in keinem Fall zufriedenstellend (Abb. 5.4 C). Die Kurvenanpassung mit einem 2-Komponenten-Modell (Gl. 5.1, $m=2$ ) führt dagegen zu einem befriedigenden Ergebnis (Abb. 5.4 D), was die scheinbare Existenz einer zweiten molekularen Spezies impliziert. In vielen Fällen muss sogar eine dritte Komponente 




Abb. 5.5: AKF einer FCS-Messung in einem mit $10 \mathrm{kDa}$ TMR-Dextran gefüllten Dendriten (identisch zu der obersten AKF in Abb. 5.3). Die AKF spiegelt die Detektion eines STES wider. Für die Beschreibung der Daten ist ein 3-Komponenten-AKF-Modell erforderlich: zwei Komponenten für räumlich begrenzte Diffusion (Gl. 5.1, Summationsindex $j=1,2$ ) und eine STE-Komponente (Gl. 5.12, Summationsindex $j=3$ ). Ergebniss der Kurvenanpassung: $\left\langle N_{\text {ges }}\right\rangle=2.012, T=0.134, \tau_{T}=4.64 \mu \mathrm{s}, \Phi_{1}=0.499, \tau_{\text {diff }}=0.209 \mathrm{~ms}, \Phi_{2}=0.375$, $\tau_{\text {diff }}=1.573 \mathrm{~ms}, \Phi_{3}=0.114$ und $\tau_{t_{3}}=239.5 \mathrm{~ms}$ (fixierter Parameter: $Y=3.79$ ).

eingeführt werden (Gl. 5.1, $m=3$ ), damit die Kurvenanpassung ein zufriedenstellendes Ergebnis liefert. Abbildung 5.5 zeigt eine AKF mit einer charakteristischen „Schulter" im Bereich großer Zeiten $\tau$. Eine stationäre AKF mit solch einem Verlauf ist charakteristisch für einen stationären uniformen Translationsprozess [33], wohingegen eine plötzlich erscheinende und mit der Zeit verschwindende AKF-Komponente dieser Form ein einzelnes Translationsereignis („single transition event“, STE) widerspiegelt (Abschnitt 5.1.3) [89]. In der Tat lässt sich ein gutes Kurvenanpassungsergebnis erzielen, wenn man ein AKF-Modell verwendet, das zwei Komponenten für räumlich begrenze Diffusion (Gl. 5.1, Summationsindex $j=1,2)$ und eine STE-Komponente, d.h. $g_{\mathrm{STE}}(\tau)$ (Gl. 5.12, Summationsindex $j=3$ ), enthält (Abb. 5.5).

Insgesamt führen die FCS-Messungen in Dendriten zu zwei bis drei Komponenten mit den relativen Anteilen $\Phi_{1}, \Phi_{2}$ und $\Phi_{3}$, und den charakteristischen Zeitkonstanten $\tau_{\text {diff }_{1}}, \tau_{\text {diff }_{2}}$ und $\tau_{\mathrm{T}_{3}}$ bzw. $\tau_{\text {diff }}$. In Abbildung 5.6 sind die Ergebnisse der Kurvenanpassungsanalysen der in Abbildung 5.3 gezeigten Messungen zusammengestellt. Bei Betrachtung der Zeitkonstanten $\tau_{\text {diff }_{1}}$ (erste Komponente), $\tau_{\text {diff }_{2}}$ (zweite Komponente) und $\tau_{\mathrm{T}_{3}}$ bzw. $\tau_{\text {diff }_{3}}$ (dritte Komponente) der nacheinander durchgeführten Messungen fällt auf, dass zwei der Zeitkonstanten eine sehr kleine Varianz aufweisen, wohingegen die dritte Zeitkonstante stark fluktuiert (Abb. 5.6 A). Die Mittelwerte für die beiden kleineren Zeitkonstanten betragen $189 \mu \mathrm{s}$ und $1.626 \mathrm{~ms}$. Trägt man die relativen Beiträge $\Phi_{1}, \Phi_{2}$ und $\Phi_{3}$ in Abhängigkeit von 



Abb. 5.6: Parameterdarstellung der in Abbildung 5.3 gezeigten AKFs. (A) Charakteristische Diffusionszeitkonstanten der sechs nacheinander gemessenen AKFs (Messungsindex i). Die beiden horizontalen Linien entsprechen den Mittelwerten $\bar{\tau}_{\text {diff }}=0.189 \mathrm{~ms}$ und $\bar{\tau}_{\text {diff }}=$ $1.626 \mathrm{~ms}$ der ersten und zweiten Diffusionszeitkonstanten. (B) Relative Beiträge $\Phi_{j}$ der fluoreszierenden Spezies in Abhängigkeit der charakteristischen Zeitkonstanten.

den charakteristischen Zeitkonstanten auf, so zeigt sich, dass die beiden Beiträge $\Phi_{1}$ und $\Phi_{2}$ eine scharfe Verteilung mit einem Anteil von 55\% und $40 \%$ aufweisen. Die dritte Komponente $\left(\tau_{\text {diff } 3}\right.$ in Fall von Diffusion und $\tau_{\mathrm{T}_{3}}$ im Fall eines STEs) variiert dagegen in einem Bereich zwischen $10 \mathrm{~ms}$ und mehr als $200 \mathrm{~ms}$ und trägt nur $10 \%$ oder weniger zur AKF bei (Abb. 5.6 B). In vielen Messungen ist die dritte Komponente nicht vorhanden (siehe z.B. Abbildung 5.6 A, Messungsindex $i=2$ ).

Die Auswertung der FCS-Messungen in Dendriten mit dem Diffusionsmodell für räumlich begrenzte Diffusion (Gl. 5.1-5.4) führt damit zu einem interessanten Ergebnis. Obwohl nur eine molekulare Spezies in die Neurone injiziert wurde, sind zwei bis drei Komponenten nötig, um die Daten zu beschreiben. Dieser scheinbare Widerspruch führt zu folgenden Fragen, die in den nächsten Abschnitten beantwortet werden:

1. Sind die Ergebnisse spezifisch für die Diffusion in Dendriten? Um diese Frage zu beantworten, wurden FCS-Messungen auch in Zellkörpern (Somata) vorgenommen.

2. Enthalten die Zellen autofluoreszierende Moleküle, die zusätzlich zum exogenen Farbstoff zur AKF beitragen? Um dies zu testen, wurden FCS-Messungen in Neuronen ohne intrazelluläres TMR-Dextran ausgeführt.

3. Führt das Zytoskelett innerhalb von Dendriten, insbesondere die parallele Struktur der Mikrotubuli (Abb. 5.11), zu einer anisotropen Diffusion des $10 \mathrm{kDa}$ TMRDextrans? Wenn dem so wäre, müssten die FCS-Daten mit einem AKF-Modell ausgewertet werden, das zwischen der Diffusion entlang des Dendriten und der Diffusion 
orthogonal zum Dendriten unterscheiden kann. Zu diesem Zweck wurde ein entsprechendes Model hergeleitet (Gl. 5.8-5.10) und auf die AKF-Daten angewendet.

4. Bindet das TMR-Dextran an zytosolische Elemente oder an die Plasmamembran? Um diese Frage zu beantworten, wurden FCS-Messungen in sehr dünnen Dendriten durchgeführt, die mit einem AKF-Modell für eindimensionale Diffusion ausgewertet werden können.

5. Ist das hergeleitete AKF-Modell (für räumlich begrenzte Diffusion, Gl. 5.1-5.4) an sich verantwortlich für die Detektion einer zusätzlichen Diffusionskomponente? Um diese Frage zu klären, wurden FCS-Messungen innerhalb von dicken Dendriten ausgeführt, die mit den Standard-Modellen für räumlich uneingeschränkte 2D- und 3D-Diffusion (2.18) ausgewertet werden können.

\subsection{Diffusion in Somata}

Die in den Somata gemessenen AKFs zeigen, wie oben schon bei den dendritischen AKFs festgestellt, teilweise starke Fluktuationen im Bereich großer Zeiten $\tau$ (Abb. 5.7 $A$ und $5.8 A$ ). Auch in diesem Fall lassen sie sich teilweise durch die Detektion von STEs großer Moleküle erklären (Abb. 5.7 B). Da Breite und Höhe der Somata $\left(d_{y}, d_{z} \geq 6 \mu \mathrm{m}\right)$ im Vergleich zu den $1 / e^{2}$-Radien des Detektionsvolumens groß genug sind (mit $r_{x y} \simeq 0.24 \mu \mathrm{m}$ und $S \simeq 7$, folgt $Y=d_{y} / r_{x y} \geq 25$ und $Z=d_{z} / r_{z} \geq 3.53$, siehe [3]), kann die räumliche Begrenzung der Diffusion durch die Plasmamembran des Zellkörpers vernachlässigt werden. Die Auswertung der FCS-Messungen innerhalb der Somata kann daher mit dem StandardAKF-Modell für räumlich uneingeschränkte Diffusion (2.18) erfolgen.

Im Gegensatz zu den FCS-Messungen in Dendriten ergeben die Messungen in Somata nur eine "stationäre" charakteristische Diffusionszeitkonstante (Abb. $5.7 C$ und $5.8 C$ ). In den Beispielen in Abbildung 5.7 und 5.8 trägt diese Komponente 75-90\% bzw. 90-100\% zur gesamten AKF bei, wohingegen die fluktuierende zweite und dritte Komponente nur einen geringen Beitrag haben (Abb. $5.7 D$ und 5.8 D). Gleiches wurde in 67 Somata beobachtet. Die zweite stationäre charakteristische Zeitkonstante $\tau_{\text {diff }_{2}}$, die in Dendriten gemessen wird, ist offenbar spezifisch für die Diffusion innerhalb von Dendriten. Die detektierten fluktuierenden Komponenten können durch den Transport oder die Diffusion von großen autofluoreszierenden Partikeln durch das Detektionsvolumen hervorgerufen werden (z.B. autofluoreszierende Mitochondrien [86]).

In vielen Fällen ist ein 1-Komponenten-AKF-Modell (Gl. 2.18, $m=1$ ) mit $\Phi_{1}=1$ (Abb. $5.8 D$ ) ausreichend, um ein sehr gutes Kurvenanpassungsergebnis zu erzielen (Abb. 5.8, $B$ und $C$, Messungsindex $i=1,3)$. Die dominierende Zeitkonstante $\tau_{\text {diff }_{1}}$ ist um den Faktor 1.2 bis 2.6 größer als die Zeitkonstante des TMR-Dextrans in wässriger Lösung $\left(\tau_{\text {diff }}=160 \mathrm{~ms}\right.$ für die im Rahmen dieser Arbeit verwendete und weiterentwickelte FCSApparatur). Dieses Ergebnis zeigt, dass das exogene $10 \mathrm{kDa}$ TMR-Dextran relativ ungehindert im Zytoplasma der Somata bzw. Nuclei (die Zellkerne füllen die Somata fast vollständig 

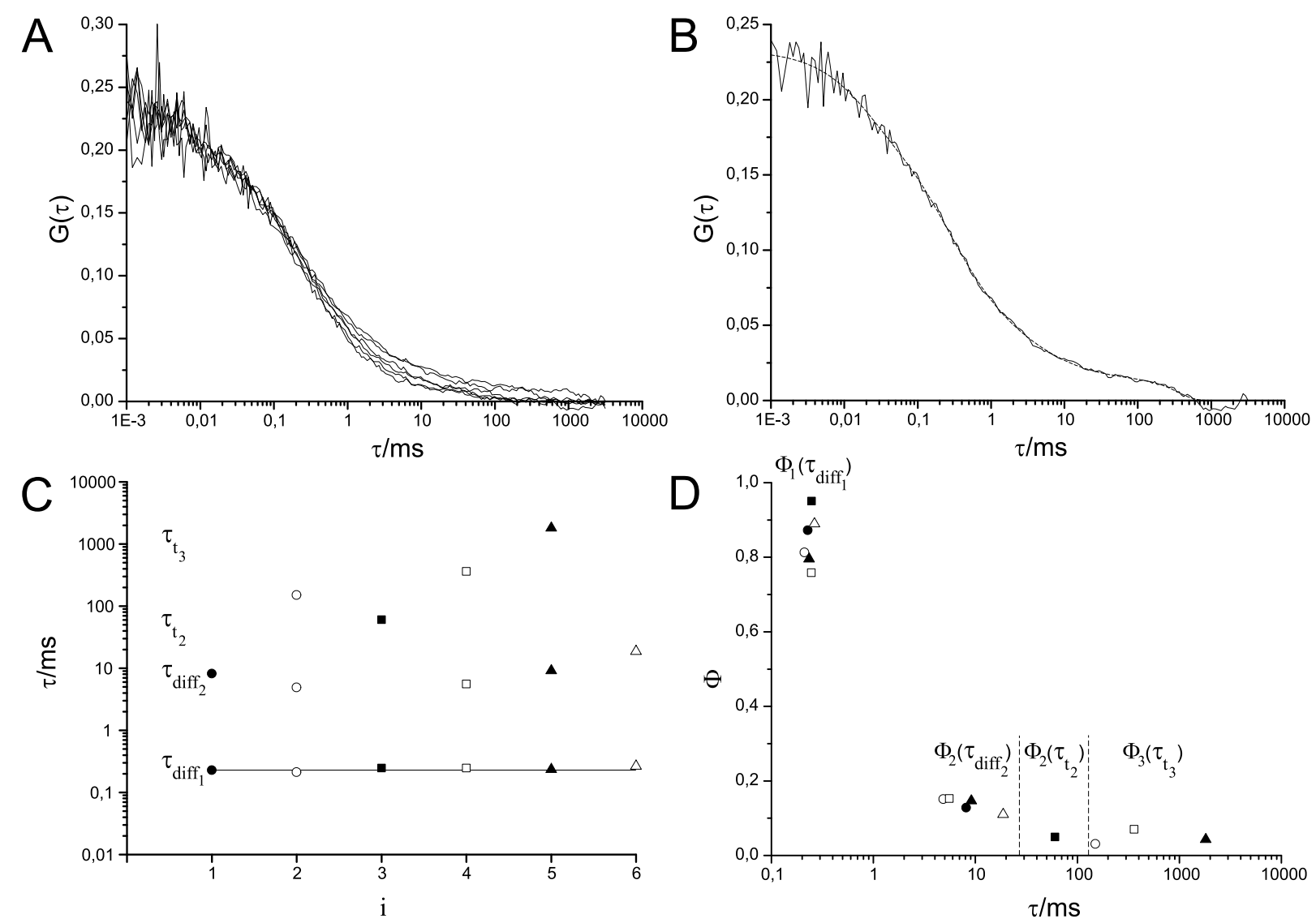

Abb. 5.7: AKFs von FCS-Messungen innerhalb eines mit TMR-Dextran gefüllten Soma. Die AKFs wurden über eine Dauer von 10 Sekunden an derselben Stelle im Soma gemessen (der Zeitabstand zwischen zwei Messungen betrug ebenfalls 10 Sekunden). Die Messungen wurden nach dem Erreichen des Diffusionsgleichgewichtes ausgeführt. (A) AKFs der aufeinander folgenden Messungen. (B) AKF mit einer STE-Komponente (identisch zu einer AKF in A). Ergebnis der Kurvenanpassung mit einem AKF-Modell mit zwei Komponenten für normale Diffusion (Gl. 2.18, Summationsindex $j=1,2$ ) und einer STE-Komponente (Gl. 5.12, Summationsindex $j=3$ ): $\left\langle N_{\text {ges }}\right\rangle=5.14, T=0.18, \tau_{T}=1.73 \mu \mathrm{s}, \Phi_{1}=0.76$, $\tau_{\text {diff }}=0.246 \mathrm{~ms}, \Phi_{2}=0.153, \tau_{\text {diff }}=5.57 \mathrm{~ms}, \Phi_{3}=0.07$ und $\tau_{t_{2}}=360.62 \mathrm{~ms}$ (fixierter Parameter: $S=7)$. (C) Charakteristische Diffusions- und Translationszeitkonstanten der in A gezeigten AKFs (Ergebnisse der Kurvenanpassungsanalysen, Messungsindex $i$ ). Die horizontale Linie bezeichnet den Mittelwert $\bar{\tau}_{\text {diff }}=0.239 \mathrm{~ms}$ der ersten Diffusionszeitkonstanten $\tau_{\text {diff }}$. (D) Relative Beiträge $\Phi_{i}$ der fluoreszierenden Spezies in Abhängigkeit von den in $C$ dargestellten Zeitkonstanten. Die intrazelluläre TMR-Dextran Konzentration betrug ca. $15 \mathrm{nM}$.

aus, siehe Abb. 5.11) diffundiert. Ähnliche Ergebnisse wurden von Politz et al. für die Diffusion von Fluoreszein-markierten Oligonukleotiden - mit ähnlicher Diffusionskonstante wie die des $10 \mathrm{kDa}$ TMR-Dextrans - innerhalb von Zellkernen kultivierter Myoblasten von 

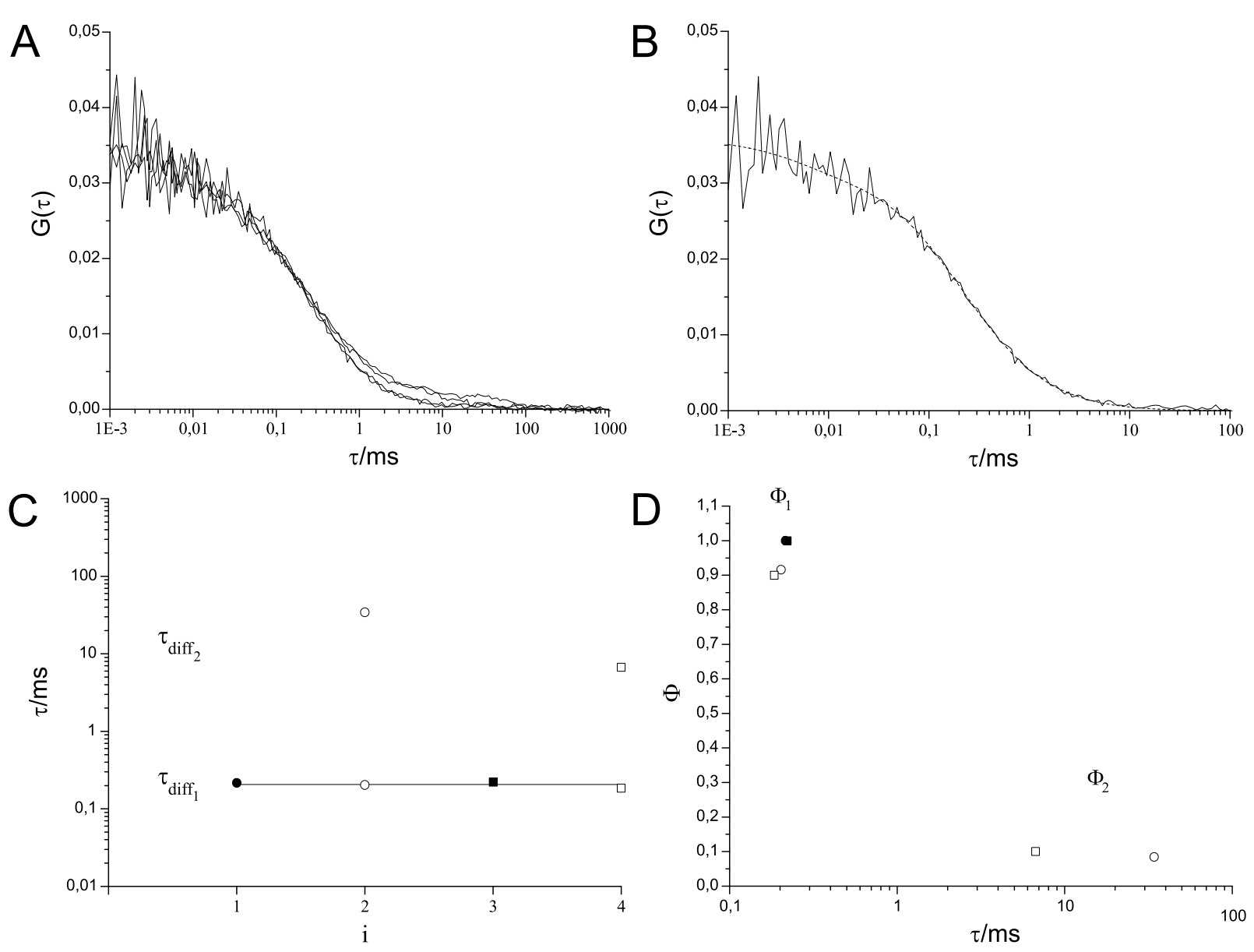

Abb. 5.8: AKFs von FCS-Messungen in einem mit TMR-Dextran gefüllten Soma. Die AKFs wurden über eine Zeitdauer von 2.6 bis 7.7 Sekunden an derselben Stelle im Soma gemessen (der Zeitabstand zwischen zwei Messungen betrug 10 Sekunden). Die Messungen wurden nach dem Erreichen des Diffusionsgleichgewichtes ausgeführt. (A) AKFs der nacheinander durchgeführten Messungen. (B) AKF, identisch zu einer der beiden untersten AKFs in $A$ (Messzeit $t_{m}=2.6 \mathrm{~s}$ ). Ergebnis der Kurvenanpassung mit einem 1-KomponentenAKF-Modell (2.18): $\langle N\rangle=31.21, T=0.109$ und $\tau_{\text {diff }}=0.216 \mathrm{~ms}$ (fixierte Parameter: $\tau_{T}=4 \mu \mathrm{s}$ und $S=7$ ). (C) Charakteristische Diffusionszeitkonstanten der in A gezeigten AKFs (Messungsindex $i$ ). Die horizontale Linie bezeichnet den Mittelwert $\bar{\tau}_{\text {diff }}=0.206 \mathrm{~ms}$ der ersten Diffusionszeitkonstanten $\tau_{\text {diff }}$. (D) Relative Beiträge $\Phi_{i}$ der fluoreszierenden Spezies in Abhängigkeit von den in $C$ dargestellten Zeitkonstanten. Die intrazelluläre TMRDextran Konzentration betrug ca. $100 \mathrm{nM}\left(\langle C\rangle=\langle N\rangle / V_{D} N_{A}, V_{D}=0.51 \mathrm{fl}\right)$.

Ratten dargestellt [85]. Sie zeigen, dass die Mobilität eines großen prozentualen Anteils von injiziertem oligo(dT) und oligo(dA) innerhalb der Zellkerne von Myoblasten um den Faktor 1.2 bis 1.4 verringert ist. Eine weitere Veröffentlichung berichtet dagegen über eine 4fach reduzierte Mobilität eines Cy3-markierten 10 kDa Dextrans innerhalb von A431- und 


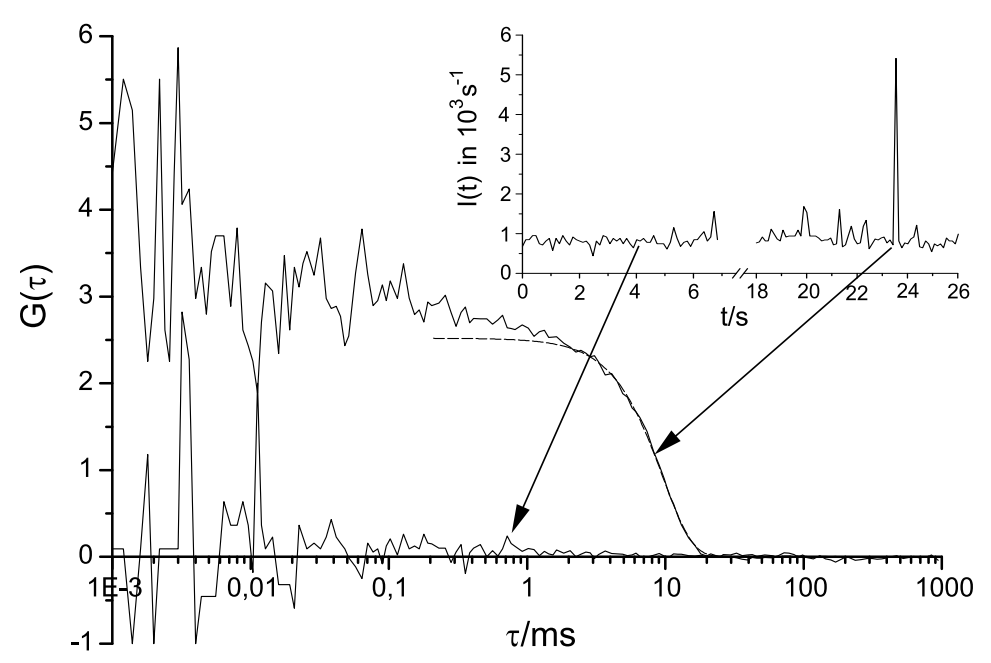

Abb. 5.9: AKFs eines FCS-Experimentes in einem Dendriten ohne TMR-Dextran. Die untere Kurve zeigt die AKF der linken Intensitätsspur (0-7s, Hintergrundintensität $I_{B} \simeq$ $\left.0.8 \cdot 10^{3} \mathrm{~s}^{-1}\right)$, die obere Kurve die der rechten Spur $(18-26 \mathrm{~s})$. Ergebnis der Kurvenanpassung mit einer STE-Komponente (Gl. 5.12) an die obere AKF: $\tau_{t}=9.57 \mathrm{~ms}$ (gestrichelte Kurve).

Her10-Zelllinien [86]. Es zeigen sich somit recht große Unterschiede zwischen verschiedenen Zelltypen.

\subsection{Detektion autofluoreszierender Partikel}

Viele FCS-Messungen zeigen unregelmäßig auftretende, stark erhöhte Intensitätsspikes, die in der AKF-Analyse zu zusätzlichen Beiträgen führen. Diese können am besten durch STE-Komponenten $\left(g_{\mathrm{STE}}(\tau)\right.$, Gl. 5.12) beschrieben werden. Die AKF-Analyse führt in diesen Fällen häufig zu großen Translationszeitkonstanten $\tau_{\mathrm{t}}$ (z.B. $\tau_{\mathrm{t}_{3}}=360.62 \mathrm{~ms}$ für die in Abb. $5.7 B$ gezeigte AKF und $\tau_{\mathrm{t}}=290 \mathrm{~ms}$ und $\tau_{\mathrm{t}}=222 \mathrm{~ms}$ für die beiden oberen AKFs in Abb. 5.15 A). Diese Einzelereignisse können die Folge großer autofluoreszierender intrazellulärer Partikel sein, die sich in unregelmäßigen Zeitabständen durch das Detektionsvolumen bewegen. FCS-Messungen innerhalb von „ungefüllten“ Neuronen bestätigen diese Interpretation. Abbildung 5.9 zeigt die AKFs eines FCS-Experimentes in einem Dendriten ohne TMR-Dextran. Die untere Kurve zeigt die AKF der linken Intensitätsspur (0-7s). Sie spiegelt die Detektion des unkorrelierten Streu- und Reflexionslichts des anregenden Laserlichtes wider (Hintergrundzählrate, $I_{B} \simeq 0.8 \cdot 10^{3} \mathrm{~s}^{-1}$, Abb. 5.9). Zu unregelmäßigen Zeitpunkten treten starke Intensitätsspikes auf (Abb. 5.9, rechte Intensitätsspur, 18 $26 \mathrm{~s}$ ), die während des Messvorgangs umittelbar zu einer ausgeprägten AKF führen (Abb. 5.9, obere AKF). Diese transiente AKF-Komponente verschwindet im Verlauf der weiteren Messung. Solche AKFs können durch das AKF-Modell für STEs (Gl. 5.12) angenähert wer- 


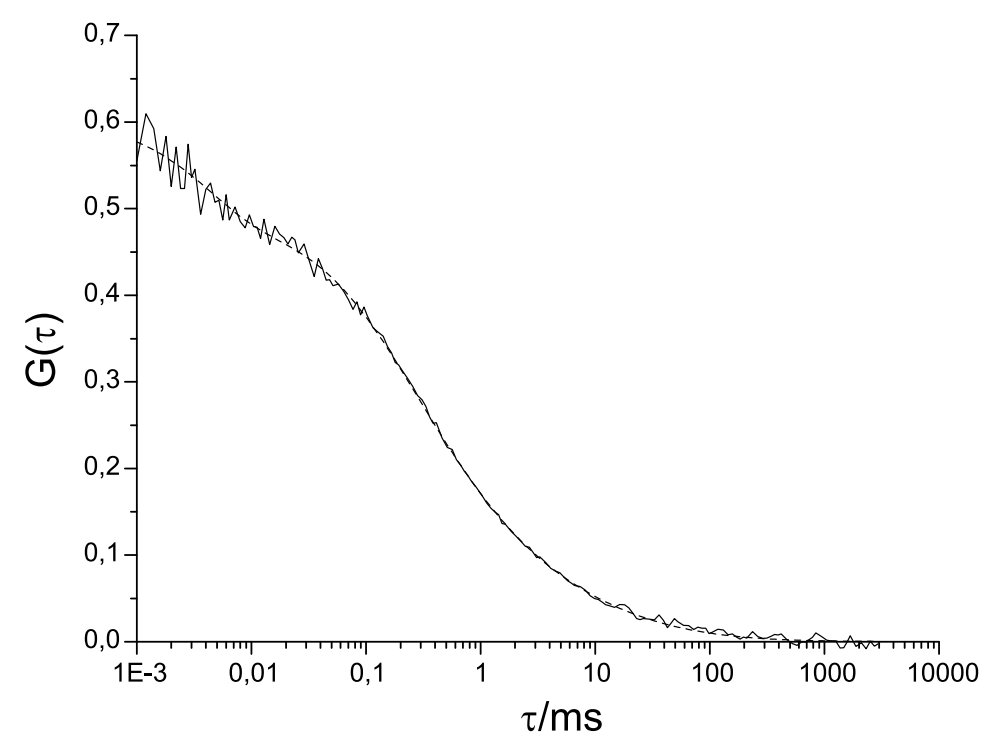

Abb. 5.10: AKF einer FCS-Messung in einem mit $10 \mathrm{kDa}$ TMR-Dextran gefüllten Dendriten (identisch zu der untersten Kurve in Abb. 5.3). Ergebnis der Kurvenanpassung mit dem AKF-Modell für anisotrope Diffusion (Gl. 5.8-5.10, gestrichelte Kurve): $\langle N\rangle=2.074$, $T=0.207, \tau_{T}=4.23 \mu \mathrm{s}, \tau_{\text {diff }}=0.179 \mathrm{~ms}$, und $\tau_{\text {diff }}=14.62 \mathrm{~ms}$ (fixierter Parameter: $Y=d_{y} / r_{x y}=3.79$, Ergebnis der Scan-Profil-Analyse des Dendriten, Abb. 5.1 B).

den (Abb. 5.9, gestrichelte Kurve). Die gemessenen Zeitkonstanten liegen im Bereich von 5 bis $1200 \mathrm{~ms}$. Dieser Zeitbereich ist identisch mit dem der Translationszeitkonstanten, der innerhalb von mit TMR-Dextran gefüllten Neuronen gemessen wurde. Sie lassen sich zum großen Teil dem aktiven Transport von autofluoreszierenden Mitochondrien [86] zuordnen (Abschnitt 6).

\subsection{Anisotrope dendritische Diffusion}

Dendriten von Mitralzellen haben ein ausgeprägtes Netzwerk von Mikrotubuli (MT). Sie verlaufen parallel zur Fortpflanzungsrichtung der Dendriten (Abb. 5.11). Der Abstand zwischen benachbarten Mikrotubuli liegt im Bereich von 10 bis $80 \mathrm{~nm}$, der mittlere Durchmesser eines Mikrotubulus beträgt $\sim 20 \mathrm{~nm}$. Der mittlere hydrodynamische Durchmesser $d_{\mathrm{h}}$ des $10 \mathrm{kDa}$ TMR-Dextrans ergibt sich aus der STOKE-Einstein-Gleichung, d.h. $d_{\mathrm{h}}=k T / 3 \pi \eta D_{\text {aq }}$. Mit der Viskosität $\eta=10^{-3} \mathrm{Ws} \cdot \mathrm{s} \cdot \mathrm{m}^{-3}$, der Dextran-Diffusionskonstante $D_{\text {aq }}=8.5 \cdot 10^{-7} \mathrm{~cm}^{2} \cdot \mathrm{s}^{-1}$ für wässrige Lösung, der Temperatur $T=297.15 \mathrm{~K}\left(\hat{=} 24^{\circ}\right)$ und der Boltzmannkonstante $k=1.38 \cdot 10^{-23} \mathrm{Ws} \cdot \mathrm{K}$ ergibt sich ein mittlerer hydrodynamischer Durchmesser von $d_{\mathrm{h}}=5.1 \mathrm{~nm}$. Mit diesen Werten erscheint es plausibel, dass das parallele Netzwerk der Mikrotubuli die Diffusion des 10 kDa TMR-Dextran orthogonal zur Dendritenachse stark behindert (im Bereich der Längenskala des $1 / e^{2}$-Radius $r_{x y}$ ), während die Diffusion entlang der Mikrotubuli kaum eingeschränkt wird. Um diese Idee zu verfolgen, 


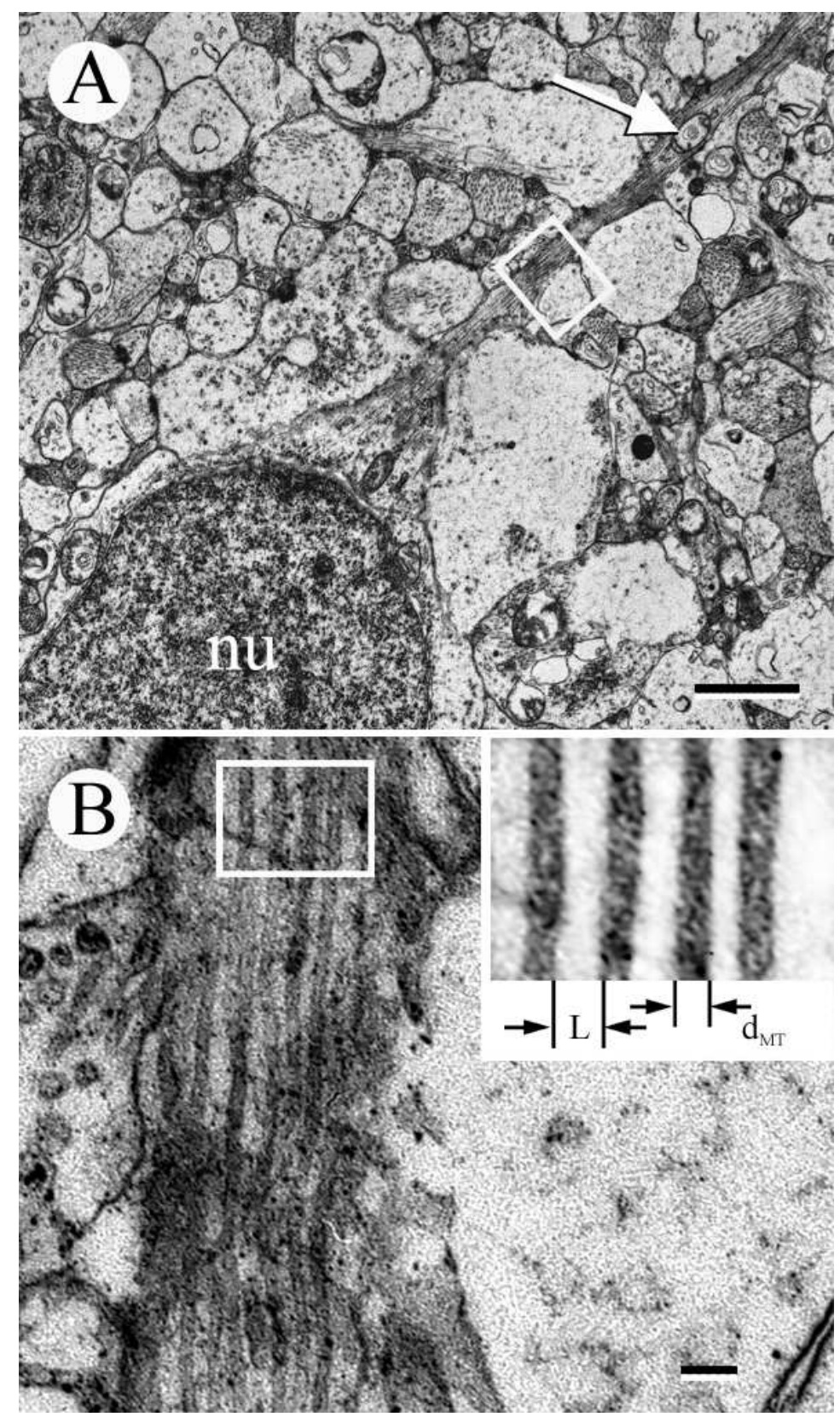

Abb. 5.11: Aufnahme einer Mitralzelle, hergestellt mit einem TransmissionsElektronenmikroskop (Dr. Leonid Nezlin, Abteilung Molekulare Neurophysiologie, Physiologisches Institut, Universität Göttingen). (A) Niedrige Auflösung des Somas (unten links) und des Dendriten mit einem Mitochondrium (Pfeil). Der Zellkern („nucleus“, nu) füllt den größten Teil des Somas aus. Maßbalken: $2 \mu \mathrm{m}$. (B) Höhere Auflösung der in A gekennzeichneten Region. Maßbalken: $100 \mathrm{~nm}$. Oben links ist eine Vergrößerung (mit verändertem Kontrast) der gekennzeichneten Region dargestellt. $L$ bezeichnet den Abstand zwischen zwei benachbarten Mikrotubuli und $d_{M T}$ den Durchmesser eines Mikrotubulus. 


\begin{tabular}{ccc}
\hline Zytosolisches & Soma/Nucleus & Dendrit \\
Kompartiment & (Anzahl der Zellen) & (Anzahl der Dendriten) \\
\hline$[D]=10^{-7} \mathrm{~cm}^{2} / \mathrm{s}$ & $3.4 \leq D_{\text {cyto }} \leq 7.3(67)$ & $4.1 \leq D_{\text {cyto } \|} \leq 7.9(88)$ \\
& $1.2 \leq D_{\text {aq }} / D_{\text {cyto }} \leq 2.6$ & $1.1 \leq D_{\text {aq }} / D_{\text {cyto }} \leq 2.1$ \\
& $0.085<D_{\text {cyto }}<0.89(73)$ \\
& $9.6<D_{\text {aq }} / D_{\text {cyto }}<100$ \\
\hline
\end{tabular}

Tab. 5.1: Mobilitäten des 10 kDa TMR-Dextrans innerhalb von kultivierten Neuronen des Bulbus olfactorius. Die Ergebnisse der FCS-Messungen innerhalb von Dendriten stammen von sehr dünnen (Abschnitt 5.7) und sehr dicken (Abschnitt 5.8) Dendriten sowie von Dendriten mit mittlerem Durchmesser.

wurden die dendritischen FCS-Daten mit einem Diffusions-Modell ausgewertet, das zwischen der Diffusion entlang des Dendriten und der Diffusion orthogonal zum Dendriten unterscheiden kann (Gl. 5.8-5.10). Wertet man die AKF-Daten ohne einen STE-Beitrag (z.B. Abb. 5.3, unterste Kurve; siehe auch Abb. 5.6 A, Messungsindex $i=2$ ) mit diesem Modell aus, so ist nur eine fluoreszierende Komponente mit $\Phi=1$ erforderlich, um ein gutes Kurvenanpassungsergebnis zu erhalten (Abb. 5.10). Die Analyse der in Abbildung 5.10 gezeigten AKF ergibt die charakteristischen Zeitkonstanten $\tau_{\text {diff }}$ und $\tau_{\text {diff }}$ für die Diffusion parallel und orthogonal zur Achse des Dendriten, $\tau_{\text {diff }}=(0.179 \pm 0.011) \mathrm{ms}$ und $\tau_{\text {diff } \perp}=(14.62 \pm 2.75) \mathrm{ms}$. In diesem Beispiel ist die Mobilität des $10 \mathrm{kDa}$ TMR-Dextrans im Vergleich zu der Diffusion in wässriger Lösung $\left(\tau_{\text {diff }}=0.16 \mathrm{~ms}\right)$ um den Faktor 1.1 enlang des Dendriten und um den Faktor 91 orthogonal zur Achse des Dendriten vermindert. Die Diffusion orthogonal zu den MT ist somit stark eingeschränkt. Ähnliche Ergebnisse ergeben die FCS-Messungen in 66 Dendriten. Tabelle 5.1 fasst die Ergebnisse der FCS-Messungen innerhalb von Somata und Dendriten zusammen. Die Diffusionskonstante $D_{\text {aq }}$ des $10 \mathrm{kDa}$ TMR-Dextrans $(100 \mathrm{nM})$, in einem Tropfen Wasser gemessen, beträgt $D_{\text {aq }}=(8.5 \pm 0.3) \times 10^{-7} \mathrm{~cm}^{2} \mathrm{~s}^{-1}$.

Um weitere Anhaltspunkte zu finden, die die Interpretation der anisotropen Diffusion in Dendriten unterstützen, wurden FCS-Messungen innerhalb von Dendriten durchgeführt, deren MT vorab zerstört worden sind. Hierzu wurden die Zellkulturen mit Nocodazol bzw. Colchizin (jeweils $10 \mu \mathrm{g} / \mathrm{ml}$, Sigma-Aldrich Chemie, Deisenhofen) inkubiert. Beide Gifte verhindern die Polymerisierung von Tubulin [90,91]. Durch den fortwährenden Auf- und Abbau von Mikrotubuli wird ihr Netzwerk mit der Zeit „zerstört“. Um den Zustand der Mikrotubuli in Abhängigkeit der Inkubationszeit kontrollieren zu können, wurden an Zellkulturen mit unterschiedlichen Inkubationsdauern Antikörper-Färbungen von $\alpha$-Tubulin durchgeführt (Abschnitt 3.4, Abb. 5.12). Nach zwei Tagen Inkubationsdauer ist das Netzwerk der Mikrotubuli vollständig abgebaut (Abb. 5.12 B). Die Scan-Profile der behandelten Dendriten zeigen, dass sich durch die Zerstörung des Mikrotubuli-Netzwerks auch die Querschnittsprofile der Dendriten ändern. In den meisten Fällen lässt sich das ScanProfil nicht mehr durch ein Kreis- oder Rechteckprofil beschreiben (Abb. 5.13 A). Die 


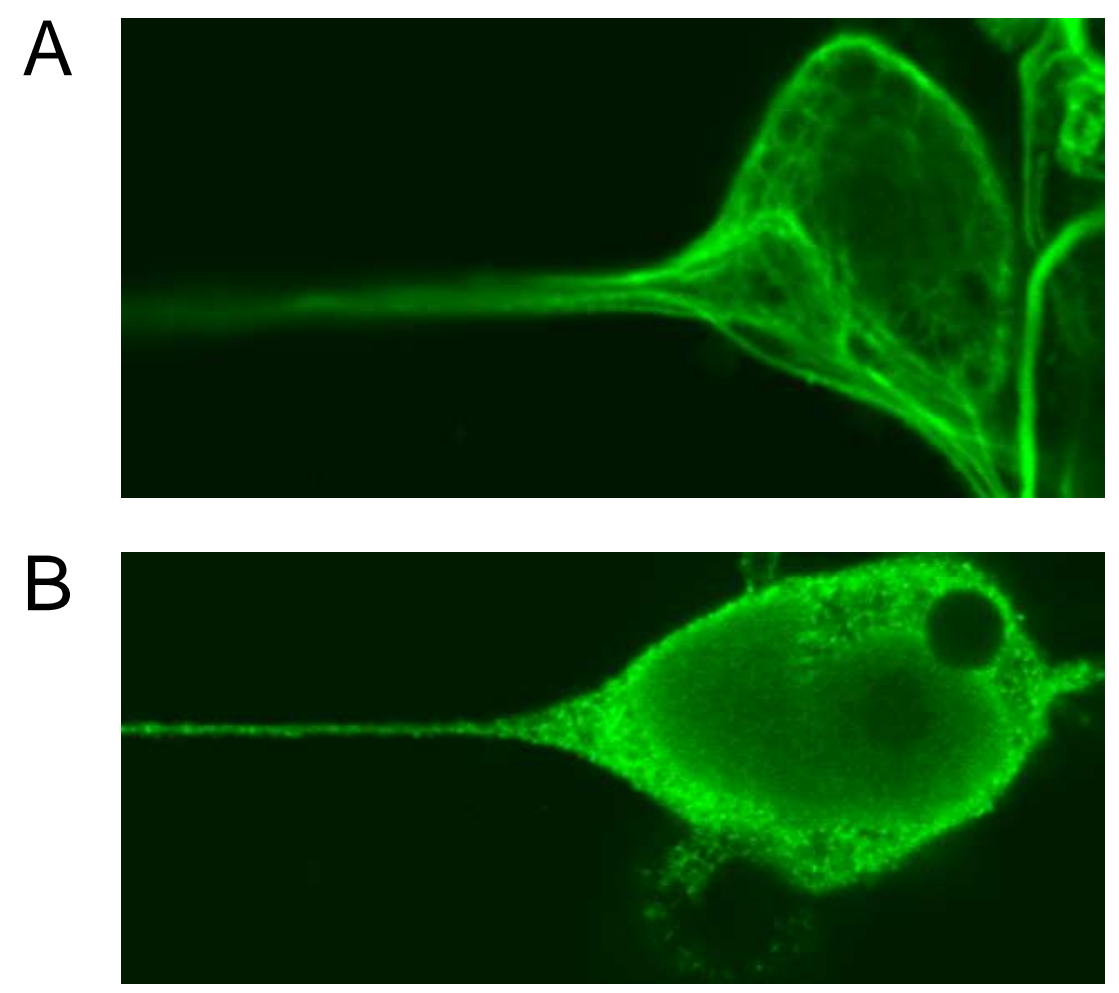

Abb. 5.12: Kultivierte Mitralzellen aus dem Bulbus olfactorius mit Antikörperfärbung von $\alpha$-Tubulin. (A) Natives Neuron mit Mikrotubuli (MTs). (B) Neuron ohne MTs nach 48 Stunden Colchizin-Inkubation.

FCS-Messungen in diesen Dendriten führten nicht zu konsistenten Ergebnissen. In wenigen Fällen konnte allerdings ein Rechteckprofil den Querschnitt beschreiben (Abb. 5.13 B). Die FCS-Messungen innerhalb dieser Dendriten ergaben nur eine fluoreszierende Spezies. Der Wert der Diffusionszeitkonstante liegt im Bereich der dominierenden kleinen Zeitkonstante, die in den Somata gemessen wurde. Abbildung 5.14 zeigt das Ergebnis einer Messung in einem mit Colchizin behandelten Neuron. Die Kurvenanpassung mit dem AKF-Modell für räumlich eingeschränkte Diffusion (Gl. 5.1) führt in diesem Beispiel zu einer charakteristischen Diffusionszeit von $\tau_{\text {diff }}=0.222 \mathrm{~ms}(\Phi=1)$. Die Diffusion des $10 \mathrm{kDa}$ TMRDextrans innerhalb dieses Dendriten ohne MT scheint somit annähernd isotrop zu sein. Die Kurvenanpassung liefert einen Einschränkungsparameter von $Y=d_{y} / r_{x y}=2.944$. Mit $r_{x y}=0.236 \mu \mathrm{m}$ folgt für den Dendritendurchmesser $d_{y}=0.695 \mu \mathrm{m}$ (Abb. 5.14). Dieser Wert stimmt mit dem Ergebnis der Auswertung des zugehörigen Scan-Profils $\left(d_{y}=0.705 \mu \mathrm{m}\right.$, Abb. 5.13 B) gut überein. 

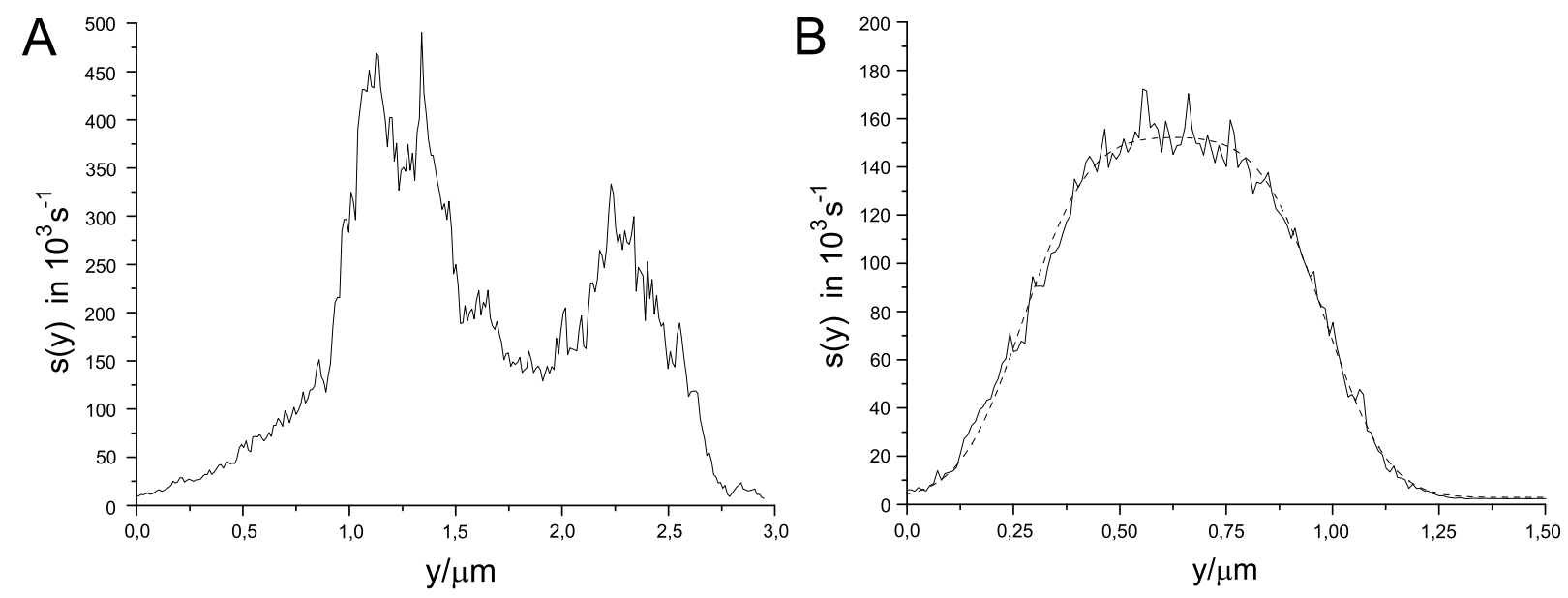

Abb. 5.13: Scan-Profile von mit $10 \mathrm{kDa}$ TMR-Dextran gefüllten Dendriten kultivierter Mitralzellen ohne MTs nach zwei Tagen Colchizin-Behandlung $(10 \mu \mathrm{g} / \mathrm{ml})$. (A) Linien-Scan durch einen dicken Dendriten. (B) Scan-Profil eines Dendriten mittleren Durchmessers. Ergebnis der Kurvenanpassung des Scan-Profils $s_{\text {rect }}^{\prime}(y)$ (Gl. 5.24) (gestrichelte Kurve): $\beta=74.87 \cdot 10^{3} \mathrm{~s}^{-1}, d_{y}=0.71 \mu \mathrm{m}, y_{0}=0.628 \mu \mathrm{m}$ und $I_{B}=2.875 \cdot 10^{3} \mathrm{~s}^{-1}$ (fixierte Parameter: $r_{x y}=0.236 \mu \mathrm{m}$ und $\left.S=7\right)$.

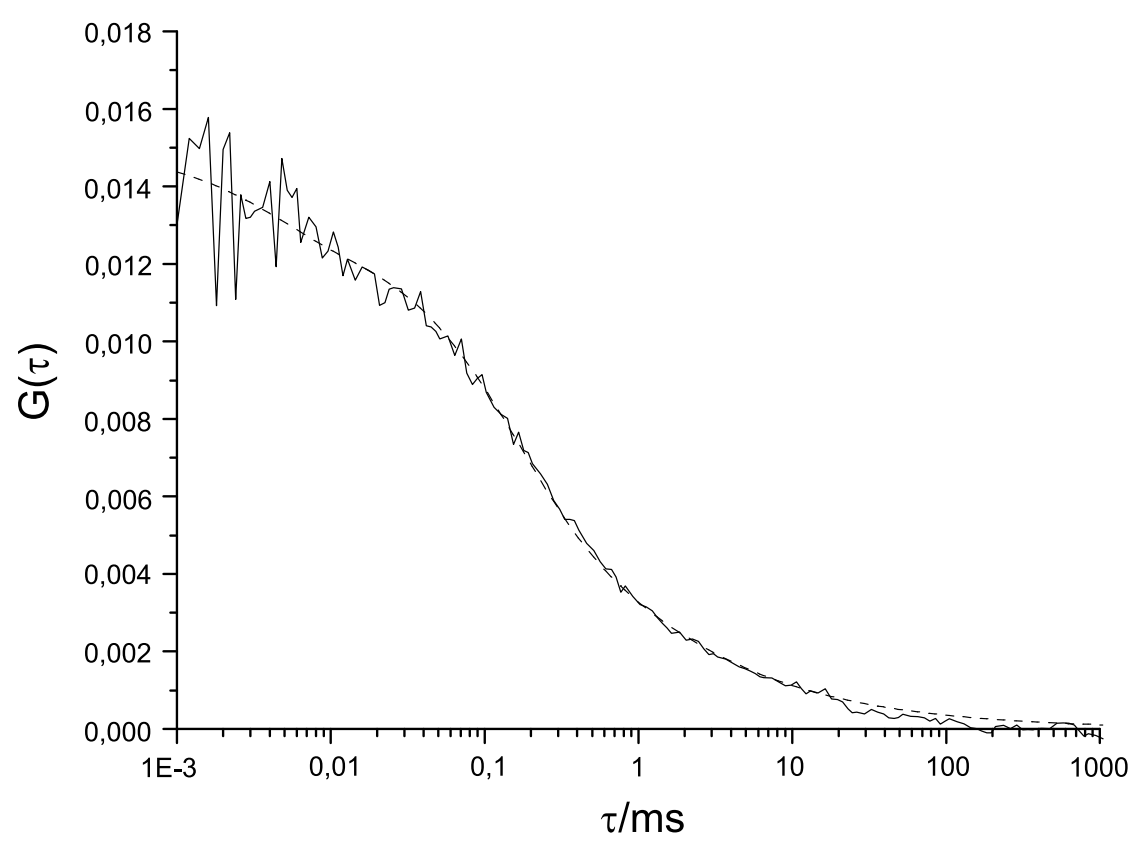

Abb. 5.14: AKF einer FCS-Messung innerhalb eines Dendriten mit $10 \mathrm{kDa}$ TMR-Dextran ohne MTs (das zugehörige Scan-Profil ist in Abb. 5.13 B zu sehen). Ergebnis der Kurvenanpassung mit einem 1-Komponenten-Modell für räumlich eingeschränkte Diffusion (Gl. 5.1, $m=1$ ) (gestrichelte Kurve): $\langle N\rangle=78.82, T=0.144, Y=d_{y} / r_{x y}=2.944, \tau_{\text {diff }}=0.222 \mathrm{~ms}$ (fixierter Parameter: $\tau_{T}=4 \mu \mathrm{s}$ ). 


\subsection{Wechselwirkung zellulärer Elemente mit TMR- Dextran}

Obwohl die Interpretation der anisotropen Diffusion plausibel erscheint, kommen zwei weitere Ursachen für die Detektion von zwei dominierenden Diffusionskomponenten (Abschnitt 5.3) in Betracht. Das TMR-Dextran könnte zum einen an zytosolische Elemente binden oder mit ihnen interagieren. Zum anderen könnte das hergeleitete AKF-Modell für räumlich begrenzte Diffusion (Gl. 5.1) als solches zur Detektion einer scheinbar vorhandenen zusätzlichen Komponente führen. Um die Bindung zwischen dem hydrophilen unpolaren TMR-Dextran und den zytosolischen Elementen auszuschließen, wurden Messungen innerhalb von sehr dünnen Dendriten $(d<200 \mathrm{~nm})$ durchgeführt. In diesen Dendriten kann die Diffusion in der $y z$-Ebene vernachlässigt werden (mit $r_{x y}=0.24 \mu \mathrm{m}$ und $r_{z}=1.7 \mu \mathrm{m}$ folgt $Y=d_{y} / r_{x y} \leq 0.83$ und $\left.Z=d_{z} / r_{z} \leq 0.83\right)$. Das heißt, die Höhe und die Breite der Dendriten sind im Vergleich zu den 1/ $e^{2}$-Radien des Detektionsvolumens klein genug [3]. Die FCS-Messungen können daher mit einem AKF-Modell für eindimensionale Diffusion (Gl. 5.7) ausgewertet werden. Abbildung 5.15 A zeigt AKFs, die innerhalb eines Dendriten mit einem Durchmesser von $\sim 190 \mathrm{~nm}$ (Abb. 5.15 D) gemessen wurden. In diesem Beipiel ist leicht zwischen stationären AKFs und solchen, die STEs widerspiegeln (siehe beide oberen AKFs in Abb. 5.15 A), zu unterscheiden. Die stationären AKFs (untere AKFs in Abb. 5.15 A) können sehr gut durch ein 1-Komponenten-Modell für eindimensionale Diffusion (1DAKF $G_{x}(\tau)$, Gl. 5.7) beschrieben werden (Abb. 5.15 B). Die stationären AKFs spiegeln somit nur eine fluoreszierende Spezies wider. Für die Kurvenanpassung der beiden oberen AKFs ist ein 2-Komponenten-Modell erforderlich, eine Komponente für 1D-Diffusion und eine Komponente für ein STE (Gl. 5.12, $\tau_{\mathrm{t}}=292 \mathrm{~ms}$ für die obere AKF und $\tau_{\mathrm{t}}=220 \mathrm{~ms}$ für die zweite Kurve von oben, Abb. 5.15 C). Die Analysen der stationären AKFs ergeben eine charakteristische Diffusionszeitkonstante von $\tau_{\text {diff } \|}=(0.233 \pm 0.013) \mathrm{ms}$. Dieser Wert liegt im Bereich der stationären charakteristischen Zeitkonstante $\tau_{\text {diff }}$ (Abb. 5.6 A), die in dickeren Dendriten gemessen und mit einem 2D-AKF-Modell analysiert wurde. Eine zweite stationäre charakteristische Zeitkonstante $\tau_{\text {diff }_{2}}$, die durch die Bindung des TMRDextrans an andere intrazelluläre Moleküle enstehen würde, wird in diesen Experimenten nicht beobachtet. Die Bindung des TMR-Dextrans an zytosolische Elemente kann deshalb ausgeschlossen werden. Die zweite stationäre charakteristische Zeitkonstante $\tau_{\text {diff }}$, die innerhalb von dicken Dendriten gemessen wird (Abb. $5.6 \mathrm{~A}$ ), ist somit der 2D-Diffusion in Dendriten zuzuordnen.

\subsection{Diffusion in dicken Dendriten}

Eine letzte Möglichkeit, die für die Detektion einer zweiten, scheinbar vorhandenen fluoreszierenden Spezies verantwortlich sein könnte, ist eine potenzielle inhärente Ungenauigkeit des AKF-Modells für räumlich eingeschränkte Diffusion (Gl. 5.1). Die in den vorangegangenen Kapiteln dargestellten und ausgewerteten AKF-Daten stammen von FCS-Messungen 

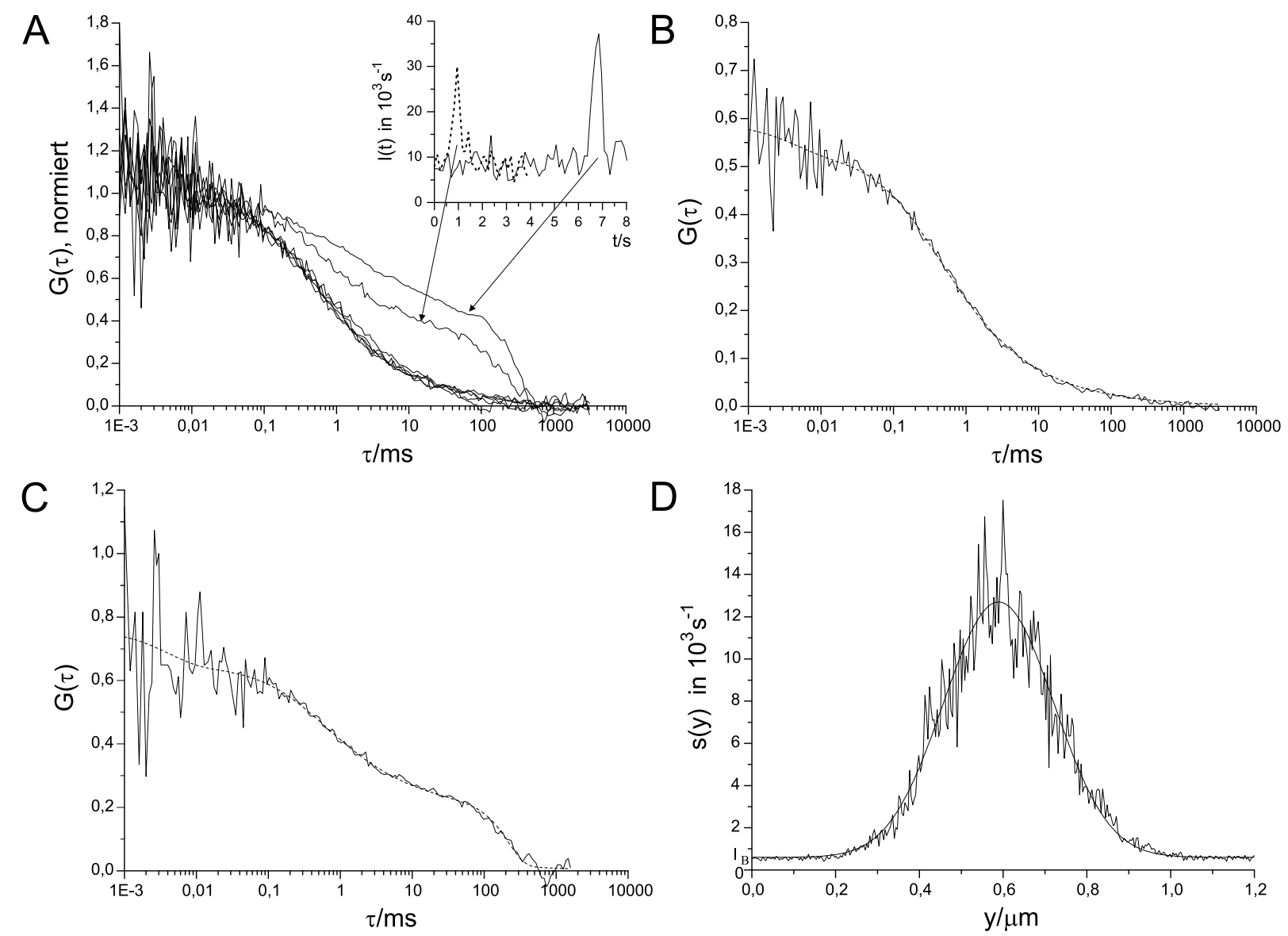

Abb. 5.15: FCS-Messungen in einem mit $10 \mathrm{kDa}$ TMR-Dextran gefüllten dünnen Dendriten. (A) AKFs, normiert auf die mittlere Molekülzahl $\langle N\rangle$ der jeweiligen Messung. Die Messzeit der AKFs lag zwischen vier und acht Sekunden. Die beiden oberen AKFs korrespondieren mit den beiden eingefügten Intensitätsspuren (obere AKF: durchgezogene Spur; zweite AKF von oben: gestrichelte Spur; Hintergrundintensität $\left.I_{B}=0.6 \cdot 10^{3} \mathrm{~s}^{-1}\right)$. Der zeitliche Abstand zwischen zwei Messungen betrug $\sim 10$ Sekunden. (B) Eine der in A gezeigten unteren AKFs (nicht normiert). Ergebnis der Kurvenanpassung mit dem 1DAKF-Modell $G_{x}(\tau)$ (Gl. 5.7): $\langle N\rangle=1.893, T=0.107, \tau_{T}=4.27 \mu$ s und $\tau_{\text {diff }}=0.217 \mathrm{~ms}$. (C) AKF mit STE-Komponente (identisch mit der in A gezeigten zweiten AKF von oben). Die Analyse mit einem AKF-Modell mit einer Komponente für normale 1D-Diffusion (Gl. 5.7) und einer STE-Komponente (Gl. 5.12) ergibt: $\left\langle N_{\text {ges }}\right\rangle=1.548, T=0.156, \Phi_{1}=0.707$, $\tau_{\text {diff } \|}=0.318 \mathrm{~ms}$ und $\tau_{t}=221.74 \mathrm{~ms}$ (fixierter Parameter: $\tau_{T}=4 \mu \mathrm{s}$ ). (D) Scan-Profil des Dendriten (verrauschte Kurve) (die zugehörigen FCS-Messungen sind in A gezeigt); ScanGeschwindigkeit: $v=38 \mathrm{~nm} / \mathrm{s}$. Ergebnis der Kurvenanpassung mit dem theoretischen ScanProfil $s_{\text {rect }}^{\prime}(y)$ (Gl. 5.24, glatte Kurve): $\beta=10.45 \cdot 10^{3} \mathrm{~s}^{-1}, d_{y}=0.19 \mu \mathrm{m}, y_{0}=0.589 \mu \mathrm{m}$ und $I_{B}=0.599 \cdot 10^{3} \mathrm{~s}^{-1}$ (fixierter Parameter: $r_{x y}=0.236 \mu \mathrm{m}$ ). 

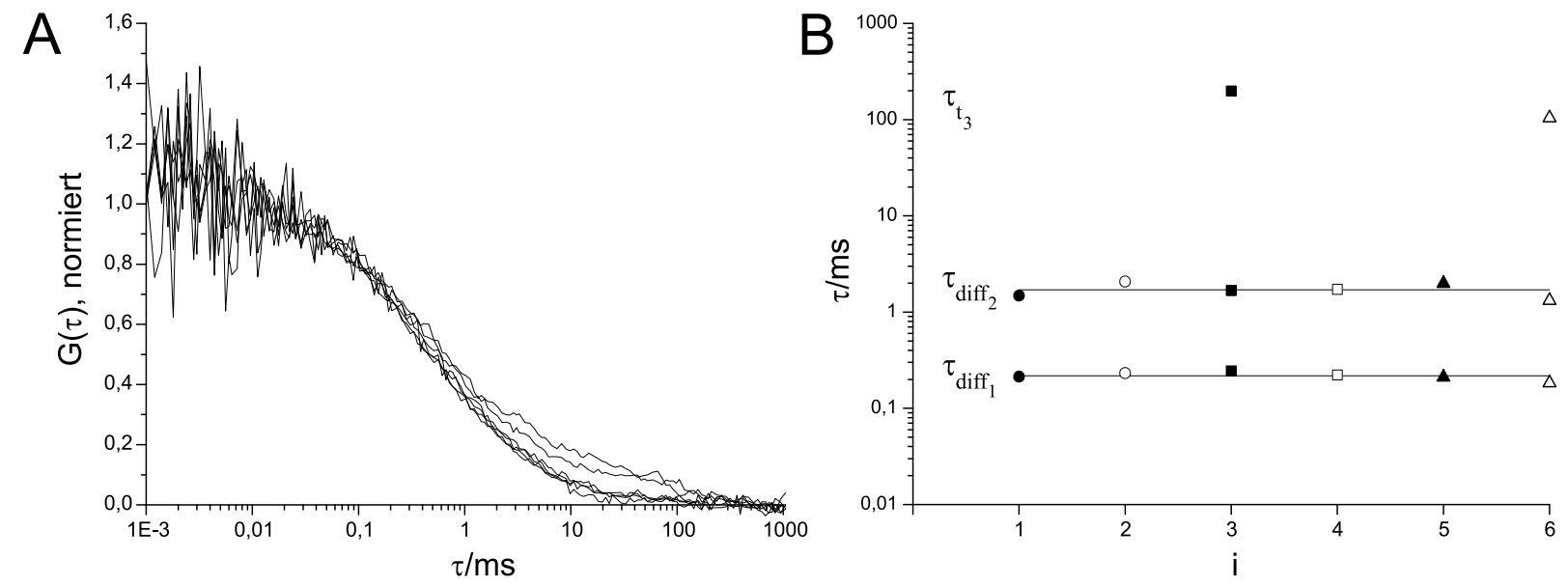

Abb. 5.16: FCS-Experiment innerhalb eines mit $10 \mathrm{kDa}$ TMR-Dextran gefüllten dicken Dendriten (Abb. 5.2 zeigt das zugehörige Scan-Profil). (A) AKFs, normiert auf die mittlere Molekülzahl $\left\langle N_{\text {ges }}\right\rangle$ der jeweiligen Messung. Die Messzeit einer AKF betrug $\sim 5 \mathrm{~s}$, um die Wahrscheinlichkeit der Detektion eines STEs zu verringern. Der zeitliche Abstand zwischen zwei Messungen betrug $10 \mathrm{~s}$. (B) Charakteristische Diffusions- und Translationszeitkonstanten (Ergebnisse der Kurvenauswertung, siehe Abb. 5.17) in Abhängigkeit des Messungsindex $i$. Die beiden horizontalen Linien bezeichnen die Mittelwerte $\bar{\tau}_{\text {diff }}=0.217 \mathrm{~ms}$ und $\bar{\tau}_{\text {diff }_{2}}=1.71 \mathrm{~ms}$ der ersten und zweiten Diffusionszeitkonstanten mit den relativen Beiträgen $\Phi_{1}$ und $\Phi_{2}$ von $60 \%$ und $40 \%$. Aufgrund des großen Strukturfaktors von $S=7$ und der räumlichen Einschränkung der Diffusion entlang der z-Achse $\left(Z=d_{z} / r_{z}=2 R / r_{z}=1.981\right.$, mit $\left.r_{z}=1.652 \mu \mathrm{m}\right)$ erhält man die gleichen Ergebnisse bei Anwendung des 2-Komponenten-Modells für 2D-Diffusion (nicht dargestellt). Da der Durchmesser des Dendriten im Vergleich zum Durchmesser des Detektionsvolumens groß genug ist ( mit $_{y}=2 R=3.27 \mu \mathrm{m}$ und $r_{x y}=0.236 \mu \mathrm{m}$ folgt $Y=d_{y} / r_{x y}=13.86$ [3]), wird die räumliche Einschränkung entlang der $y$-Achse vernachlässigt.

innerhalb von Dendriten, deren Querschnittsprofile am besten durch ein Rechteckprofil beschrieben werden. Das heißt nicht, dass die experimentellen Profile perfekt durch ein Rechteckprofil beschrieben sind. Das AKF-Modell für räumlich eingeschränkte Diffusion beschreibt die Brownsche Molekularbewegung innerhalb eines durch ebene Wände begrenzten Diffusionsraumes [3]. Weicht das Querschnittsprofil eines Dendriten vom Rechteckprofil ab, könnte die Anwendung dieses Diffusionsmodells zu Ungenauigkeiten führen. Diese Ungenauigkeiten könnten für die Detektion der zweiten fluoreszierenden Spezies verantwortlich sein. FCS-Experimente in dicken Dendriten, die mit dem Standard-AKFModell für räumlich uneingeschränkte Diffusion (Gl. 2.18) ausgewertet werden können, sollten daher zur Detektion von nur einer Spezies führen.

Abbildung 5.16 A zeigt AKFs eines FCS-Experimentes innerhalb eines Dendriten mit einem Durchmesser von $1.64 \mu \mathrm{m}$ (Ergebnis der Auswertung des zugehörigen Scan-Profils, Abb. 5.2). Die Auswertung der AKFs kann in diesem Fall mit dem Standard-3D-AKF- 

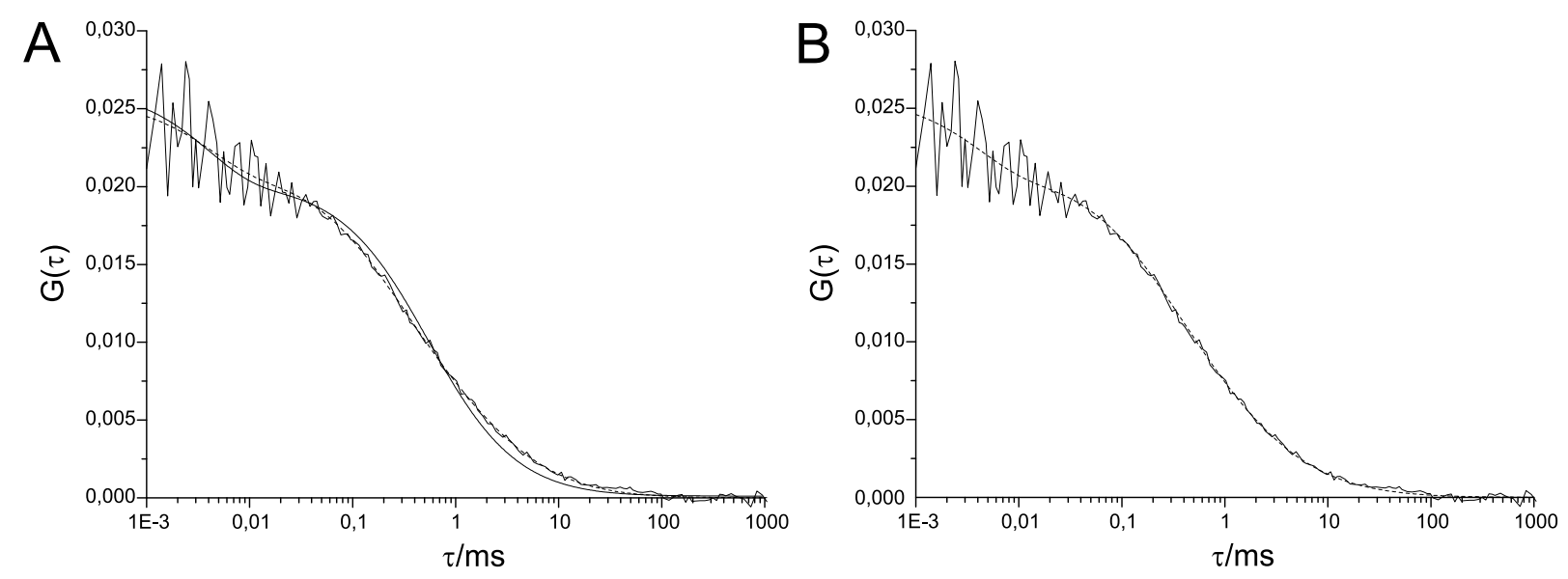

Abb. 5.17: AKF einer FCS-Messung in einem mit TMR-Dextran gefüllten dicken Dendriten (verrauschte Kurve in $A$ und B, identisch zu einer der unteren in Abb. 5.16 A dargestellten AKFs). (A) Ergebnis der Kurvenanpassung mit dem Standard-2-Komponenten 3D-AKFModell (Gl. 2.18, $m=2$, gestrichelte Kurve): $\left\langle N_{\text {ges }}\right\rangle=47.38, T=0.175, \Phi_{1}=0.621$, $\tau_{\text {diff }}=0.211 \mathrm{~ms}$ und $\tau_{\text {diff }}=1.99 \mathrm{~ms}$ (fixierte Parameter: $\tau_{T}=4 \mu \mathrm{S}$ und $S=7$ ). Ergebnis der Auswertung mit dem Standard-1-Komponenten AKF-Modell (Gl. 2.18, $m=1$, durchgezogene glatte Kurve): $\langle N\rangle=49.64, T=0.233$ und $\tau_{\text {diff }}=0.561 \mathrm{~ms}$ (fixierte Parameter: $\tau_{T}=4 \mu \mathrm{s}$ und $\left.S=7\right)$. (B) Ergebnis der Kurvenauswertung der in A dargestellten AKF mit dem AKF-Modell für anisotrope Diffusion (Gl. 5.6, gestrichelte Kurve): $\langle N\rangle=47.98$, $T=0.191, \tau_{\text {diff }}=0.187 \mathrm{~ms}$ und $\tau_{\text {diff }}=4.169 \mathrm{~ms}$ (fixierte Parameter: $\tau_{T}=4 \mu \mathrm{s}$ und $S=7$ ). Die Farbstoffkonzentration innerhalb des Dendriten betrug ca. $170 \mathrm{nM}\left(\langle C\rangle=\left\langle N_{\text {ges }}\right\rangle / V_{D}^{*} N_{A}\right.$, mit $\left.V_{D}^{*}=\pi^{3 / 2} r_{x y}^{2} r_{z}[\operatorname{erf}(Z / \sqrt{2})]^{2} / \operatorname{erf}(Z)=0.467 f 1[3]\right)$.

Modell (Gl. 2.18) oder dem analogen Modell für anisotrope (uneingeschränkte) Diffusion (Gl. 5.6) erfolgen (siehe Legende von Abb. 5.16). Abbildung 5.16 B zeigt die charakteristischen Diffusionszeitkonstanten der in Abbildung 5.16 $\mathrm{A}$ dargestellten AKFs. Es ist offensichtlich, dass die Analyse dieser FCS-Messungen zu zwei stationären Zeitkonstanten führt. Die dritte Zeitkonstante $\tau_{\mathrm{t}_{3}}$ (Ergebnis der Auswertung der beiden oberen AKFs in 5.16 A) spiegelt die Detektion von STEs wider. Die STE-freien AKFs (Abb. 5.16 A) können durch das Standard-Modell für zwei fluoreszierende Spezies (Gl. 2.18, $m=2$ ) beschrieben werden (Abb. 5.17 A). Die Kurvenanalyse mit einem 1-Komponenten-Modell ist hingegen nicht zufriedenstellend (Abb. 5.17 A). Diese Ergebnisse zeigen, dass die Detektion der zweiten charakteristischen Diffusionszeitkonstanten $\tau_{\text {diff }_{2}}$ nicht Folge einer Ungenauigkeit des AKF-Modells für räumlich eingeschränkte Diffusion ist. Die Interpretation der anisotropen Diffusion in Dendriten verbleibt somit als einzige Erklärung der Analyseergebnisse. In der Tat führt die Auswertung der in dicken Dendriten gemessenen und mit dem AKFModell für anisotrope Diffusion (Gl. 5.6) ausgewerteten STE-freien AKFs (Abb. 5.16 A) zu genau einer fluoreszierenden Spezies (Abb. 5.17 B). 


\section{Kapitel 6}

\section{Aktiver Transport von Mitochondrien in Dendriten}

Bislang gibt es keine Untersuchungen über den submikroskopischen aktiven Transport von Organellen in lebenden Zellen, die sowohl Bewegung als auch Form- und Größenveränderungen der Organellen berücksichtigen. Das liegt in erster Linie daran, dass es keine Methoden gibt, mit denen Bewegung, Form und Größe von Organellen in lebenden Zellen mit einer Genauigkeit bis zu wenigen Nanometern analysiert werden können. Ein Ziel dieser Arbeit ist deshalb, „Tracking“-Algorithmen zu entwickeln, mit denen Größenveränderungen und Bewegungen von Organellen mit einer Genauigkeit bis weit unter die Auflösungsgrenze des Mikroskops untersucht werden können. Diese Algorithmen dienen als Grundlage für die Untersuchung des submikroskopischen dendritischen Transports von Mitochondrien in kultivierten Neuronen. Experimente und Simulationen ermöglichen dabei, die Genauigkeit der Algorithmen - im Folgenden als „Faltungproduktanalyse“ (FPA) und Korrelationsanalyse (KA) bezeichnet - in Abhängigkeit des Signal-Rausch-Verhältnisses (SNR) in den Fluoreszenzbildern quantitativ zu vergleichen.

\subsection{Lokalisierung und Größenbestimmung fluoreszierender Objekte}

\subsubsection{Häufig verwendete „Tracking“"-Algorithmen}

Eine weit verbreitete Methode, um die Bewegungen und Trajektorien von fluoreszierenden Molekülen zu verfolgen, ist die Computeranalyse von Fluoreszenzbildern („Single Particle Tracking“, SPT). SPT wird hauptsächlich in der biophysikalischen Forschung verwendet, um die laterale Diffusion von Lipiden und Proteinen in Zellmembranen (Plasma- und Kernmembranen) und künstlichen Membranen zu messen (Übersichtsarbeit: [92]). Auch für die Analyse von Protein-Bewegungen in Lösungen und Zellen [93-96], Kinesin-basiertem in 
vitro Transport von fluoreszierenden „Kügelchen“ entlang von Mikrotubuli [11] sowie der Myosin-getriebenen in vitro Bewegung von fluoreszierenden Aktinfilamenten [97] kommt sie zum Einsatz. SPT basiert auf der Auswertung von Intensitätssignalen fluoreszierender Partikel in zeitlich nacheinander aufgenommenen Bildern. Die üblichen Algorithmen analysieren den gewichteten Intensitätsschwerpunkt („centroid-algorithm“, [98, 99]), werten die Intensitätsverteilungen direkt durch Anpassung einer zweidimensionalen GAUssVerteilung aus („Gaussian-fit algorithm“, [100,101]) oder verwenden die Kreuzkorrelationsanalyse zwischen den fortlaufenden Bildern und einem ausgewählten Bild („Kernel“) aus der Bild-Serie („cross-correlation algorithm“, [11,102]). Die Genauigkeit der Algorithmen hängt vom Hintergrundsignal in den Bildern, der Intensität und der Form des Objektes und vom Aufösungsvermögen des optischen Systems ab [103]. Das begrenzte optische Auflösungsvermögen verhindert, Details innerhalb des Intensitätsspots einer Punktlichtquelle zu erkennen. Trotzdem kann das Zentrum des Spots und damit das Zentrum des Objekts mit einer hohen Genauigkeit lokalisiert werden, wenn die Anzahl der Photonen im Spot hoch genug ist $[104,105]$.

In den für SPT-Experimente üblichen optischen Aufbauten, wie dem CCD-basierten Weitfeld-Fluoreszenzmikroskop (WFM) [106] und dem CLSM (Abschnitt 4), kann die laterale Intensitätsverteilung eines kleinen fluoreszierenden Objektes $\left(d \ll \lambda_{\text {em }}\right)$ in der Bildebene durch eine zweidimensionale Gauss-Verteilung angenähert werden ${ }^{1}$. Diese Näherung ist genau genug, solange die Ausdehnung des Objektes vernachlässigt werden kann, d.h. solange die Bedingung $d \ll \lambda_{\text {em }}$ gilt. Ansonsten muss die Ausdehnung des Objektes berücksichtigt werden. In diesem Fall lässt sich die Intensitätsverteilung nicht mehr genau genug durch eine Gauss-Verteilung approximieren. Die meisten SPTExperimente analysieren die Bewegungen von kleinen fluoreszierenden Molekülen bzw. mit Farbstoffmolekülen markierten Objekten. In diesen Experimenten findet daher häufig der GAuss-Anpassungsalgorithmus Anwendung. Blieben Form und Größe eines ausgedehnten Objektes während des Experimentes konstant, könnten die Schwerpunkts- und die Kreuzkorrelationsanalyse weiterhin angewendet werden. Wenn sich jedoch die Form eines stationären Objekts während der Messung ändert, kann sich der Intensitätsschwerpunkt bzw. das Maximum der Korrelationsfunktion von einem Bild zum nächsten verschieben. In dieser Situation ermöglichen die Schwerpunkts- und Korrelationsanalyse keine Aussagen über die tatsächliche Bewegung der Objektgrenzen. Dafür müssen Form und Größe des Objektes mit in die Lokalisierungsanalyse einbezogen werden. Durch die Interpolation der lateralen Intensitätsverteilung in den Fluoreszenzbildern (Abschnitt 6.1.2) bzw. der zweidimensionalen Korrelationsfunktion der Bilder (Abschnitt 6.1.3) mit theoretischen

\footnotetext{
${ }^{1}$ Die Intensitätsverteilung eines Objektes in der Bildebene ist durch das Faltungsprodukt zwischen der Punktübertragungsfunktion („point-spread function“, PSF) des optischen Systems (WFM) bzw. der detektierbaren Emissionsintensitätsverteilung $I_{E}(\vec{r})(2.11)(\mathrm{CLSM})$ und der Objektfunktion $\chi_{\mathrm{obj}}(x, y, z=0)$ (Abschnitt 5.1.3 und 5.2) des Partikels gegeben. Kann die Objektfunktion durch eine DiRAC $\delta$-Funktion angenähert werden („Punktlichtquelle“), ist die Intensitätsverteilung gerade durch die jeweilige Übertragungsfunktion des Systems gegeben. Die PSF des WFM kann durch eine axialsymmetrische AIRYVerteilung beschrieben werden [62]. Diese lässt sich bei SPT-Experimenten in guter Näherung durch eine zweidimensionale Gauss-Verteilung approximieren [106].
} 
Modellfunktionen ist es möglich, Aussagen über Gestalt und Größe der Objekte und deren Lage innerhalb der Fluoreszenzbilder zu machen.

\subsubsection{Faltungsproduktanalyse (FPA)}

Wird die Bewegung von lebenden Zellen in einer Zellkultur untersucht, ist es schwierig, die tatsächliche Form der Zellen zu modellieren. Häufig haben sie weder einfache definierte Formen noch fluoreszieren sie gleichmäßig. Vesikel, Organellen und Bakterien können dagegen in vielen Fällen durch eine Kugel-, Ellipsoid- oder Zigarren-Form (Zylinder mit Kugeloder Ellipsoidkappen) beschrieben werden. In diesem Abschnitt werden - aufbauend auf LSM-Aufnahmen von stationären fluoreszierenden Escherichia coli Bakterien - theoretische Intensitätsverteilungen dreidimensionaler Objektmodelle hergeleitet, die es ermöglichen, Größe, Form, Position und Orientierung von fluoreszierenden Organellen in LSM-Bildern zu analysieren. Dabei zeigt sich, dass sich viele Ecoli-Bakterien wie auch dendritische Mitochondrien (Abschnitt 6.3) sehr gut durch einfache theoretische Modellfunktionen beschreiben lassen.

Die Intensitätsverteilung $I_{\mathrm{obj}}(x, y)$ eines homogen mit Farbstoff gefüllten Objektes im LSM-Bild ist durch das Faltungsprodukt zwischen der Objektfunktion $\chi_{\text {obj }}(x, y, z)$ (liefert den Wert „1" innerhalb des Objektes und den Wert „0“ für alle anderen Orte) und der radialsymmetrischen detektierbaren Emissionsintensitätsverteilung $I_{E}(x, y, z)(2.11)$ des Detektionsvolumens gegeben ${ }^{2}$ :

$$
I_{\text {obj }}(x, y)=\langle C\rangle \int_{-\infty}^{+\infty} \mathrm{d} x^{\prime} \int_{-\infty}^{+\infty} \mathrm{d} y^{\prime} \int_{-\infty}^{+\infty} \mathrm{d} z^{\prime} \chi_{\text {obj }}\left(x^{\prime}, y^{\prime}, z^{\prime}\right) \cdot I_{E}\left(x-x^{\prime}, y-y^{\prime}, z^{\prime}\right) .
$$

Hierbei bezeichnet $\langle C\rangle$ die mittlere Farbstoffkonzentration im Objekt. Die meisten EcoliBakterien und dendritischen Mitochondrien lassen sich durch ein Ellipsoid oder durch einen Zylinder mit Kugel- oder Ellipsoidkappen approximieren. Abbildung 6.1 zeigt ein theoretisches Objektmodell in Zigarrenform. Das dargestellte Objektmodell besteht aus einem Zylinder der Länge $d_{x}$ und dem Durchmesser $d_{y}$ sowie jeweils einer Hälfte eines Ellipsoids am vorderen und hinteren Ende des Zylinders. Die Ellipsoidkappen sind durch die großen Halbachsen $d_{1}$ und $d_{2}$ sowie durch den Zylinderdurchmesser festgelegt. Da die Analyse der lateralen Objektintensität $I_{\text {obj }}(x, y)$ keine quantitative Aussage über die „Höhe“ $d_{z}$ des Objektes erlaubt, ist es sinnvoll, die Ausdehnung des Objektes $d_{z}$ entlang der optischen Achse mit der Breite $d_{y}$ des Objektes gleichzusetzen. Hierdurch kann die Anzahl der Modellparameter verringert werden.

Aufgrund der Rotationssymmetrie des Objektes um die gestrichelte Achse empfehlen sich für die Berechnung der Objekt-Intensitätsverteilung die Zylinderkoordinaten $x^{\prime}, r$ und $\theta$, mit $y^{\prime}=r \cos \theta+\tilde{y}_{0}$ und $z^{\prime}=r \sin \theta$. Für die Objektintensität $I_{\text {obj }}(\tilde{x}, \tilde{y})$ bezüglich des

\footnotetext{
${ }^{2}$ Vor Beginn der eigentlichen LSM-Messung wird das fluoreszierende Objekt im Scan-Betrieb mit dem z-Trieb des Mikroskops und dem Piezo-Translator (Abschnitt 4.6) fokussiert. Somit gilt: $z=0$.
} 


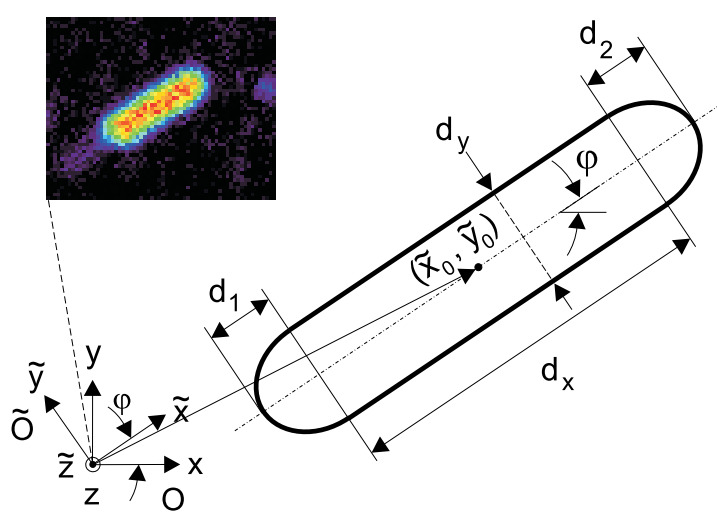

Abb. 6.1: Schematische Darstellung des Zigarrenmodells. Das Zentrum der Koordinatensysteme $\mathcal{O}$ und $\tilde{\mathcal{O}}$ liegt in der linken unteren Ecke des eingefügten LSM-Bildes. Die Lage des Objektmodells ist durch die Koordinaten $\left(\tilde{x}_{0}, \tilde{y}_{0}\right)$ im Zentrum des Zylinders (bezüglich $\tilde{\mathcal{O}}$ ) und dem Winkel $\varphi$ festgelegt. Die Rotationsachse des Zigarrenmodells verläuft parallel zur $\tilde{x}$-Achse des Koordinatensystems $\tilde{\mathcal{O}}$. Das eingefügte LSM-Bild zeigt ein mit MitoTracker gefärbtes Ecoli-Bakterium. Bildgröße: $61 \times 51$ Pixel; Pixelgröße: 89 nm; Scanzeit pro Pixel: $3.45 \mu \mathrm{s}$.

Koordinatensystems $\tilde{\mathcal{O}}$ folgt aus (6.1):

$$
\begin{aligned}
I_{\mathrm{obj}}(\tilde{x}, \tilde{y})= & \langle C\rangle \int_{-\infty}^{+\infty} \mathrm{d} x^{\prime} \int_{0}^{+\infty} \mathrm{d} r \int_{0}^{2 \pi} \mathrm{d} \theta r \\
& \cdot \chi_{\mathrm{obj}}\left(x^{\prime}, r\right) \cdot I_{E}\left(\tilde{x}-x^{\prime}, \tilde{y}-\tilde{y}_{0}-r \cos \theta, r \sin \theta\right) .
\end{aligned}
$$

Unter Verwendung der „charakteristischen Funktion“

$$
\chi_{[a, b]}(\gamma)=\left\{\begin{array}{l}
1 \text { für } a \leq \gamma \leq b \\
0 \text { sonst, }
\end{array}\right.
$$

kann dann für die Objektfunktion $\chi_{\text {obj }}\left(x^{\prime}, r\right)$ geschrieben werden:

$$
\begin{aligned}
\chi_{\mathrm{obj}}\left(x^{\prime}, r\right)= & \chi_{\left[\tilde{x}_{0}-d_{1}-d_{x} / 2, \tilde{x}_{0}-d_{x} / 2\right]}\left(x^{\prime}\right) \\
& \cdot \chi_{\left[0, d_{y} / 2\left\{1-\left(x^{\prime}-\tilde{x}_{0}+d_{x} / 2\right)^{2} / d_{1}^{2}\right\}^{1 / 2}\right]}(r) \\
& +\chi_{\left[\tilde{x}_{0}-d_{x} / 2, \tilde{x}_{0}+d_{x} / 2\right]}\left(x^{\prime}\right) \cdot \chi_{\left[0, d_{y} / 2\right]}(r) \\
& +\chi_{\left[\tilde{x}_{0}+d_{x} / 2, \tilde{x}_{0}+d_{x} / 2+d_{2}\right]}\left(x^{\prime}\right) \\
& \cdot \chi_{\left[0, d_{y} / 2\left\{1-\left(x^{\prime}-\tilde{x}_{0}-d_{x} / 2\right)^{2} / d_{2}^{2}\right\}^{1 / 2}\right]}(r) .
\end{aligned}
$$

Mit $I_{E}(x, y, z)(2.11),(6.2)$ und (6.3) folgt schließlich nach einigen Substitutionen für die Objektintensität

$$
I_{\mathrm{obj}}(\tilde{x}, \tilde{y})=I_{\mathrm{obj}}^{\mathrm{ell1}}(\tilde{x}, \tilde{y})+I_{\mathrm{obj}}^{\mathrm{zyl}}(\tilde{x}, \tilde{y})+I_{\mathrm{obj}}^{\mathrm{ell2}}(\tilde{x}, \tilde{y})
$$


mit

$$
\begin{aligned}
I_{\mathrm{obj}}^{\mathrm{ell1}}(\tilde{x}, \tilde{y})= & q \int_{-d_{1}}^{0} \mathrm{~d} x^{\prime} \int_{0}^{1} \mathrm{~d} \rho \int_{0}^{2 \pi} \mathrm{d} \theta \cdot \rho \cdot\left(\frac{d_{y}}{2}\right)^{2}\left(1-\frac{x^{\prime 2}}{d_{1}^{2}}\right) \\
& \cdot \exp \left[-2\left(\tilde{x}-\tilde{x}_{0}+d_{x} / 2-x^{\prime}\right)^{2} / r_{x y}^{2}\right] \\
& \cdot \exp \left[-2\left\{\tilde{y}-\tilde{y}_{0}-\left(d_{y} / 2\right)\left(1-x^{\prime 2} / d_{1}^{2}\right)^{1 / 2} \cdot \rho \cdot \cos \theta\right\}^{2} / r_{x y}^{2}\right] \\
& \cdot \exp \left[-2\left(d_{y} / 2\right)^{2}\left(1-x^{\prime 2} / d_{1}^{2}\right) \cdot \rho^{2} \cdot \sin ^{2} \theta / r_{z}^{2}\right] \\
I_{\mathrm{obj}}^{\text {zyl }}(\tilde{x}, \tilde{y})= & q \int_{-d_{x} / 2}^{d_{x} / 2} \mathrm{~d} x^{\prime} \int_{0}^{d_{y} / 2} \mathrm{~d} r \int_{0}^{2 \pi} \mathrm{d} \theta \cdot r \cdot \exp \left[-2\left(\tilde{x}-\tilde{x}_{0}-x^{\prime}\right)^{2} / r_{x y}^{2}\right] \\
& \cdot \exp \left[-2\left(\tilde{y}-\tilde{y}_{0}-r \cdot \cos \theta\right)^{2} / r_{x y}^{2}\right] \\
& \cdot \exp \left[-2 r^{2} \sin ^{2} \theta / r_{z}^{2}\right], \\
I_{\mathrm{obj}}^{\mathrm{ell} 2}(\tilde{x}, \tilde{y})= & q \int_{0}^{d_{2}} \mathrm{~d} x^{\prime} \int_{0}^{1} \mathrm{~d} \rho \int_{0}^{2 \pi} \mathrm{d} \theta \cdot \rho \cdot\left(\frac{d_{y}}{2}\right)^{2}\left(1-\frac{x^{\prime 2}}{d_{2}^{2}}\right) \\
& \cdot \exp \left[-2\left(\tilde{x}-\tilde{x}_{0}-d_{x} / 2-x^{\prime}\right)^{2} / r_{x y}^{2}\right] \\
& \cdot \exp \left[-2\left\{\tilde{y}-\tilde{y}_{0}-\left(d_{y} / 2\right)\left(1-x^{\prime 2} / d_{2}^{2}\right)^{1 / 2} \cdot \rho \cdot \cos \theta\right\}^{2} / r_{x y}^{2}\right] \\
& \cdot \exp \left[-2\left(d_{y} / 2\right)^{2}\left(1-x^{\prime 2} / d_{2}^{2}\right) \cdot \rho^{2} \cdot \sin ^{2} \theta / r_{z}^{2}\right] .
\end{aligned}
$$

und

$$
q=\langle C\rangle g Q I_{0} .
$$

Die Funktionen $I_{\mathrm{obj}}^{\mathrm{ell1}}(\tilde{x}, \tilde{y}), I_{\mathrm{obj}}^{\mathrm{ell} 2}(\tilde{x}, \tilde{y})$ und $I_{\mathrm{obj}}^{\mathrm{zyl}}(\tilde{x}, \tilde{y})$ entsprechen den einzelnen Intensitätsbeiträgen, die sich durch die Faltung der detektierbaren Emissionsintensitätsverteilung $I_{E}(\tilde{x}, \tilde{y}, \tilde{z})$ mit den Ellipsoidkappen und dem Zylinder des Objektmodells ergeben. Die Intensitätsverteilung $I_{\text {obj }}(x, y)$ bezüglich des Koordinatensystems $O$ ergibt sich aus $I_{\text {obj }}(\tilde{x}, \tilde{y})$ (6.4) durch die Koordinatentransformationen

$$
\begin{aligned}
& \tilde{x}=x \cos \varphi+y \sin \varphi \text { und } \\
& \tilde{y}=y \cos \varphi-x \sin \varphi .
\end{aligned}
$$

Bei entsprechender Wahl der Parameter $d_{1}, d_{2}, d_{x}$ und $d_{y}=d_{z}$ kann das Objektmodell die Form eines Ellipsoids, einer Kugel oder eines Zylinders mit Kugelkappen annehmen. Die berechnete Intensitätsverteilung $I_{\text {obj }}(x, y)$ kann direkt verwendet werden, um Größe, Form und Position von Organellen in LSM-Bildern zu analysieren (Abschnitt 6.2 und 6.3). Die Parameter $q, d_{1}, d_{2}, d_{y}, d_{x}, \tilde{x}_{0}, \tilde{y}_{0}$ und $\varphi$ sowie eine zusätzliche Konstante $I_{\mathrm{B}}$ für die Hintergrundfluoreszenz dienen als freie Parameter bei den Kurvenanpassungsanalysen.

Es zeigt sich allerdings, dass die computergestützte Faltungsproduktanalyse mit dem abgeleiteten Ausdruck (6.4) sehr rechenaufwändig ist, weil eine numerische Berechnung 
A

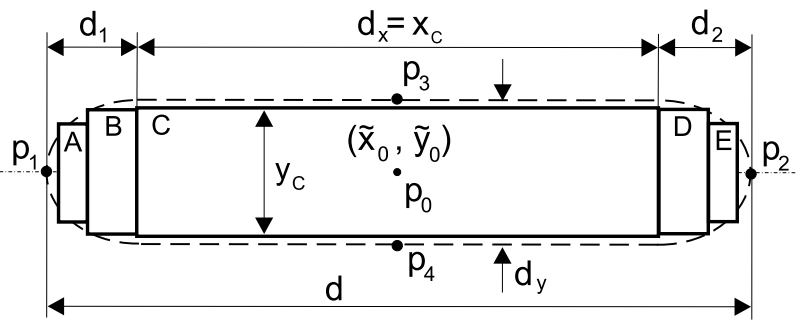

B

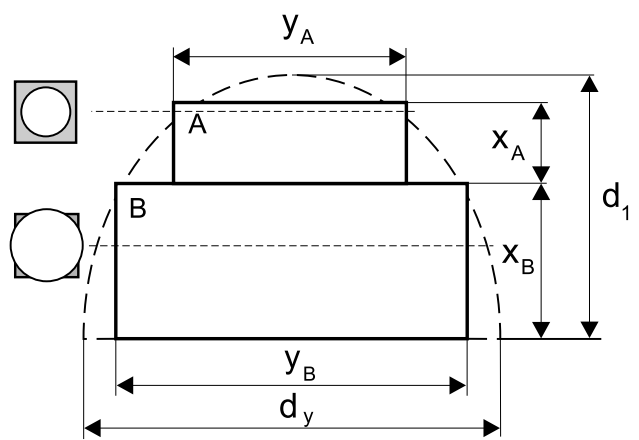

Abb. 6.2: Annäherung des Zigarrenmodells durch Kästen. (A) Die Approximation erfolgt durch fünf Kästen unterschiedlicher Ausdehnung. Der Zylinder der Länge $d_{x}$ und der Breite $d_{y}$ (gestrichelte Linien) wird durch einen rechteckigen Kasten derselben Länge und die beiden Ellipsoidkappen durch jeweils zwei „Rechteckscheiben“ approximiert. (B) Anordnung der Kästen am Beispiel der Ellipsoidkappe der Länge $d_{1}$ mit Parameterbeschriftung.

der Dreifachintegrale erforderlich ist. Je nach Größe des LSM-Bildes benötigt der FPAnpassungsalgorithmus bei Verwendung eines Pentium III-PCs bis zu mehreren Stunden pro Bild, um die optimalen Parameter zu berechnen. Es erschien daher sinnvoll, das Zigarrenmodell (Abb. 6.1) durch eine Kombination von rechteckigen Kästen zu approximieren. Dies führt bei der Faltungsproduktberechnung zu separablen Integrationsvariablen und dadurch zu einfacheren Ausdrücken. Die Güte der Approximation hängt von der Anzahl und der räumlichen Anordung der approximierenden Kästen ab. Abbildung 6.2 zeigt eine mögliche Approximation des Zigarrenmodells durch fünf Kästen verschiedener Ausdehnung.

Die Approximation des Zigarrenmodells erfolgt in Teilabschnitten: Die Ellipsoidkappen mit den Volumina $V_{1}$ und $V_{2}$ werden durch je zwei Kästen (Kästen A, B, C und D in Abbildung 6.2 A), der Zylinder durch einen Kasten angenähert (Kasten C). Abbildung 6.2 B zeigt als Beispiel die Approximation der linken Ellipsoidkappe mit der Länge $d_{1}$. Die optimalen Kastenparameter $x_{A}, x_{B}, y_{A}=z_{A}$ und $y_{B}=z_{B}$ berechnen sich - mit gegebenen Ellipsoidkappenparametern $d_{1}$ und $d_{y}=d_{z}$ - durch die Minimierung des außerhalb der Ellipsoidkappe liegenden Kastenvolumens $V_{A+B}$ ohne $V_{1}$ (siehe grau gekennzeichnete Flächenelemente in den dargestellten Schnitten in Abbildung 6.2 B). Dabei wird die Nebenbedingung des gleichen Volumens $V_{1}=V_{A+B}=V_{A}+V_{B}$, d.h. $2 / 3 * \pi d_{1}\left(d_{y} / 2\right)^{2}=x_{A} y_{A} z_{A}+x_{B} y_{B} z_{B}$, einbezogen. Die Berechnung des Volumens $V_{A+B}$ ohne $V_{1}$ in Abhängigkeit der gesuchten und der gegebenen Parameter führt zu einem analytisch nicht lösbaren Ausdruck. Dennoch existiert ein absolutes Minimum. Die numerische Auswertung liefert schließlich für beide Ellipsoidkap- 
penapproximationen:

$$
\begin{aligned}
& x_{A}=0.305579 d_{1} \\
& x_{B}=0.585352 d_{1} \\
& x_{D}=0.585352 d_{2} \\
& x_{E}=0.305579 d_{2} \\
& y_{A}=y_{E}=0.593244 d_{y} \\
& y_{B}=y_{D}=0.843075 d_{y} .
\end{aligned}
$$

Die Breite $y_{C}=z_{C}$ des mittleren Kastens der Länge $x_{C}=d_{x}$, berechnet sich direkt aus der Bedingung $V_{\mathrm{zy} 1}=V_{C}$, d.h. $\pi d_{y}^{2} d_{x} / 4=y_{C}^{2} d_{x}$. Daraus folgt:

$$
y_{C}=z_{C}=\sqrt{\pi} d_{y} / 2
$$

Die gesuchten Rechteckscheiben- und Kastenparameter $x_{A}, \ldots, x_{E}, y_{A}, \ldots, y_{E}$ und $z_{A}, \ldots, z_{E}$ sind eindeutig durch die Gleichungen (6.11) bis (6.17) bestimmt.

Wenn die Objektfunktion $\chi_{\text {obj }}(\tilde{x}, \tilde{y})$ des approximierten Modells mit Hilfe Heavysidescher Sprungfunktionen ausgedrückt wird, lässt sich die Intensitätsverteilung $\mathcal{I}_{\text {obj }}(\tilde{x}, \tilde{y})$ des approximierten Zigarrenmodells leicht berechnen. Für das Faltungsprodukt (6.1) bezüglich des Koordinatensystems $\tilde{\mathcal{O}}$ kann schließlich geschrieben werden:

$$
\mathcal{I}_{\text {obj }}(\tilde{x}, \tilde{y})=\mathcal{I}_{A}(\tilde{x}, \tilde{y})+\mathcal{I}_{B}(\tilde{x}, \tilde{y})+\mathcal{I}_{C}(\tilde{x}, \tilde{y})+\mathcal{I}_{D}(\tilde{x}, \tilde{y})+\mathcal{I}_{E}(\tilde{x}, \tilde{y})
$$

mit

$$
\begin{aligned}
\mathcal{I}_{A}(\tilde{x}, \tilde{y})= & p \cdot \operatorname{erf}\left(\frac{z_{A}}{\sqrt{2} r_{z}}\right)\left\{\operatorname{erf}\left(\frac{\sqrt{2}}{r_{x y}}\left[\tilde{x}-\tilde{x}_{0}+\frac{x_{C}}{2}+x_{B}+x_{A}\right]\right)\right. \\
& \left.-\operatorname{erf}\left(\frac{\sqrt{2}}{r_{x y}}\left[\tilde{x}-\tilde{x}_{0}+\frac{x_{C}}{2}+x_{B}\right]\right)\right\} \\
& \cdot\left\{\operatorname{erf}\left(\frac{\sqrt{2}}{r_{x y}}\left[\tilde{y}-\tilde{y}_{0}+\frac{y_{A}}{2}\right]\right)-\operatorname{erf}\left(\frac{\sqrt{2}}{r_{x y}}\left[\tilde{y}-\tilde{y}_{0}-\frac{y_{A}}{2}\right]\right)\right\}, \\
\mathcal{I}_{B}(\tilde{x}, \tilde{y})= & p \cdot \operatorname{erf}\left(\frac{z_{B}}{\sqrt{2} r_{z}}\right)\left\{\operatorname{erf}\left(\frac{\sqrt{2}}{r_{x y}}\left[\tilde{x}-\tilde{x}_{0}+\frac{x_{C}}{2}+x_{B}\right]\right)\right. \\
& \left.-\operatorname{erf}\left(\frac{\sqrt{2}}{r_{x y}}\left[\tilde{x}-\tilde{x}_{0}+\frac{x_{C}}{2}\right]\right)\right\} \\
& \cdot\left\{\operatorname{erf}\left(\frac{\sqrt{2}}{r_{x y}}\left[\tilde{y}-\tilde{y}_{0}+\frac{y_{B}}{2}\right]\right)-\operatorname{erf}\left(\frac{\sqrt{2}}{r_{x y}}\left[\tilde{y}-\tilde{y}_{0}-\frac{y_{B}}{2}\right]\right)\right\},
\end{aligned}
$$




$$
\begin{aligned}
\mathcal{I}_{C}(\tilde{x}, \tilde{y})= & p \cdot \operatorname{erf}\left(\frac{z_{C}}{\sqrt{2} r_{z}}\right)\left\{\operatorname{erf}\left(\frac{\sqrt{2}}{r_{x y}}\left[\tilde{x}-\tilde{x}_{0}+\frac{x_{C}}{2}\right]\right)\right. \\
& \left.-\operatorname{erf}\left(\frac{\sqrt{2}}{r_{x y}}\left[\tilde{x}-\tilde{x}_{0}-\frac{x_{C}}{2}\right]\right)\right\} \\
& \cdot\left\{\operatorname{erf}\left(\frac{\sqrt{2}}{r_{x y}}\left[\tilde{y}-\tilde{y}_{0}+\frac{y_{C}}{2}\right]\right)-\operatorname{erf}\left(\frac{\sqrt{2}}{r_{x y}}\left[\tilde{y}-\tilde{y}_{0}-\frac{y_{C}}{2}\right]\right)\right\}, \\
\mathcal{I}_{D}(\tilde{x}, \tilde{y})= & p \cdot \operatorname{erf}\left(\frac{z_{D}}{\sqrt{2} r_{z}}\right)\left\{\operatorname{erf}\left(\frac{\sqrt{2}}{r_{x y}}\left[\tilde{x}-\tilde{x}_{0}-\frac{x_{C}}{2}\right]\right)\right. \\
& \left.\cdot \operatorname{erf}\left(\frac{\sqrt{2}}{r_{x y}}\left[\tilde{x}-\tilde{x}_{0}-\frac{x_{C}}{2}-x_{D}\right]\right)\right\} \\
& \left.\operatorname{erf}\left(\frac{\sqrt{2}}{r_{x y}}\left[\tilde{y}-\tilde{y}_{0}+\frac{y_{D}}{2}\right]\right)-\operatorname{erf}\left(\frac{\sqrt{2}}{r_{x y}}\left[\tilde{y}-\tilde{y}_{0}-\frac{y_{D}}{2}\right]\right)\right\}, \\
& \left.-\operatorname{erf}\left(\frac{\sqrt{2}}{r_{x y}}\left[\tilde{x}-\tilde{x}_{0}-\frac{x_{C}}{2}-x_{D}-x_{E}\right]\right)\right\} \\
& \left.\cdot\left\{\operatorname{erf}\left(\frac{\sqrt{2}}{r_{x y}}\left[\tilde{y}-\tilde{y}_{0}+\frac{y_{E}}{2}\right]\right)-\operatorname{erf}\left(\frac{\sqrt{2}}{r_{x y}}\left[\tilde{y}-\tilde{y}_{0}-\frac{y_{E}}{2}\right]\right)\right\}\right]
\end{aligned}
$$

und

$$
p=\langle C\rangle g Q I_{0} \frac{1}{4}\left(\frac{\pi}{2}\right)^{3 / 2} r_{x y}^{2} r_{z}
$$

Die Intensitätsverteilung $\mathcal{I}_{\text {obj }}(\tilde{x}, \tilde{y})$ setzt sich also aus der Summe der Faltungsprodukte zwischen den fünf homogen mit Farbstoff gefüllten Kästen und der detektierbaren Intensitätsverteilung $I_{E}(x, y, z)(2.11)$ zusammen. Die Verteilung $\mathcal{I}_{\text {obj }}(x, y)$ bezüglich des Koordinatensystems $O$ ergibt sich aus (6.18) mit Hilfe der Koordinatentransformationen (6.9) und (6.10).

Es stellt sich die Frage, wie genau die Approximation des Zigarrenmodells (Abb. 6.1) durch das Kasten- und Rechteckscheibenmodell (Abb. 6.2) ist. Die Beantwortung dieser Frage erfordert, die Intensitätsverteilung des Zigarrenmodells $I_{\mathrm{obj}}(x, y)$ - berechnet mit bekannten Parametern - mit dem Faltungsprodukt $\mathcal{I}_{\text {obj }}(x, y)$ zu analysieren. Die Faltungsproduktbildung der Objektfunktionen $\chi_{\text {obj }}(x, y, z)$ des exakten und approximierten Modells und der detektierbaren Intensitätsverteilung $I_{E}(x, y, z)$ des CLSM führt dazu, dass die Genauigkeit der Approximation, d.h. die Übereinstimmung der exakten Verteilung $I_{\text {obj }}(x, y)$ mit der approximierten Verteilung $\mathcal{I}_{\text {obj }}(x, y)$, von der Größe des Objektes abhängt. Daher ist es sinnvoll, die Genauigkeit des Modells für ein spezifisches Objekt, d.h. für ein gegebenes Experiment, zu analysieren. Hierzu wird ein LSM-Bild aus der Bildserie eines 

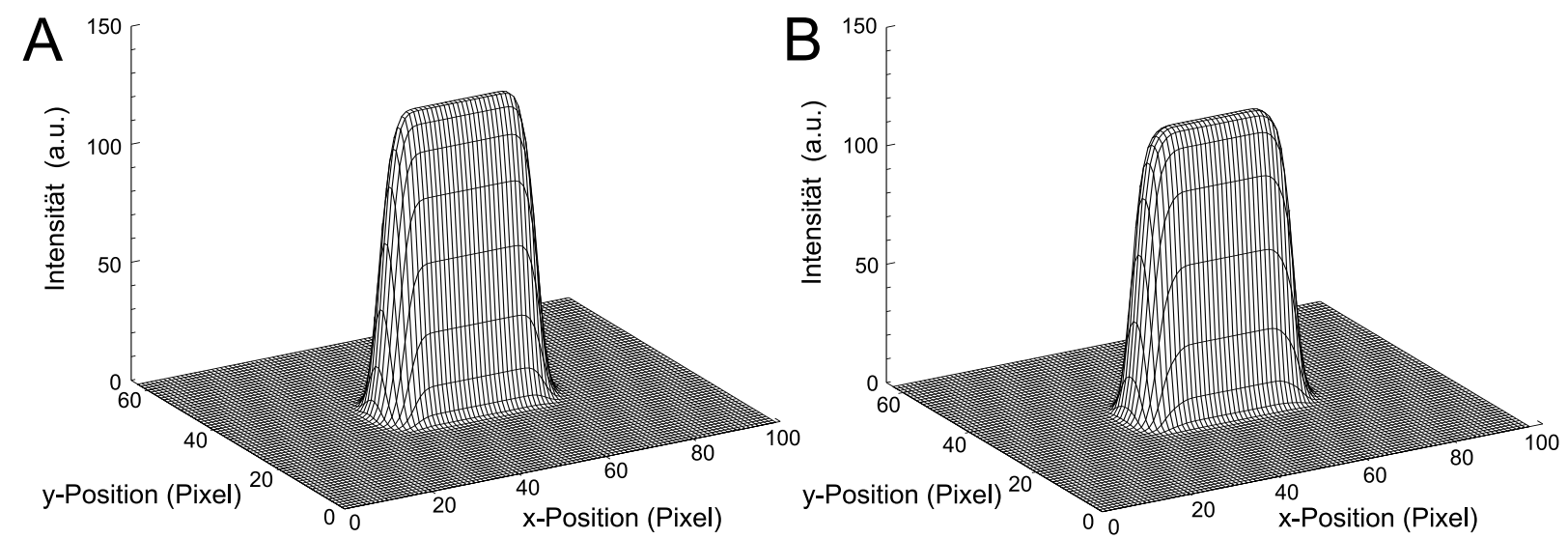

Abb. 6.3: Zur Genauigkeit des approximierten Zigarrenmodells. (A) Exakte Intensitätsverteilung $I_{\text {obj }}(x=\tilde{x}, y=\tilde{y}$ ) (6.4) eines Modell-Bakteriums in Zigarrenform, berechnet mit den Parametern (in Pixel): $d_{x}=25$ Pixel, $d_{1}=d_{2}=5.5$ Pixel, $d_{y}=11$ Pixel, $\varphi=0$ und $\left(x_{0}, y_{0}\right)=(49,32)$. Gesamtobjektlänge $d=36$ Pixel. (B) Intensitätsverteilung $\mathcal{I}_{\text {obj }}(\tilde{x}, \tilde{y})$ (6.18) des approximierten Modells. Ergebnis der FP-Analyse: $d_{x}=24.7$ Pixel, $d_{1}=5.66$ Pixel, $d_{2}=5.658$ Pixel, $d_{y}=10.492$ Pixel, $\tilde{x}_{0}=x_{0}=49$ Pixel, $\tilde{y}_{0}=y_{0}=32$ Pixel und $\varphi=0\left(\chi^{2}=5456.9746\right)$. Es ergibt sich eine Objektlänge von $d=36.018$ Pixel.

„Wildtyp“-Objektes mit der exakten Intensitätsverteilung $I_{\text {obj }}(x, y)(6.4)$ ausgewertet. Das Faltungsprodukt $\mathcal{I}_{\text {obj }}(x, y)$ (6.18) des approximierten Modells kann dann an das Ergebnis $I_{\text {obj }}(x, y)$ der FPA angepasst werden. Ein Vergleich der Objektparameter $d_{1}, d_{2}, d_{x}$ und $d_{y}$ liefert schließlich die Information, wie präzise das approximierte Modell ist.

Abbildung 6.3 A zeigt ein Beispiel für die theoretische Intensitätsverteilung $I_{\mathrm{obj}}(x, y)$ des Zigarrenmodells. Bei einer Pixelgröße von $88 \mathrm{~nm}$ entspricht die Größe des Modells mit einer Gesamtlänge von $\sim 3.2 \mu \mathrm{m}$ und einem Durchmesser von $\sim 1 \mu \mathrm{m}$ der Größe eines typischen Ecoli-Bakteriums (siehe Abb. 6.5). Analysiert man die dargestellte Verteilung mit dem Faltungsprodukt $\mathcal{I}_{\text {obj }}(x, y)$ des approximierten Modells, zeigt sich, dass die Länge des Objektes sehr genau bestimmt werden kann. Abbildung 6.3 B und Abbildung 6.4 veranschaulichen das Ergebnis der Analyse. Teil A der Abbildung 6.4 zeigt, dass die approximierte Verteilung die abfallenden Intensitätswerte im Bereich der linken und rechten Seite sehr präzise beschreibt. Die Objektlänge $d=d_{1}+d_{x}+d_{2}$ weicht mit 36.018 Pixel nur um 0.05\% vom tatsächlichen Wert von 36 Pixel ab. Bei einer Pixelgröße von $88 \mathrm{~nm}$ entspricht diese Abweichung einem Wert von $1.6 \mathrm{~nm}$. Die Experimente in diesem Teil der Arbeit zeigen, dass diese Abweichungen hier gegenüber der typisch erreichbaren experimentellen Genauigkeit von $5 \mathrm{~nm}$ bis $50 \mathrm{~nm}$ vernachlässigt werden können. Der Objektdurchmesser liegt dagegen mit 10.492 Pixel um 5\% neben dem tatsächlichen Durchmesser von 11 Pixel. Dies entspricht einer Differenz von $\sim 45 \mathrm{~nm}$. Diese Ungenauigkeit der Modellapproximation ist auf das Kreisprofil des Zigarrenmodells zurückzuführen (siehe Abbildung 6.2 B), welches an allen Stellen entlang der Symmetrieachse des Zigarrenmodells durch ein Rechteckprofil angenähert wird. Die dadurch entstehende Ungenauigkeit ist die 

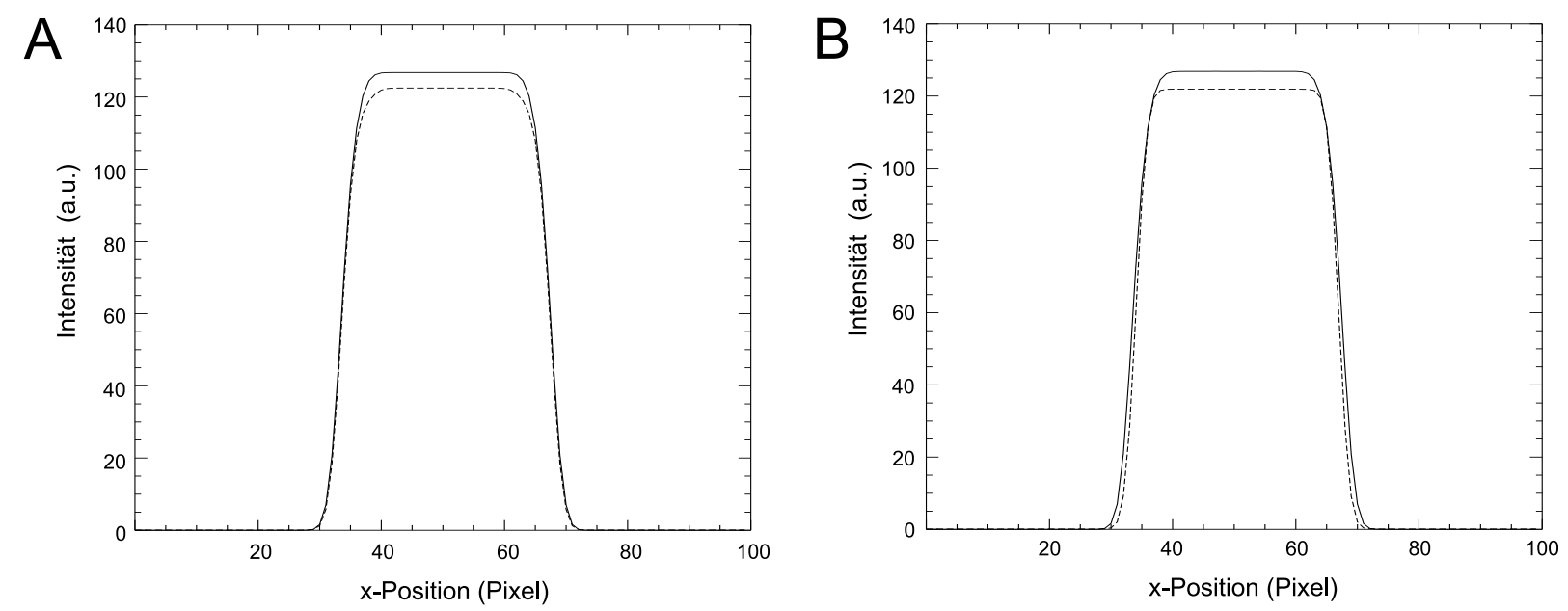

Abb. 6.4: Zur Genauigkeit des Kasten- und Rechteckscheibenmodells. (A) Schnitt enlang der $x$-Achse durch das Zentrum der in Abbildung 6.3 A dargestellten theoretischen Verteilung (durchgezogene Kurve) und des angepassten Faltungsproduktes $\mathcal{I}_{\text {obj }}(x, y)$ (Abbildung 6.3 B) für das approximierte Zigarrenmodell (gestrichelte Kurve). (B) Ergebnis der Analyse mit der Verteilung $\mathcal{I}_{\text {obj }}(x, y)$ mit $d_{1}=d_{2}=0$ für einen einfachen Kasten (gestrichelte Kurve): $d_{x}=32.886$ Pixel, $d_{y}=10.3$ Pixel und $\varphi=0\left(\chi^{2}=15250.221\right)$.

Ursache für die Abweichung im Bereich der maximalen Intensitäten in Abbildung 6.4. Wird der FP-Anpassungsalgorithmus zum Vergleich mit der Intensitätsverteilung eines Kastens ohne Rechteckscheiben an beiden Enden $\left(\mathcal{I}_{\text {obj }}(x, y)\right.$ mit $\left.d_{1}=d_{2}=0\right)$ ausgeführt, so wirkt sich auch hier die Ungenauigkeit des Modells auf die Detektion der „Objektkanten“ in $x$-Richtung aus (Abb. 6.4 B).

Eine Annäherung der Ellipsoidkappen und des Zylinders des Zigarrenmodells durch jeweils zwei Rechteckscheiben und einen Kasten liefert sehr genaue Ergebnisse, um so die absolute Länge eines Zigarrenmodells von der Größe eines Ecoli-Bakteriums zu bestimmen. Weitergehende Analysen zeigen dennoch, dass die Abweichungen zwischen dem exakten und dem approximierten Modell bei relativen Größenänderungen in axialer und in lateraler Richtung im Vergleich zu den experimentellen Messgenauigkeiten vernachlässigbar sind. Berechnet man beispielsweise die Intensitätsverteilung $I_{\mathrm{obj}}(x, y)$ mit den gleichen Parametern wie in Abbildung 6.3, nimmt aber einen größeren Objektdurchmesser von $d_{y}=11.1$ Pixel (anstelle von $d_{y}=11$ Pixel), liefert die FPA mit der Verteilung $\mathcal{I}_{\text {obj }}(x, y)$ des approximierten Modells einen Durchmesser von $d_{y}=10.59$ Pixel. Zusammen mit dem Ergebnis aus Abbildung $6.3 \mathrm{~B}$ von $d_{y}=10.492$ Pixel ergibt sich eine detektierte Änderung des Durchmessers von $\Delta d_{y}=0.098$ Pixel. Im Vergleich zu der tatsächlichen Änderung von 0.1 Pixel ist das eine Abweichung von 0.002 Pixel. Bei einer Pixelgröße von $88 \mathrm{~nm}$ liegt die Abweichung also im Angström-Bereich. Zudem können leichte Längenänderungen eines „unsymmetrischen" Zigarrenmodells $\left(d_{1} \neq d_{2}\right)$ sehr gut mit einem symmetrischen, approximierten Modell $\left(d_{1}=d_{2}\right)$ ausgewertet werden. Aufgrund dieser Eigenschaft ist es möglich, die Anzahl 
der Modellparameter zu verringern. Erhöht man etwa die Länge $d_{1}$ der linken Ellipsoidkappe am Beispielobjekt in Abbildung 6.3 von $d_{1}=5.5$ Pixel auf $d_{1}=6 \operatorname{Pixel}\left(\Delta d_{1}=\Delta d=0.5\right.$ Pixel), so resultiert aus der FPA mit dem Faltungsprodukt des approximierten Modells (unter Berücksichtigung der Nebenbedingung $d_{2}=d_{1}$ ) eine Längenänderung von $\Delta d=0.503$ Pixel. Die Abweichung liegt auch hier im Bereich von wenigen Angström. Insgesamt zeigen die Analysen, dass relative Änderungen des Durchmessers und der Länge eines Zigarrenmodells von der Größe eines Ecoli-Bakteriums oder eines dendritischen Mitochondriums mit Hilfe der Verteilung $\mathcal{I}_{\text {obj }}(x, y)$ mit einer hohen Genauigkeit detektiert werden können. Typische Werte der erreichbaren Lokalisierungsgenauigkeiten bei der Detektion von Objektkanten liegen für die Messungen an Ecoli-Bakterien und Mitochondrien im Bereich von 5 bis $50 \mathrm{~nm}$, abhängig vom Hintergrundsignal im LSM-Bild, der Objektintensität und der Größe des Objektes. Abweichungen zwischen dem Zigarrenmodell und dem Rechteckscheibenmodell können daher bei der Bestimmung von Größenveränderungen vollständig vernachlässigt werden.

\subsubsection{Korrelationsanalyse (KA)}

Eine weit verbreitete Methode, um die Bewegung von kleinen Objekten $\left(d \ll \lambda_{\text {em }}\right)$ zwischen aufeinanderfolgenden Bildern zu analysieren, ist die Kreuzkorrelationsanalyse von Bildern. Üblicherweise werden hierzu die KKFs zwischen den fortlaufenden Bildern und einem ausgewählten Bild aus der Bild-Serie („Kernel“) berechnet. Die bisher verwendeten Algorithmen analysieren dabei die räumliche Verschiebung des Korrelationsmaximums in den berechneten zweidimensionalen KKFs der aufeinander folgenden Bilder („crosscorrelation algorithm“, $[11,102])$. Die spezielle Form der zweidimensionalen KKF wird hingegen in den bisherigen Arbeiten nicht berücksichtigt [11,103,107]. Verändert sich nämlich die Orientierung oder die Größe eines endlichen Objektes $\left(d \nless \lambda_{\mathrm{em}}\right)$ während der Messung, kann sich das Maximum der KKF von einem Bild zum nächsten verschieben, ohne dass tatsächlich eine räumliche netto-Bewegung in eine bestimmte Richtung stattfindet. In diesem Fall ermöglicht die Analyse des Korrelationsmaximums keine quantitative Aussage über die Bewegung der Grenzen des Objekts.

In diesem Abschnitt wird - aufbauend auf der Auto- und Kreuzkorrelationsanalyse von LSM-Bildern - eine Methode entwickelt, die Form, Größe, Position und Orientierung von fluoreszierenden Objekten analysieren kann. Im nachfolgenden Abschnitt wird mit Hilfe von Computersimulationen die Genauigkeit der Faltungsprodukt- und der Korrelationsanalyse verglichen.

Die normierte räumliche Kreuzkorrelationsfunktion $G(\xi, \eta)$ zweier Intensitätsverteilungen $I^{(1)}(x, y)$ und $I^{(2)}(x, y)$ ist durch den Ausdruck

$$
G(\xi, \eta)=\frac{\left\langle I^{(1)}(x, y) I^{(2)}(x+\xi, y+\eta)\right\rangle}{\left\langle I^{(1)}(x, y)\right\rangle\left\langle I^{(2)}(x, y)\right\rangle}
$$

gegeben. Hierbei bezeichnet \langle\rangle die Integration über die räumlichen Koordinaten $x$ und $y$. Liegen die Werte der Intensitätsverteilungen - wie beispielsweise im Fall von LSM-Bildern 
- in Form einer Matrix mit $M$ Spalten und $N$ Reihen in diskreten Werten vor, so kann die KKF wie folgt berechnet werden $[108,109]$ :

$$
G(\xi, \eta)=\frac{\frac{1}{M N} \sum_{m=1}^{M} \sum_{n=1}^{N} I^{(1)}(m, n) I^{(2)}(m+\xi, n+\eta)}{\left[\frac{1}{M N} \sum_{m=1}^{M} \sum_{n=1}^{N} I^{(1)}(m, n)\right]\left[\frac{1}{M N} \sum_{m=1}^{M} \sum_{n=1}^{N} I^{(2)}(m, n)\right]}
$$

Hierbei wird die Intensiätsverteilung $I^{(2)}(x, y)$ des zweiten Bildes mit der Verteilung $I^{(1)}(x, y)$ des ersten Bildes quantitativ verglichen. $I^{(2)}(x, y)$ wird relativ $\mathrm{zu} I^{(1)}(x, y)$ in „ein-Pixel“-Inkrementen verschoben. Für jede Verschiebung wird ein Korrelationswert berechnet. Dieser beschreibt, wie gut die Werte im zweiten Bild mit den Werten im ersten Bild übereinstimmen. Bei derjenigen Verschiebung, bei der $I^{(2)}(x, y)$ und $I^{(1)}(x, y)$ am ähnlichsten sind, ergibt sich das Korrelationsmaximum. Die Berechnung dieses Ausdrucks ist im Fall von größeren Bildern sehr rechenaufwändig. Es empfiehlt sich daher, die KKF mit den zweidimensionalen FouRIER-Transformationen der Bilder zu berechnen [108]:

$$
G(\xi, \eta)=\frac{\mathcal{F}^{-1}\left[\mathcal{F}\left[I^{(1)}(x, y)\right] \cdot \mathcal{F}^{*}\left[I^{(2)}(x, y)\right]\right]}{\left\langle I^{(1)}(x, y)\right\rangle\left\langle I^{(2)}(x, y)\right\rangle} .
$$

Da effiziente FOURIER-Transformations-Algorithmen verfügbar sind, ist die Berechnung der KKF (6.25) bzw. der Autokorrelationsfunktion (AKF)

$$
G(\xi, \eta)=\frac{\langle I(x, y) I(x+\xi, y+\eta)\rangle}{\langle I(x, y)\rangle^{2}}
$$

eines Bildes auf diese Weise sehr schnell.

Abbildung 6.5 A zeigt die Beispielmessung eines fluoreszierenden Ecoli-Bakteriums und die zugehörige AKF des Bildes (Abbildung 6.5 B). Um Aussagen über Größe, Form und Orientierung eines Objektes innerhalb eines Bildes machen zu können, kann grundsätzlich die AKF eines LSM-Bildes ausgewertet werden. Zu beachten ist hierbei, dass alle fluoreszierenden Strukturen und das Hintergrundrauschen in den LSM-Bildern zur AKF des Bildes beitragen. Hintergrundrauschen und räumliche Fluktuationen der Objektintensität spiegeln sich dabei besonders im zentralen Maximum der Korrelationsfunktion wider. Je nach Größe der zusätzlichen Spitze auf der AKF ist es erforderlich, diese Pixelwerte bei der AKF-Anpassungsanalyse auszuschließen oder sie durch geeignete Interpolationswerte zu ersetzen. Wenn sich dieser Beitrag jedoch nur über das zentrale Pixel erstreckt, kann man diesen Pixelwert im ersten Schritt durch den Mittelwert der direkt benachbarten AKFWerte ersetzen. Passt man dann eine zweidimensionale GAuss-Funktion an diesen und an die vier nächsten Nachbarwerte an [103], kann schließlich der Maximalwert der GaUssFunktion als Substitutionswert verwendet werden. Die Auswirkung dieser Vorgehensweise auf die Genauigkeit der AKF-Analyse wird in Abschnitt 6.1.5 quantitativ untersucht. Im Fall der in Abbildung 6.5 B gezeigten AKF ist dieser Beitrag durch die niedrige Hintergundfluoreszenz und das hohe SNR der Objektintensität kaum zu erkennen. 



Abb. 6.5: Bild-Korrelationsanalyse. (A) Intensitätsverteilung und LSM-Bild eines mit MitoTracker gefärbten Ecoli-Bakteriums. Bildgröße: $100 \times 64$ Pixel; Scanzeit pro Bild: $64.64 \mathrm{~ms}$; Pixelgröße: $88 \mathrm{~nm}$. (B) AKF des in A dargestellten Bildes. Die Auswertung der experimentellen $2 D$-AKF mit der theoretischen Korrelationsfunktion $G(\xi, \eta)(6.51)$ des approximierten Objektmodells führt zu: $d_{x}=2196.7 \mathrm{~nm}, d_{1}=576 \mathrm{~nm}, d_{2}=448.2 \mathrm{~nm}$, $d_{y}=1001.2 \mathrm{~nm}$ und $\varphi=0.55599$. Die Gesamtlänge des Objektes beträgt $d=d_{1}+d_{x}+d_{2}=$ $3220.8 \mathrm{~nm}$. (C) Kernel: theoretische Intensitätsverteilung $\mathcal{I}_{\text {obj }}(x, y)$ des Ecoli-Bakteriums, berechnet mit den Ergebnisparametern der AKF-Analyse. Das Zentrum des Modells $\left(x_{0}, y_{0}\right)$ liegt im Mittelpunkt des Bildes. (D) KKF des LSM-Bildes und des Kernels.

Je nach Ausdehnung der Objektintensität trägt das Hintergrundrauschen aber auch zur gesamten AKF bei. Wird etwa bei der Berechnung der AKF (6.28) die ausgedehnte zweidimensionale Intensitätsverteilung des Objektes über Bildbereiche mit Hintergrundfluoreszenz geschoben, so entsteht bei der anschließenden Integration ein von null verschiedener Beitrag. In dem Beispiel in Abbildung 6.5 B zeigt sich der Anteil der Hintergrundfluoreszenz an der gesamten AKF durch einen „welligen“ Offset. Bei der Auswertung der experimentellen AKF mit einer theoretischen AKF eines Objektmodells kann dieser Anteil durch eine zusätzliche Konstante berücksichtigt werden. Das relativ niedrige Hintergrundrauschen ist auf die verwendete Avalanchephotodiode zurückzuführen. Die Dunkelzählrate der APD liegt bei 100 Photonencounts pro Sekunde. Im Fall der in Abbildung 6.5 A dargestellten 
LSM-Messung mit einer Bildaufnahmedauer von 64.64 Millisekunden sind dies im Mittel 6 Photonen pro Bild. Dieser Anteil kann vernachlässigt werden. Die Hintergrundfluoreszenz in den Bildern wird durch die frei diffundierenden oder gebundenen Farbstoffmoleküle außerhalb des Objektes dominiert. Diese Beiträge sind im Vergleich zur Objektintensität relativ gering.

Für die Bestimmung der Position des Objektes innerhalb des LSM-Bildes ist es erforderlich, die KKF zwischen dem LSM-Bild und einem Kernel auszuwerten. Der Kernel entspricht einer bekannten theoretischen Intensitätsverteilung. Das der Verteilung zugrundeliegende theoretische Objekt sollte dem Wildtyp-Objekt sehr ähnlich sein und die gleiche räumliche Orientierung aufweisen. Hierdurch erhält man ein ausgeprägtes und steiles Korrelationsmaximum. Die Auswertung der KKF-Form und -Position ermöglicht dann eine direkte Aussage über Ausdehnung und Form des Wildtyp-Objektes und dessen Position im LSM-Bild. Die Parameter des Objektmodells, die für die Berechnung des Kernels erforderlich sind, werden durch die Analyse der experimentellen AKF bestimmt.

Im Folgenden wird - aufbauend auf das in Abschnitt 6.1.2 abgeleitete Faltungsprodukt $\mathcal{I}_{\text {obj }}(x, y)(6.18)$ des approximierten Zigarrenmodells - eine theoretische Korrelationsfunktion berechnet, mit der man experimentelle zweidimensionale AKFs und KKFs quantitativ analysieren kann, um so Form, Größe, Orientierung und Position eines Objektes innerhalb eines LSM-Bildes zu bestimmen. Die Berechnung der Korrelationsfunktion führt - aufgrund des aus fünf Kästen bestehenden approximierten Zigarrenmodells (Abbildung 6.6) - zu einer Summe von 25 Ausdrücken. Demgegenüber würde die Berechnung der Korrelationsfunktion $G(\xi, \eta)$ der Verteilung $I_{\mathrm{obj}}(x, y)(6.4) \mathrm{zu}$ einer Summe von analytisch nicht lösbaren Mehrfachintegralen führen. Die numerische Berechnung dieser Ausdrücke ist sehr zeitaufwändig. Im Fall des approximierten Objektmodells lassen sich die Ausdrücke der AKF durch eine Kombination von einfach berechenbaren Exponential- und Fehlerfunktionen beschreiben. Dies gilt auch für die KKF, wenn die den Intensitätsverteilungen $\mathcal{I}_{\text {obj }}^{(1)}(x, y)$ und $\mathcal{I}_{\text {obj }}^{(2)}(x, y)$ zugrundeliegenden approximierten Zigarrenmodelle die gleiche räumliche Orientierung aufweisen, also den gleichen Winkel $\varphi$ mit der $x$-Achse des Bildes einschließen. Dies ist der Fall, wenn der Kernel für jedes Bild neu - mit den entsprechenden Ergebnisparametern der AKF-Analyse - berechnet wird. Abbildung 6.5 C zeigt ein solches Beispiel. Der dargestellte Kernel entspricht der Intensiätsverteilung $\mathcal{I}_{\text {obj }}(x, y)$ des approximierten Zigarrenmodells, berechnet mit den Ergebnisparametern der AKF-Anpassung. Die Auswertung der KKF von LSM-Bild und Kernel (Abbildung 6.5 D) liefert die räumliche Verschiebung zwischen dem theoretischen Objekt und dem Wildtyp-Objekt.

Abbildung 6.6 zeigt eine schematische Darstellung zur Veranschaulichung der Kreuzkorrelationsanalyse zweier Objektintensitätsverteilungen. Die Zentren der beiden mittleren Kästen der Objektmodelle sind bezüglich der $\tilde{x}$ - und $\tilde{y}$-Achse des Koordinatensystems $\tilde{\mathcal{O}}$ um die Werte $\tilde{d}_{C C}$ und $\tilde{d}_{y}$ gegeneinander verschoben. Die Modelle weisen die gleiche Orientierung auf. Die Intensitätsverteilungen $\mathcal{I}_{\mathrm{obj}}^{(1)}(\tilde{x}, \tilde{y})$ und $\mathcal{I}_{\mathrm{obj}}^{(2)}(\tilde{x}, \tilde{y})$ ergeben sich aus der Summe 


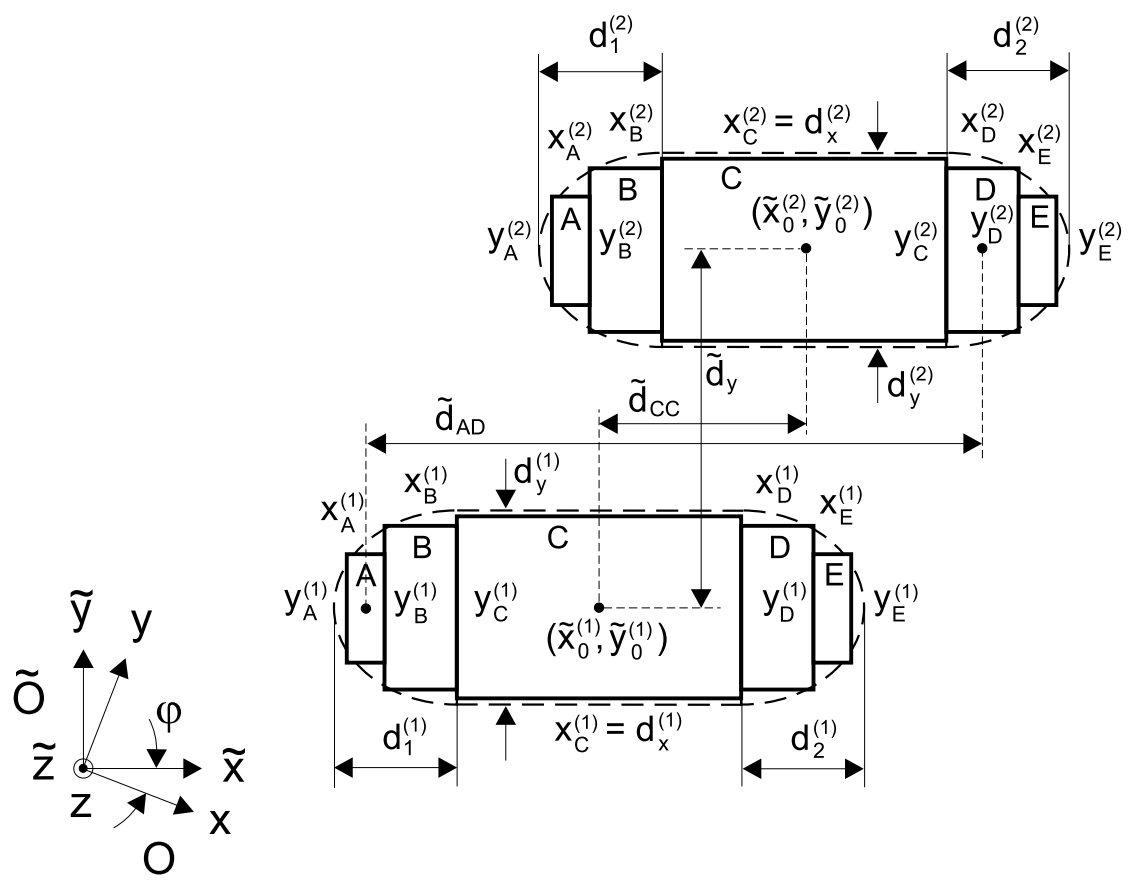

Abb. 6.6: Zur Kreuzkorrelationsanalyse der Intensitätsverteilungen $\mathcal{I}_{\text {obj }}^{(1)}(\tilde{x}, \tilde{y})$ und $\mathcal{I}_{\text {obj }}^{(2)}(\tilde{x}, \tilde{y})$ zweier gegeneinander verschobener Objektmodelle.

der Intensitätsbeiträge der einzelnen Kästen A bis E, d.h.

$$
\mathcal{I}_{\text {obj }}^{(1)}(\tilde{x}, \tilde{y})=\sum_{U \in \mathcal{M}} \mathcal{I}_{U}^{(1)}(\tilde{x}, \tilde{y})
$$

und

$$
\mathcal{I}_{\mathrm{obj}}^{(2)}(\tilde{x}, \tilde{y})=\sum_{V \in \mathcal{M}} \mathcal{I}_{V}^{(2)}(\tilde{x}, \tilde{y})
$$

mit $\mathcal{M}=\{A, B, C, D, E\}$. Die unnormierte $\operatorname{KKF} G^{\prime}(\tilde{\xi}, \tilde{\eta})$ der beiden Verteilungen ist durch den Ausdruck

$$
G^{\prime}(\tilde{\xi}, \tilde{\eta})=\sum_{U, V \in \mathcal{M}} G_{U V}^{\prime}(\tilde{\xi}, \tilde{\eta})
$$

mit

$$
G^{\prime}{ }_{U V}(\tilde{\xi}, \tilde{\eta})=\int_{-\infty}^{\infty} \int_{-\infty}^{\infty} \mathrm{d} \tilde{x} \mathrm{~d} \tilde{y} \mathcal{I}_{U}^{(1)}(\tilde{x}, \tilde{y}) \mathcal{I}_{V}^{(2)}(\tilde{x}+\tilde{\xi}, \tilde{y}+\tilde{\eta})
$$

gegeben. Sie setzt sich aus allen Kombinationen von Kreuzkorrelationsprodukten der Intensitätsverteilungen $\mathcal{I}_{U}^{(1)}(\tilde{x}, \tilde{y})$ und $\mathcal{I}_{V}^{(2)}(\tilde{x}, \tilde{y})$, mit $U, V \in \mathcal{M}$, zusammen. Als Beispiel dient die $\operatorname{KKF} G^{\prime}{ }_{\mathrm{CC}}(\tilde{\xi}, \tilde{\eta})$ der Intensitätsverteilungen $\mathcal{I}_{C}^{(1)}(\tilde{x}, \tilde{y})$ und $\mathcal{I}_{C}^{(2)}(\tilde{x}, \tilde{y})$ der beiden mittleren Kästen. Alle anderen KKFs lassen sich daraus durch geeignete Substitutionen erzeugen. 
Ausgangspunkt sind die Intensitätsverteilungen

$$
\mathcal{I}_{C}^{(1)}(\tilde{x}, \tilde{y})=q_{1} \sqrt{\frac{\pi}{2}} r_{z} \operatorname{erf}\left(\frac{z_{C}^{(1)}}{\sqrt{2} r_{z}}\right) \int_{\tilde{x}_{o}^{(1)}-x_{C}^{(1)} / 2}^{\tilde{x}_{o}^{(1)}+x_{C}^{(1)} / 2} \mathrm{~d} x^{\prime} \int_{\tilde{y}_{o}^{(1)}-y_{C}^{(1)} / 2}^{\tilde{y}_{o}^{(1)}+y_{C}^{(1)} / 2} \mathrm{~d} y^{\prime} e^{-2 \frac{\tilde{x}-x^{\prime}}{r_{x y}^{2}}} e^{-2 \frac{\tilde{y}-y^{\prime}}{r_{x y}^{2}}}
$$

und

$$
\mathcal{I}_{C}^{(2)}(\tilde{x}, \tilde{y})=q_{2} \sqrt{\frac{\pi}{2}} r_{z} \operatorname{erf}\left(\frac{z_{C}^{(2)}}{\sqrt{2} r_{z}}\right) \int_{\tilde{x}_{o}^{(2)}-x_{C}^{(2)} / 2}^{\tilde{x}_{o}^{(2)}+x_{C}^{(2)} / 2} \mathrm{~d} x^{\prime \prime} \int_{\tilde{y}_{o}^{(2)}-y_{C}^{(2)} / 2}^{\tilde{y}_{o}^{(2)}+y_{C}^{(2)} / 2} \mathrm{~d} y^{\prime \prime} e^{-2 \frac{\tilde{x}-x^{\prime \prime}}{r_{x}^{2} y}} e^{-2 \frac{\tilde{y}-y^{\prime \prime}}{r_{x}^{2} y}}
$$

mit $q_{1}=g Q I_{0}\left\langle C_{1}\right\rangle$ und $q_{2}=g Q I_{0}\left\langle C_{2}\right\rangle$. Hierbei bezeichnen $\left\langle C_{1}\right\rangle$ und $\left\langle C_{2}\right\rangle$ die jeweilige Farbstoffkonzentration in den beiden Objektmodellen und $z_{C}^{(1)}=y_{C}^{(1)}$ und $z_{C}^{(2)}=y_{C}^{(2)}$ die jeweilige Kastenhöhe. Die beiden Verteilungen ergeben sich unmittelbar aus Gleichung (6.1) mit den entsprechenden Kastenobjektfunktionen

$$
\begin{aligned}
\chi_{C}^{(1)}\left(x^{\prime}, y^{\prime}, z^{\prime}\right)= & \chi_{\left[\tilde{x}_{o}^{(1)}-x_{C}^{(1)} / 2, \tilde{x}_{o}^{(1)}+x_{C}^{(1)} / 2\right]}\left(x^{\prime}\right) \\
& \cdot \chi_{\left[\tilde{y}_{o}^{(1)}-y_{C}^{(1)} / 2, \tilde{y}_{o}^{(1)}+y_{C}^{(1)} / 2\right]}\left(y^{\prime}\right) \\
& \cdot \chi_{\left[-z_{C}^{(1)} / 2, z_{C}^{(1)} / 2\right]}\left(z^{\prime}\right)
\end{aligned}
$$

und

$$
\begin{aligned}
\chi_{C}^{(2)}\left(x^{\prime \prime}, y^{\prime \prime}, z^{\prime \prime}\right)= & \chi_{\left[\tilde{x}_{o}^{(2)}-x_{C}^{(2)} / 2, \tilde{x}_{o}^{(2)}+x_{C}^{(2)} / 2\right]}\left(x^{\prime \prime}\right) \\
& \cdot \chi_{\left[\tilde{y}_{o}^{(2)}-y_{C}^{(2)} / 2, \tilde{y}_{o}^{(2)}+y_{C}^{(2)} / 2\right]}\left(y^{\prime \prime}\right) \\
& \cdot \chi_{\left[-z_{C}^{(2)} / 2, z_{C}^{(2)} / 2\right]}\left(z^{\prime \prime}\right) .
\end{aligned}
$$

Führt man die Integrationen bezüglich der Koordinaten $\tilde{x}, \tilde{y}, x^{\prime}$ und $y^{\prime}$ aus, folgt für die $\operatorname{KKF} G^{\prime}{ }_{\mathrm{CC}}(\tilde{\xi}, \tilde{\eta})$ :

$$
\begin{array}{r}
G_{C C}^{\prime}(\tilde{\xi}, \tilde{\eta})=q_{1} q_{2} \frac{\pi^{3}}{2^{7}} r_{x y}^{4} r_{z}^{2} x_{C}^{(2)} y_{C}^{(2)} \operatorname{erf}\left(\frac{z_{C}^{(1)}}{\sqrt{2} r_{z}}\right) \operatorname{erf}\left(\frac{z_{C}^{(2)}}{\sqrt{2} r_{z}}\right) \\
\cdot \int_{-1}^{1} \mathrm{~d} x^{\prime \prime}\left[\operatorname{erf}\left(\frac{\tilde{\xi}-\tilde{d}_{C C}-x^{\prime \prime} \frac{x_{C}^{(2)}}{2}+\frac{x_{C}^{(1)}}{2}}{r_{x y}}\right)-\operatorname{erf}\left(\frac{\left.\tilde{\xi}-\tilde{d}_{C C}-x^{\prime \prime} \frac{x_{C}^{(2)}}{2}-\frac{x_{C}^{(1)}}{2}\right)}{r_{x y}}\right)\right] \\
\cdot \int_{-1}^{1} \mathrm{~d} y^{\prime \prime}\left[\operatorname{erf}\left(\frac{\tilde{\eta}-\tilde{d}_{y}-y^{\prime \prime} \frac{y_{C}^{(2)}}{2}+\frac{y_{C}^{(1)}}{2}}{r_{x y}}\right)-\operatorname{erf}\left(\frac{\tilde{\eta}-\tilde{d}_{y}-y^{\prime \prime} \frac{y_{C}^{(2)}}{2}-\frac{y_{C}^{(1)}}{2}}{r_{x y}}\right)\right],
\end{array}
$$


mit $\tilde{d}_{C C}=\tilde{x}_{0}^{(2)}-\tilde{x}_{0}^{(1)}$ und $\tilde{d}_{y}=\tilde{y}_{0}^{(2)}-\tilde{y}_{0}^{(1)}$. Dieser Ausdruck kann schließlich in der Form

$$
\begin{array}{r}
G_{C C}^{\prime}(\tilde{\xi}, \tilde{\eta})=q_{1} q_{2} \frac{\pi^{5 / 2}}{2^{5}} r_{x y}^{5} r_{z}^{2} \operatorname{erf}\left(\frac{z_{C}^{(1)}}{\sqrt{2} r_{z}}\right) \operatorname{erf}\left(\frac{z_{C}^{(2)}}{\sqrt{2} r_{z}}\right) \\
\cdot \sum_{\varepsilon_{1}, \varepsilon_{2} \in\{ \pm 1\}} \varepsilon_{1} \varepsilon_{2}\left\{\exp \left[-\mathcal{A}\left(\varepsilon_{1}, \varepsilon_{2}\right)^{2} / r_{x y}^{2}\right]+\frac{\sqrt{\pi}}{r_{x y}} \mathcal{A}\left(\varepsilon_{1}, \varepsilon_{2}\right) \operatorname{erf}\left[\mathcal{A}\left(\varepsilon_{1}, \varepsilon_{2}\right) / r_{x y}\right]\right\} \\
\cdot \sum_{\varepsilon_{1}, \varepsilon_{2} \in\{ \pm 1\}} \varepsilon_{1} \varepsilon_{2}\left\{\exp \left[-\mathcal{B}\left(\varepsilon_{1}, \varepsilon_{2}\right)^{2} / r_{x y}^{2}\right]+\frac{\sqrt{\pi}}{r_{x y}} \mathcal{B}\left(\varepsilon_{1}, \varepsilon_{2}\right) \operatorname{erf}\left[\mathcal{B}\left(\varepsilon_{1}, \varepsilon_{2}\right) / r_{x y}\right]\right\},
\end{array}
$$

mit

$$
\mathcal{A}\left(\varepsilon_{1}, \varepsilon_{2}\right)=\left(\tilde{\xi}-\tilde{d}_{C C}+\varepsilon_{1} \frac{x_{C}^{(1)}}{2}+\varepsilon_{2} \frac{x_{C}^{(2)}}{2}\right)
$$

und

$$
\mathcal{B}\left(\varepsilon_{1}, \varepsilon_{2}\right)=\left(\tilde{\eta}-\tilde{d}_{y}+\varepsilon_{1} \frac{y_{C}^{(1)}}{2}+\varepsilon_{2} \frac{y_{C}^{(2)}}{2}\right),
$$

geschrieben werden. Die computergestützte Analyse von experimentellen zweidimensionalen Korrelationsfunktionen mit einer theoretischen KKF - kombiniert aus Ausdrücken der Form (6.38) - umgeht somit die relativ zeitaufwändigen Berechnungen von numerischen Integralen. Die meisten Programmiersprachen besitzen dagegen sehr effiziente Implementierungen der Fehlerfunktion.

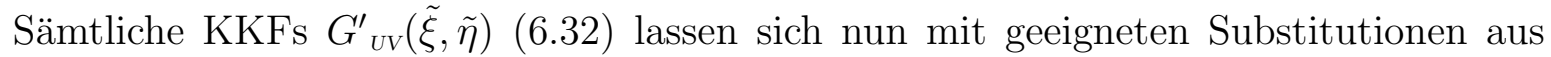
dem abgeleiteten Ausdruck (6.38) konstruieren. Als Beispiel sei hier auf die Konstruktion der $\operatorname{KKF} G_{A D}^{\prime}(\tilde{\xi}, \tilde{\eta})$ der Intensitätsverteilungen $\mathcal{I}_{A}^{(1)}(\tilde{x}, \tilde{y})$ und $\mathcal{I}_{D}^{(2)}(\tilde{x}, \tilde{y})$ der Kästen A und $\mathrm{D}$ der beiden Objektmodelle verwiesen. Für die Konstruktion sind die Größenparameter $x_{C}^{(1)}, x_{C}^{(2)}, y_{C}^{(1)}=z_{C}^{(1)}$ und $y_{C}^{(2)}=z_{C}^{(2)}$ durch die entsprechenden Parameter $x_{A}^{(1)}, x_{D}^{(2)}$, $y_{\mathrm{A}}^{(1)}=z_{\mathrm{A}}^{(1)}$ und $y_{D}^{(2)}=z_{D}^{(2)}$ auszutauschen. Zudem wird der Abstand $\tilde{d}_{C C}$ der beiden mittleren Objektkästen in Gleichung (6.39) durch den Zentrenabstand $\tilde{d}_{A D}$ der Kästen A und D der beiden Objektmodelle ersetzt (Abb. 6.6). Dieser wird hierzu in Abhängigkeit des Verschiebungsparameters $\tilde{d}_{C C}$ formuliert (der Abstand $\tilde{d}_{y}$ bezüglich der $\tilde{\eta}$-Achse ist für alle Kästen gleich und braucht nicht ersetzt werden):

$$
\tilde{d}_{A D}=\tilde{d}_{C C}+\frac{x_{C}^{(1)}}{2}+x_{B}^{(1)}+\frac{x_{A}^{(1)}}{2}+\frac{x_{C}^{(2)}}{2}+\frac{x_{D}^{(2)}}{2} .
$$

Alle anderen $\mathrm{KKFs}_{G^{\prime}}{ }_{U V}(\tilde{\xi}, \tilde{\eta})$ lassen sich analog erzeugen.

Für die normierte $\operatorname{KKF} G(\tilde{\xi}, \tilde{\eta})$ der Intensitätsverteilungen $\mathcal{I}_{\text {obj }}^{(1)}(\tilde{x}, \tilde{y})$ (6.29) und $\mathcal{I}_{\text {obj }}^{(2)}(\tilde{x}, \tilde{y})(6.30)$ bezüglich $\tilde{\mathcal{O}}$ folgt schließlich

$$
G(\tilde{\xi}, \tilde{\eta})=\frac{\sum_{U, V \in \mathcal{M}} G_{U V}^{\prime}(\tilde{\xi}, \tilde{\eta})}{\sum_{U, V \in \mathcal{M}}\left\langle\mathcal{I}_{U}^{(1)}(\tilde{x}, \tilde{y})\right\rangle\left\langle\mathcal{I}_{V}^{(2)}(\tilde{x}, \tilde{y})\right\rangle} .
$$


Mit

$$
\begin{aligned}
\left\langle\mathcal{I}_{U}^{(\mathrm{i})}(\tilde{x}, \tilde{y})\right\rangle & =\int_{-\infty}^{\infty} \int_{-\infty}^{\infty} \mathrm{d} \tilde{x} \mathrm{~d} \tilde{y} \mathcal{I}_{U}^{(\mathrm{i})}(\tilde{x}, \tilde{y}) \\
& =q_{i}\left(\frac{\pi}{2}\right)^{3 / 2} r_{x y}^{2} r_{z} x_{U}^{(\mathrm{i})} y_{U}^{(\mathrm{i})} \operatorname{erf}\left[z_{U}^{(\mathrm{i})} /\left(\sqrt{2} r_{z}\right)\right]
\end{aligned}
$$

$(i=1,2)$, folgt weiter

$$
G(\tilde{\xi}, \tilde{\eta})=\frac{\sum_{U, V \in \mathcal{M}} G_{U V}^{\prime}(\tilde{\xi}, \tilde{\eta})}{q_{1} q_{2} \frac{\pi^{3}}{8} r_{x y}^{4} r_{z}^{2} \sum_{U, V \in \mathcal{M}} x_{U}^{(1)} x_{V}^{(2)} y_{U}^{(1)} y_{V}^{(2)} \operatorname{erf}\left[z_{U}^{(1)} /\left(\sqrt{2} r_{z}\right)\right] \operatorname{erf}\left[z_{V}^{(2)} /\left(\sqrt{2} r_{z}\right)\right]}
$$

Die gesuchte normierte $\operatorname{KKF} G(\xi, \eta)(6.25)$ bezüglich des $(\xi, \eta)$-Koordinatensystems mit der $\xi$-Achse parallel zur $x$-Achse des Koordinatensystems $\mathcal{O}$ erhält man letztendlich aus (6.45) zusammen mit den Koordinatentransformationen

$$
\begin{aligned}
\tilde{\xi} & =\xi \cos \varphi+\eta \sin \varphi \text { und } \\
\tilde{\eta} & =\eta \cos \varphi-\xi \sin \varphi
\end{aligned}
$$

Mit den Definitionen

$$
g_{U V}^{\prime}(\xi, \eta)=\frac{2^{5}}{q_{1} q_{2} \pi^{5 / 2} r_{x y}^{5} r_{z}^{2}} G_{U V}^{\prime}(\xi, \eta)
$$

und

$$
G_{0}=\frac{r_{x y}}{4 \sqrt{\pi}}\left(\sum_{U, V \in \mathcal{M}} x_{U}^{(1)} x_{V}^{(2)} y_{U}^{(1)} y_{V}^{(2)} \operatorname{erf}\left[z_{U}^{(1)} /\left(\sqrt{2} r_{z}\right)\right] \operatorname{erf}\left[z_{V}^{(2)} /\left(\sqrt{2} r_{z}\right)\right]\right)^{-1}
$$

folgt schließlich

$$
G(\xi, \eta)=G_{0} \cdot \sum_{U, V \in \mathcal{M}} g_{U V}^{\prime}(\xi, \eta)
$$

Die normierte $\operatorname{KKF} G(\xi, \eta)$ ist somit nicht mehr von den Farbstoffkonzentrationen $\left\langle C_{1}\right\rangle$ und $\left\langle C_{2}\right\rangle$ in den beiden Objekten abhängig, denn die Konstanten $q_{1}=g Q I_{0}\left\langle C_{1}\right\rangle$ und $q_{2}=g Q I_{0}\left\langle C_{2}\right\rangle$ kürzen sich in dem Ausdruck (6.48) heraus. Die Normierung der experimentellen AKFs und KKFs ist von Vorteil, wenn die Korrelationsfunktionen von Objekten gleicher Größe aber mit unterschiedlichem Färbungsgrad verglichen werden sollen. Werden unnormierte Korrelationsfunktionen ausgewertet, so dient $G_{0}$ als zusätzlicher freier Anpassungsparameter.

Die Hintergrundfluoreszenz in den experimentellen LSM-Bildern führt zu einem Offset in den AKFs und KKFs (Abbildung 6.5 B und D). Da die abgeleitetet $\operatorname{KKF} G(\xi, \eta)(6.50)$ 
keinen Rausch-Beitrag berücksichtigt, muss schließlich eine zusätzliche Konstante eingefügt werden

$$
G(\xi, \eta)=g_{0}+G_{0} \cdot \sum_{U, V \in \mathcal{M}} g_{U V}^{\prime}(\xi, \eta)
$$

Bei der Implementierung dieser Funktion in benutzerdefinierte Computeralgorithmen sind zusätzlich die Parametergleichungen (6.11) bis (6.17) zu berücksichtigen. Die Parameter des Algorithmus' sind der Amplitudenfaktor $G_{0}$ (kann bei der Analyse normierter AKFs und KKFs als freier Parameter entfallen, wenn er entsprechend Gl. 6.49 in den Algorithmus eingefügt wird), die Größenparameter $d_{1}^{(1)}, d_{1}^{(2)}, d_{x}^{(1)}, d_{x}^{(2)}, d_{2}^{(1)}, d_{2}^{(2)}, d_{y}^{(1)}, d_{y}^{(2)}$ der beiden Objektmodelle, die Verschiebungswerte $\tilde{d}_{C C}$ und $\tilde{d}_{y}$ sowie die Orientierung $\varphi$ der Objekte bezüglich der $\xi$-Achse und die Konstante $g_{0}$. Wird der Ausdruck (6.51) verwendet, um experimentelle AKFs auszuwerten, sind die Größenparameter der beiden Objektmodelle entsprechend aneinander zu binden, d.h. $d_{1}^{(1)}=d_{1}^{(2)}, d_{x}^{(1)}=d_{x}^{(2)}$ etc., und die Verschiebungswerte $\tilde{d}_{C C}=0$ und $\tilde{d}_{y}=0$ anzunehmen.

Die Analyse der experimentellen AKF eines LSM-Bildes liefert die Größenparameter des Objektes und den Orientierungswinkel $\varphi$ bezüglich der $\xi$-bzw. $x$-Achse. Mit diesen Daten kann dann die theoretische Intensitätsverteilung $\mathcal{I}_{\text {obj }}(x, y)$ des Kernels berechnet werden. Der abgeleitete Ausdruck (6.51) wird schließlich verwendet, um die experimentelle KKF des LSM-Bildes und des Kernels quantitativ zu analysieren. In dem KKFAnpassungsalgorithmus werden dazu die Größenparameter des Kernelobjektes sowie der Orientierungswinkel $\varphi$ fixiert. Die freien Parameter sind die Größenparameter des Objektes im LSM-Bild - die so erneut analysiert werden - sowie die relativen Verschiebungsparameter $\tilde{d}_{C C}$ und $\tilde{d}_{y}$. Da die Position des Kernelobjektes im Bild bekannt ist, kann mit den Verschiebungsparametern die Position des Objektes im LSM bestimmt werden.

\subsubsection{Definition: Lokalisationsgenauigkeit und Signal-Rausch- Verhältnis (SNR)}

Die Genauigkeit der Tracking-Algorithmen bei der Bestimmung von Objektzentrumskoordinaten, Koordinaten der Objektgrenzen oder Objektgrößenparametern hängt stark von der Hintergrundfluoreszenz in den LSM-Bildern, der Intensität und der Größe des Objektes sowie dem Auflösungsvermögen des optischen Systems ab (Abschnitt 6.1.5) [103-105]. Die Lokalisierungsgenauigkeit ist durch die Standardabweichung der Messgröße definiert [93]. Die Lokalisierungsgenauigkeit der Schwerpunktskoordinaten eines beugungsbegrenzten Intensitätssignals kann weit unterhalb der Auflösungsgrenze des optischen Systems liegen, sofern die Anzahl der Photonen im Spot hoch genug ist [104,105]. Im Rahmen dieser Arbeit sind Lokalisierungsgenauigkeiten im Bereich von $5-50 \mathrm{~nm}$ erreicht worden. In den folgenden Abschnitten werden an entsprechenden Stellen Parameterwerte mit Genauigkeiten bis in den Angströmbereich hinein angegeben. Dies ist notwendig, um die Algorithmen quantitativ zu vergleichen und um mögliche Fehler der Algorithmen gegenüber den erreichbaren Genauigkeiten abzugrenzen. 
Von wesentlicher Interesse ist die Abhängigkeit der Genauigkeit eines Algorithmus' vom Signal-Rausch-Verhältnis (SNR) der Fluoreszenzbilder. Das Rauschen in den Bildern wird bei den vorliegenden Messungen durch das Rauschen über dem Objekt dominiert. Somit wird das SNR maßgeblich durch die Fluktuationen der Objektintensität bestimmt:

$$
\mathrm{SNR} \simeq \frac{I_{\max }}{\sigma_{\text {sig }}}
$$

Hierbei bezeichnet $\sigma_{\text {sig }}$ die Standardabweichung des Fluoreszenzsignals des Objektes und $I_{\max }$ die mittlere maximale Signalamplitude über dem mittleren Hintergrundsignal $I_{B}$.

Für die Lokalisierung von Objektgrenzen ist es von entscheidender Bedeutung, die abfallenden Flanken einer Intensitätsverteilung möglichst genau zu detektieren (Abschnitt 6.1.2, Abbildung 6.4). Fluktuationen in diesem Teil der Intensitätsverteilung wirken sich also direkt auf die erreichbare Lokalisierungsgenauigkeit der Objektgrenzen aus. Daher sollte das SNR das Rauschen der ganzen gemessenen Intensitätsverteilung berücksichtigen. Um ein Maß für das gesamte Rauschen der Objektintensität zu erhalten, wird die Standardabweichung $\sigma_{\text {sig }}$ des Intensitätssignals direkt aus einem LSM-Bild abgeleitet. Für die Berechnung der Standardabweichung werden sämtliche Fluktuationen $\delta I_{\text {sig }}(x, y)=$ $I_{\text {sig }}(x, y)-\bar{I}_{\text {sig }}(x, y)$ der zweidimensionalen Intensitätsverteilung berücksichtigt. Das mittlere Fluoreszenzsignal $\bar{I}_{\text {sig }}(x, y)$ des Objektes lässt sich dabei durch die FPA ( $\chi^{2}$-Minimierung) der experimentell gemessenen Objektintensität mit der theoretischen Intensitätsverteilung $\mathcal{I}_{\text {obj }}(x, y)$ (6.18 mit 6.9 und 6.10) des theoretischen Objektmodells berechnen. Das Anpassungsergebnis beschreibt in sehr guter Näherung die mittlere Objektintensität, d.h. $\bar{I}_{\text {sig }}(x, y) \simeq \mathcal{I}_{\text {obj }}(x, y)$. Ist die ortsabhängige mittlere Intensitätsverteilung $\bar{I}_{\text {sig }}(x, y)$ bekannt, kann die Standardabweichung durch den Ausdruck

$$
\sigma_{\text {sig }}=\sqrt{\frac{\sum_{(i, j) \in \mathcal{M}_{o b j}}\left[I_{\text {sig }}(i, j)-\bar{I}_{\text {sig }}(i, j)\right]^{2}}{\operatorname{card}\left(\mathcal{M}_{o b j}\right)-1}}
$$

berechnet werden. Hierbei bezeichnet $\operatorname{card}\left(\mathcal{M}_{\text {obj }}\right)$ die Kardinalität der Menge

$$
\mathcal{M}_{\text {obj }}=\left\{(i, j) \in x \times y \mid \bar{I}_{\text {sig }}(x, y) \geq 10^{-2} \cdot I_{\max }\right\},
$$

d.h. die Anzahl der Elemente in $\mathcal{M}_{o b j}$. Es werden somit sämtliche Bildpixel berücksichtigt, deren mittlere Objektintensitätswerte mindestens 1\% des maximalen Wertes $I_{\max }$ betragen. Dies verhindert, dass Bildpixel außerhalb der zweidimensionalen Objektintensitätsverteilung einbezogen werden. Wird die Standardabweichung auf diese Weise berechnet, ist das SNR (6.52) ein Maß für die Qualität der gesamten zweidimensionalen Objektintensitätsverteilung.

\subsubsection{Vergleich der Faltungsprodukt- und Korrelationsanalyse}

In diesem Abschnitt wird nun mit Hilfe von Computersimulationen untersucht, welche der beiden Methoden - FPA oder KA - die genauere ist. 

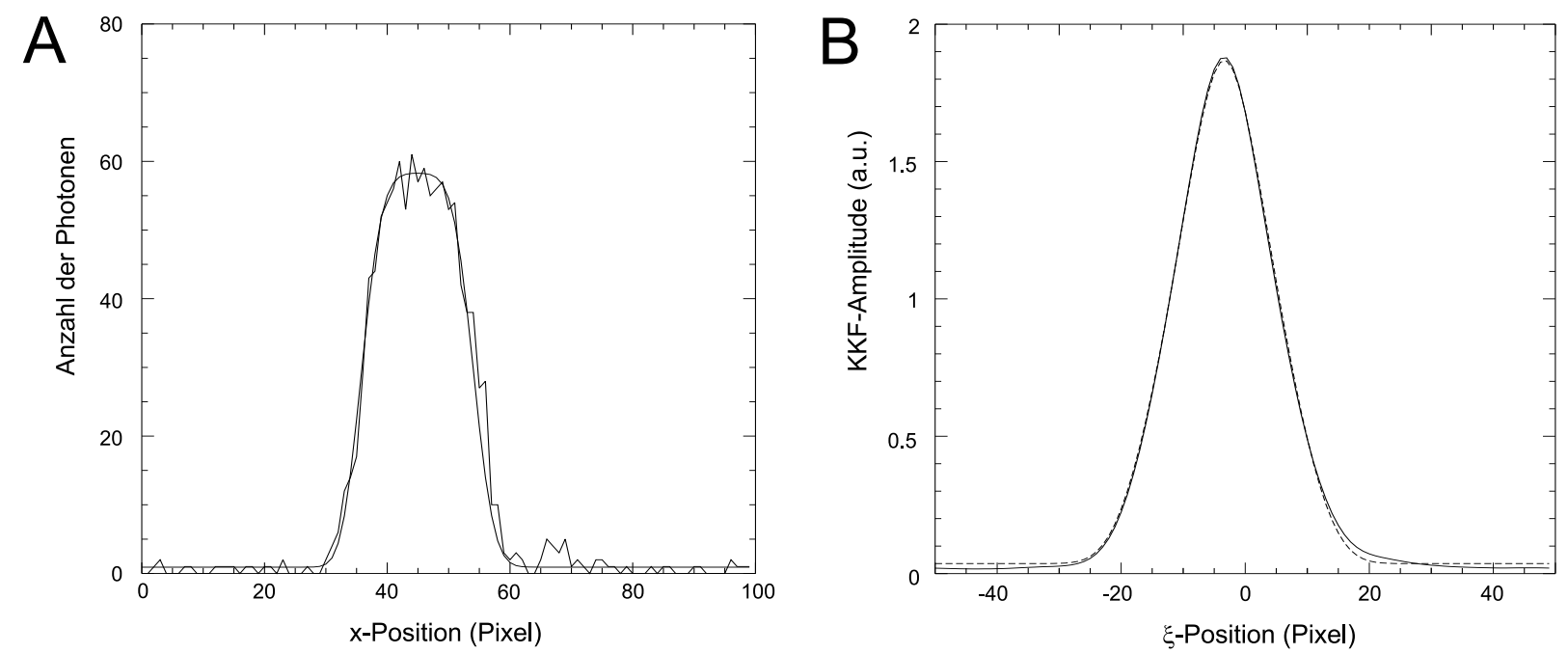

Abb. 6.7: Faltungsproduktanalyse versus Korrelationsanalyse. Analyseergebnisse der in Abbildung $6.5 \mathrm{~A}$ und $D$ dargestellten Daten. (A) Schnitt entlang der $x$-Achse $(y=30)$ durch die zweidimensionale Intensitätsverteilung des Ecoli-Bildes aus Abbildung $6.5 \mathrm{~A}$ (verrauschte Kurve) und der angepassten theoretischen Intensitätsverteilung $\mathcal{I}_{\text {obj }}(x, y)$ (6.18 mit 6.9 und 6.10) des approximierten Zigarrenmodells (glatte Kurve). Ergebnis der Auswertung: $d_{x}=2129.2 \mathrm{~nm}, d_{1}=664.6 \mathrm{~nm}, d_{2}=445.4 \mathrm{~nm}, d_{y}=964.2 \mathrm{~nm}$ und $\varphi=0.5609$ $\left(\chi^{2}=17946.66\right)$. Es ergibt sich eine Objektlänge von $d=3239.3 \mathrm{~nm}$. Die Analyse mit der Verteilung $I_{\text {obj }}(x, y)$ (6.4) des exakten Zigarrenmodells liefert: $d_{x}=2152.7 \mathrm{~nm}$, $d_{1}=620.5 \mathrm{~nm}, d_{2}=467.4 \mathrm{~nm}, d_{y}=1009.1 \mathrm{~nm}$ und $\varphi=0.5611\left(\chi^{2}=17190.805\right)$. Daraus folgt eine Objektlänge von $d=3240.6 \mathrm{~nm}$. (B) Schnitt entlang der $\xi$-Achse durch das Maximum der experimentellen KKF aus Abbildung 6.5 D (durchgezogene Kurve) und der angepassten $K K F G(\xi, \eta)$ (6.51) (gestrichelte Kurve). Die angepasste KKF beschreibt die Kreuzkorrelation zwischen den Intensitätsverteilungen $\mathcal{I}_{\text {obj }}^{(1)}(x, y)$ und $\mathcal{I}_{\text {obj }}^{(2)}(x, y)$ zweier approximierter Zigarrenmodelle, d.h. zwischen dem in Abbildung 6.5 C dargestellten Kernel (feste Parameter bei der Kurvenanpassung) und der Verteilung eines Objektmodells mit freien Parametern. Ergebnis der Analyse: $d_{x}=2186.8 \mathrm{~nm}, d_{1}=613.9 \mathrm{~nm}, d_{2}=428.6 \mathrm{~nm}$, $d_{y}=1002.1 \mathrm{~nm}$ und $\varphi=0.5558\left(\chi^{2}=1.7759 E-06\right)$. Aus den Parametern berechnet sich eine Objektlänge von $d=3229.3 \mathrm{~nm}$.

Abbildung 6.7 zeigt die Ergebnisse der Faltungsprodukt- und der Korrelationsanalyse des Ecoli-Bakteriums aus Abbildung 6.5. Die FPA des Ecoli-Bildes mit der Intensitätsverteilung $\mathcal{I}_{\text {obj }}(x, y)$ des approximierten Zigarrenmodells liefert eine Ecoli-Gesamtlänge von $d=3239.3 \mathrm{~nm}$ (Rechenzeit: 40 Sekunden). Analysiert man das LSM-Bild mit der rechenaufwändigen Intensitätsverteilung $I_{\text {obj }}(x, y)(6.4)$ des exakten Zigarrenmodells, ergibt sich eine Ecoli-Länge von $d=3240.6 \mathrm{~nm}$ (Rechenzeit: 9.5 Stunden). Die Abweichung von $1.3 \mathrm{~nm}$ liegt somit im erwarteten Bereich (Abschnitt 6.1.2).

In Abbildung 6.7 B ist das Ergebnis der KA dargestellt. Sie liefert eine Ecoli-Länge von 
$d=3229.3 \mathrm{~nm}$. Vergleicht man das Ergebnis mit dem der FPA, ergibt sich eine Längendifferenz von $\sim 10 \mathrm{~nm}$. Doch welche Analysemethode liefert das genauere Ergebnis? Dies kann nur beantwortet werden, wenn man beide Analysemethoden auf ein Bakterium anwendet, dessen tatsächliche Form und Größe bekannt sind. Ausgangspunkt der Analysen ist in diesem Fall also ein theoretisches Modell-Ecoli-Bakterium.

Um die Genauigkeit der beiden Algorithmen in Abhängigkeit verschiedener SNRs zu testen, müssen Fluoreszenzbilder eines Ecoli-Bakteriums mit verschiedenen Rauschanteilen simuliert werden. Im ersten Schritt wird mit der Intensitätsverteilung $\mathcal{I}_{\text {obj }}(x, y)\left(I_{\mathrm{B}}=0\right)$ das rauschfreie Bild eines theoretischen Objektes mit bekannten und konstanten Parametern von der Größe und der Form eines Ecoli-Bakteriums berechnet. Dazu wird ein Ecoli-Bakterium mit einer typischen Länge von $\sim 3.2 \mu \mathrm{m}$ und einer Breite von $\sim 1 \mu \mathrm{m}$ $\left(d_{1}=d_{2}=5.5\right.$ Pixel, $d_{x}=25$ Pixel und $d_{y}=11$ Pixel; Pixelgröße: $\left.88 \mathrm{~nm}\right)$ gewählt. Dieses ist parallel zur $x$-Achse orientiert $(\varphi=0)$ und im Zentrum des Bildes $(96 \times 30$ Pixel $)$ lokalisiert. Im zweiten Schritt wird PoIsson-Rauschen addiert (Abschnitt 3.6), so dass das entstehende Bild das gewünschte SNR aufweist. Durch die Wahl des Poisson-Rauschens können die Analyseergebnisse mit den Ergebnissen anderer Veröffentlichungen verglichen werden [103].

Die Lokalisierungsgenauigkeit der Objektkoordinaten ist durch die Standardabweichung der jeweiligen Messgröße definiert (Abschnitt 6.1.4). Deshalb ist es nötig, die Analysen für eine bestimmte Anzahl von simulierten Bildern - berechnet mit denselben Parametern - zu wiederholen und die Standardabweichungen und Mittelwerte der gemessenen Parameter zu berechnen. Untersucht werden die Genauigkeit und der mittlere Fehler bei der Bestimmung der Objektlänge $d$, der Breite $d_{y}$, der Lokalisierung des Objektzentrums $p_{0}$ (bezüglich der $x$ - und $y$-Achse), des linken und des rechten Endes $p_{1}$ und $p_{2}$ (bezüglich der $x$-Achse) und der Seitenpunkte $p_{3}$ und $p_{4}$ (bezüglich der $y$-Achse) des Objektes (siehe Abbildung 6.1). Der mittlere Fehler ist dabei durch die Differenz zwischen dem Mittelwert des gemessenen Parameters und dem bekannten tatsächlichen Parameterwert gegeben. Liegt kein systematischer Fehler vor, so sollte der mittlere Fehler mit steigender Bildzahl bzw. mit SNR $\rightarrow \infty$ gegen Null gehen.

Es werden 100 Bilder pro SNR simuliert und nacheinander mit dem Faltungsproduktund Korrelationsalgorithmus ausgewertet. Die Beschränkung auf 100 Bilder ist erforderlich, um die Analysezeit für ein gegebenes SNR einzuschränken. Die Analysezeit beider Algorithmen kann durch die Beschränkung auf eine minimale Anzahl von relevanten Anpassungsparametern verringert werden. Es werden sowohl die Hintergrundkonstanten $I_{\mathrm{B}}=0 \mathrm{bzw}$. $g_{0}=0$ als auch der Orientierungswinkel $\varphi=0$ fixiert. Unter diesen Bedingungen benötigt der Korrelationsalgorithmus für die Auswertung von 100 Bildern mit einem Pentium-III-PC $\sim 50$ Stunden. Die FPA ist dagegen in 30 Minuten abgeschlossen.

Die FPA wird mit der Intensitätsverteilung $\mathcal{I}_{\text {obj }}(x, y)$ des approximierten Zigarrenmodells ausgeführt, also mit derselben Verteilung, mit der das rauschfreie theoretische Bild berechnet wird. Die freien Anpassungsparameter sind die Ellipsoidkappenlänge $d_{1}=d_{2}$, die Länge des Zylinders $d_{x}$, der Durchmesser $d_{y}$ und das Objektzentrum $p_{0}=\left(x_{0}, y_{0}\right)$. Sind 
die Größenparameter und das Objektzentrum $p_{0}$ durch die FPA bestimmt, lassen sich die weiteren Objektpunkte $p_{1}$ bis $p_{4}$ berechnen.

Für die KA wird zuerst die AKF eines Bildes berechnet und mit der theoretischen Korrelationsfunktion $G(\xi, \eta)(6.51)$ ausgewertet. Zuvor wird die zentrale Spitze auf der experimentellen AKF - die durch das Rauschen der Objektintensität ensteht - durch einen Interpolationswert ersetzt (siehe Abschnitt 6.1.3). Die freien Anpassungsparameter bei der AKF-Analyse sind dann die Objektgrößenparameter $d_{1}^{(1)}=d_{1}^{(2)}=d_{2}^{(1)}=d_{2}^{(2)}, d_{x}^{(1)}=d_{x}^{(2)}$ und $d_{y}^{(1)}=d_{y}^{(2)}$ (die Verschiebungsabstände $\tilde{d}_{C C}=0$ und $\tilde{d}_{y}=0$ sind dabei fixiert). Mit den Ergebnisparametern der AKF-Analyse wird die Intensitätsverteilung $\mathcal{I}_{\text {obj }}(x, y)$ des Kernelobjektes berechnet, wobei das Zentrum des Objektes im Mittelpunkt des Bildes liegt. Die KKF des simulierten Bildes und des Kernels wird dann mit der Korrelationsfunktion $G(\xi, \eta)(6.51)$ analysiert, wobei nun die Größenparameter $d_{1}^{(1)}=d_{2}^{(1)}, d_{x}^{(1)}$ und $d_{y}^{(1)}$ sowie die Verschiebungsabstände $\tilde{d}_{C C}$ und $\tilde{d}_{y}$ variiert werden (Abbildung 6.6). Die Parameter des Kernelobjektes $d_{1}^{(2)}=d_{2}^{(2)}, d_{x}^{(2)}, d_{y}^{(2)}$ sind fixiert. Da die Position des Objektes im Kernelbild bekannt ist, können schließlich mit den Größenparametern und den Verschiebungsabständen $\tilde{d}_{C C}$ und $\tilde{d}_{y}$ - die die Kreuzkorrelationsanalyse liefert - sämtliche Objektpunkte $p_{1}$ bis $p_{4}$ berechnet werden.

Abbildung 6.8 zeigt die Ergebnisse der Simulationen und Analysen. Sie lassen sich wie folgt zusammenfassen:

1. Die Genauigkeit der FPA und der KA nimmt - wie erwartet - monoton für alle Parameter mit steigendem SNR zu;

2. der Durchmesser $d_{y}$ des Objektes kann genauer bestimmt werden als die Länge $d$ (KA: 5.3fach; FPA: 3.8fach);

3. die Lokalisierungsgenauigkeit der Seitenpunkte $p_{3}(y)$ und $p_{4}(y)$ ist besser als die der Objektenden $p_{1}(x)$ und $p_{2}(x)$ (KA: 4.6fach; FPA: 3.4fach);

4. die Lokalisierungsgenauigkeit des Objektzentrums $p_{0}$ bezüglich der $y$-Achse $\left(p_{0}(y)\right)$ ist besser als die bezüglich der $x$-Achse $\left(p_{0}(x)\right)$ (KA: 3.1fach; FPA: 2.3fach);

5. die Lokalisierungsgenauigkeit des Objektzentrums $p_{0}(x)$ bzw. $p_{0}(y)$ ist besser als die der Objektenden $p_{1}(x)$ und $p_{2}(x)$ (KA: 2.3fach; FPA: 2.6fach) bzw. $p_{3}(y)$ und $p_{4}(y)$ (KA: 1.6fach; FPA: 1.8fach);

6. die FPA weist eine höhere Genauigkeit bei der Bestimmung der Objektlänge $d$ (1.3fach), der Objektenden $p_{1}(x)$ und $p_{2}(x)$ (1.3fach) sowie des Objektzentrums $p_{0}(x)$ (1.5fach) auf als die KA;

7. im Gegensatz dazu ist die Genauigkeit der KA bei der Bestimmung des Durchmessers $d_{y}$ etwas besser als die der FPA (1.1fach); 

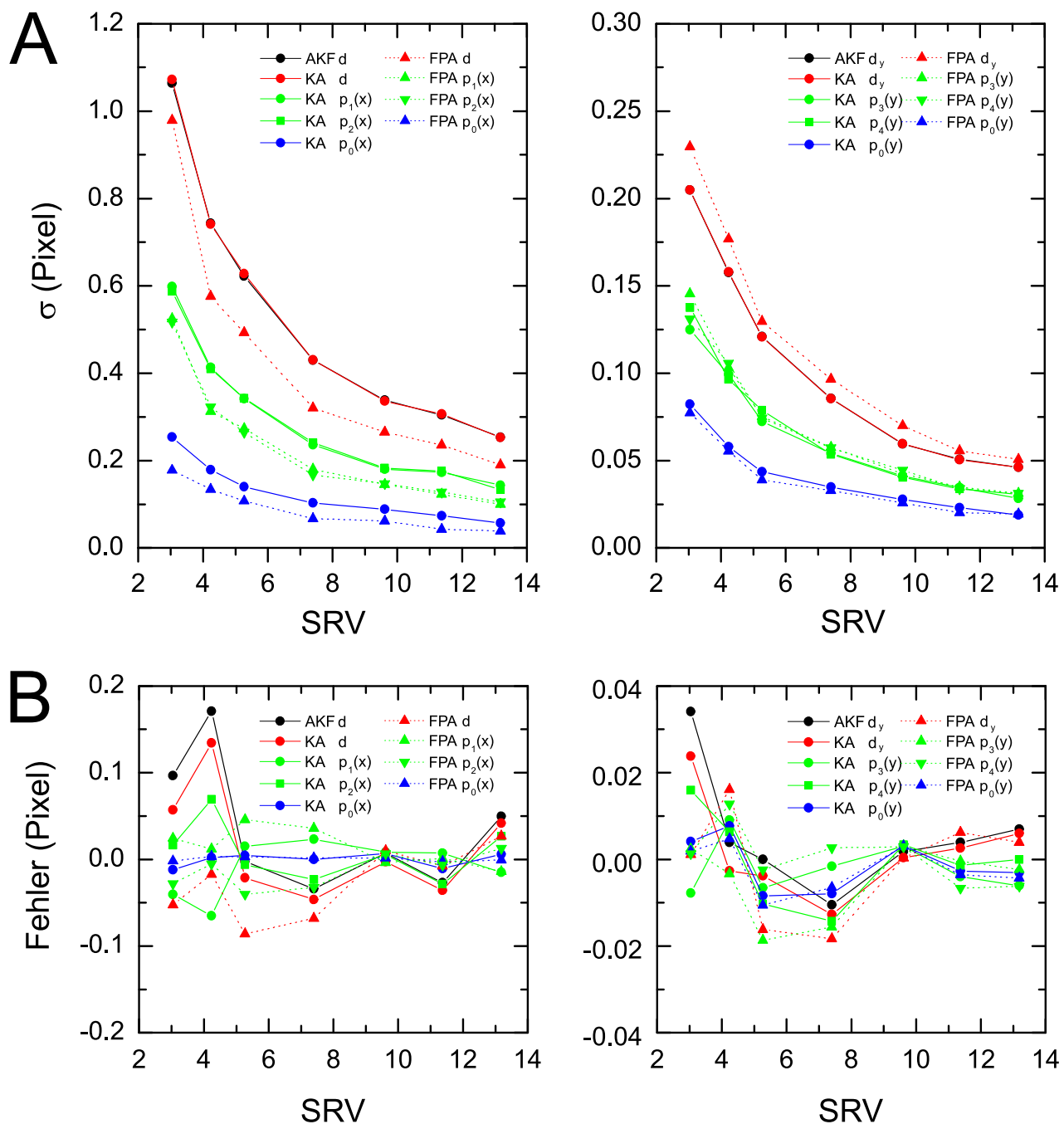

Abb. 6.8: Ergebnisse der Computersimulationen zur Genauigkeit des Korrelations- und des FP-Algorithmus' (für die Durchführung der Simulationen, die Auswertung der simulierten Bilder und für die verwendeten Parameter, siehe Text). (A) Genauigkeit der Korrelationsanalyse (durchgezogene Kurven) und FPA (gestrichelte Kurven) bei der Bestimmung der Objektlänge d, der Lokalisierung der Objektenden $p_{1}(x)$ und $p_{2}(x)$ und des Objektzentrums $p_{0}(x)$ (linker Graph), sowie des Objektdurchmessers $d_{y}$, der Lokalisierung der Objektseitenpunkte $p_{3}(y)$ und $p_{4}(y)$ und des Objektzentrums $p_{0}(y)$ (rechter Graph). (B) Abweichungen zwischen den Mittelwerten der gemessenen und der tatsächlichen Parameter.

Die Ergebnisse ermöglichen kein allgemein gültiges Urteil darüber, welche der beiden Methoden die genauere ist. Die Genauigkeit der Algorithmen ist von der Ausdehnung des Objektes in $x$ - und $y$-Richtung abhängig. Denn während die FPA eine kleinere Standard- 
abweichung bei der Bestimmung der Ecoli-Länge aufweist, ist die KA genauer bei der Bestimmung des im Vergleich zur Länge $d$ kleineren Objektdurchmessers $d_{y}$.

Die Genauigkeit der KA bei der Detektion von Objektkanten hängt davon ab, wie Steil die Flanken der Korrelationsfunktion abfallen [110]. Wird beispielsweise die Ausdehnung eines Objektes in $x$-Richtung erhöht, nimmt zugleich auch die Breite der Korrelationsfunktion in dieser Richtung zu. Zudem verringert sich die Steilheit der Korrelationsfunktion in $x$-Richtung. Dadurch nimmt die Lokalisierungsgenauigkeit der zur $x$-Richtung orthogonalen Objektkanten ab. Dies gilt dagegen nicht für die FPA: Wird etwa die Länge $d_{x}$ des Zylinders des Objektmodells erhöht (die Längen $d_{1}=d_{2}$ der Ellipsoidkappen seien konstant), sollte sich dies bei der FPA nicht auf die Genauigkeit der Längenbestimmung auswirken - vorausgesetzt der Durchmesser des konfokalen Detektionsvolumens ist gegenüber der Länge $d_{x}$ klein, d.h. $2 r_{x y}<d_{x}$. Denn die Intensitätsverteilung im Bereich der Objektenden wird bei der Verlängerung des Mittelteils unter diesen Bedingungen nicht verändert. Eine Verlängerung des Objektes in $x$-Richtung bewirkt aber sowohl für die FPA als auch für die KA eine erhöhte Lokalisationsgenauigkeit der Objektseitenpunkte $p_{3}(y)$ und $p_{4}(y)$, d.h. der Objektkanten orthogonal zur $y$-Richtung. Diese Eigenschaft ist eine unmittelbare Folge der zunehmenden Anzahl von Datenpunkten, die in die Bestimmung der seitlichen Objektkanten eingehen.

Um die letzten Aussagen zu verifizieren, wurden die FPA und die KA mit Hilfe von Simulationen in Abhängigkeit verschiedener Objektlängen - bei gleichem konstanten Durchmesser $d_{y}=11$ Pixel und einem festen SNR von $\sim 11$ - getestet. Damit ein Vergleich der Genauigkeit beider Algorithmen in Abhängikeit der Länge und der Breite des Objektes möglich ist, wurde ein einfacher Kasten gewählt. Der Kasten liegt im Zentrum des Bildes mit der langen Seite parallel zur $x$-Achse. Die zugrundeliegenden Bilder haben eine Höhe von 30 Pixel ( $y$-Richtung). Um die Rechenzeit zu reduzieren, wird die Breite der Bilder ( $x$-Richtung) entsprechend der Kastenlänge $d_{x}$ angepasst (das Verhältnis von Bildhöhe zur Kastenbreite $d_{y}$ entspricht für alle Bilder dem Verhältnis von Bildbreite zur Kastenlänge $\left.d_{x}\right)$. Es werden 500 Bilder pro Parameterkonstellation simuliert und analysiert. Die Simulationen und Analysen erfolgen analog zu denen aus Abbildung 6.8 (die Größenparameter $d_{1}=d_{2}=0$ sind bei der FPA und der KA fixiert). Abbildung $6.9 \mathrm{~A}$ und B zeigen die Ergebnisse der Simulationen und Analysen.

Daraus wird deutlich, dass die Genauigkeit der FPA bei der Längenbestimmung des Objektes und der Lokalisierung der Positionen $p_{1}(x)$ und $p_{2}(x)$ der Objektkanten und des Objektzentrums $p_{0}(x)$ unabhängig von der Länge $d_{x}$ des Objektes ist, wohingegen die Standardabweichungen derselben Parameter bei der KA mit der Objektlänge zunehmen (Abb. 6.9 A, linker Graph). Zudem wird bei der Vergrößerung des Objektes in $x$-Richtung die Genauigkeit beider Algorithmen bei der Lokalisierung der Positionen $p_{3}(y)$ und $p_{4}(y)$ der seitlichen Objektgrenzen, des Objektzentrums $p_{0}(y)$ und bei der Durchmesserbestimmung des Objektes verbessert (Abb. 6.9 A, rechter Graph). Die mittleren Fehler der Analysen (Abb. 6.9 B) sind aufgrund der höheren Anzahl von simulierten Bildern (500 anstatt von 100 pro Parameter) kleiner als die der Analysen aus Abbildung 6.8 B. 

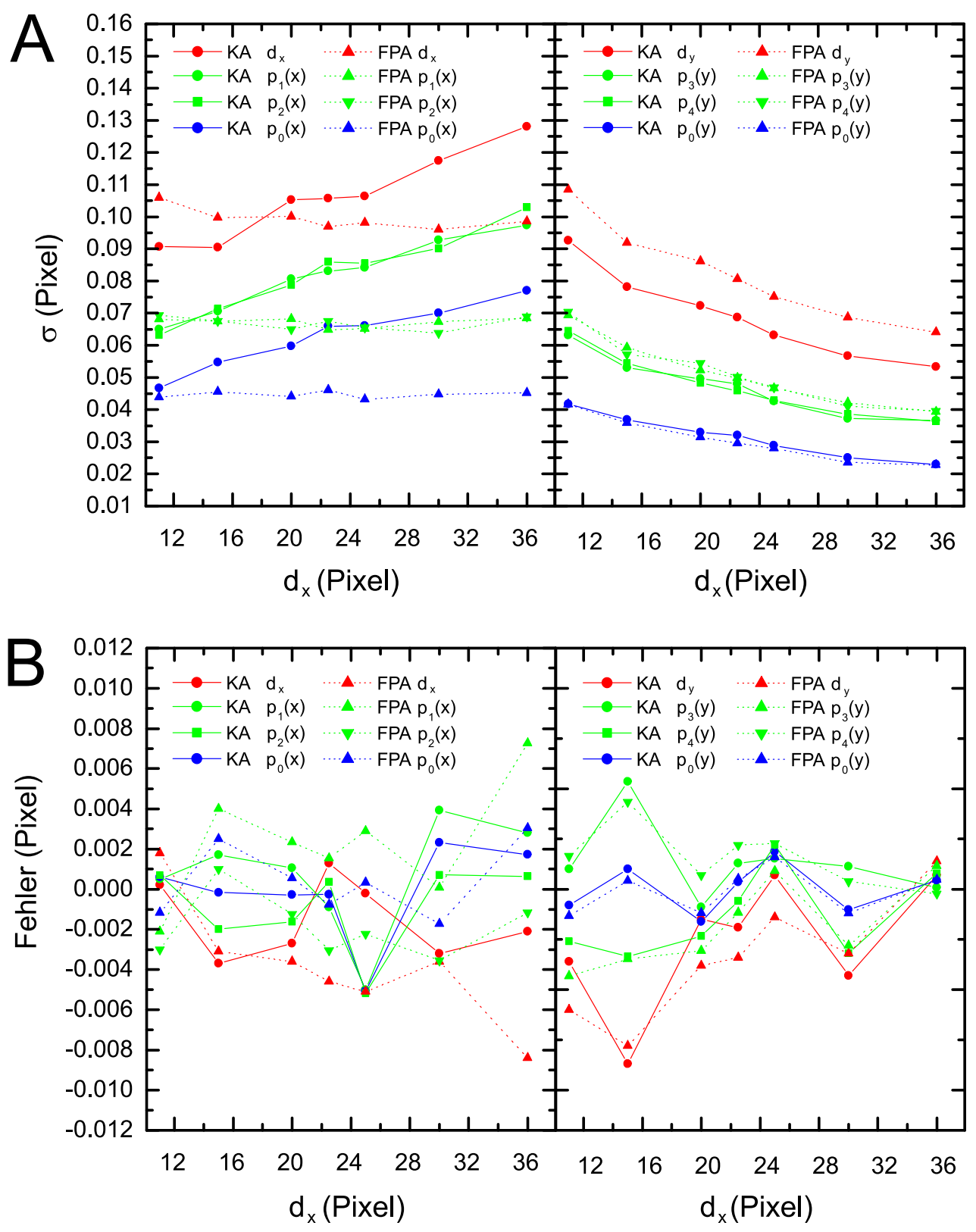

Abb. 6.9: Vergleich des Korrelations- und des FP-Algorithmus' in Abhängigkeit von der Länge $d_{x}$ eines Kastens der Breite $d_{y}=11$ Pixel (die Höhe $d_{z}$ des Kastens ist gleich der Breite $\left.d_{y}\right)$. (A) Genauigkeit der Algorithmen bei der Bestimmung der Objektlänge $d_{x}$, der Positionen $p_{1}(x)$ und $p_{2}(x)$ des vorderen und hinteren Endes des Objektes und des Objektzentrums $p_{0}(x)$ (rechter Graph) sowie des Objektdurchmessers $d_{y}$, der Lokalisierung der Positionen $p_{3}(y)$ und $p_{4}(y)$ der linken und rechten Seite des Objektes und des Objektzentrums $p_{0}(y)$ (linker Graph) (KA: durchgezogene Kurven; FPA: gestrichelte Kurven). (B) Mittlerer Fehler der gemessenen Größen in Abhängigkeit der Objektlänge $d_{x}$. 
Ein Vergleich der Ergebnisse beider Algorithmen zeigt, dass die KA zu einer kleineren Standardabweichung für die gemessene Objektlänge $d_{x}$ führt, wenn die Länge $d_{x}$ einen Wert von $\sim 18$ Pixel unterschreitet (Abb. 6.9 A, linker Graph). Bei einer Länge kleiner als $\sim 13.5$ Pixel bzw. $\sim 9$ Pixel sind dann auch die Genauigkeiten der KA bei der Lokalisierung der Seitenpunkte $p_{1}(x)$ und $p_{2}(x)$ bzw. des Objektzentrums $p_{0}(x)$ besser als die der FPA. Die Genauigkeit der KA verbessert sich im Vergleich zu der der FPA demnach mit abnehmender Objektlänge Schritt für Schritt für die verschiedenen Parameter.

Die Ergebnisse in Abbildung 6.9 sind abhängig von der lateralen Ausdehnung des konfokalen Detektionsvolumens. Der 1/ $e^{2}$-Radius $r_{x y}$ beträgt in diesem Fall 2.5 Pixel. Bei einer Pixelgröße von $100 \mathrm{~nm}$ nimmt $r_{x y}$ mit $250 \mathrm{~nm}$ einen typischen Wert an. Die KA scheint somit im Fall von Objekten mit einem Durchmesser kleiner als dem vier- bis fünffachen $1 / e^{2}$-Radius $r_{x y}$ genauer zu sein als die FPA. Dies wird durch weitere Simulationen bestätigt: Die KA ist z.B. bei der Analyse von 500 simulierten Bildern $\left(r_{x y}=2.5\right.$ Pixel; $\mathrm{SNR}=18.7)$ eines Kastens mit einer Länge und einer Breite von nur einem Pixel - dies entspricht bei einer Pixelgröße von $100 \mathrm{~nm}$ der Ausdehnung eines kleinen Vesikels - um den Faktor 1.5 besser als die FPA bei der Bestimmung der Seitenlängen $d_{x}$ und $d_{y}$ sowie der Objektpositionen $p_{1}(x), p_{2}(x), p_{3}(y)$ und $p_{4}(y)$ und um einen Faktor von 1.24 besser bei der Lokalisation der Zentrumskoordinaten $p_{0}(x)$ und $p_{0}(y)$.

Die Ursache für die besseren Resultate der KA bei kleineren Objekten liegt darin, dass die Wirkung der Rauschbefreiung der Daten durch die Korrelationsanalyse bei kleinen Objekten zunimmt. Der Kernel wirkt - analog zu einem Faltungskern - Rausch mindernd. Da der Kernel auf das Objekt optimal angepasst ist - im Idealfall sind die Spektren der mittleren Intensitätsverteilung des Wildtyp-Objektes und der Verteilung des Kernelobjektes gleich - wird ein Teil des Rauschspektrums, das sich dem Spektrum der mittleren Intensitätsverteilung des Wildtyp-Objektes überlagert, optimal unterdrückt. Die Ergebnisse in Abbildung 6.9 B zeigen, dass potenzielle Ungenauigkeiten bei der Bestimmung des Kernelobjektes durch die AKF-Analyse (Abb. 6.8 B, sowie auch Abschnitt 6.1.3) keinen signifikanten Einfluss auf die Präzision, d.h. den Fehler der Kreuzkorrelationsanalyse, haben. Da die theoretische Korrelationsfunktion $G(\xi, \eta)(6.51)$ kein Rauschen berücksichtigt (abgesehen von einer Hintergrundkonstante $g_{0}$ ), werden durch die optimale Rauschminderung bessere Anpassungsergebnisse erzielt. Dies führt zu einer höheren Genauigkeit der Anpassung. Diesem positiven Effekt wirkt aber bei zunehmender Objektgröße die verringerte Genauigkeit des Algorithmus' durch die abnehmende Steilheit der Korrelationsfunktion entgegen. Es sind somit zwei Effekte, die gegensätzlich wirken.

Es ist somit eine Frage der Objektgröße, welche der beiden Algorithmen genauer ist. Bei Objekten mit der Größe von Ecoli-Bakterien - insbesondere bei der Lokalisation des vorderen und hinteren Endes von Bakterien - ist die FPA wegen der dargestellten Eigenschaften (Abb. 6.9), der erreichbaren Genauigkeit und nicht zuletzt aufgrund der leichteren Implementierbarkeit und der deutlich geringeren Rechenzeit der KA vorzuziehen. 

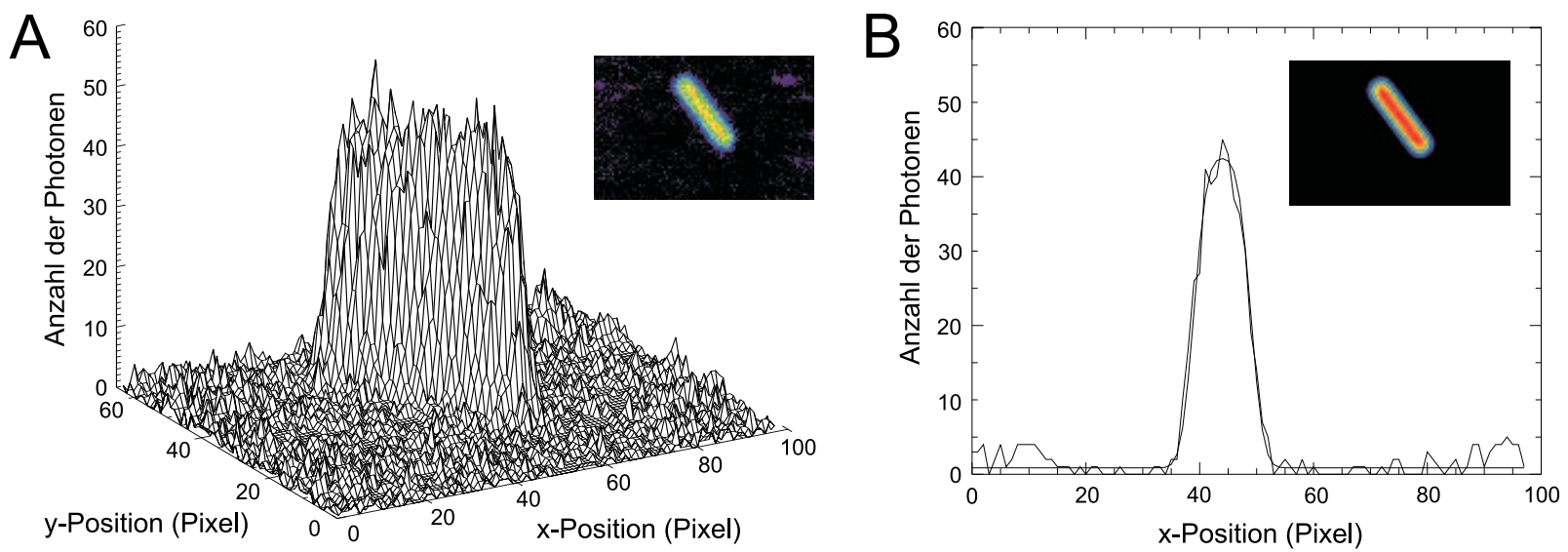

Abb. 6.10: LSM-Messung und FP-Analyse eines mit MitoTracker gefärbten, stationären Ecoli-Bakteriums. (A) Intensitätsverteilung und LSM-Bild des Bakteriums (erstes Bild von insgesamt 100 aufgenommenen Bildern; Bildabtastfrequenz: $15.47 \mathrm{~Hz}$ ). Bildgröße: $98 \times 64$ Pixel; Scanzeit pro Pixel: $3.45 \mu \mathrm{s}$; Pixelgröße: $88 \mathrm{~nm}$. (B) Schnitt entlang der $x$-Achse $(y=45)$ durch die in $A$ dargestellte experimentelle (verrauschte Kurve) und angepasste theoretische Intensitätsverteilung $\mathcal{I}_{\text {obj }}(x, y)$ (6.18 mit 6.9 und 6.10) des approximierten Zigarrenmodells (glatte Kurve). Das LSM-Bild der angepassten Verteilung ist eingefügt. Ergebnis der FP-Analyse: $d_{x}=2448.9 \mathrm{~nm}, d_{1}=495.4 \mathrm{~nm}\left(d_{2}=d_{1}\right.$, fixiert), $d_{y}=804.5 \mathrm{~nm}$, $I_{B}=0.85308, \tilde{x}_{0}=1.525$ Pixel, $\tilde{y}_{0}=-62.165$ Pixel und $\varphi=2.21297\left(\chi^{2}=13005.649\right)$. Es ergibt sich eine Objektlänge von $d=3439.7 \mathrm{~nm}$. Das mittlere SNR der Bilder beträgt $11.21 \pm 0.43$.

\subsection{Hochauflösende Lokalisierung von Ecoli-Bakterien in vitro}

In diesem Abschnitt soll nun der FP-Algorithmus - als Beispiel für in vitro Messungen - auf Bildsequenzen von stationären Ecoli-Bakterien angewendet werden, und zwar bei verschiedenen SNRs.

Abbildung 6.10 A zeigt das erste aus einer Serie von 100 Bildern eines stationären fluoreszierenden Ecoli-Bakteriums. In Teil B der Abbildung ist das Ergebnis der zweidimensionalen Anpassung der theoretischen Verteilung $\mathcal{I}_{\text {obj }}(x, y)$ des approximierten Zigarrenmodells an das LSM-Bild des Bakteriums dargestellt. Ein Schnitt entlang der $x$-Achse durch die experimentelle und angepasste Verteilung macht deutlich, dass die Verteilungen an den Kanten gut übereinstimmen. Das mittlere SNR der Bilder liegt bei 11. Die FPA sämtlicher Bilder dieser Sequenz liefert als Parameter die an dem in Abbildung 6.11 A eingefügten Objektmodell gekennzeichneten Positionen $p_{0}, p_{1}, p_{2}, p_{3}$ und $p_{4}$, d.h. die Positionen des Objektzentrums, des vorderen und hinteren Ecoli-Endes sowie der Seitenpunkte des Bakteriums. Die Fluktuationen der Objektpunkte im Verlauf der Bildserie sind in dieser Darstellung kaum zu erkennen (mittlerer Teil der Abbildung: Trajektorien der Objektpunkte $p_{0}$ 

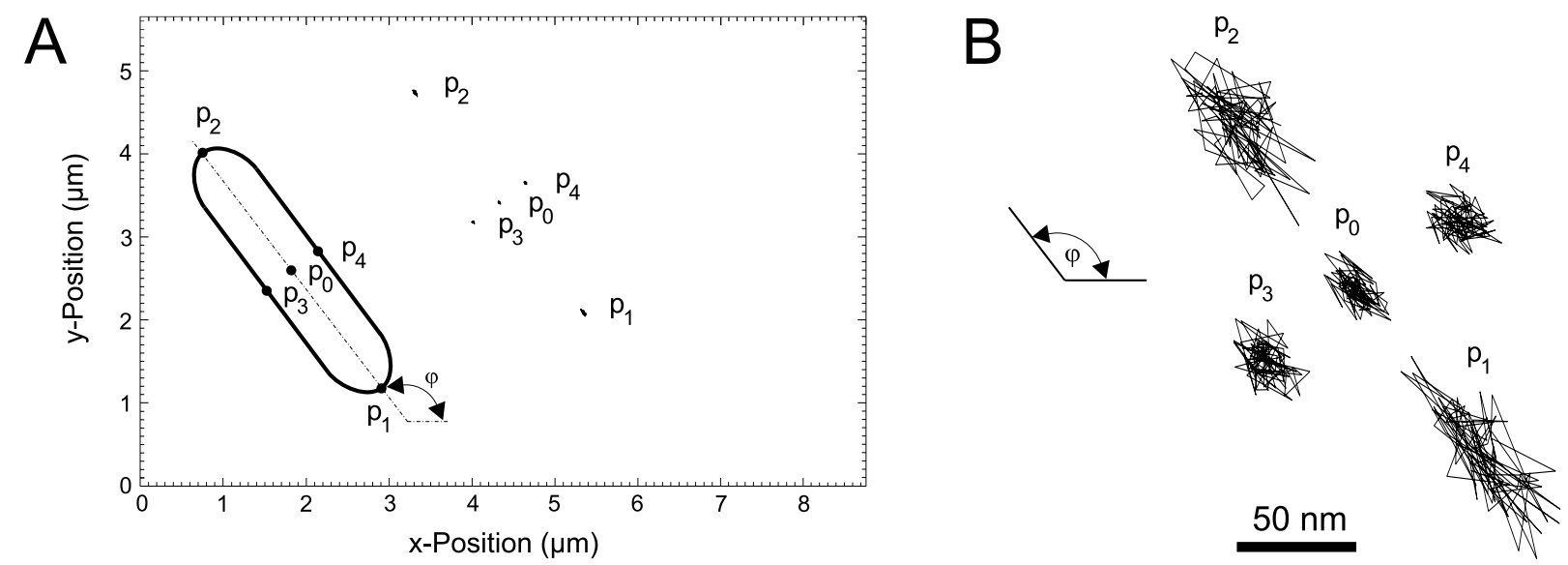

Abb. 6.11: Ergebnis der FP-Analyse von 100 nacheinander aufgenommenen LSM-Bildern eines mit MitoTracker gefärbten stationären Ecoli-Bakteriums (Abbildung 6.10 A zeigt das erste Bild der Bildserie). Die Analyse erfolgt mit der Intensitätsverteilung $\mathcal{I}_{\text {obj }}(x, y)$ des approximierten Zigarrenmodells (Kurvenanpassungsparameter: $p, d_{x}, d_{y}, d_{1}=d_{2}, \tilde{x}_{0}, \tilde{y}_{0}$, $I_{B}$ und $\varphi$ ). (A) Lokalisierte Positionen der beiden Objektenden $\left(p_{1}\right.$ und $\left.p_{2}\right)$, der linken und rechten Seitenpunkte $\left(p_{3}\right.$ und $\left.p_{4}\right)$ und des Zentrums $\left(p_{0}\right)$ des Bakteriums. Das eingezeichnete Zigarrenmodell im linken Teil des Graphen veranschaulicht die Lage der angegebenen Punkte $p_{0}$ bis $p_{4}$. (B) Trajektorien der lokalisierten Punkte in vergrößertem Maßstab. Die Abstände der Punkttrajektorien untereinander stimmen nicht mit den tatsächlichen, der Skalierung entsprechenden Abständen überein.

\begin{tabular}{cccccc}
\hline Objektpunkt & $p_{0}$ & $p_{1}$ & $p_{2}$ & $p_{3}$ & $p_{4}$ \\
\hline$\sigma_{\tilde{x}}(\mathrm{~nm})$ & 8.4 & 21.6 & 18 & 8.9 & 8.1 \\
$\sigma_{\tilde{y}}(\mathrm{~nm})$ & 4.3 & 7.3 & 9.2 & 6.1 & 6.2 \\
\hline
\end{tabular}

Tab. 6.1: Standardabweichungen der lokalisierten Punkte $p_{0}, p_{1}, p_{2}, p_{3}$ und $p_{4}$ bezüglich der $\tilde{x}$ - und $\tilde{y}$-Achse von $\tilde{\mathcal{O}}$ (Daten zum Experiment aus Abbildung 6.11).

bis $p_{4}$, jeweils links neben dem entsprechenden Parametername eingezeichnet). Abbildung 6.11 B zeigt eine vergrößerte Darstellung der gemessenen Objektpunkte. Die einzelnen Punkttrajektorien sind mit unveränderter Orientierung dicht beieinander gezeichnet. Die Ergebnisse zeigen deutlich, dass das Zentrum $p_{0}$ des Bakteriums die kleinsten Fluktuationen und die beiden Ecoli-Enden $p_{1}$ und $p_{2}$ die größten aufweisen. Zudem ist eine starke Anisotropie der Fluktuationen zu erkennen: Die größten Fluktuationen treten in Richtung der Symmetrieachse des Bakteriums auf. In Tabelle 6.1 sind die Standardabweichungen $\sigma_{\tilde{x}_{i}}$ und $\sigma_{\tilde{y}_{i}}$ der gemessenen Positionen $p_{i}$ bezüglich der $\tilde{x}$ - und $\tilde{y}$-Achse des Koordinatensystems $\mathcal{O}$ zusammengefasst. Es zeigt sich, dass das Objektzentrum mit einer Genauigkeit von weniger als $10 \mathrm{~nm}$ bestimmt werden kann.

Um die Abhängigkeit der Lokalisierungsgenauigkeiten der verschiedenen Objektpunkte 
vom SNR der Bilder im Experiment zu verdeutlichen, ist in Abbildung 6.12 eine Messung mit einem mittleren SNR von $\sim 16$ dargestellt (das höhere SNR entsteht durch die längere Inkubation der Bakterien mit der Farbstofflösung). Durch das erhöhte Fluoreszenzsignal erfolgt die Detektion im nicht-linearen Bereich der APD. Dadurch kommt es $\mathrm{zu}$ einer Abflachung des Intensitätsmaximums der gemessenen (Abbildung $6.12 \mathrm{~A}$ ) und der angepassten Verteilung (Abbildung 6.12 B). Das breitere Intensitätsmaximum spiegelt zudem den im Vergleich zum ersten Beispiel größeren Durchmesser des Ecoli-Bakteriums wider. Obwohl die APD verstärkt im nicht-linearen Bereich betrieben wird, ist der Fehler der dadurch bei der Detektion der relativen Bewegungen der Objektgrenzen entsteht, im Vergleich zu den erreichbaren Lokalisationsgenauigkeiten vernachlässigbar. Berechnet man aus der angepassten Intensitätsverteilung $\mathcal{I}_{\text {obj }}(x, y)$ (Abb. 6.12) die totzeitkorrigierte Intensitätsverteilung $\mathcal{I}^{\prime}{ }_{\text {obj }}(x, y)$ (Abschnitt 4.4.1) und unterzieht diese wiederum einer FPA, so zeigt sich, dass sowohl leichte symmetrische als auch unsymmetrische Längenänderungen des Objektes durch die Analyse beider Verteilungen sehr genau detektiert werden können: Wird z.B. die Intensitätsverteilung $\mathcal{I}_{\text {obj }}(x, y)$ nach einer symmetrischen Längenänderung des Objektes von $\Delta d=\Delta d_{x}=0.1$ Pixel neu berechnet, resultiert aus der FPA der zugehörigen totzeitkorrigierten Verteilungen $\mathcal{I}^{\prime}{ }_{\text {obj }}(x, y)$ eine detektierte Längenänderung von $\Delta d=0.093$ Pixel. Bei einer Pixelgröße von $88 \mathrm{~nm}$ ergibt sich daraus eine Abweichung von $0.6 \mathrm{~nm}$. Wird die Länge des Objektes durch Erhöhung der Ellipsoidkappenlänge $d_{1}$ unsymmetrisch verändert, $\Delta d=\Delta d_{1}=0.1$ Pixel, so ergibt die FPA der korrigierten Verteilungen $\mathcal{I}^{\prime}{ }_{\text {obj }}(x, y)$ bei Annahme eines symmetrischen Objektes $\left(d_{1}=d_{2}\right)$ eine Längenänderung von $\Delta d=0.111$ Pixel. Mit einer Pixelgröße von $88 \mathrm{~nm}$ ergibt sich ein Fehler von $1 \mathrm{~nm}$. Es zeigt sich somit, dass relative Verschiebungen der Objektgrenzen auch im stark nicht-linearen Bereich der totzeitbehafteten APD sehr genau detektiert werden können.

Abbildung 6.12 C und D zeigen das Ergebnis der FPA der gesamten Bildsequenz. Es wird deutlich, dass die Lokalisierungsgenauigkeit zugenommen hat. Tabelle 6.2 fasst die gemessenen Standardabweichungen der Objektpunkte zusammen. Die Messungen zeigen, dass bei entsprechendem SNR Lokalisierungsgenauigkeiten von bis $\mathrm{zu} \sim 5 \mathrm{~nm}$ und besser erreichbar sind. Diese Werte liegen sogar noch etwas oberhalb der tatsächlichen Lokalisierungsgenauigkeiten, denn die Detektion des Intensitätssignals mit der totzeitbehafteten APD führt zu einer erhöhten relativen Standardabweichung des Intensitätssignals (Abschnitt 4.4.1). Dies führt zu einem schlechteren SNR der Bilder und gleichzeitig zu einer schlechteren Lokalisierungsgenauigkeit. Die gemessenen Lokalisierungsgenauigkeiten von $\sim 5 \mathrm{~nm}$ und besser, stellen somit eine obere Grenze der Genauigkeit des LSM dar. Diese Daten spiegeln somit die hohe Präzision des im Rahmen dieser Arbeit entwickelten LSM wider. 

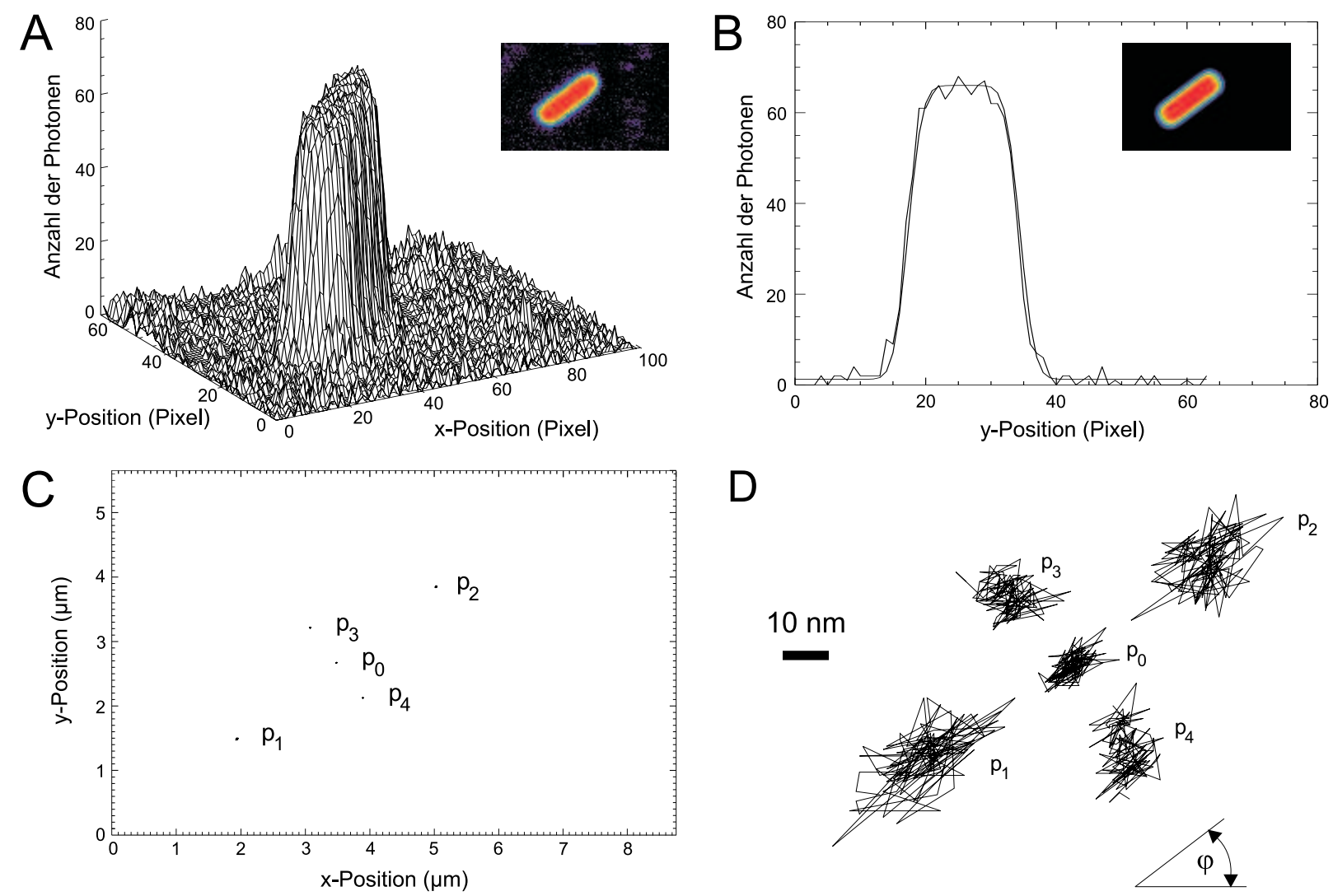

Abb. 6.12: LSM-Messung und FP-Analyse eines mit MitoTracker gefärbten, stationären Ecoli-Bakteriums. (A) Intensitätsverteilung und LSM-Bild des Bakteriums (erstes Bild von insgesamt 120 aufgenommenen Bildern; Bildabtastfrequenz: $15.47 \mathrm{~Hz}$ ). Bildgröße: $100 \times 64$ Pixel; Scanzeit pro Pixel: $3.4 \mu \mathrm{s}$; Pixelgröße: $88 \mathrm{~nm}$. (B) Schnitt entlang der $y$-Achse $(x=37)$ durch die in A dargestellte experimentelle (verrauschte Kurve) und angepasste Intensitätsverteilung $\mathcal{I}_{\text {obj }}(x, y)$ (6.18 mit 6.9 und 6.10) (glatte Kurve). Ergebnis der FPA: $d_{x}=2294.3 \mathrm{~nm}, d_{1}=826.7 \mathrm{~nm}\left(d_{2}=d_{1}\right.$, fixiert $), d_{y}=1363.2 \mathrm{~nm}, I_{B}=0.7036$, $\tilde{x}_{0}=49.811$ Pixel, $\tilde{y}_{0}=0.1377$ Pixel und $\varphi=0.647\left(\chi^{2}=20138.709\right)$. Ecoli-Gesamtlänge: $d=3947.8 \mathrm{~nm}$. (C) Positionen der Objektenden $p_{1}$ und $p_{2}$, der Seitenpunkte $p_{3}$ und $p_{4}$ sowie des Zentrums $p_{0}$ des Bakteriums (Ergebnis der FPA der gesamten Bildsequenz). (D) Trajektorien der lokalisierten Punkte im vergrößerten Maßstab. Die Abstände der Punkttrajektorien untereinander stimmen nicht mit den tatsächlichen, der Skalierung entsprechenden Abständen überein. Das mittlere SNR der Bilder beträgt $16.34 \pm 0.37$.

\begin{tabular}{cccccc}
\hline Objektpunkt & $p_{0}$ & $p_{1}$ & $p_{2}$ & $p_{3}$ & $p_{4}$ \\
\hline$\sigma_{\tilde{x}}(\mathrm{~nm})$ & 3.7 & 8.7 & 6.7 & 3.7 & 4.1 \\
$\sigma_{\tilde{y}}(\mathrm{~nm})$ & 1.9 & 4.1 & 4.5 & 3.8 & 4.6 \\
\hline
\end{tabular}

Tab. 6.2: Standardabweichungen der lokalisierten Punkte $p_{0}, p_{1}, p_{2}, p_{3}$ und $p_{4}$ bezüglich $\operatorname{der} \tilde{x}$ - und $\tilde{y}$-Achse von $\tilde{\mathcal{O}}$ (Daten zum Experiment aus Abbildung 6.12). 




Abb. 6.13: Fluoreszenzbild eines mit MitoTracker gefärbten Mitochondriums. Das Bild zeigt den horizontalen Abschnitt eines Dendriten. Die Messung erfolgte nach einminütiger Inkubation mit einer 20 nM MitoTracker-Badlösung. Bildgröße: $261 \times 32$ Pixel; Pixelgröße: $44 \mathrm{~nm}$; Bildabtastfrequenz: $31 \mathrm{~Hz}$.

\subsection{Verfolgung von Mitochondrien in vivo}

Mitochondrien sind für das Überleben von Zellen essentiell. Sie generieren den größten Teil des intrazellulären ATP und sind an der Regulierung der zytoplasmatischen Kalziumkonzentration beteiligt $[111,112]$. Der größte Teil des axonalen und dendritschen Transports von Mitochondrien basiert auf dem Mikrotubuli-Transportsystem [7, 24].

In diesem Teil der Arbeit wird mit der FPA der submikroskopische dendritische Transport von Mitochondrien in kultivierten Neuronen untersucht. Hierbei steht die Frage im Mittelpunkt, ob die Analyse von Bewegungen des Objektzentrums sowie des vorderen und hinteren Endes von aktiv transportierten Mitochondrien erlaubt, neue Einblicke in die Aktivität der gegenläufigen molekularen Motorproteine Kinesin und zytoplasmatischem Dynein zu gewinnen.

\subsubsection{Visualisierung von Mitochondrien}

Mitochondrien sind schwach autofluoreszierende Organellen [86]. Dadurch unterscheiden sie sich von anderen zytosolischen Bestandteilen. Damit die Bewegung von Mitochondrien auf einer submikroskopischen Skala verfolgt werden kann, muss trotzdem der Kontrast erhöht werden. Hierzu werden die Mitochondrien mit einem exogenen Farbstoff markiert. Durch das stark negative mitochondriale Membranpotenzial von -120 bis -140 mV können sie leicht mit einem membranpermeablen kationischen Farbstoff gefärbt werden. Hierzu stehen eine Reihe von Mitochondria-spezifischen Farbstoffen zur Verfügung [67]. Wegen seiner spektralen Eigenschaften wird der Farbstoff MitoTracker Orange verwendet (Abschnitt 3.3.3). Abbildung 6.13 zeigt das LSM-Bild eines mit MitoTracker angereicherten Mitochondriums.

Der anterograde und retrograde dendritische Transport von Mitochondrien erfolgt mit Geschwindigkeiten im Bereich von $0.1 \mu \mathrm{m} \cdot \mathrm{s}^{-1}$ bis zu $2 \mu \mathrm{m} \cdot \mathrm{s}^{-1}$ [7]. Bewegt sich das Mitochondrium während der Messung, kann dies - bei entsprechend langer Scanzeit pro Bild - zu einer Verzerrung des LSM-Bildes führen. Daher ist es wichtig, die Aufnahmezeit möglichst gering zu halten. Da der Transport von Mitochondrien entlang von Mikrotubuli stattfindet, die parallel zur Achse des Dendriten verlaufen (Abb. 5.11), kann die Anzahl der 
Linien-Scans und damit die Aufnahmezeit pro Bild stark verringert werden: Dazu wird die Kulturschale im Halterahmen so gedreht, dass die Achse des Dendriten horizontal verläuft. Die meisten dendritischen Mitochondrien haben eine längliche Zigarrenform (Abb. 6.13). Daher sind meist nur wenige Zeilen nötig, um das Objekt vollständig zu erfassen. In dem in Abbildung 6.13 gezeigten Beispiel mit einer Scanzeit von einer Millisekunde pro Zeile und einer Pixelgröße von $44 \mathrm{~nm}$ erstreckt sich das Mitochondrium über ca. 10 Zeilen. Würde sich das Mitochondrium während der Messung mit einer maximalen Transportgeschwindigkeit von $2 \mu \mathrm{m} \cdot \mathrm{s}^{-1}$ nach links bewegen, wäre der untere Teil des Mitochondriums um $20 \mathrm{~nm}$ und der mittlere Teil um $10 \mathrm{~nm}$ gegenüber dem oberen Teil nach links verschoben. Die folgenden Messungen zeigen, dass mögliche Ungenauigkeiten bei der Größenbestimmung von Mitochondrien - durch die leicht verzerrte Form des Objektes bei hohen Transportgeschwindigkeiten - im Vergleich zu den in den Experimenten erzielten Lokalisierungsgenauigkeiten vernachlässigbar sind.

\subsubsection{Trajektorien aktiv transportierter Mitochondrien}

Abbildung 6.14 zeigt die LSM-Aufnahme eines kleinen Mitochondriums innerhalb eines Dendriten (das Soma der Zelle befindet sich $\sim 160 \mu \mathrm{m}$ zur Linken). Dargestellt ist das erste Bild aus einer Sequenz von 100 Bildern. Die gemessene Intensitätsverteilung des Mitochondriums lässt sich durch die Intensitätsverteilung $\mathcal{I}_{\text {obj }}(x, y)$ eines Ellipsoid-Modells beschreiben (Gl. 6.18 mit 6.9 und 6.10; $d_{x}=0$ ) (Abbildung 6.14 B und C).

Die Auswertung der Bildsequenz ergibt ein mittleres Intensitätsmaximum $I_{\max }$ von 5.9 Photonen pro Pixel. Bei einer Scan-Zeit von $1.25 \mu$ s pro Pixel entspricht dies einem Wert von $4.7 \cdot 10^{6} \mathrm{~s}^{-1}$. Die Detektion der höheren Intensitätswerte $\left(>1 \cdot 10^{6} \mathrm{~s}^{-1}\right)$ erfolgt im nichtlinearen Bereich der APD (Abschnitt 4.4.1). Wie in Abschnitt 6.2 für Intensitätswerte von bis zu $20 \cdot 10^{6} \mathrm{~s}^{-1}$ im Fall von fluoreszierenden Ecoli-Bakterien gezeigt wurde, sind die Fehler die durch die Messungen im nicht-linearen Bereich der APD bei der Detektion von relativen Verschiebungen der Objektgrenzen enstehen, im Vergleich zu den erreichbaren Lokalisationsgenauigkeiten vernachlässigbar. Dass dies auch für kleinere Objekte wie dem Mitochondrium aus Abbildung 6.14 gilt, lässt sich durch die Analysen der entsprechenden totzeitkorrigierten Intensitätsverteilungen $\mathcal{I}_{\text {obj }}^{\prime}(x, y)$ (Abschnitt 4.4.1) zeigen: Wird die Ellipsoidkappenlänge $d_{1}$ der angepassten Verteilung $\mathcal{I}_{\text {obj }}(x, y)$ (Abb. 6.14 B) um 0.1 Pixel erhöht (unsymmetrische Längenänderung), so resultiert aus der FPA der zugehörigen totzeitkorrigierten Intensitätsverteilungen $\mathcal{I}_{\text {obj }}^{\prime}(x, y)$ unter Annahme eines symmetrischen Objektes $\left(d_{1}=d_{2}\right)$ eine Längenänderung von $\Delta d=0.099$ Pixel. Bei einer Pixelgröße von $44 \mathrm{~nm}$ enstpricht dies einem Fehler von 0.44 Angström. Eine Längenänderung von $\Delta d=\Delta d_{1}=1$ Pixel führt bei der FPA der entsprechenden totzeitkorrigierten Verteilungen zu einer detektierten Längenänderung von $\Delta d=0.99$ Pixel und somit zu einem Fehler von 4.4 Angström. Auch die Fehler bei der Detektion von relativen Durchmesserveränderungen sind im Vergleich zu den erreichbaren Lokalisationsgenauigkeiten vernachlässigbar: Eine Durchmesserveränderung von $\Delta d_{y}=0.1$ Pixel führt bei der FPA der entsprechenden totzeitkorrigierten Verteilungen zu einer detektierten Veränderung von $\Delta d_{y}=0.085$ Pixel 

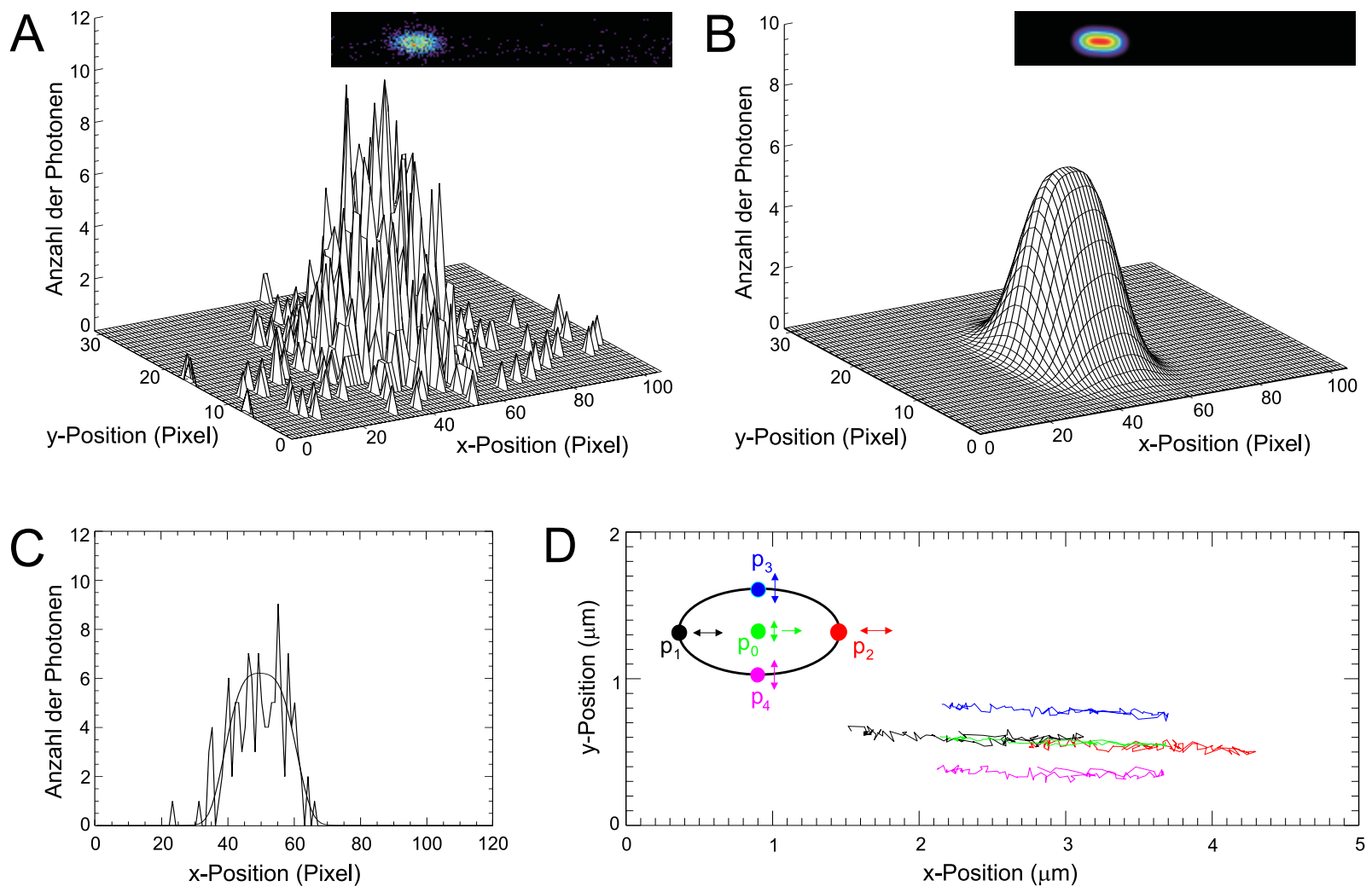

Abb. 6.14: LSM-Messung und FP-Analyse eines mit MitoTracker gefärbten, aktiv transportierten Mitochondriums. (A) Intensitätsverteilung des Mitochondriums (linker Abschnitt des eingefügten LSM-Bildes; erstes Bild von insgesamt 100 aufgenommenen Bildern; Bildabtastfrequenz: $30.94 \mathrm{~Hz}$; Größe des LSM-Bildes: $200 \times 32$ Pixel; Scanzeit pro Pixel: $1.25 \mu \mathrm{s}$; Pixelgröße: $44 \mathrm{~nm}$; SNR der Bilder: $4.86 \pm 0.24)$. (B) Intensitätsverteilung der angepassten Funktion $\mathcal{I}_{\text {obj }}(x, y)$ (6.18 mit 6.9 und 6.10). Ergebnis der FP-Analyse: $p=10.853, d_{x}=0$ (fixiert), $d_{1}=608 \mathrm{~nm}\left(d_{2}=d_{1}\right.$, fixiert), $d_{y}=436 \mathrm{~nm}, I_{B}=0.0233$, $\tilde{x}_{0}=48.976$ Pixel, $\tilde{y}_{0}=16.196$ Pixel und $\varphi=-0.05163\left(\chi^{2}=1171.5134\right)$. Es ergibt sich eine Objektlänge von $d=1216 \mathrm{~nm}$. (C) Schnitt entlang der $x$-Achse $(y=14)$ durch die in $A$ und $B$ dargestellte experimentelle und angepasste theoretische Intensitätsverteilung. $(D)$ Trajektorien der beiden Objektenden $p_{1}$ (schwarze Spur) und $p_{2}$ (rote Spur), der Seitenpunkte $p_{3}$ (blaue Spur) und $p_{4}$ (violette Spur) und des Objektzentrums $p_{0}$ (grüne Spur) des Mitochondriums. Das eingezeichnete Modell im linken Teil des Graphen veranschaulicht die Lagen der Punkte $p_{0}$ bis $p_{4}$.

und somit zu einem Fehler von $0.66 \mathrm{~nm}$. Ist die absolute Größe des Mitochondriums von Interesse, so kann entsprechend die korrigierte Intensitätsverteilung $\mathcal{I}^{\prime}{ }_{\text {obj }}(x, y)$ ausgewertet werden: Im Vergleich zu den Anpassungsergebnissen der in Abbildung 6.14 B dargestellten Verteilung $\left(d=1216 \mathrm{~nm}\right.$ und $d_{y}=436 \mathrm{~nm}$ ) ergibt die Auswertung der korrigierten Verteilung eine Länge von $d=1191 \mathrm{~nm}$ und einen Durchmesser von $d_{y}=374 \mathrm{~nm}$. Die Größe wird somit durch die Detektion mit der totzeitbehafteten APD leicht überschätzt. In die- 


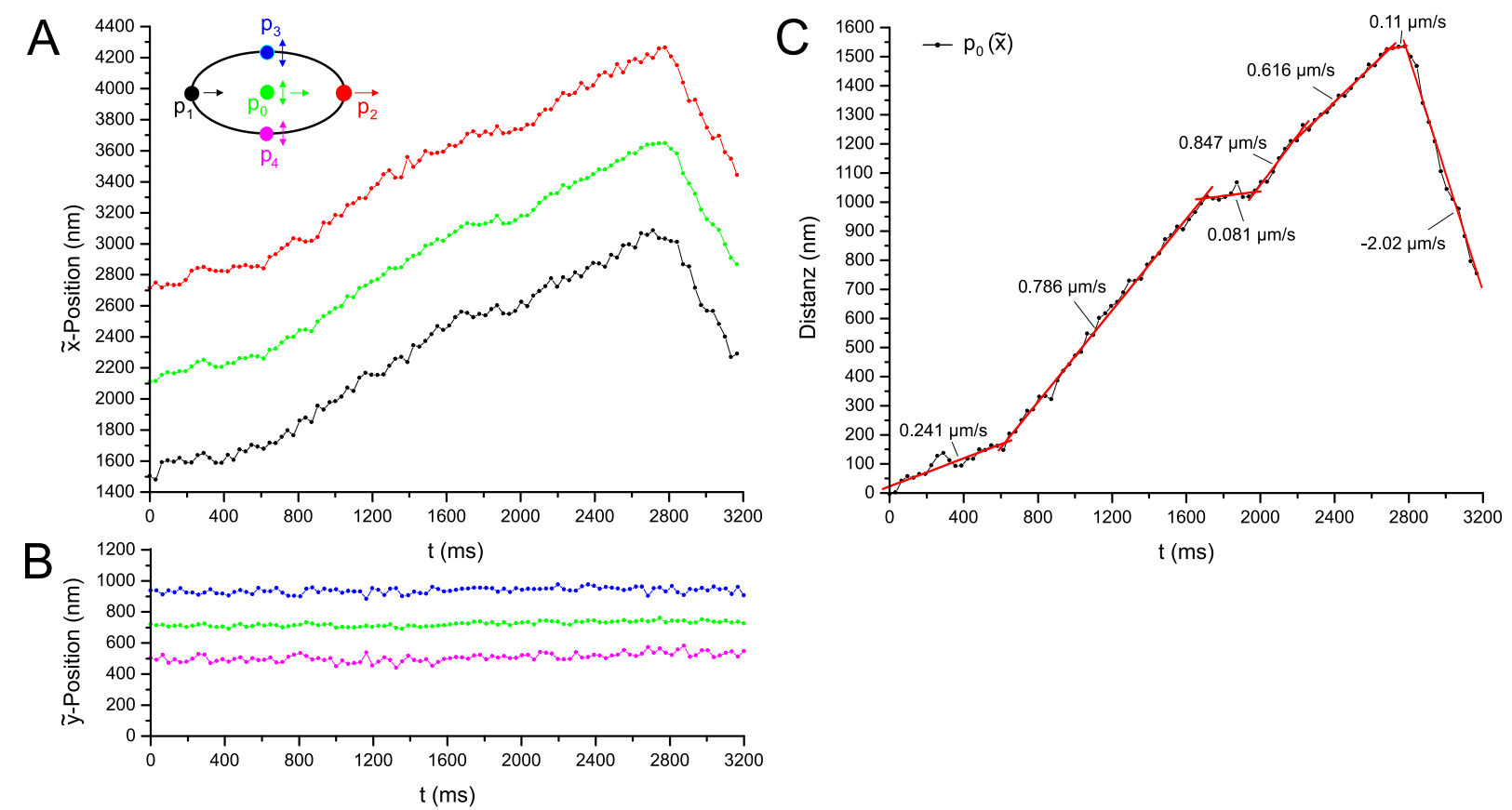

Abb. 6.15: Veranschaulichung der Bewegung der Objektpunkte $p_{0}, p_{1}, p_{2}, p_{3}$ und $p_{4}$ bezüglich des gedrehten Koordinatensystems $\tilde{O}\left(\varphi=-3^{\circ}\right.$, Mittelwert sämtlicher gemessener Winkel)(Daten zum Experiment aus Abbildung 6.14). (A) Gemessene Positionen $p_{1}(\tilde{x})$ (schwarze Kurve), $p_{2}(\tilde{x})$ (rote Kurve) und $p_{0}(\tilde{x})$ (grüne Kurve) in Abhängigkeit der Messzeit. (B) Positionen der Seitenpunkte $p_{3}(\tilde{y})$ (blaue Kurve), $p_{4}(\tilde{y})$ (violette Kurve) und des Zentrums $p_{0}(\tilde{y})$ (grüne Kurve). (C) Zurückgelegte Distanz des Objektzentrums $p_{0}(\tilde{x})$ (schwarze Kurve) in Abhängigkeit der Messzeit. Die roten Geraden (Kurvenanpassungsergebnisse) geben die mittlere Bewegung in den jeweiligen Teilabschnitten wider.

sem Abschnitt sind nur relative Verschiebungen des vorderen und hinteren Endes und der Seitenpunkte von aktiv transportierten Mitochondrien von Interesse, eine Korrektur der gemessenen Intensitätsverteilungen ist somit nicht erforderlich.

Die FPA sämtlicher Bilder führt zu den in Abbildung 6.14 D dargestellten Trajektorien der Objektpunkte $p_{0}$ bis $p_{4}$. Der Transport erfolgt mit einer Orientierung von $\varphi \simeq-3^{\circ}$ bezüglich der $x$-Achse des Koordinatensystems $\mathcal{O}$. Abbildung 6.15 veranschaulicht die Bewegung des Mitochondriums im gedrehten Koordinatensystem $\tilde{\mathcal{O}}$ (Bewegung parallel zur $\tilde{x}$-Achse). Es zeigt sich, dass sich das Mitochondrium innerhalb von 2.8 Sekunden $1.5 \mu \mathrm{m}$ in anterograder Richtung - d.h. vom Zellkörper weg - bewegt und nach einer Richtungsumkehr mit erhöhter Geschwindigkeit in retrograder Richtung transportiert wird.

Die Intensitätsschwankungen in den LSM-Bildern (Abb. 6.14 A) führen zu Fluktuationen in den gemessenen Positionskurven (Abb. 6.15). Diese sind besonders in den Kurven der äußeren Objektpunkte $p_{1}(\tilde{x}), p_{2}(\tilde{x}), p_{3}(\tilde{y})$ und $p_{4}(\tilde{y})$ sichtbar (siehe auch Abschnitt 6.1.5). Die Positionskurven $p_{0}(\tilde{x})$ und $p_{0}(\tilde{y})$ des Objektzentrums weisen - wie erwartet - die klein- 
sten Fluktuationen auf. Abbildung 6.15 C zeigt die in $\tilde{x}$-Richtung zurückgelegte Distanz des Objektzentrums $p_{0}$. Die Kurve lässt sich in Segmente einteilen, die sich in guter Näherung durch Geradenabschnitte beschreiben lassen. Offenbar bewegt sich das Mitochondrium mit verschiedenen mittleren Geschwindigkeiten im Bereich von $-2 \mu \mathrm{m} \cdot \mathrm{s}^{-1} \leq v \leq 0.85 \mu \mathrm{m} \cdot \mathrm{s}^{-1}$.

Abbildung 6.16 fasst die Distanzkurven aller Objektpunkte zusammen. Die Kurven der Seitenpunkte $p_{3}(\tilde{y})$ und $p_{4}(\tilde{y})$ sowie des Objektzentrums $p_{0}(\tilde{y})$ entstehen aus den in Abbildung 6.15 B dargestellten Kurven durch die folgende Vorgehensweise:

1. Subtraktion des mittleren gemessenen Durchmessers $d_{y}$ von der Positionskurve $p_{3}(\tilde{y})$;

2. Subtraktion des halben mittleren Durchmessers von der Positionskurve $p_{0}(\tilde{y})$;

3. von den beiden entstehenden Kurven und der Positionskurve $p_{4}(\tilde{y})$ wird anschließend der Mittelwert der drei Anfangspositionen abgezogen.

Die Distanzkurven der Objektenden $p_{1}(\tilde{x})$ und $p_{2}(\tilde{x})$ sowie des Objektzentrums $p_{0}(\tilde{x})$ sind analog zu den Distanzkurven der Seitenpunkte berechnet worden, nur dass statt der mittleren gemessenen Länge $d=1178 \mathrm{~nm}$ die im achten LSM-Bild gemessene Länge $d=$ $1236 \mathrm{~nm}$ des Mitochondriums für die Schritte 1 und 2 verwendet wurde. Diese Darstellung ermöglicht weitere Einblicke in die submikroskopische Bewegung des linken und des rechten Endes des Mitochondriums. Es zeigt sich, dass sich die Länge des Mitochondriums während des Transports ändert: Betrachtet man beispielsweise die ersten acht Datenpunkte der Distanzkurven $p_{1}(\tilde{x})$ und $p_{2}(\tilde{x})$ (Abb. $6.16 \mathrm{~A}$ ), fällt auf, dass sich das linke Ende des Mitochondriums zwischen dem zweiten und dritten LSM-Bild um $\sim 100 \mathrm{~nm}$ nach rechts in anterograder Richtung bewegt, während das rechte Ende unverändert dieselbe Position beibehält. Die Länge des Mitochondriums nimmt demnach zwischen dem zweiten und dem dritten Bild um $100 \mathrm{~nm}$ ab. Erst sechs Datenpunkte später - dies entspricht einer Zeit von $\sim 194 \mathrm{~ms}$ - vollzieht das rechte Ende eine ähnliche Bewegung wie das linke Ende.

In den gemessenen Positionskurven ist zu erkennen, dass das rechte Ende des Mitochondriums während des Transports in anterograder Richtung der Bewegung des linken Endes mit einer zeitlichen Verzögerung folgt. Das linke Ende übernimmt somit die „führende Rolle". Dies wird besonders deutlich, wenn man die gemittelten Datenpunkte betrachtet (Abb. 6.16 B, siehe gekennzeichnete Kurvenabschnitte). Zeitlich versetzt stattfindende, auffällig ähnliche Bewegungsabläufe des hinteren und des vorderen Endes von Mitochondrien werden im folgenden unter dem Begriff „Phasenverschiebungen“ zusammengefasst. Im Gegensatz zu den mittleren Bewegungen des linken und rechten Endes weisen die Distanzkurven der beiden Seitenpunkte $p_{3}(\tilde{y})$ und $p_{4}(\tilde{y})$ keine sichtbaren Phasenverschiebungen auf. Zudem sind die Fluktuationen des Durchmessers des Mitochondriums kleiner als die der Länge: Die Standardabweichungen der gemessenen Länge $d$ und des Durchmessers $d_{y}$ betragen $\sigma_{d}=48.6 \mathrm{~nm}$ und $\sigma_{d_{y}}=34.4 \mathrm{~nm}$.

Abbildung 6.17 zeigt ein Beispiel für den submikroskopischen Transport eines Mitochondriums. Die FPA der aufgenommenen Bildsequenz macht die submikroskopische Bewegung 




Abb. 6.16: Bewegungen eines Mitochondriums innerhalb eines Dendriten (Abbildung 6.14 $D$ zeigt die zugehörigen Trajektorien der Objektpunkte $p_{0}$ bis $\left.p_{4}\right)$. (A) Zurückgelegte Distanzen des Objektzentrums $p_{0}(\tilde{x})$ (grüne Kurve), des linken und des rechten Endes $p_{1}(\tilde{x})$ und $p_{2}(\tilde{x})$ entlang der $\tilde{x}$-Achse sowie Fluktuationen des Zentrums $p_{0}(\tilde{y})$ und der Seitenpunkte $p_{3}(\tilde{y})$ und $p_{4}(\tilde{y})$ des Mitochondriums bezüglich der $\tilde{y}$-Achse des Koordinatensystems $\tilde{\mathcal{O}}$. (B) Gemittelte Kurven (Mittelwerte über jeweils drei benachbarte Datenpunkte). 

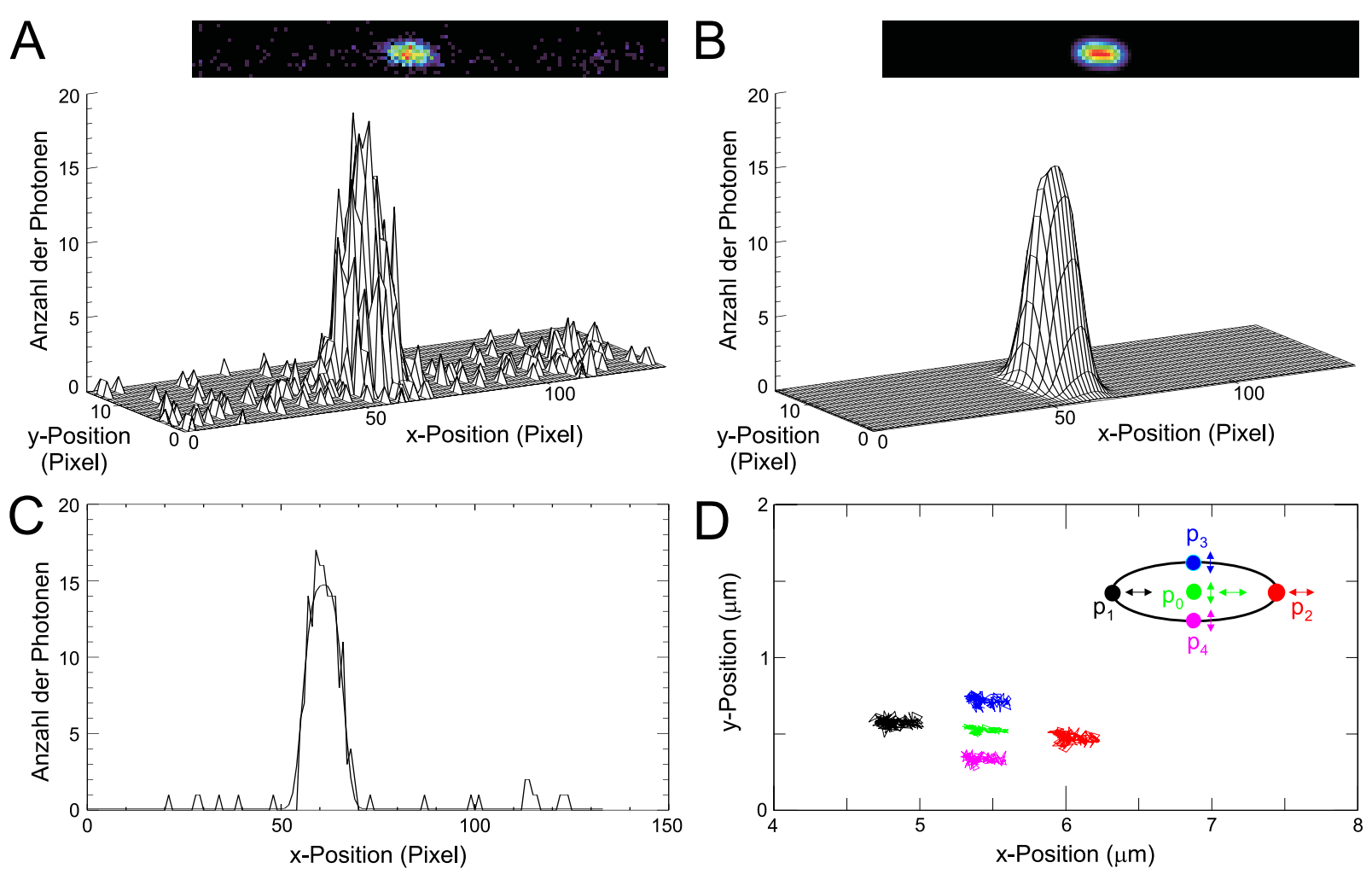

Abb. 6.17: LSM-Messung und FP-Analyse eines mit MitoTracker gefärbten, aktiv transportierten Mitochondriums. (A) Intensitätsverteilung und LSM-Bild des Mitochondriums (erstes Bildes von insgesamt 200 aufgenommenen Bildern; Bildabtastfrequenz: $61.88 \mathrm{~Hz}$; Größe des LSM-Bildes: $134 \times 16$ Pixel; Scanzeit pro Pixel: $2.55 \mu$ s; Pixelgröße: 88 nm; SNR der Bilder: $7.6 \pm 0.7)$. (B) Intensitätsverteilung der angepassten Funktion $\mathcal{I}_{\text {obj }}(x, y)(6.18$ mit 6.9 und 6.10). Ergebnis der FP-Analyse: $p=24.034, d_{x}=0$ (fixiert), $d_{1}=607 \mathrm{~nm}$ $\left(d_{2}=d_{1}\right.$, fixiert), $d_{y}=458.1 \mathrm{~nm}, I_{B}=0.081, \tilde{x}_{0}=59.981$ Pixel, $\tilde{y}_{0}=11.647$ Pixel und $\varphi=-0.09036\left(\chi^{2}=773.095\right)$. Es ergibt sich eine Objektlänge von $d=1214 \mathrm{~nm}$. (C) Schnitt entlang der $x$-Achse $(y=6)$ durch die in $A$ und $B$ dargestellte experimentelle und angepasste theoretische Intensitätsverteilung. (D) Trajektorien der beiden Objektenden $p_{1}$ (schwarze Spur) und $p_{2}$ (rote Spur), der Seitenpunkte $p_{3}$ (blaue Spur) und $p_{4}$ (violette Spur) und des Objektzentrums $p_{0}$ (grüne Spur) des Mitochondriums. Das eingezeichnete Modell im rechten Teil des Graphen veranschaulicht die Lage der Punkte $p_{0}$ bis $p_{4}$.

sichtbar. Der Transport erfolgt mit einer Orientierung von $\varphi \simeq-5^{\circ}$ bezüglich der $x$-Achse des Koordinatensystems $\mathcal{O}$. Die Positionskurven der Objektenden und des Objektzentrums spiegeln die Bewegung des Mitochondriums mit wechselnder Transportrichtung wider (Abb. 6.18). Die Bewegung findet auf einem Längenabschnitt von nur $\sim 300 \mathrm{~nm}$ statt. Dies wird besonders deutlich, wenn man die Distanzkurven betrachtet (Abb. 6.19). Die Kurven der einzelnen Objektpunkte ergeben sich analog zu der auf Seite 99 beschriebenen Vorgehensweise (Schritte 1 bis 3). Zur besseren Übersichtlichkeit sind die Distanzkurven der Seiten- 

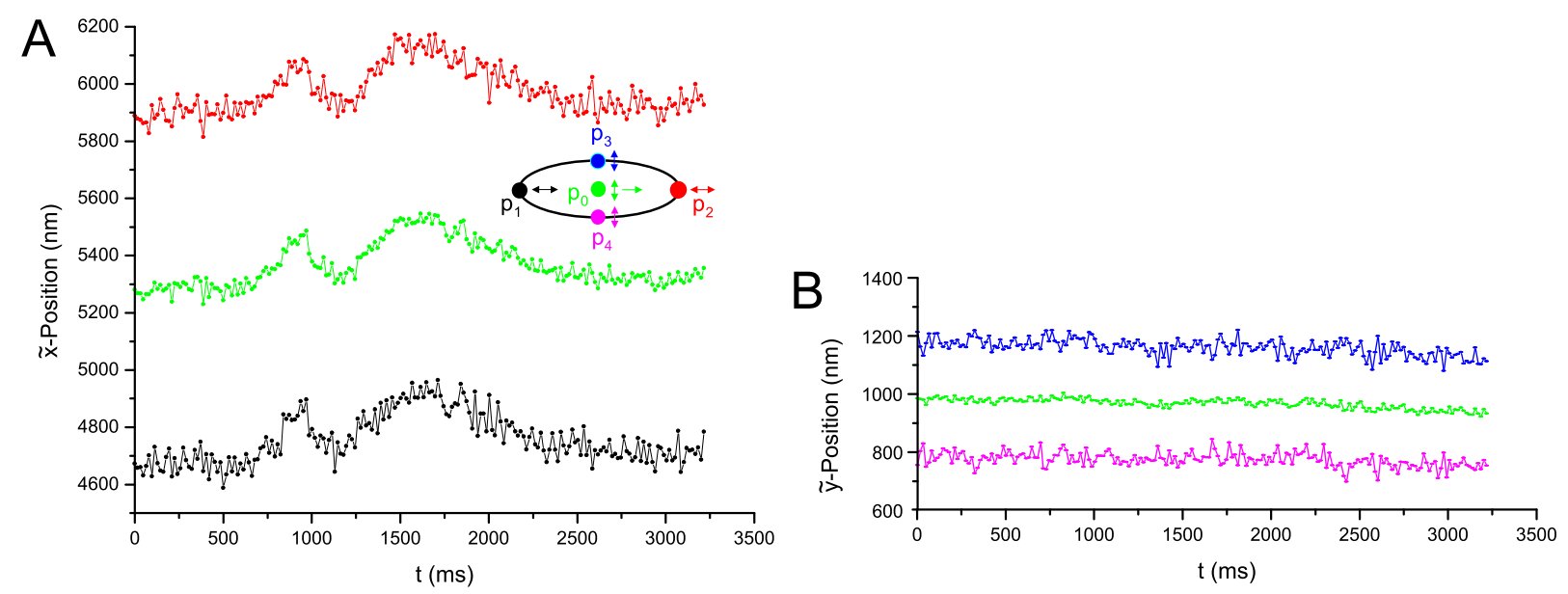

Abb. 6.18: Bewegungen der Objektpunkte $p_{0}, p_{1}, p_{2}, p_{3}$ und $p_{4}$ bezüglich des gedrehten Koordinatensystems $\tilde{O}\left(\varphi=-4.65^{\circ}\right.$, Mittelwert sämtlicher gemessener Winkel) (Daten zum Experiment aus Abbildung 6.17). (A) Gemessene Positionen $p_{1}(\tilde{x})$ (schwarze Kurve), $p_{2}(\tilde{x})$ (rote Kurve) und $p_{0}(\tilde{x})$ (grüne Kurve) in Abhängigkeit der Messzeit. (B) Positionen der Seitenpunkte $p_{3}(\tilde{y})$ (blaue Kurve), $p_{4}(\tilde{y})$ (violette Kurve) und des Zentrums $p_{0}(\tilde{y})$ (grüne Kurve).

punkte $p_{3}(\tilde{y})$ und $p_{4}(\tilde{y})$ sowie des Objektzentrums $p_{0}(\tilde{y})$ mit einem Offset von $-100 \mathrm{~nm}$ versehen.

Das Rauschen in den LSM-Bildern führt zu starken Fluktuationen in den gemessenen Distanzkurven (Abb. 6.19 A). Abbildung 6.19 B zeigt die gemittelten Kurven. Auch hier werden Phasenverschiebungen zwischen dem vorderen und dem hinteren Ende des Mitochondriums sichtbar (siehe gekennzeichneter Kurvenabschnitt in Abbildung 6.19 B). Die mittleren Geschwindigkeiten liegen in einem Bereich von $-0.66 \mu \mathrm{m} \cdot \mathrm{s}^{-1} \leq v \leq 0.66 \mu \mathrm{m} \cdot \mathrm{s}^{-1}$. Für die gemessene Länge $d$ und den Durchmesser $d_{y}$ des Mitochondriums ergeben sich Standardabweichungen von $\sigma_{d}=55.3 \mathrm{~nm}$ und $\sigma_{d_{y}}=42.8 \mathrm{~nm}$. Die Standardabweichung der gemessenen Länge ist somit auch in diesem Beispiel größer als die des Durchmessers.

In Abbildung 6.20 ist als weiteres Beispiel die Messung eines Mitochondriums in Zigarrenform dargestellt. Sie besteht aus einer Sequenz von 100 aufgenommenen LSM-Bildern. Abbildung 6.20 C und D zeigen jeweils einen Schnitt durch die experimentelle Intensitätsverteilung des ersten Bildes (Abb. 6.20 A) zusammen mit der angepassten theoretischen Verteilung $\mathcal{I}_{\text {obj }}(x, y)$ des approximierten Modells (Abb. $\left.6.20 \mathrm{C}\right)$ (Rechenzeit: 30 Sekunden) und des exakten Zigarrenmodells $I_{\text {obj }}(x, y)$ (Abb. 6.20 D) (Rechenzeit: $~ 5.5$ Stunden). Die Auswertung mit den beiden Verteilungen ergibt eine Objektlänge von $d=3788.4 \mathrm{~nm}$ bzw. $d=3790.5 \mathrm{~nm}$. Die Differenz von $2.1 \mathrm{~nm}$ bestätigt auch hier wieder die ausgezeichnete Annäherung des Zigarrenmodells durch die fünf Kästen des approximierten Objektmodells (Abschnitt 6.1.2).

Die FPA der gesamten Bildsequenz mit der Intensitätsverteilung $\mathcal{I}_{\text {obj }}(x, y)$ führt zu 

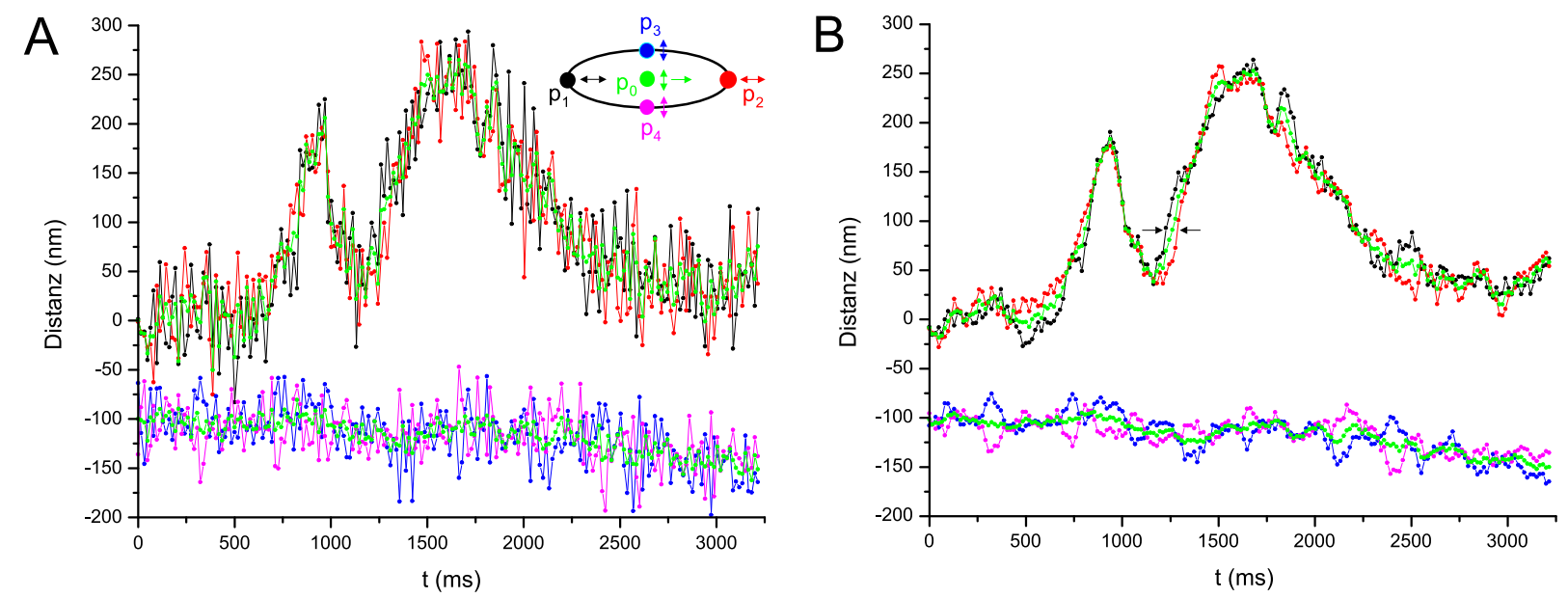

Abb. 6.19: Bewegungen eines Mitochondriums innerhalb eines Dendriten (Abbildung 6.17 $D$ zeigt die zugehörigen Trajektorien der Objektpunkte $p_{0}$ bis $\left.p_{4}\right)$. (A) Zurückgelegte Distanzen des Objektzentrums $p_{0}(\tilde{x})$ (grüne Kurve), des linken und des rechten Endes $p_{1}(\tilde{x})$ und $p_{2}(\tilde{x})$ entlang der $\tilde{x}$-Achse sowie Fluktuationen des Zentrums $p_{0}(\tilde{y})$ und der Seitenpunkte $p_{3}(\tilde{y})$ und $p_{4}(\tilde{y})$ des Mitochondriums bezüglich der $\tilde{y}$-Achse des Koordinatensystems $\tilde{\mathcal{O}}$. (B) Gemittelte Kurven (Mittelwerte über jeweils fünf benachbarte Datenpunkte).

den in Abbildung 6.20 B dargestellten Trajektorien der Objektpunkte $p_{0}$ bis $p_{4}$. Das Mitochondrium wird über eine Distanz von $\sim 400 \mathrm{~nm}$ in retrograder Richtung transportiert. In diesem Beispiel wird die Auswirkung der länglichen Form des Mitochondriums auf die unterschiedlichen Lokalisierungsgenauigkeiten für die beiden Seitenpunkte $p_{3}(\tilde{y})$ und $p_{4}(\tilde{y})$ und der Objektenden $p_{1}(\tilde{x})$ und $p_{2}(\tilde{x})$ besonders deutlich (Abb. 6.21 A). Die Standardabweichungen für die Länge $d$ und den Durchmesser $d_{y}$ betragen in diesem Fall $\sigma_{d}=53.6 \mathrm{~nm}$ und $\sigma_{d_{y}}=18.4 \mathrm{~nm}$.

Betrachtet man die gemittelten Positionskurven (Abb. 6.21 B), so werden Bereiche sichtbar, in denen der aktive Transport des Mitochondriums für kurze Zeit unterbrochen wird. Auch in diesem Beispiel bewegen sich das vordere und das hintere Ende des Mitochondriums stellenweise scheinbar phasenverschoben (Abb. 6.21 B, gekennzeichneter Abschnitt im linken Teil der Abbildung). Zudem sind gegenläufige Bewegungungen sichtbar (Abb. 6.21 B, eingezeichnete Pfeile im rechten Teil der Abbildung).

Die Analyse von insgesamt elf ausgewerteten Experimenten führt $\mathrm{zu}$ den folgenden Beobachtungen:

1. Mitochondrien bewegen sich während des Transports in eine Richtung häufig abschnittsweise mit unterschiedlichen mittleren Geschwindigkeiten, sowohl auf einer mikroskopischen als auch auf einer submikroskopischen Skala;

2. der Transport wechselt oft zwischen anterograder und retrograder Richtung; 

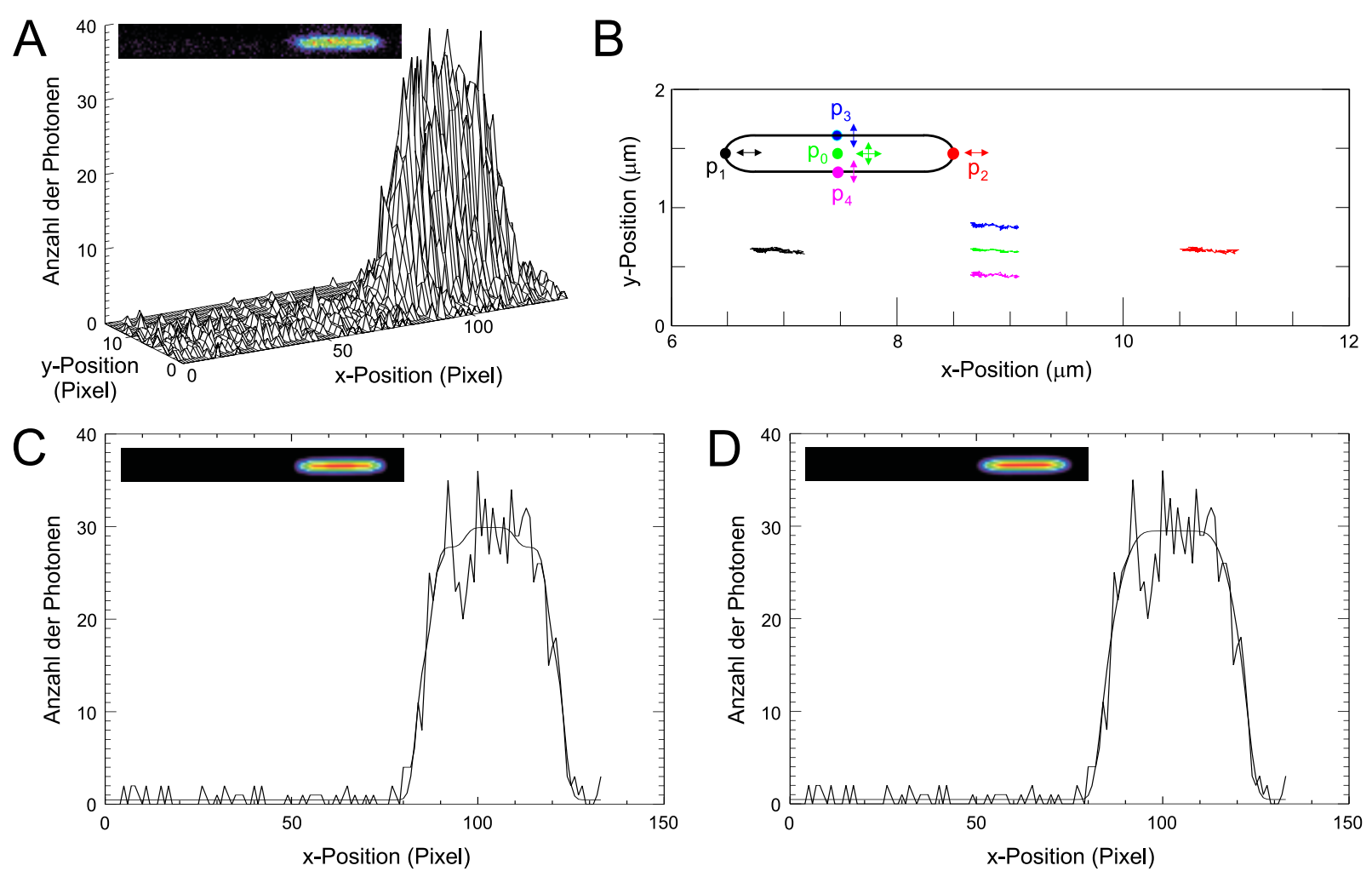

Abb. 6.20: Bewegungsanalyse eines mit MitoTracker gefärbten, aktiv transportierten Mitochondriums. (A) Intensitätsverteilung und LSM-Bild des Mitochondriums (erstes Bildes von insgesamt 100 aufgenommenen Bildern; Bildabtastfrequenz: $61.88 \mathrm{~Hz}$; Größe des LSMBildes: $134 \times 16$ Pixel; Scanzeit pro Pixel: $2.55 \mu \mathrm{s}$; Pixelgröße: $88 \mathrm{~nm}$; SNR der Bilder: $9.42 \pm 0.68$ ). (B) Trajektorien der beiden Objektenden $p_{1}$ (schwarze Spur) und $p_{2}$ (rote Spur), der Seitenpunkte $p_{3}$ (blaue Spur) und $p_{4}$ (violette Spur) und des Objektzentrums $p_{0}$ (grüne Spur) des Mitochondriums. (C) Schnitt entlang der $x$-Achse $(y=7)$ durch die in A dargestellte experimentelle (verrauschte Kurve) und angepasste theoretische Intensitätsverteilung $\mathcal{I}_{\text {obj }}(x, y)$ (6.18 mit 6.9 und 6.10) des approximierten Zigarrenmodells (glatte Kurve). Ergebnis der FP-Analyse: $d_{x}=1169.7 \mathrm{~nm}, d_{1}=1309.4 \mathrm{~nm}\left(d_{2}=d_{1}\right.$, fixiert), $d_{y}=405.6 \mathrm{~nm}, I_{B}=0.48095, \tilde{x}_{0}=103.365$ Pixel, $\tilde{y}_{0}=6.1157$ Pixel und $\varphi=0.008655$ $\left(\chi^{2}=4250.94\right)$. Es ergibt sich eine Objektlänge von $d=3788.4 \mathrm{~nm}$. (D) Schnitt durch die experimentelle und angepasste Verteilung $I_{\text {obj }}(x, y)(6.4)$ des exakten Zigarrenmodells. Ergebnis der Anpassung: $d_{x}=1368.3 \mathrm{~nm}, d_{1}=1211.1 \mathrm{~nm}\left(d_{2}=d_{1}\right.$, fixiert $), d_{y}=419.5 \mathrm{~nm}$, $I_{B}=0.4668, \tilde{x}_{0}=103.286$ Pixel, $\tilde{y}_{0}=6.1062$ Pixel und $\varphi=0.008745\left(\chi^{2}=4193.66\right)$. Es ergibt sich eine Objektlänge von $d=3790.5 \mathrm{~nm}$.

3. die mittleren Bewegungen des vorderen und des hinteren Endes eines Mitochondriums weisen stellenweise ausgeprägte Phasenverschiebungen auf;

4. eines der beiden Enden eines Mitochondriums dominiert oft die Bewegungen während des Transports in eine Richtung; 

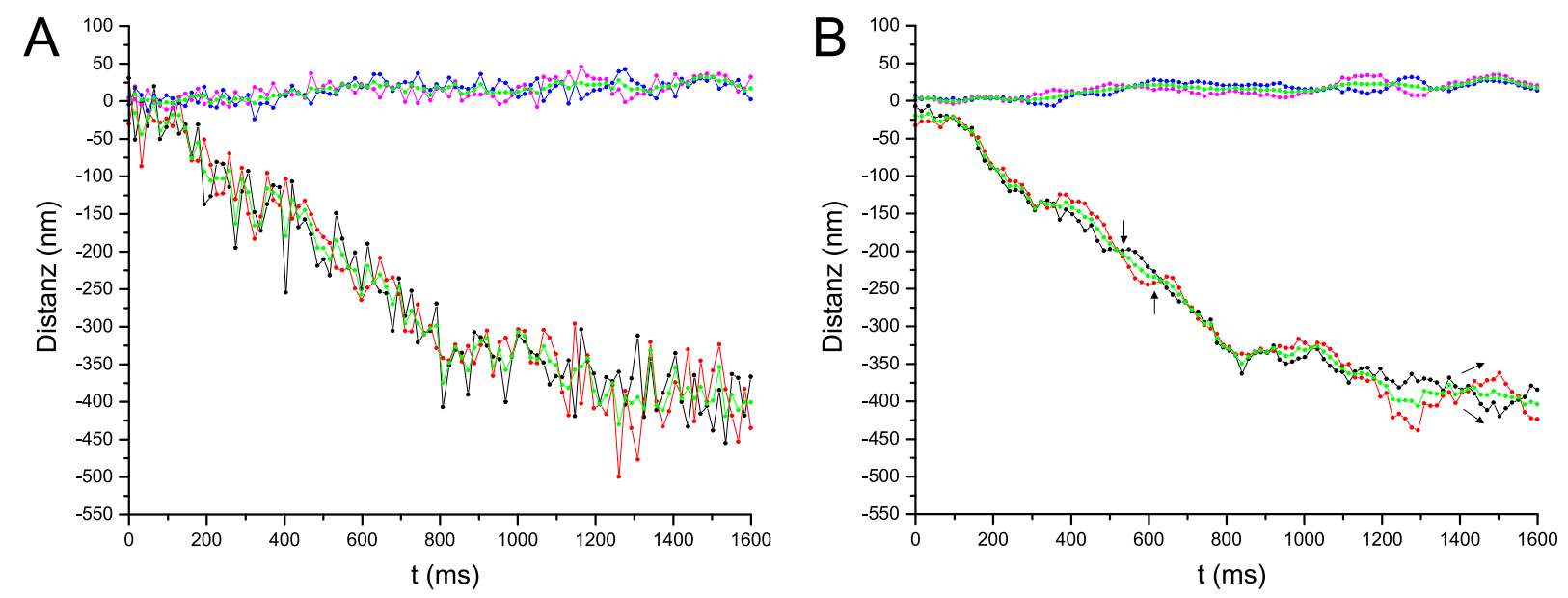

Abb. 6.21: Transport eines Mitochondriums innerhalb eines Dendriten (Abbildung 6.20 B zeigt die zugehörigen Trajektorien der Objektpunkte $p_{0}$ bis $p_{4}$ ). (A) Zurückgelegte Distanzen des Objektzentrums $p_{0}(\tilde{x})$ (grüne Kurve), des linken und des rechten Endes $p_{1}(\tilde{x})$ (schwarze Kurve) und $p_{2}(\tilde{x})$ (rote Kurve) entlang der $\tilde{x}$-Achse sowie Fluktuationen des Zentrums $p_{0}(\tilde{y})$ (grüne Kurve) und der Seitenpunkte $p_{3}(\tilde{y})$ (blaue Kurve) und $p_{4}(\tilde{y})$ (violette Kurve) des Mitochondriums bezüglich der $\tilde{y}$-Achse des Koordinatensystems $\tilde{\mathcal{O}}$. (B) Gemittelte Kurven (Mittelwerte über jeweils fünf benachbarte Datenpunkte).

5. stellenweise bewegen sich das vordere und das hintere Ende eines Mitochondriums in gegensätzliche Richtungen;

6. Mitochondrien zeigen submikroskopische Größenveränderungen;

7. die gemessenen Längenfluktuationen sind größer als die des Durchmessers eines Mitochondriums;

8. Mitochondrien weisen mikroskopische und submikroskopische „saltatorische“, d.h. durch kurze Pausen unterbrochene, Bewegungen auf.

\subsubsection{Simulation bewegter Mitochondrien}

Die Analysen des submikroskopischen dendritischen Transports von Mitochondrien haben $\mathrm{zu}$ vielen interessanten Ergebnissen geführt (Abschnitt 6.3.2). Ob die beobachteten Größenveränderungen und insbesondere die detektierten Phasenverschiebungen zwischen den mittleren Bewegungen des vorderen und des hinteren Endes von Mitochondrien (Abb. 6.16) tatsächliche Vorgänge sind oder ob das Hintergrundrauschen in den LSM-Bildern und die Fluktuationen der Objektintensität zu diesen Beobachtungen führen können, muss durch Simulationen von stationären und bewegten simulierten Mitochondrien - mit konstanter und bekannter Größe - geklärt werden. 



Abb. 6.22: Zur Statistik eines mit MitoTracker gefärbten Mitochondriums (Abbildung 6.14 zeigt das zugehörige Experiment). (A) Mittleres Fluoreszenzsignal des Mitochondriums (zur Berechnung siehe Text). (B) Varianz des Photonensignals in Abhängigkeit der mittleren detektierten Photonenzählrate. Die gestrichelte Gerade beschreibt die Varianz der Zählrate für einen Photodetektor mit PoIsson-Statistik: $\left\langle\delta N^{2}\right\rangle=\langle N\rangle$.

Die Simulation von LSM-Bildern erfolgt unter Berücksichtigung der Rauschcharakteristik des Photonendetektionssystems (Abschnitt 3.6). Abbildung 6.22 A zeigt die mittlere gemessene Intensitätsverteilung des aktiv transportierten Mitochondriums aus Abbildung 6.14. Für die Berechnung des mittleren Photonensignals und dessen Varianz (Abb. 6.22 B) werden die gemessenen Objektintensitäten in den LSM-Bildern - unter Berücksichtigung der vorab mit der FPA bestimmten Objektzentren - in einem festgelegten Bildbereich verschoben. Anschließend wird mit den entstehenden Bildern der Mittelwert der Intensität und die Varianz für jedes Pixel berechnet. In dem in Abbildung 6.22 gezeigten Beispiel sind die gemessenen Intensitätsverteilungen sämtlicher LSM-Bilder an die Startposition des Mitochondriums im ersten Bild verschoben wurden. Abbildung 6.22 B zeigt die Varianzen der gemessenen mittleren Photonenzählraten. Die Varianzen folgen - mit einer gewissen Streuung - dem Polynom 4. Grades aus Abbildung 4.2. Ist das mittlere Intensitätssignal des Mitochondriums durch die FPA sämtlicher gemessener LSM-Bilder bekannt, kann mit Hilfe des Polynoms eine entsprechende Bildsequenz simuliert werden (Abschnitt 3.6).

Abbildung 6.23 zeigt das Ergebnis der Simulation zum ersten Beispielexperiment aus Abbildung 6.14. Die Parameter für das theoretische rauschfreie Mitochondrium - berechnet mit der Intensitätsverteilung $\mathcal{I}_{\text {obj }}(x, y)$ - sind die Mittelwerte sämtlicher Parameter, die sich aus der FPA des Experimentes ergeben. Vergleicht man die gemessenen Varianzen der Objektintensitätswerte der zugrundeliegenden Messung (Abbildung 6.22 B) mit denen der Simulation (Abbildung $6.23 \mathrm{C}$ ), so zeigt sich die gute Übereinstimmung der Rauschcharakteristik. Tabelle 6.3 fasst die für die Größe der Intensitätsfluktuationen entscheidenden Parameter zusammen.

Um Anhaltspunkte zu finden, ob das Rauschen in den LSM-Bildern zu den beobachteten 

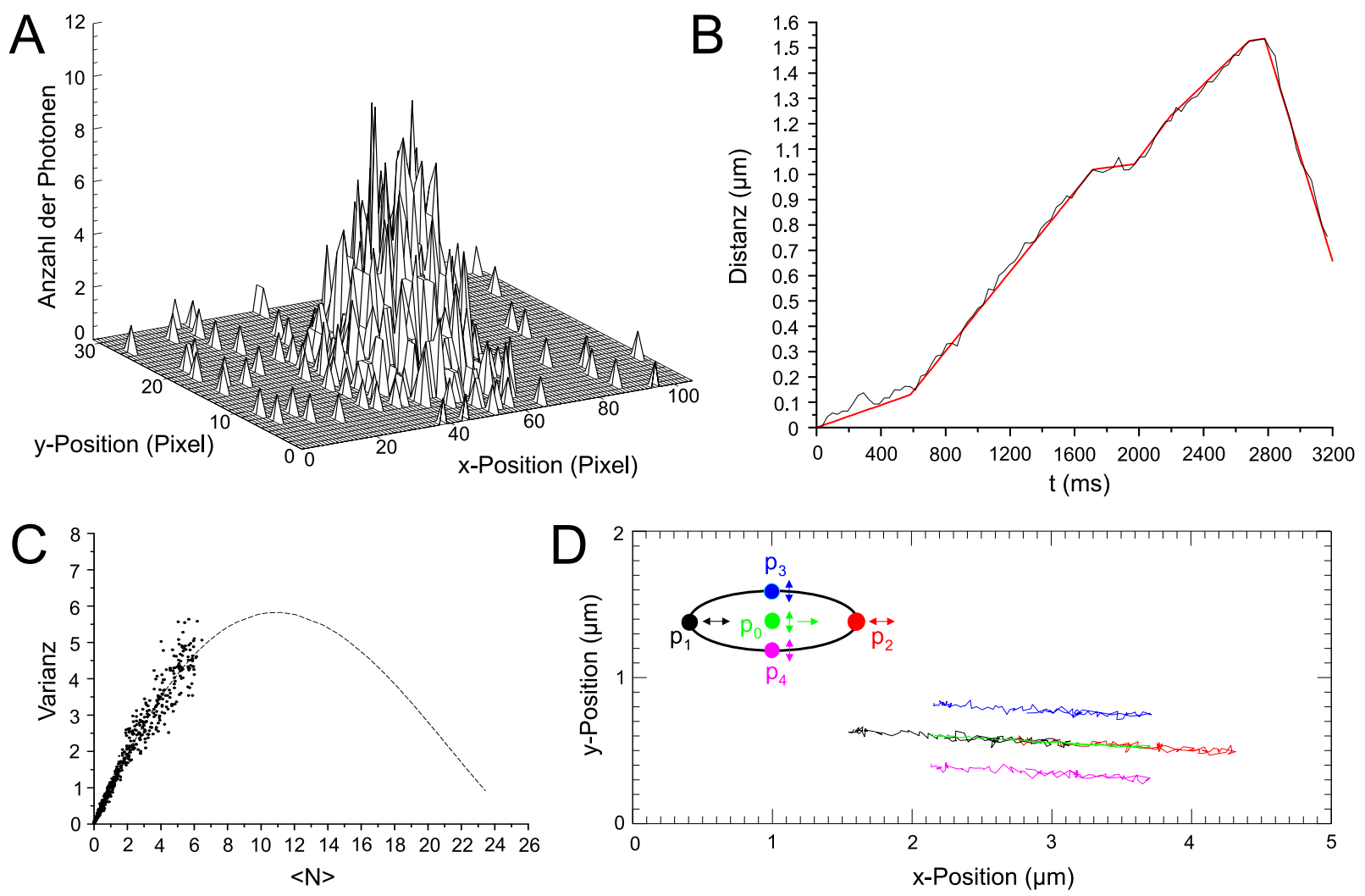

Abb. 6.23: Simulation eines bewegten Mitochondriums. Die Parameter der rauschfreien Intensitätsverteilung $\mathcal{I}_{\text {obj }}(x, y)$ (6.18 mit 6.9 und 6.10) sind die Mittelwerte aus der FPAnalyse des Experimentes aus Abbildung 6.14: $p=10.73, d_{x}=0, d_{1}=d_{2}=589.2 \mathrm{~nm}$, $d_{y}=431.4 \mathrm{~nm}, I_{B}=0.025$ und $\varphi=-0.0521$. (A) Intensität des Mitochondriums in der ersten Startposition (linker Teil des ersten LSM-Bildes; Größe des LSM-Bildes: $200 \times$ 32 Pixel). (B) Gemessene (Daten zum Experiment aus Abbildung 6.14, schwarze Kurve) und die der Simulation zugrundeliegende Trajektorie (rote Kurve) des Objektzentrums $p_{0}(\tilde{x})$ (Zeitauflösung: $32.32 \mathrm{~ms}$ ). (C) Varianz der Objektintensitätswerte als Funktion der mittleren Objektintensität, berechnet aus der gesamten Sequenz von 100 simulierten LSMBildern (Berechnung siehe Text). (D) Trajektorien der beiden Objektenden $p_{1}$ (schwarze Spur) und $p_{2}$ (rote Spur), der Seitenpunkte $p_{3}$ (blaue Spur) und $p_{4}$ (violette Spur) und des Objektzentrums $p_{0}$ (grüne Spur) des Mitochondriums, Ergebnis der FP-Analyse der simulierten Bildsequenz.

Phasenverschiebungen zwischen den mittleren Bewegungen von vorderem und hinterem Endes des Mitochondriums führen kann, wird das Zentrum des simulierten Mitochondriums von Bild zu Bild - entsprechend der mittleren Bewegung des Wildtyp-Mitochondriums weiterbewegt (Abschnitt 3.6). Die Trajektorie des theoretischen Mitochondriums ist in Abbildung 6.23 B dargestellt. Sie gibt die mittlere Bewegung des Objektzentrums $p_{0}(\tilde{x})$ des Wildtyp-Mitochondriums wider. Die FPA der simulierten LSM-Bilder führt zu den in 


\begin{tabular}{ccc}
\hline Parameter & Experiment & Simulation \\
\hline SNR & $4.86 \pm 0.24$ & $4.89 \pm 0.27$ \\
$I_{\max }$ & $5.9 \pm 0.36$ & $6.1 \pm 0.33$ \\
$\sigma_{\text {sig }}$ & $1.22 \pm 0.057$ & $1.24 \pm 0.059$ \\
$I_{B}$ & $0.02516 \pm 0.00497$ & $0.02532 \pm 0.00504$ \\
\hline
\end{tabular}

Tab. 6.3: Mittelwerte und Standardabweichungen des SNR, der mittleren maximalen Signalamplitude $I_{\max }$ über dem mittleren Hintergrundsignal $I_{B}$ sowie der Standardabweichung $\sigma_{\text {sig }}$ der Objektintensität (berechnet nach Gleichung 6.53) für das Experiment (Abb. 6.14) und die Simulation (Abb. 6.23).

Abbildung 6.23 D dargestellten Trajektorien der Objektpunkte $p_{0}$ bis $p_{4}$. Der Transport des simulierten Mitochondriums erfolgt mit derselben mittleren Orientierung von $\varphi \simeq-3^{\circ}$ bezüglich der $x$-Achse des Koordinatensystems $\mathcal{O}$ wie die des Experimentes.

Abbildung 6.24 zeigt die Distanzkurven der Objektpunkte. Die Kurven geben die gleiche mittlere Bewegung wider wie die des aktiv transportierten Wildtyp-Mitochondriums. Die FPA führt zu den Standardabweichungen $\sigma_{d}=33.5 \mathrm{~nm}$ und $\sigma_{d_{y}}=30.1 \mathrm{~nm}$ für die Länge $d$ und den Durchmesser $d_{y}$ des theoretischen simulierten Mitochondriums. Vergleicht man diese Werte mit denen des Experimentes $\left(\sigma_{d}=48.6 \mathrm{~nm}\right.$ und $\left.\sigma_{d_{y}}=34.4 \mathrm{~nm}\right)$, so fällt auf, dass die Standardabweichung der Länge des simulierten Mitochondriums mit 31.1\% stärker von der des Experimentes abweicht als die Standardabweichung des Durchmessers $(12.5 \%$ Abweichung zwischen Simulation und Experiment). Dieser Sachverhalt spiegelt sich auch in den Distanzkurven der Simulation wider (Abb. 6.24): Während die Kurvenverläufe der Seitenpunkte $p_{3}(\tilde{y})$ und $p_{4}(\tilde{y})$ des simulierten Mitochondriums (Abb. 6.24 A und B) mit denen des Experimentes (Abb. 6.16 A und B) vergleichbar sind - abgesehen von einer leichten "Drift" des Wildtyp-Mitochondriums in $\tilde{y}$-Richtung -, unterscheiden sich die Distanzkurven der beiden Objektenden $p_{1}(\tilde{x})$ und $p_{2}(\tilde{x})$ signifikant von denen des Experimentes. Es zeigt sich, dass die simulierten Kurven - im Gegensatz zu denen der Messung - sehr gut zur Deckung kommen. Ausgeprägte Phasenverschiebungen und mittlere Längenänderungen von bis zu $\sim 100 \mathrm{~nm}$ - wie die im Experiment beobachteten - sind nicht zu erkennen. Dieser Sachverhalt wird durch zehn weitere Simulationen bestätigt. Das Resultat zeigt, dass die im Experiment gemessenen mittleren Längenänderungen und Phasenverschiebungen zwischen den mittleren Bewegungen des vorderen und hinteren Endes des Wildtyp-Mitochondriums nicht allein durch das Rauschen in den LSM-Bildern und der damit zusammenhängenden Unsicherheit des FP-Algorithmus' erklärt werden können. Da die Längenfluktuationen mit der Richtung des aktiven Transports des Mitochondriums übereinstimmen, deutet das Ergebnis vielmehr auf einen mit dem aktiven Transport zusammenhängenden Prozess hin.

Abbildung 6.25 zeigt das Ergebnis der Simulation zum Experiment aus Abbildung 6.17. Es wird die gleiche mittlere Bewegung wie die des Wildtyp-Mitochondriums simuliert. In Abbildung 6.25 A sind sowohl die Varianzen der Objektintensität des Wildtyp- 



Abb. 6.24: Bewegungen eines simulierten Mitochondriums (Abbildung 6.23 D zeigt die zugehörigen Trajektorien der Objektpunkte $p_{0}$ bis $p_{4}$ ). (A) Distanzkurven des Objektzentrums $p_{0}(\tilde{x})$ (grüne Kurve), des linken und des rechten Endes $p_{1}(\tilde{x})$ (schwarze Kurve) und $p_{2}(\tilde{x})$ (rote Kurve) sowie des Zentrums $p_{0}(\tilde{y})$ und der Seitenpunkte $p_{3}(\tilde{y})$ und $p_{4}(\tilde{y})$ des Mitochondriums. (B) Gemittelte Kurven (Mittelwerte über jeweils drei benachbarte Datenpunkte).

Mitochondriums als auch die des simulierten Mitochondriums dargestellt. Auch hier zeigt sich eine gute Übereinstimmung der Rauschcharakteristik. Die für die Größe der Intensitätsfluktuationen entscheidenen Parameter sind in Tabelle 6.4 zusammengefasst.

\begin{tabular}{ccc}
\hline Parameter & Experiment & Simulation \\
\hline SNR & $7.56 \pm 0.69$ & $7.7 \pm 0.69$ \\
$I_{\max }$ & $13.47 \pm 1.19$ & $14.12 \pm 0.9$ \\
$\sigma_{\text {sig }}$ & $1.79 \pm 0.23$ & $1.84 \pm 0.2$ \\
$I_{B}$ & $0.0909 \pm 0.0094$ & $0.0912 \pm 0.0084$ \\
\hline
\end{tabular}

Tab. 6.4: Mittelwerte und Standardabweichungen des SNR, der mittleren maximalen Signalamplitude $I_{\max }$ sowie der Standardabweichung $\sigma_{\text {sig }}$ der Objektintensität für das Experiment (Abb. 6.17) und die Simulation (Abb. 6.25).

Die Position des simulierten Mitochondriums wird von Bild zu Bild - entsprechend der vorgegebenen Trajektorie (Abb. 6.25 B, rote Geraden) - verändert. Die FPA der simulierten Bildsequenz führt zu den in Abbildung 6.25 C dargestellten Distanzkurven. Vergleicht man die gemittelten Kurven der Simulation (Abb. 6.25 D) mit denen des Experimentes (Abb. 6.19 B), so lässt sich in diesem Fall scheinbar keine klare Aussage treffen: Auf den ersten Blick weisen die Kurven des Experiments und der Simulation vergleichbare Phasenverschiebungen zwischen den mittleren Bewegungen des vorderen und hinteren Endes des Mitochondriums und ähnliche mittlere Längen- und- Durchmesserveränderungen auf. 

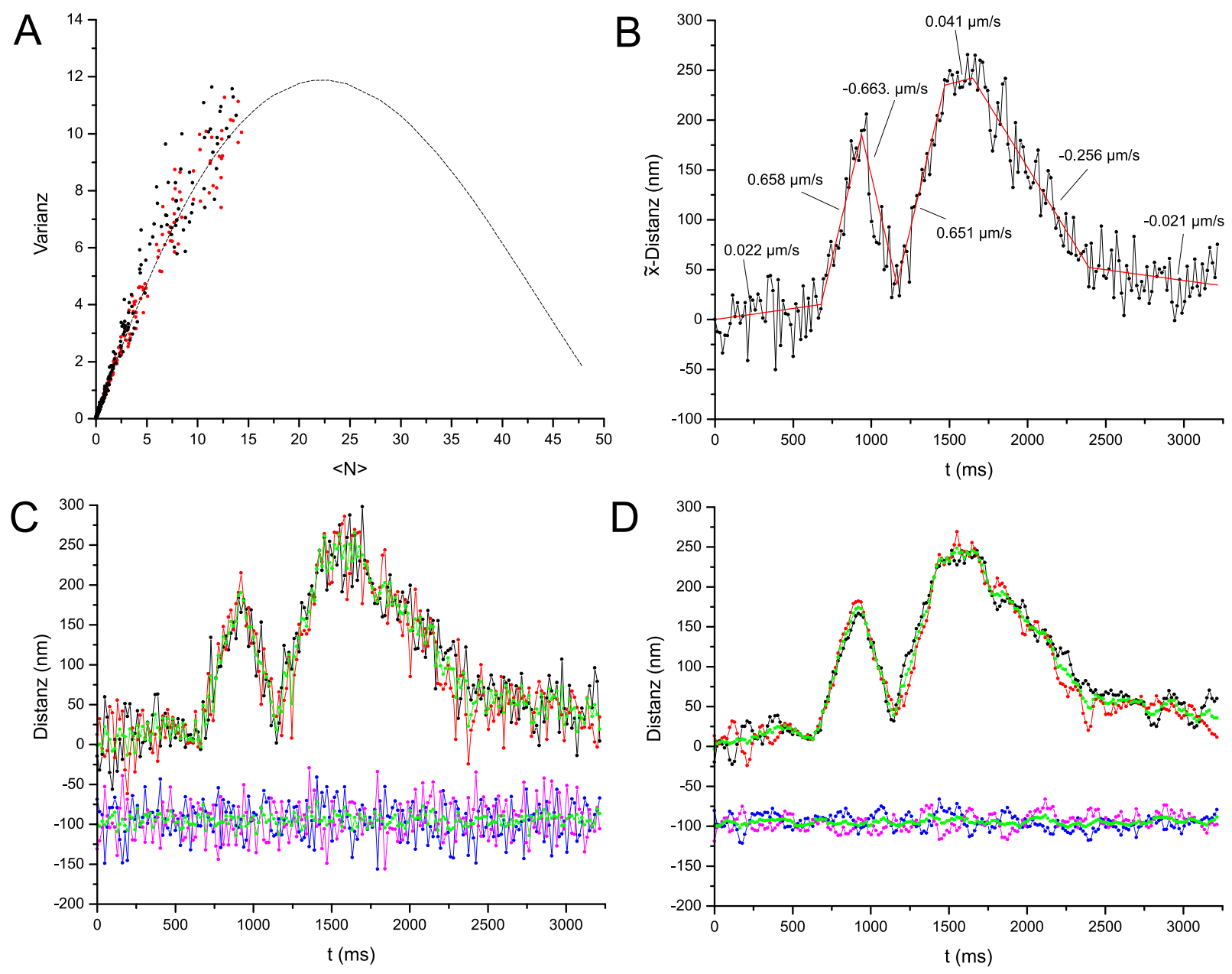

Abb. 6.25: Simulation eines aktiv transportierten Mitochondriums (Simulation zum Experiment aus Abbildung 6.17). Die konstanten Parameter der rauschfreien Intensitätsverteilung $\mathcal{I}_{\text {obj }}(x, y)$ (6.18 mit 6.9 und 6.10) des theoretischen Mitochondriums sind die Mittelwerte aus der FP-Analyse des Experimentes: $p=29.5, d_{x}=0, d_{1}=d_{2}=609.2 \mathrm{~nm}, d_{y}=385.7 \mathrm{~nm}$, $I_{B}=0.09088$ und $\varphi=-0.08108$. Die Größe der simulierten und der experimentellen LSM-Bilder ist identisch $(134 \times 16$ Pixel). Pixelgröße: 88 nm; Zeitauflösung: 16.16 ms. (A) Varianz der Objektintensität des zugrundeliegenden Wildtyp-Mitochondriums (schwarze Punkte, Daten zum Experiment in Abbildung 6.17) und des simulierten Mitochondriums (rote Punkte), berechnet aus der Sequenz von 200 simulierten LSM-Bildern. (B) Distanzkurve des Objektzentrums $p_{0}(\tilde{x})$ des Wildtyp-Mitochondriums (schwarze Kurve, siehe auch Abbildung 6.19) und Bewegungsverlauf des simulierten Mitochondriums (rote Geraden). (C) Distanzkurven des Objektzentrums $p_{0}(\tilde{x})$ (grüne Kurve), des linken und des rechten Endes $p_{1}(\tilde{x})$ (schwarze Kurve) und $p_{2}(\tilde{x})$ (rote Kurve), sowie des Zentrums $p_{0}(\tilde{y})$ und der Seitenpunkte $p_{3}(\tilde{y})$ und $p_{4}(\tilde{y})$ des simulierten Mitochondriums. Zur besseren Übersicht sind die Distanzkurven der Seitenpunkte $p_{3}(\tilde{y})$ und $p_{4}(\tilde{y})$ sowie des Objektzentrums $p_{0}(\tilde{y})$ mit einem Offset von $-100 \mathrm{~nm}$ versehen. (D) Gemittelte Kurven (Mittelwerte über jeweils fünf benachbarte Datenpunkte). 
Ein Vergleich der Standardabweichungen der Länge $d$ und des Durchmessers $d_{y}$ deckt dennoch einen Unterschied auf: Die FPA der Simulation führt zu den Standardabweichungen $\sigma_{d}=45.1 \mathrm{~nm}$ und $\sigma_{d_{y}}=44.7 \mathrm{~nm}$, die des Experimentes zu $\sigma_{d}=55.3 \mathrm{~nm}$ und $\sigma_{d_{y}}=42.8 \mathrm{~nm}$. Es zeigt sich somit, dass die Simulation zu ähnlichen Standardabweichungen für die Länge und den Durchmesser führt, während sich die des Experimentes deutlich unterscheiden. Die fast identischen Standardabweichungen für den Durchmesser des simulierten und des gemessenen Mitochondriums (4\% Abweichung) bestätigen die gute Übereinstimmung der Rauschcharakteristik und der damit zusammenhängenden Genauigkeit des Algorithmus'. Die Standardabweichung der Länge des simulierten Mitochondriums weicht dagegen um $19 \%$ von der des Experimentes ab.

Die Experimente führen somit im Vergleich zu den entsprechenden Simulationen zu unterschiedlichen Standardabweichungen für die Länge eines Mitochondriums. Die Standardabweichung der Messung ist größer als die der zugehörigen Simulation. Zudem sind die Abweichungen zwischen den Standardabweichungen der Simulation und des Experimentes für die Länge größer als die des Durchmessers.

\subsubsection{Statistische Analyse der Größenfluktuationen von Mitochondrien}

Die Analysen in den beiden letzten Abschnitten machen deutlich, dass die Größe von Mitochondrien während des aktiven Transports stark fluktuiert. Ein Vergleich mit den Simulationen zeigt, dass die Standardabweichung $\sigma_{d}$ der gemessenen Länge $d$ von WildtypMitochondrien größer ist als die der simulierten Mitochondrien. In diesem Abschnitt wird die Hypothese untersucht, ob das Rauschen in den experimentellen LSM-Bildern eines aktiv transportierten Mitochondriums die Ursache für die vergleichsweise großen Längenfluktuationen sein kann.

Es wird nach der Wahrscheinlichkeit $\mathcal{P}\left(\sigma_{m} / \sigma_{s} \geq \alpha\right)$ gefragt, mit der das Verhältnis der gemessenen Standardabweichung $\sigma_{m}$ und der Standardabweichung $\sigma_{s}$ der Simulation, $\sigma_{m} / \sigma_{s}$, einen gegebenen Wert $\alpha>1$ (ist $\sigma_{m}$ kleiner $\sigma_{s}$, so müssen Zähler und Nenner vertauscht werden) unter der Annahme („Nullhypothese“) überschreiten kann, dass die den Standardabweichungen $\sigma_{m}$ und $\sigma_{s}$ zugrundeliegenden Messwerte statistisch unabhängig und nach einer Normalverteilung mit einer unbekannten Standardabweichung identisch verteilt sind.

Dass das Rauschen in den simulierten Bildern von theoretischen Mitochondrien konstanter Größe bei der Auswertung mit dem FP-Algorithmus zu einer normalverteilten Länge $d$ bzw. Durchmesser $d_{y}$ führt, ist eine berechtigte und sinnvolle Annahme und wird durch die Analysen bestätigt (Abb. 6.26). Für diese Annahme spricht der zentrale Grenzwertsatz, der besagt, dass eine Summe von unabhängigen, identisch verteilten Zufallsvariablen durch eine normalverteilte Zufallsvariable dargestellt werden kann [49,113]. Diese Näherung liefert schon sehr gute Resultate ab 30 Messwerten [49]. Die Messwerte resultieren indirekt aus einer Mittelwertbildung: Die Größe eines Objektes in einem LSM-Bild ergibt 
sich durch Anpassung der theoretischen Intensitätsverteilung an die gemessene Verteilung des Objektes. Im Anpassungsalgorithmus ( $\chi^{2}$-Minimierung) werden die Parameter dabei so variiert, dass die theoretische und die experimentelle Verteilung möglichst gut übereinstimmen. Dies entspricht einer Mittelwertbildung über die Daten im Bild. Die Länge und der Durchmesser des Objektes resultieren somit aus der Auswertung der gesamten zweidimensionalen Verteilung. Da die Intensitätsverteilung der Mitochondrien in den simulierten LSM-Bildern aus vielen Pixeln besteht (typischerweise > 400), deren Intensitätswerte statistisch unabhängig sind - die Simulation berücksichtigt gerade die statistischen Natur der Photonendetektion - lässt sich der zentrale Grenzwertsatz anwenden. Die Hypothese einer normal verteilten Länge bzw. eines normal verteilten Durchmessers ist somit berechtigt.

Die Wahrscheinlichkeit $\mathcal{P}\left(\sigma_{m} / \sigma_{s} \geq \alpha\right)$ wird wie folgt berechnet: Die unbekannte Standardabweichung der Normalverteilung sei $\sigma$. Der Mittelwert der Verteilung sei ohne Einschränkung der Allgemeinheit gleich Null. Zunächst wird die Wahrscheinlichkeit in Abhängigkeit eines frei wählbaren Parameters $R>0$ abgeschätzt. Anschließend wird der Parameter $R$ so gewählt, dass die Abschätzung optimal wird.

Für ein gegebenes $R>0$ ist das Verhältnis $\sigma_{m} / \sigma_{s}<\alpha$, wenn $\sigma_{m}<\alpha R \sigma$ und $\sigma_{s} \geq R \sigma$. Daher gilt

$$
\begin{aligned}
\mathcal{P}\left(\frac{\sigma_{m}}{\sigma_{s}} \geq \alpha\right) & =1-\mathcal{P}\left(\frac{\sigma_{m}}{\sigma_{s}}<\alpha\right) \\
& \leq 1-\mathcal{P}\left(\sigma_{m}<\alpha R \sigma \wedge \sigma_{s} \geq R \sigma\right)
\end{aligned}
$$

Mit der statistischen Unabhängigkeit der Messwerte folgt weiter:

$$
\begin{aligned}
\mathcal{P}\left(\frac{\sigma_{m}}{\sigma_{s}} \geq \alpha\right) & \leq 1-\mathcal{P}\left(\sigma_{m}<\alpha R \sigma\right) \cdot \mathcal{P}\left(\sigma_{s} \geq R \sigma\right) \\
& =1-\left(1-q_{m}\right) \cdot\left(1-p_{s}\right)=q_{m}+p_{s}-q_{m} p_{s} \\
& <q_{m}+p_{s},
\end{aligned}
$$

mit

$$
q_{m}=\mathcal{P}\left(\sigma_{m} \geq \alpha R \sigma\right)=1-\mathcal{P}\left(\sigma_{m}<\alpha R \sigma\right)
$$

und

$$
p_{m}=\mathcal{P}\left(\sigma_{s}<R \sigma\right) .
$$

Es ist somit erforderlich, die Wahrscheinlichkeit $\mathcal{P}(\sigma<k \sigma)$ für eine gegebene empirische Standardabweichung $\sigma$ und einen beliebigen Faktor $k>0$ zu berechnen. Für die empirische Varianz $\sigma^{2}$ gilt:

$$
\sigma^{2}=\frac{1}{N-1} \sum_{i=1}^{N} x_{i}^{2},
$$

wobei $x_{i}$ die Messwerte und $N$ die Anzahl der Werte bezeichnet $\left(\left\langle x_{i}\right\rangle=0\right)$. Führt man den $N$-dimensionalen Vektor $\vec{x}_{N}=\left(x_{1}, \cdots, x_{N}\right)$ ein, so gilt

$$
\sigma^{2}=\frac{1}{N-1} \vec{x}_{N}^{2}
$$


Hierbei bezeichnet $\vec{x}_{N}^{2}$ die EukLIDische Länge. Für die Wahrscheinlichkeit $\mathcal{P}(\sigma<k \sigma)$ folgt dann

$$
\begin{aligned}
\mathcal{P}(\sigma<k \sigma) & =\mathcal{P}\left(\sigma^{2}<k^{2} \sigma^{2}\right) \\
& =\mathcal{P}\left(\vec{x}_{N}^{2}<(N-1) k^{2} \sigma^{2}\right) \\
& =\int_{\left|\vec{x}_{N}\right|<\sqrt{N-1} k \sigma} p\left(x_{1}, x_{2}, \cdots, x_{N}\right) \mathrm{d} \vec{x}_{N} \\
& =\int_{\left|\vec{x}_{N}\right|<\sqrt{N-1} k \sigma} p\left(x_{1}\right) \cdot p\left(x_{2}\right) \cdots p\left(x_{N}\right) \mathrm{d} \vec{x}_{N} .
\end{aligned}
$$

Dabei ist die GAUsssche-Wahrscheinlichkeitsdichte $p$ definiert durch:

$$
p(x)=\frac{1}{\sqrt{2 \pi \sigma^{2}}} e^{-\frac{x^{2}}{2 \sigma^{2}}} .
$$

Dann ergibt sich

$$
\mathcal{P}(\sigma<k \sigma)=\frac{1}{{\sqrt{2 \pi \sigma^{2}}}^{N}} \int_{\left|\vec{x}_{N}\right|<\sqrt{N-1} k \sigma} e^{-\frac{\vec{x}_{N}^{2}}{2 \sigma^{2}}} \mathrm{~d} \vec{x}_{N}
$$

Nach Transformation in $N$-dimensionale Polarkoordinaten [114] resultiert schließlich:

$$
\begin{aligned}
\mathcal{P}(\sigma<k \sigma) & =\frac{2^{1-\frac{N}{2}}}{\sigma^{N} \cdot \Gamma\left(\frac{N}{2}\right)} \int_{0}^{\sqrt{N-1} k \sigma} r^{N-1} \cdot e^{-\frac{r^{2}}{2 \sigma^{2}}} \mathrm{~d} r \\
& =\frac{2^{1-\frac{N}{2}}}{\Gamma\left(\frac{N}{2}\right)} \int_{0}^{\sqrt{N-1} k} t^{N-1} \cdot e^{-\frac{t^{2}}{2}} \mathrm{~d} t
\end{aligned}
$$

wobei $\Gamma$ die Gammafunktion

$$
\Gamma(x)=\int_{0}^{\infty} e^{-t} t^{x-1} \mathrm{~d} t
$$

bezeichnet. Für die Wahrscheinlichkeiten $q_{m}$ (6.57) und $p_{s}$ (6.58) folgt dann

$$
q_{m}=1-\frac{2^{1-\frac{N}{2}}}{\Gamma\left(\frac{N}{2}\right)} \int_{0}^{\sqrt{N-1} \alpha R} t^{N-1} \cdot e^{-\frac{t^{2}}{2}} \mathrm{~d} t
$$

und

$$
p_{s}=\frac{2^{1-\frac{M}{2}}}{\Gamma\left(\frac{M}{2}\right)} \int_{0}^{\sqrt{M-1} R} t^{M-1} \cdot e^{-\frac{t^{2}}{2}} \mathrm{~d} t
$$


Hierbei bezeichnen $N$ und $M$ die Anzahl der Messwerte des Experimentes und der Simulation.

Die gesuchte Wahrscheinlichkeit $\mathcal{P}\left(\sigma_{m} / \sigma_{s} \geq \alpha\right)$ (6.55) lässt sich somit durch den Ausdruck

$$
\mathcal{P}\left(\frac{\sigma_{m}}{\sigma_{s}} \geq \alpha\right)<1-\frac{2^{1-\frac{N}{2}}}{\Gamma\left(\frac{N}{2}\right)} \int_{0}^{\sqrt{N-1} \alpha R} t^{N-1} \cdot e^{-\frac{t^{2}}{2}} \mathrm{~d} t+\frac{2^{1-\frac{M}{2}}}{\Gamma\left(\frac{M}{2}\right)} \int_{0}^{\sqrt{M-1} R} t^{M-1} \cdot e^{-\frac{t^{2}}{2}} \mathrm{~d} t
$$

abschätzen. Liegen die Anzahl $N$ und die Anzahl $M$ der jeweiligen Messwerte vor, kann für ein gegebenes $\alpha>1$ der Faktor $R>0$ so variiert werden, dass die rechte Seite des Ausdrucks (6.69) ein Minimum erreicht. Dieser Ausdruck kann z.B. mit dem Computerprogramm Mathematica (Mathemathica 4.0, Wolfram Research, Champaign, IL, USA) ausgewertet werden.

Mit der Ungleichung (6.69) lässt sich nun die Wahrscheinlichkeit abschätzen, ob das Rauschen in den LSM-Bildern zu den - im Vergleich zu den Simulationen - großen gemessenen Längenfluktuationen von Mitochondrien führen kann. Da die simulierten Bilder die gleiche Rauschcharakteristik aufweisen wie die experimentellen LSM-Bilder (gleiches $\sigma_{\text {sig }}, I_{\max }$, und $I_{B}$, einschließlich der Standardabweichungen dieser Parameter; Abschnitt 6.3.3) und die theoretischen Objekte eine konstante Form und Größe haben, kann bei einer vernachlässigbaren Wahrscheinlichkeit ausgeschlossen werden, dass die Fluktuationen der Objektintensität in den experimentellen LSM-Bildern der Grund für die vergleichweise großen Längenfluktuationen sind.

Die erste Beispielmessung eines aktiv transportierten Mitochondriums (Abb. 6.14) führte zu den Standardabweichungen $\sigma_{d}=48.6 \mathrm{~nm}$ und $\sigma_{d_{y}}=34.4 \mathrm{~nm}$ für die Länge $d$ und den Durchmessers $d_{y}$ des Mitochondriums $(N=100)$. Die entsprechende Simulation (Abb. 6.23) ergab dagegen die Werte $\sigma_{d}=33.5 \mathrm{~nm}$ und $\sigma_{d_{y}}=30.1 \mathrm{~nm}(M=100)$. Für das Verhältnis der Standardabweichungen der Länge ergibt sich somit $\alpha=1.45$. Die Abschätzung (6.69) der Wahrscheinlichkeit, dass ein Wert von $\alpha \geq 1.45$ erreicht wird, ergibt dann:

$$
\mathcal{P}\left(\sigma_{m} / \sigma_{s} \geq 1.45\right)<0.008974,
$$

mit $N=100, M=100$ und $R=0.825134$. Die Wahrscheinlichkeit ist somit kleiner als 1\%. Die Hypothese kann daher verworfen werden. Für das Verhältnis $\alpha=1.14$ der Standardabweichungen des Durchmessers folgt dagegen

$$
\mathcal{P}\left(\sigma_{m} / \sigma_{s} \geq 1.14\right)<0.355212,
$$

mit $R=0.939959$. Die Wahrscheinlichkeit von kleiner als 35.5\% lässt keine Verwerfung der Annahme bezüglich der Fluktuationen des Durchmessers zu. Die vergleichweise große Standardabweichung der Länge ist somit sehr viel unwahrscheinlicher eine Folge des Rauschen als die des Durchmessers.

Noch eindeutiger wird das Ergebnis im Fall der zweiten Beispielmessung (Abb. 6.17). Die Standardabweichungen des Experimentes betrugen in diesem Fall $\sigma_{d}=55.3 \mathrm{~nm}$ und 


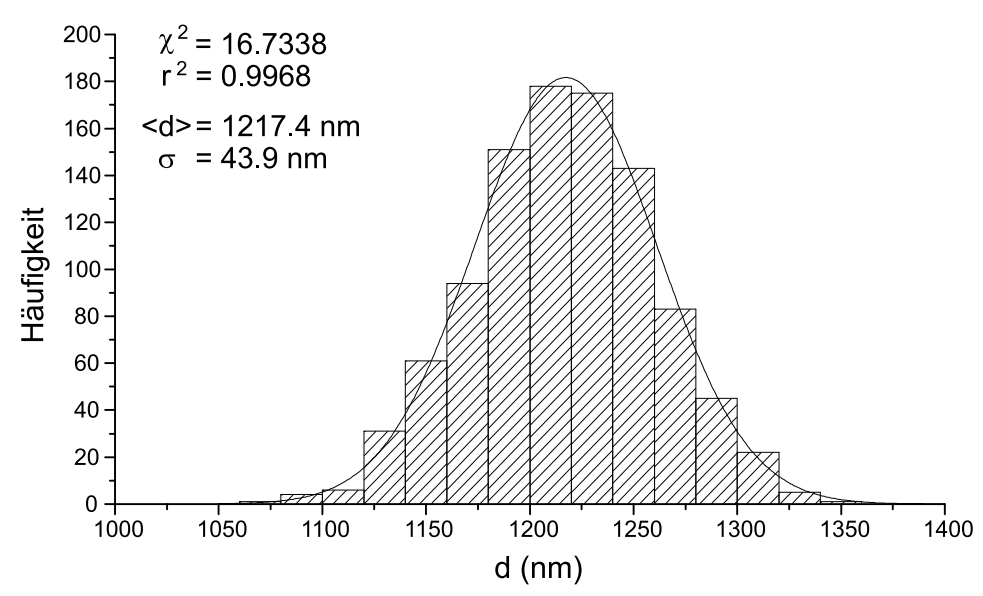

Abb. 6.26: Histogramm der gemessenen Länge d des simulierten stationären Mitochondriums und angepasste GAUss verteilung. Ergebnis von 1000 simulierten Bildern (Parameter der Simulation, siehe Abb. 6.25).

$\sigma_{d_{y}}=42.8 \mathrm{~nm}(N=200)$, die der zugehörigen Simulation (Abb. 6.25) $\sigma_{d}=45.1 \mathrm{~nm}$ und $\sigma_{d_{y}}=44.7 \mathrm{~nm}(M=200)$. Die Abschätzung des Verhältnisses $\alpha=1.23$ der Standardabweichungen der Länge ergibt

$$
\mathcal{P}\left(\sigma_{m} / \sigma_{s} \geq 1.23\right)<0.03883
$$

mit $R=0.900714$. Die Wahrscheinlichkeit ist somit kleiner als 3.9\%. Die Wahrscheinlichkeit für ein Verhältnis der Standardabweichungen des Durchmessers von größer als $\alpha=1.044$ (die größere Standardabweichung muss im Zähler stehen) ist dagegen $66.7 \%$ $(R=0.981005)$. Noch eindeutiger werden die Ergebnisse, wenn für die Analysen 1000 Bilder eines stationären Mitochondriums simuliert werden (mit denselben Parametern wie in Abb. 6.25). In diesem Fall ergeben sich Standardabweichungen von $\sigma_{d}=43.6 \mathrm{~nm}$ und $\sigma_{d_{y}}=42 \mathrm{~nm}$ (Abb. 6.26 zeigt das Histogramm der gemessenen Längen einschließlich einer angepassten Gaussverteilung). Mit einem Verhältnis von $\alpha=1.268$ für die Standardabweichungen der Länge und $M=1000$ folgt nun:

$$
\mathcal{P}\left(\sigma_{m} / \sigma_{s} \geq 1.268\right)<0.0007245,
$$

mit $R=0.922651$. Die Wahrscheinlichkeit ist somit kleiner als 0.073\%. Die Hypothese, dass das Rauschen in den LSM-Bildern zu den vergleichsweise großen Längenfluktuationen führt, kann somit zweifelsfrei verworfen werden. Für das Verhältnis $\alpha=1.019$ der Standardabweichungen des Durchmessers ergibt sich dagegen eine Wahrscheinlichkeit von

$$
\mathcal{P}\left(\sigma_{m} / \sigma_{s} \geq 1.019\right)<0.685
$$

mit $R=0.971717$. Die Wahrscheinlichkeit von kleiner als $68.5 \%$ ermöglicht somit keine Verwerfung der Annahme, dass das Rauschen in den Bildern zu der gemessenen Standardabweichung von $\sigma_{d_{y}}=42.8 \mathrm{~nm}$ führt. Vielmehr deutet der ähnliche Wert der Simulation 
von $\sigma_{d_{y}}=42 \mathrm{~nm}$ darauf hin, dass das Rauschen in der gemessenen Bildsequenz des Experimentes einen großen Anteil an den gemessenen Durchmesserfluktuationen hat. Ein Beweis für diese Aussage kann auf diese Weise aber nicht geführt werden. Generell ist zu erwarten, dass leichte Fluktuationen der äußeren mitochondrialen Membran - in alle räumlichen Richtungen - zu den gemessenen Größenfluktuationen beitragen. Die Varianz dieser Fluktuationen addiert sich - aufgrund der statistischen Unabhängigkeit beider Prozesse zu der Varianz, die durch das Rauschen hervorgerufen wird. In diesen Fall scheint dieser zusätzliche Beitrag aber sehr gering zu sein.

Die Ergebnisse zeigen ohne Zweifel, dass das Rauschen in den LSM-Bildern und die damit zusammenhängende Unsicherheit des FP-Algorithmus nicht die Ursache für die im Vergleich zu den Simulationen großen Standardabweichungen der Länge von gemessenen, aktiv transportierten Mitochondrien ist. Zudem kann ausgeschlossen werden, dass das Zeilen-Scan-Verfahren des LSM für die vergleichsweise großen Längenfluktuationen von aktiv transportierten Mitochondrien verantwortlich ist. Messungen und Simulationen von stationären Ecoli-Bakterien (siehe auch Abschnitt 6.2), deren Symmetrieachsen - wie im Fall der Mitochondrien - parallel zur $x$-Achse verlaufen, führten nicht zu den obigen Beobachtungen: Die Unterschiede zwischen den Standardabweichungen der Länge von Wildtyp-Bakterien im Vergleich zu den denen der zugehörigen simulierten Bakterien sind nicht größer als die Unterschiede zwischen den Standardabweichungen des Durchmessers. Die Übereinstimmung von Transportrichtung und Richtung der Größenfluktuationen deutet vielmehr auf einen mit dem aktiven Tranport zusammenhängenden Prozess hin. Diese Aussage wird zweifelsfrei durch die Positionskurven des vorderen und des hinteren Endes sowie der Seitenpunkte des Mitochondriums aus Abbildung 6.14 bestätigt (Abb. 6.16).

\subsubsection{Interpretation der Messergebnisse}

Die LSM-Messungen und die FP-Analysen von aktiv transportierten Mitochondrien haben $\mathrm{zu}$ vielen interessanten Ergebnissen geführt (Abschnitt 6.3.2, Seite 103). In den letzten beiden Abschnitten wurde gezeigt, dass die beobachteten ausgeprägten Phasenverschiebungen zwischen den mittleren Bewegungen von vorderem und hinterem Ende des aktiv transportierten Mitochondriums aus Abbildung 6.14 echte submikroskopische Vorgänge sind. Die statistischen Analysen bestätigen zudem eindrucksvoll, dass die beobachteten Längenveränderungen von Mitochondrien immer zu einem signifikanten Anteil die Folge des aktiven Transportprozesses sind, wohingegen die gemessenen Durchmesserschwankungen im Bereich der durch das Rauschen in den Bildern hervorgerufenen Messunsicherheit liegen.

Es ist sehr wahrscheinlich, dass die beobachteten Phasenverschiebungen und Längenveränderungen eine Folge zeitlich unterschiedlicher Aktivitäten derjenigen Motorproteine sind, die das Mitochondrium transportieren. Beginnt z.B. ein am hinteren Ende des Mitochondriums gebundenes Kinesin-Motorprotein die mitochondriale Membran Schritt für Schritt entlang eines Mikrotubulus in anterograder Richtung zu bewegen (Kinesin be- 
wegt sich in $8 \mathrm{~nm}$-Schritten zum schnell wachsenden „plus-Ende“ von Mikrotubuli [115]), während am vorderen Ende keine Aktivität zu verzeichnen ist, so wird das Mitochondrium entsprechend dem zurückgelegten Weg gestaucht. Die ursprüngliche Länge des Mitochondriums wird wieder hergestellt, sobald die Motoren am vorderen Ende der Bewegung der hinteren Motoren folgen. Dass das vordere Ende durch Motoren weiterbewegt wird und nicht durch elastische Kräfte - hervorgerufen durch eine Stauchung des Mitochondriums -, wird durch die Beobachtung unterstützt, dass die Geschwindigkeiten, mit der sich das hintere und das vordere Ende bewegen, im Mittel gleich sind. Zudem ist es aufgrund der dichten Packung des Zytoskeletts innerhalb der Dendriten - bestehend u.a. aus Mikrotubuli, Aktinfilamenten und assoziierten Proteinen - unwahrscheinlich, dass sich eine 50 bis $100 \mathrm{~nm}$-Verkürzung oder -Verlängerung eines Mitochondriums mit einer Gesamtlänge von 1 bis $4 \mu \mathrm{m}$ auf das entgegengesetzte Ende elastisch auswirkt. Die Längenveränderungen deuten vielmehr darauf hin, dass die Motorproteine stellenweise nicht synchron arbeiten. Bis jetzt gibt es keine Daten darüber, wieviele Motorproteine ein Mitochondrium transportieren, noch darüber, wie deren Koordination erfolgt.

Die Messungen haben zudem gezeigt, dass sich Mitochondrien sowohl auf mikroskopischer als auch auf submikroskopischer Skala abschnittsweise mit verschiedenen mittleren Geschwindigkeiten linear bewegen (Abb. 6.15 C) und zudem „saltatorische“, durch kurze Pausen unterbrochene Bewegungen aufweisen. Dies kann auf einen unterschiedlichen Grad der Koordination der Motoren in den Teilabschnitten hindeuten oder auf lokal variierende ATP-Konzentrationen. Denn die ATP-Konzentration bestimmt die enzymatische Aktivität der Motorproteine und damit die Geschwindigkeit des Transports [116]. Es ist auch denkbar, dass kurze Pausen durch das Umleiten eines Mitochondriums vom Ende eines Mikrotubuls zum Anfang des nächsten enstehen können, z.B. über den Transport entlang von Aktinfilamente durch Myosin-Motorproteine [5].

Die Experimente haben außerdem zu der interessanten Beobachtung geführt, dass das vordere oder das hintere Ende eines Mitochondriums die Bewegung sowohl in anterograder als auch retrograder Richtung „anführen" kann (siehe z.B. Abb. 6.16 B). Die Art der Bewegung erinnert an die eines Wurms. Ein entsprechendes Modell wurde kürzlich zur Beschreibung des Laufmechanismus' von Kinesin selbst vorgesschlagen [117]: In diesem sogenannten „,inchworm“-Laufmechanismus bewegt sich ein Kinesin-Protein mit seinen beiden „Motorköpfen“ entlang eines Mikrotubulus', indem der vordere, führende Kopf einen Schritt vorwärts macht und der hintere diesem Schritt folgt. In diesem Laufmechanismus behält der vordere Kopf immer die führende Position bei - im Gegensatz zum weit verbreiteten „hand-over-hand“-Modell, bei dem beide Köpfe (analog zum Gang eines Menschen) abwechselnd die führende Rolle übernehmen [118-121].

Eine bedeutende Frage im Feld der Motorproteinforschung ist, wie die gegenläufigen Motorproteine Kinesin und zytoplasmatisches Dynein reguliert werden und ob ein „Tauziehen" zwischen den Motoren möglich ist. Die aktuellen Untersuchungen zeigen, dass die Aktivität beider Motorsorten vom Protein Dynaktin abhängen [18, 20,122,123]. Es wird vermutet, dass eine Motorsorte „ausgeschaltet“ wird, bevor die andere mit der Aktivität beginnt [18]. Ob dem so ist, kann aufgrund der gegenwärtigen Datenlage nicht beurteilt 
werden. Die vorliegenden Messungen haben gezeigt, dass die FPA von LSM-Bildern aktiv transportierter Mitochondrien wertvolle Informationen über die Aktivität beider Motorsorten liefern kann: Die Beobachtung, dass sich das vordere und das hintere Ende eines Mitochondriums mitunter gleichzeitig in entgegengesetzte Richtungen bewegen (Abb. 6.21 B), könnte ein Hinweis darauf sein, dass beide Motorsorten - zumindest für kurze Zeit gleichzeitig arbeiten können. Dies wäre somit eine weitere mögliche Ursache für die detektierten Längenänderungen.

Die Messergebnisse bestätigen eindrucksvoll, welches Potenzial in vivo Experimente von aktiv transportierten Mitochondrien haben, wenn sie mit den hier entwickelten Algorithmen ausgewertet werden. Dadurch stehen zahlreiche Möglichkeiten offen, um intrazelluläre Transportprozesse von Organellen zu analysieren. 


\section{Kapitel 7}

\section{Zusammenfassung und Ausblick}

Im Rahmen der vorliegenden Arbeit wurde - aufbauend auf einer FCS-Apparatur - ein hochsensitives computergesteuertes Laserrastermikroskop (LSM) konstruiert sowie LSMbasierte Methoden und FCS-Algorithmen entwickelt, die präzise Messungen von Moleküldynamiken innerhalb kleiner zellulärer Kompartimente ermöglichen. Dadurch konnte erstmalig die Diffusion eines Dextrans von der Größe eines kleinen Proteins in Dendriten von Neuronen charakterisiert werden. Zudem wurden Algorithmen entwickelt, mit denen Größenveränderungen und Bewegungen von mikroskopischen Objekten in LSMBildsequenzen mit einer Genauigkeit bis weit unter der Auflösungsgrenze des Mikroskops analysiert werden können. Computersimulationen ermöglichten dabei, die Genauigkeit der Algorithmen in Abhängigkeit der Objektgröße und des Signal-Rausch-Verhältnisses (SNR) in den Fluoreszenzbildern quantitativ zu vergleichen. Diese Algorithmen dienten als Grundlage für in vitro Lokalisationsmessungen von fluoreszierenden Escherichia coli Bakterien sowie für in vivo Untersuchungen des submikroskopischen dendritischen Transports von Mitochondrien in kultivierten Neuronen.

Die dafür entwickelte LSM- und FCS-Apparatur (FCLSM) vereint die Vorteile beider Methoden: So können etwa Diffusionskonstanten, Konzentrationen und Bindungskonstanten fluoreszierender Moleküle an beliebigen Stellen innerhalb von lebenden Zellen gemessen und im Anschluss LSM-Messungen durchgeführt werden, um dadurch Informationen über zelluläre Strukturen und den für die Moleküle zur Verfügung stehenden Diffusionsraum zu erhalten. Durch die Kombination beider optischer Methoden in einem Gerät ist es möglich, in schneller zeitlicher Abfolge nicht invasive FCS- und LSM-Messungen an einer Zellprobe durchzuführen.

Erfolgen FCS-Experimente in kleinen zellulären Kompartimenten, deren Ausdehnung in derselben Größenordnung liegt wie die des konfokalen Detektionsvolumens, so muss die Plasmamembran als Diffusionsbarriere mit in die Analysen einbezogen werden. Im Rahmen dieser Arbeit wurde ein FCS-Modell hergeleitet, das eine räumlich begrenzte Diffusion von Molekülen berücksichtigt. Um die Anpassungsparameter des Modells kontrollieren zu könnnen, sind weitere - über die FCS-Daten hinausgehende - Informationen über den 
für die Moleküle zur Verfügung stehenden Diffusionsraum erforderlich. Dazu wurde eine LSM-basierte Methode entwickelt, mit der Form und Ausdehnung eines zellulären Kompartimentes auf einer submikroskopischen Skala bestimmt werden können. FCS- und LSMMessungen an mit Farbstoff gefüllten Dendriten kultivierter Neurone zeigen die exzellente Übereinstimmung der Ergebnisparameter beider Methoden. Mit diesen Algorithmen und dem FCS-Modell ist es nunmehr möglich, Moleküldynamiken in kleinen, durch Diffusionsbarrieren begrenzten zellulären Kompartimenten quantitativ zu analysieren.

Neben der Entwicklung des experimentellen Aufbaus und der LSM- und FCSAlgorithmen lag ein weiterer Schwerpunkt in der Anwendung der FCS in Nervenzellen, insbesondere bei der Untersuchung molekularer Prozesse in olfaktorischen Neuronen. Die entwickelten Algorithmen wurden benutzt, um die Mobilität eines $10 \mathrm{kDa}$ Tetramethylrhodamin (TMR)-Dextrans innerhalb von Somata und Dendriten kultivierter Mitralzellen aus dem Bulbus olfactorius von Xenopus laevis Kaulquappen zu analysieren. Im Mittelpunkt stand hierbei die Frage, ob sich die Mobilität des TMR-Dextrans innerhalb der Somata und der Dendriten von Neuronen unterscheidet und inwieweit sie von der normalen Brownschen Diffusion in wässriger Lösung abweicht. Die Untersuchungen haben gezeigt, dass die Diffusionskonstante von TMR-Dextran innerhalb von Somata nur 1.2 bis 2.6fach kleiner ist als in wässriger Lösung. Die Messungen spiegeln somit eine relativ ungehinderte Diffusion innerhalb der Zellkörper von Mitralzellen wider. FCS-Messungen in Dendriten führten dagegen zu einem unerwarteten, wenn auch a postriori sehr plausiblen Ergebnis, nähmlich dass die Diffusion von TMR-Dextran innerhalb von Dendriten nicht allein durch räumlich begrenzte Diffusion beschrieben werden kann, sondern dass sie als hochgradig anisotrop angesehen werden muss. Die Diffusion entlang der Dendritenachse stellte sich als 10 bis 100fach schneller heraus als die Diffusion quer zur Dendritenrichtung - ein Ergebnis, das für die Orientierung von Signalkaskaden in Dendriten bedeutsam sein dürfte. Ursache für die Anisotropie sind sehr wahrscheinlich Mikrotubuli, die parallel zur Fortpflanzungsrichtung der Dendriten verlaufen.

Ein weiterer Schwerpunkt dieser Arbeit lag auf der Entwicklung einer optischen Methode, mit der Organellen in vivo hochaufgelöst verfolgt und gleichzeitig Form- und Größenveränderungen der Organellen detektiert werden können. Entsprechende Techniken standen bisher nicht zur Verfügung. Die Anwendung solcher „Finite Particle Tracking“ (FPT)Methoden ist von großer Bedeutung, besonders im Forschungsbereich der molekularen Motorproteine und der intrazellulären Transportprozesse. Aufbauend auf beugungsbegrenzten LSM-Bildern farbstoffmarkierter Ecoli-Bakterien und dendritischer Mitochondrien, wurden zwei Algorithmen entwickelt, mit denen Bewegung, Orientierung, Größe und Form von mikroskopischen Objekten mit Genauigkeiten bis zu wenigen Nanometern analysiert werden können. Diese Algorithmen basieren sowohl auf der direkten Analyse von LSMBildern von Organellen mit theoretischen Modellfunktionen („Faltungsproduktanalyse“) als auch auf der Auto- und Kreuzkorrelationsanalyse der LSM-Bilder („Korrelationsanalyse"). Mit Hilfe von Computersimulationen konnten die Genauigkeiten der Algorithmen in Abhängigkeit des SNR und der Objektgröße quantitativ verglichen werden. Während die Faltungsproduktanalyse bei großen Objekten $(d>2.5 \lambda)$ die genaueren Re- 
sultate liefert, ist die Korrelationsanalyse bei kleinen Objekten vorzuziehen. Bei der Implementierbarkeit und Rechenzeit besticht hingegen die Faltungsproduktanalyse.

Mit diesen Techniken konnte erstmalig der submikroskopische dendritische Transport von Mitochondrien untersucht werden. Die Messungen haben zu einem interessanten, bisher unbekannten Ergebnis geführt, nämlich dass sich Mitochondrien teilweise wie "Würmer" fortbewegen: Während die Bewegung mit dem hinteren Ende der Organellen beginnt, folgt das vordere Ende der gleichen Bewegung erst mit einer zeitlichen Verzögerung von bis zu $200 \mathrm{~ms}$ und umgekehrt. Die beobachteten entgegengesetzt gerichteten simultanen Bewegungen des vorderen und des hinteren Endes von Mitochondrien könnten zudem darauf hinweisen, dass die beiden gegenläufigen Motorproteine Kinesin und zytoplasmatisches Dynein gleichzeitig aktiv sein können - eine Möglichkeit, die zur Zeit intensiv diskutiert wird. Mit Hilfe von Experimenten, Simulationen und statistischen Analysen konnte zudem gezeigt werden, dass die Länge von Mitochondrien als Folge des motorgestützten Transports signifikant schwankt, während die detektierten Durchmesserveränderungen im Bereich der durch das Rauschen in den Bildern hervorgerufenen Messungenauigkeit liegen.

Die entwickelten Algorithmen ermöglichen einen einzigartigen Zugang zu molekularen Prozessen in lebenden Zellen. Die FCS- und FPT-Experimente an olfaktorischen Neuronen zeigen, dass die Anwendung der Techniken zu neuartigen Einblicken in die Mobilität von Molekülen und Organellen innerhalb subzellulärer Kompartimente führen kann. So können die hier entwickelten Algorithmen und Techniken in Zukunft einen bedeutenden Beitrag zur neurowissenschaftlichen Forschung und zellulären Biophysik leisten. 


\section{Anhang A}

\section{Schaltungsbeschreibung der PCH}

Die PCH ist das Bindeglied zwischen dem Photodetektor und dem LSM-PC (Abschnitt 4.4.2). Sie wandelt die von der APD generierten Spannungspulse in ein $20 \mathrm{MHz}$ „Bitstream" (TTL-Signal) um und sendet ihn nach einer Seriell-Parallel-Wandlung in Form von 32-Bit-Worten an den im LSM-PC integrierten PCI-Controller (Abschnitt 4.5). Im folgenden wird die Funktionsweise der PCH (Seite 29, Abb. 4.4) detailiert dargestellt.

Die PCH verfügt über sechs TTL-Anschlüsse:

- Photodiodensignaleingang (J1)

- Photocountsignalausgang für den FCS-PC (J2)

- Schreibsignal für den PCI-Controller (WRFIFO\#) (J3)

- Eingang zum externen Stoppen der PCH (J4)

- Eingang zum externen Starten der PCH (J5)

- 100 kHz Taktausgang zur Synchronisierung der DSP-Karte (J6)

Der Photodiodensignaleingang (J1) wird durch die integrierten Schaltkreise IC 13A und IC 12A gebildet. Der Eingang von IC 13A (bzw. das Ende des Photodiodenkabels) ist über einen $50 \Omega$ - Abschlusswiderstand (R1) mit der Masse verbunden, um eine Verzerrung der APD-Pulse durch Leitungsreflexionen zu vermeiden [79]. IC 13A gewährleistet, dass die von der APD generierten $2 \mathrm{~V}$ - Spannungspulse sicher vom nachgeschalteten Schaltkreis IC 12A detektiert werden. Dieser benötigt einen minimalen Eingangsspannungspegel von 3.8V, um einen Spannungspuls zu erkennen. IC 13A erkennt Signale mit einer minimalen Amplitude von 0.9-1.9V. IC 12A ist ein „triggerbarer monostabiler Multivibrator". Durch die externe Beschaltung mit dem RC-Glied R2-C1 wandelt er Eingangspannungspulse mit einer Dauer von weniger als 50 ns (die Spannungspulse der APD haben eine Breite von 9 
ns) in Pulse mit einer Dauer von 50 ns um. Das nachgeschaltete „D-Flip-Flop“ (IC 8A) synchronisiert die eingelesenen Spannungspulse mit der $20 \mathrm{MHz}$ Taktfrequenz der PCH. Auf diese Weise werden die Spannungspulse der APD in einen Bitstream mit einer Taktdauer von 50 ns „eingebettet“. Die Taktfrequenz wird durch einen $20 \mathrm{MHz}$ Quarzoszillator (IC 6) erzeugt. Der Ausgang des D-Flip-Flops ist mit dem Eingang einer 32-Bit Registerbank (IC 1 bis IC 4, 8-Bit Schieberegister) verbunden. Der $20 \mathrm{MHz}$ Bitstream wird seriell in die Registerbank eingelesen. Die Schieberegister verfügen über einen getrennt steuerbaren Eingangs- und Ausgangsspeicherbereich (jeweils acht D-Flip-Flops). Die eingelesenen Bits werden erst dann zum Ausgang durchgeschaltet, wenn 32 Bits eingelesen sind. Die Bits werden im Takt von $1.6 \mu$ s durch eine positive Flanke am RCLK-Eingang der Register (,storage register clock input“) zum Ausgang durchgeschaltet. Das 32-Bit Wort steht dann dem PCI-Controller parallel über ein Flachbandkabel (J1AB) zur Verfügung. Das RCLKSignal ( $5 \mathrm{~V}$ - Spannungspuls mit einer Dauer von $t_{p}=50 \mathrm{~ns}$ und einer Wiederholungsrate von $1.6 \mu \mathrm{s}$ ) sowie das WRFIFO-Signal (invertiertes RCLK-Signal) werden durch zwei 4-Bit Binärzähler (IC 5 und IC 7), zwei D-Flip-Flops (IC 14A und IC 14B) und logischen AND(IC 9A bis IC 9D sowie IC 10A und IC 10B) und NAND-Gliedern (IC 11A bis IC11C) erzeugt. Das Schaltungsdesign erfolgte unter Berücksichtigung der Schalt- und Signallaufzeiten der ICs. Das WRFIFO-Signal (J3) ist mit Hilfe der Schaltkreise IC 17 und IC 18 mit dem $33 \mathrm{MHz}$-Taktsignal (BCLK) des PCI-Controllers synchronisiert. Die beiden ICs befinden sich auf einer kleinen Zusatzplatine $(3 \times 3.5 \mathrm{~cm})$. Um Störungen durch das hochfrequente BCLK-Signal zu vermeiden, ist sie direkt neben dem PCI-Controller montiert. Die Schaltung verhindert, dass die ansteigende Flanke des WRFIFO-Signals innerhalb eines Bereiches von 4 ns vor und 4 ns nach einer ansteigenden Flanke des BCLK-Signals fällt. Diese Maßnahme ist aufgrund eines Chipfehlers im PCI-Controller (Errata D8, AMCC, San Diego, CA, USA) im asynchronen Speicherzugriffsmodus notwendig ${ }^{1}$. Durch die Einbindung des D-Flip-Flops IC 14B und der NAND-Glieder IC 15C und IC 15D ist es möglich, dass RCLK- und WRFIFO-Signal über zwei Signaleingänge freizuschalten (J5) bzw. abzuschalten (J4). Hierdurch kann die Datenaufnahme und Datenübertragung der PCH extern gesteuert werden. Die beiden Eingänge sind mit dem DSP verbunden. Im Ruhezustand liegt an den Steuereingängen J4 und J5 ein 5 V - Pegel. Eine ansteigende Flanke am Eingang J5 gibt das RCLK- und WRFIFO-Signal frei (Startsignal) und ein 0 V-Pegel an J4 schaltet die Signale ab (Stopsignal). Zum Starten und Stoppen der PCH generiert der DSP $0 \mathrm{~V}$-Spannungspulse (ausgehend von einem Ruhepegel von 5V) mit einer Dauer von $\sim 1 \mu \mathrm{s}$. Das Event-Triggersignal für den DSP wird durch die PCH generiert. Hierzu wird der durch 8 geteilte PCH-Takt (IC 5, Pin 12) mit dem Teilerbaustein IC 16 (:25) in ein $100 \mathrm{kHz}$ Signal umgewandelt. Somit löst die PCH im Abstand von $10 \mu$ s ein DSPEvent aus. Der Teilerbaustein (IC 16) sowie die 4-Bit Zähler IC 5 und IC 7 werden vor Beginn des Zählvorgangs der PCH durch das Startsignal an J5 zurückgesetzt. Hierdurch wird gewährleistet, dass die PCH nicht mit beliebigen Zählerständen startet.

\footnotetext{
${ }^{1}$ Der synchrone Scheibzugriff erfolgt im BCLK-Takt von $33 \mathrm{MHz}$, ist somit für diese Anwendung nicht brauchbar.
} 


\section{Abkürzungsverzeichnis}

$\begin{array}{ll}\text { APD } & \text { Avalanchephotodiode } \\ \text { AKF } & \text { Autokorrelationsfunktion } \\ \text { ATP } & \text { Adenosin-5'-Triphosphat } \\ \text { CLSM } & \begin{array}{l}\text { Konfokales Laserrastermikroskop } \\ \text { (confocal laser scanning microscope) }\end{array} \\ \text { DSP } & \text { Digitaler Signalprozessor } \\ \text { Ecoli } & \text { Escherichia coli } \\ \text { FCS } & \text { Fluoreszenzkorrelationsspektroskopie } \\ \text { FPA } & \text { (fluorescence correlation spectroscopy) } \\ \text { IPS } & \text { Faltungsproduktanalyse } \\ \text { KA } & \text { Image-Processing-Software } \\ \text { KKF } & \text { Korrelationsanalyse } \\ \text { LSM } & \text { Kreuzkorrelationsfunktion } \\ \text { PCH } & \text { Laserrastermikroskop (laser scanning microscope) } \\ \text { PSF } & \text { Photon-Counting-Hardware } \\ \text { RNA } & \text { Punktübertragungsfunktion (point spread function) } \\ \text { SPT } & \text { Ribonucleinsäure (ribonucleic acid) } \\ \text { SRV } & \text { single particle tracking } \\ \text { STE } & \text { Signal-Rausch-Verhältnis } \\ \text { TMR } & \text { single transition event } \\ \text { WFM } & \text { Tetramethylrhodamin } \\ & \end{array}$




\section{Literaturverzeichnis}

[1] Elson EL. Fluorescence correlation spectroscopy measures molecular transport in cells. Traffic, 2:789-796, 2001.

[2] Berg JM, Tymoczko JL, und Stryer L. Biochemistry. W. H. Freeman and Company, New York, USA, 2002.

[3] Gennerich A und Schild D. Fluorescence correlation spectroscopy in small cytosolic compartments depends critically on the diffusion model used. Biophys. J., 79:3294$3306,2000$.

[4] Brown SS. Cooperation between microtubule- and actin-based motor proteins. Annu. Rev. Cell Dev. Biol., 15:63-80, 1999.

[5] Hollenbeck PJ. The pattern and mechanism of mitochondrial transport in axons. Frontiers in Bioscience, 1:d91-102, 1996.

[6] Morris RL und Hollenbeck PJ. Axonal transport of mitochondria along microtubules and F-actin in living vertebrate neurons. J. Cell Biol., 131:1315-1326, 1995.

[7] Ligon LA und Oswald S. Role of microtubules and actin filaments in the movement of mitochondria in the axons and dendrites of cultured hippocampal neurons. $J$. Comp. Neurol., 427:351-361, 2000.

[8] Brady ST. Molecular motors in the nervous system. Neuron, 7:521-533, 1991.

[9] Vallee RB und Bloom GS. Mechanisms of fast and slow axonal transport. Annu. Rev. Neurosci., 14:59-92, 1991.

[10] Skoufias DA und Scholey JM. Cytoplasmic microtubule-based motor proteins. Curr. Opin. Cell Biol., 5:95-104, 1993.

[11] Gelles J, Schnapp BJ, und Sheetz MP. Tracking kinesin-driven movements with nanometre-scale precision. Nature, 331:450-453, 1988.

[12] Schnitzer MJ und Block SM. Kinesin hydrolyses one ATP per 8-nm step. Nature, 388:386-390, 1997. 
[13] Coy DL, Wagenbach M, und Howard J. Kinesin takes one 8-nm step for each ATP that it hydrolyzes. J. Biol. Chem., 274:3667-3671, 1999.

[14] Böhm KJ, Stracke R, und Unger E. Speeding up kinesin-driven microtubule gliding in vitro by variation of cofactor composition and physiochemical parameters. Cell Biol. Int., 24:335-341, 2000.

[15] Svoboda K, Mitra PP, und Block SM. Fluctuation analysis of motor protein movement and single enzyme kinetics. Proc. Natl. Acad. Sci. USA, 91:11782-11786, 1994.

[16] Nishiyama M, Muto E, Inoue Y, Yanagida T, und Higuchi H. Substeps within the 8-nm step of the ATPase cycle of single kinesin molecules. Nat. Cell Biol., 3:425-428, 1996.

[17] Hua W, Young EC, Fleming ML, und Gelles J. Coupling of kinesin steps to ATP hydrolysis. Nature, 388:390-393, 1997.

[18] Gross SP, Welte MA, Block SM, und F WE. Coordination of opposite-polarity microtubule motors. J. Cell Biol., 156:715-724, 2002.

[19] Schroer TA. Structure and function of dynactin. Cell Dev. Biol., 7:321-328, 1996.

[20] Deacon SW, Serpinskaya AS, Vaughan PS, Lopez Fanarraga M, Vernos I, Vaughan KT, und Gelfand VI. Dynactin is required for bidirectional organelle transport. J. Cell Biol., 160:297-301, 2003.

[21] Dell KR. Dynactin polices two-way organelle traffic. J. Cell Biol., 160:291-293, 2003.

[22] Steinberg G und Schliwa M. Organelle movements in the wild type and wall-less fz;sg;os-1 mutants of neurospora crassa are mediated by cytoplasmic microtubules. J. Cell Sci., 106:555-564, 1993.

[23] Morris RL und Hollenbeck PJ. The regulation of bidirectional mitochondrial transport is coordinated with axonal outgrowth. J. Cell Sci., 104:917-927, 1993.

[24] Ligon LA und Oswald S. Movement of mitochondria in axons and dendrites of cultured hippocampal neurons. J. Comp. Neurol., 427:340-350, 2000.

[25] Magde D, Elson EL, und Webb WW. Thermodynamic fluctuations in a reacting system - measurement by fluorescence correlation spectroscopy. Phys. Rev. Lett., 29(11):705-708, 1972.

[26] Elson EL und Magde D. Fluorescence correlation spectroscopy. I. Conceptual basis and theory. Biopolymers, 13:1-27, 1974.

[27] Magde D, Elson EL, und Webb WW. Fluorescence correlation spectroscopy. II. An experimental realization. Biopolymers, 13:29-61, 1974. 
[28] Ehrenberg M und Rigler R. Rotational brownian motion and fluorescence intensity fluctuations. Chem. Phys., 4:390-401, 1974.

[29] Ehrenberg M und Rigler R. Fluorescence correlation spectroscopy applied to rotational diffusion of macromolecules. Quat. Rev. Biophys., 9(1):69-81, 1976.

[30] Aragón SR und Pecora R. Fluorescence correlation spectroscopy and brownian rotational diffusion. Biopolymers, 14:119-138, 1975.

[31] Köhler RH, Schwille P, Webb WW, und Hanson MR. Active protein transport through plastid tubules: velocity quantified by fluorescence correlation spectroscopy. J. Cell Sci., 113:3921-3930, 2000.

[32] Koppel DE, Axelrod D, Schlessinger J, Elson EL, und Webb WW. Dynamics of fluorescene marker concentration as a probe of mobility. Biophys. J, 16:1315-1329, 1976.

[33] Magde D, Webb WW, und Elson EL. Fluorescence correlation spectroscopy. III. Uniform translation and laminar flow. Biopolemers, 17:361-376, 1978.

[34] Asai H. Proposal of a simple method of fluorescence correlation spectroscopy for measuring the direction and magnitude of a flow of fluorophores. Jpn. J. Appl. Phys., 19(11):2279-2282, 1980.

[35] Widengren J, Mets, und Rigler R. Fluorescence correlation spectroscopy of triplet states in solution: a theoretical and experimental study. J. Phys. Chem., 99(36):13368-13379, 1995.

[36] Malvezzi-Campeggi F, Jahnz M, Heinze KG, Dittrich P, und Schwille P. Lightinduced flickering of DsRed provides evidence for distinct and interconvertible fluorescent states. Biophys. J., 81:1776-1785, 2001.

[37] Krichevsky O und Bonnet G. Fluorescence correlation spectroscopy: the technique and its application. Rep. Prog. Phys., 65:251-297, 2002.

[38] Hess ST, Huang S, Heikal AA, und Webb WW. Biological and chemical application of fluorescence correlation spectroscopy: a review. Biochemistry, 41(3):697-705, 2002.

[39] Schwille P. Fluorescence correlation spectroscopy and its potential for intracellular applications. Cell Biochem. Biophys., 34:383-408, 2001.

[40] Rigler R und Elson ES. Fluorescence Correlation Spectroscopy. Springer-Verlag, Berlin, 2000.

[41] Rigler $\mathrm{R}$ und Widengren J. Ultrasensitive detection of single molecules by fluorescence correlation spectroscopy. In Klinge B und Owmar C (Hg.), BioScience, 180-183. 1990. 
[42] Rigler R, Mets, Widengren J, und Kask P. Fluorescence correlation spectroscopy with high count rate and low background: analysis of translational diffusion. Eur. Biophys. J., 22:169-175, 1993.

[43] Eigen M und Rigler R. Sorting single molecules: application to diagnostics and evolutionary biotechnology. Proc. Natl. Acad. Sci. USA, 91:5740-5747, 1994.

[44] v Smoluchowski M. Zusammenfassende Bearbeitungen: Drei Vorträge über Diffusion, Brownsche Molekularbewegung und Koagulation von Kolloidteilchen. Physik. Zeitschr., 17:557-571, 585-599, 1916.

[45] v Smoluchowski M. Notiz über die Berechnung der Brownschen Molekularbewegung bei der Ehrenhaft-Millikanschen Versuchsanordnung. Physik. Zeitschr., 16:318-321, 1915.

[46] Einstein A. Zur Theorie der Brownschen Bewegung. Ann. d. Phys., 19:371-381, 1906.

[47] Einstein A. Über die von der molekularkinetischen Theorie der Wärme geforderte Bewegung von in ruhenden Flüssigkeiten suspendierten Teilchen. Ann. d. Phys., 17:549-560, 1905.

[48] v Smoluchowski M. Molekular-kinetische Theorie der Opaleszenz von Gasen im kritischen Zustande, sowie einiger verwandter Erscheinungen. Ann. d. Phys., 10:205226, 1908.

[49] Papoulis A. Probability, Random Variables, and Stochastic Processes. McGraw-Hill, New York, 1991.

[50] Qian H und Elson EL. Analysis of confocal laser-microscope optics for 3-D fluorescence correlation spectroscopy. Appl. Opt., 30(10):1185-1195, 1991.

[51] Aragón SR und Pecora R. Fluorescence correlation spectroscopy as a probe of molecular dynamics. J. Chem. Phys., 64(4):1791-1803, 1976.

[52] Korobov VE und Chibisov AK. Russ. Chem. Rev., 52:27, 1983.

[53] Widengren J, Rigler R, und Mets. Triplet-state monitoring by fluorescence correlation spectroscopy. J. Fluoresc., 4(3):255-258, 1994.

[54] Koppel DE. Statistical accuracy in fluorescence correlation spectroscopy. Phys. Rev. A, 10(6):1938-1945, 1974.

[55] Thompson NL. Fluorescence Correlation Spectroscopy. In: Topics in Fluorescence Spectroscopy, J. R. Lakowicz, Herausgeber. Band 1, Seite 337-378, Plenum Press, New York, 1991. 
[56] Minsky M. Memoir on inventing the confocal scanning microscope. Scanning, 10:128$138,1988$.

[57] Sheppard CJR und Choudhury A. Image formation in the scanning microscope. Opt. Acta, 24:1051-1073, 1977.

[58] Wilson T und Sheppard CJR. Theory and Practice of Scanning Optical Microscopy. Academic Press, London, 1984.

[59] Kogelnik H und Li T. Laser beams and resonators. Appl. Optics, 5(10):1550-1567, 1966.

[60] Demtröder W. Laser Spectroscopy: Basic Concepts and Instrumentation. SpringerVerlag, Berlin, 1998.

[61] Self SA. Focusing of sperical gaussian beams. Appl. Opt., 22(5):658-661, 1983.

[62] Hecht E. Optics. Addison-Wesley, 2002.

[63] Bischofberger J. Laserrastermikroskopische Calcium- und Patch-Clamp-Messungen zur somato-dendritischen Signalverarbeitung im Bulbus olfactorius. Dissertation, Georg-August-Universität zu Göttingen, 1995.

[64] Bischofberger J, Geiling H, Engel J, Schultens HA, und Schild D. A cultured netwerk of olfactory bulb neurons of Xenopus laevis tadpoles: calcium imaging and spontaneous activity. In: Chemical Signals in Vertebrates, R. Apfelbach, D. MüllerSchwarze, K. Reutter, und E. Weiler, Herausgeber. Band VII, Seite 133-139. Elsevier, Oxford, 1995.

[65] Hamill OP, Marty A, Neher E, Sakmann B, und Sigworth FJ. Improved patch-clamp techniques for high-resolution current recording from cells and cell-free membrane patches. Pflügers Arch, 391:85-100, 1981.

[66] Soper SA. The photophysical constants of several fluorescent dyes pertaining to ultrasensitive fluorescence spectroscopy. Photochem. Photobiol., 57(6):972-977, 1993.

[67] Haugland RP. Handbook of fluorescent probes and research products. Molecular Probes, Leiden, Niederlande, 1998.

[68] Ronot X, Benel L, Adolphe M, und Mounolou JC. Mitochondrial analysis in living cells: the use of rhodamine 123 and flow cytometry. Biol. Cell, 57:1-8, 1986.

[69] Chen LB. Fluorescent labeling of mitochondria. Methods Cell Biol., 29:103-123, 1989.

[70] Whitaker JE, Moore PL, Haugland RP, und Haugland RP. Dihydrotetramethylrosamine: a long wavelenght, fluorogenic peroxidase substrate evaluated in vitro and in a model phagocyte. Biochem. Biophys. Res. Commun., 175:387-393, 1991. 
[71] Press WH, Flannery BP, Teukolsky SA, und Vetterling WT. Numerical recipes. Cambridge University Press, New York, 1997.

[72] Numberger M und Draguhn A. Patch-Clamp-Technik. Spektrum-Verlag, Heidelberg, 1996.

[73] Stelzer EHK. The intermediate optical system of laser-scanning confocal microscopes. In: Handbook of biological confocal microscopy, J. B. Pawley, Herausgeber. Seite 139154, Plenum Press, New York, 1995.

[74] Melle S und MacGregor A. How to choose avalanche photodiodes. Laser Focus World, 10:145-156, 1995.

[75] Li LQ und Davis LM. Single photon avalanche diode for single molecule detection. Rev. Sci. Instrum., 64(6):1524-1529, 1993.

[76] Yu DF und Fessler JA. Mean and variance of single photon counting with deadtime. Phys. Med. Biol., 45:2043-2056, 2000.

[77] Spinelli A, Davis LM, und Dautet H. Actively quenched single-photon avalanche diode for high repetion rate time-gated photon counting. Rev. Sci. Instrum., 67(1):5561, 1996.

[78] Dautet H, Deschamps P, Dion B, MacGregor AD, MacSween D, McIntyre RJ, Trottier C, und Webb PP. Photon counting techniques with silicon avalanche photodiodes. Appl. Opt., 32(21):3894-3900, 1993.

[79] EG\&G. SPCM-AQ-141, Datenblatt. EG\&G Optoelectronics, Dumberry, Kanada, 1998.

[80] Eid JS, Müller JD, und Gratton E. Data acquisition card for fluctuation correlation spectroscopy allowing full access to the detected photon sequence. Rev. Sci. Instr., 71:361-368, 2000.

[81] ADbasic. Das Echtzeit-Entwicklungstool für ADwin-Systeme. Jäger Computergesteuerte Messtechnik GmbH, Lorsch, 1999.

[82] ALV. ALV-5000 Multiple tau digital correlator, Handbuch. ALV-Laser Vertriebsgesellschaft, Langen, Deutschland, 1993.

[83] Wohland T, Rigler R, und Vogel H. The standard deviation in fluorescence correlation spectroscopy. Biophys. J., 80:2987-2999, 2001.

[84] Berland KM, So PTC, und Gratton E. Two-photon fluorescence correlation spectroscopy: method and application to the intracellular environment. Biophys. J., 68:694-701, 1995. 
[85] Politz JC, Browne ES, Wolf DE, und Pederson T. Intranuclear diffusion and hybridization state of oligonucleotides measured by fluorescence correlation spectroscopy in living cells. Proc. Natl. Acad. Sci. USA, 95:6043-6048, 1998.

[86] Brock R, Hink MA, und Jovin TM. Fluorescence correlation microscopy of cells in the presence of autofluorescence. Biophys. J., 75:2547-2557, 1998.

[87] Schwille P, Haupts U, Maiti S, und Webb WW. Molecular dynamics in living cells observed by fluorescence correlation spectroscopy with one- and two-photon excitation. Biophys. J., 77:2251-2265, 1999.

[88] Wachsmuth M, Waldeck W, und Langowski J. Anomalous diffusion of fluorescent probes inside living cell nuclei investigated by spatially-resolved fluorescence correlation spectroscopy. J. Mol. Biol., 298:677-689, 2000.

[89] Gennerich A und Schild D. Anisotropic diffusion in mitral cell dendrites revealed by fluorescence correlation spectroscopy. Biophys. J., 83:510-522, 2002.

[90] Hoebeke J, Van Nijen G, und De Brabander M. Interaction of onocodazole (R 17934), a new anti-tumoral drug, with rat brain tubulin. Biochem. Biophys. Res. Commu., 69:319-324, 1976.

[91] Andreu JM und Timasheff SN. Tubulin bound to colchicine forms polymers different from microtubules. Proc. Natl. Acad. Sci. (USA), 79:6753-6756, 1982.

[92] Saxton MJ und Jacobson K. Single-particle tracking: applications to membrane dynamics. Annu. Rev. Biophys. Biomol. Struct., 26:373-399, 1997.

[93] Kubitscheck U, Kückmann O, Kues T, und Peters R. Imaging and tracking of single GFP molecules in solution. Biophys. J., 78:2170-2179, 2000.

[94] Kues T, Peters P, und Kubitscheck U. Visualization and tracking of single protein molecules in the cell nucleus. Biophys. J., 80:2954-2967, 2001.

[95] Kues T, Dickmanns A, Lührmann R, Peters P, und Kubitscheck U. High intranuclear mobility and dynamic clustering of the splicing factor U1 snRNP observed by single particle tracking. Proc. Natl. Acad. Sci. USA, 98:12021-12026, 2001.

[96] Goulian M und Simon SM. Tracking single proteins within cells. Biophys. J., 79:21882198, 2000.

[97] Work SS und Warshaw DM. Computer-assisted tracking of actin filament motility. Anal. Biochem., 202:275-285, 1992.

[98] Ghosh RN und Webb WW. Automated detection and tracking of individual and clustered cell surface low density lipoprotein receptor molecules. Biophys. J., 66:13011318, 1994. 
[99] Lee GM, Ishihara A, und Jacobson KA. Direct observation of brownian motion of lipids in a membrane. Proc. Natl. Acad. Sci. USA, 88:6274-6278, 1991.

[100] Anderson CM, Georgiou GN, Morrison IEG, Stevenson GVW, und Cherry RJ. Tracking of cell surface receptors by fluorescence digital imaging microscopy using a charge-coupled device camera. J. Cell Sci., 101:415-425, 1992.

[101] Schütz GJ, Schindler H, und Schmidt T. Single-molecule microscopy an model membranes reveals anomalous diffusion. Biophys. J., 73:1073-1080, 1997.

[102] Kusumi A, Sako Y, und Yamamoto M. Confined lateral diffusion of membrane receptors as studied by single particle tracking (nanovid microscopy). effect of calciuminduced differentiation in cultured epithelial cells. Biophys. J., 65:2021-2040, 1993.

[103] Cheezum MK, Walker WF, und Guilford WH. Quantitative comparison of algorithms for tracking single fluorescent particles. Biophys. J., 81:2378-2388, 2001.

[104] Bobroff N. Position measurement with a resolution and noise-limited instrument. Rev. Sci. Instrum., 57:1152-1157, 1986.

[105] Thompson RE, Larson SR, und Webb WW. Precise nanometer localization analysis for individual fluorescent probes. Biophys. J., 82:2775-2783, 2002.

[106] Kues T. Visualisierung einzelner Proteinmoleküle und Analyse ihrer Trajektorien in intakten Zellkernen mittels Weitfeld-Fluoreszenzmikroskopie. Dissertation, Universität Bremen, 2001.

[107] Schnapp BJ, Gelles J, und Sheetz MP. Nanometer-scale measurements using video light microscopy. Cell Motil. Cytoskel., 10:47-53, 1988.

[108] Srivastava M und Petersen NO. Image cross-correlation spectroscopy: a new experimental biophysical approach to measurement of slow diffusion of fluorescent molecules. Methods Cell Sci., 18:47-54, 1996.

[109] Petersen NO, Höddelius PL, Wiseman PW, Seger O, und Magnusson KE. Quantitation of membrane receptor distributions by image correlation spectroscopy: concept and application. Biophys. J., 65:1135-1146, 1993.

[110] Walker WF und Trahey GE. A fundamental limit on the performance of correlation based phase correction and flow estimation techniques. IEEE Trans. Ultrason. Ferroelec. Freq. Cont., 41:644-654, 1994.

[111] Miller RJ. Neuronal $\mathrm{Ca}^{2+}$ : getting it up and keeping it up. Trends Neurosci., 15:317319, 1992.

[112] Wong-Riley MTT. Cytochrome oxidase: an endogenous metabolic marker for neuronal activity. Trends Neurosci., 12:94-101, 1989. 
[113] Honerkamp J. Stochastische Dynamische Systeme. VCH Verlagsgesellschaft mbH, Weinheim, 1990.

[114] Fichtenholz GM. Differential- und Integralrechnung III. VEB Deutscher Verlag der Wissenschaften, Berlin, 1964.

[115] Svoboda K, Schmidt CF, Schnapp BJ, und Block SM. Direct observation of kinesin stepping by optical trapping interferometry. Nature, 365:721-727, 1993.

[116] Svoboda K und Block SM. Force and velocity measured for single kinesin molecules. Cell, 77:773-784, 1994.

[117] Hua W, Chung J, und Gelles J. Distinguishing inchworm and hand-over-hand processive kinesin movement by neck rotation measurements. Science, 295:844-848, 2002.

[118] Cross RA. On the hand-over-hand footsteps of kinesin heads. J. Muscle Res. Cell Motil., 16:91-94, 1995.

[119] Howard J. The movement of kinesin along microtubules. Annun. Rev. Physiol., 58:703-729, 1996.

[120] Hancock WO und Howard J. Processivity of the motor protein kinesin requires two heads. J. Cell Biol., 140:1395-1405, 1998.

[121] Vale RD und Milligan RA. The way things move: looking under the hood of molecular motor proteins. Science, 288:88-95, 2000.

[122] Gross SP, Welte MA, Block SM, und F WE. Dynein-mediated cargo transport in vivo: a switch controls travel distance. J. Cell Biol., 148:945-955, 2000.

[123] Welte MA, Gross SP, Postner M, Block SM, und F WE. Developmental regulation of vesicle transport in drosphila embryos: forces and kinetics. Cell, 92:547-557, 1998. 


\title{
Liste der Veröffentlichungen
}

\author{
Orginalarbeiten
}

- Czesnik D, Rössler W, Kirchner F, Gennerich A, und Schild D. Neuronal representation of odourants in the olfactory bulb of Xenopus laevis tadpoles. Eur. J. Neurosci., 17:113-118, 2003.

- Gennerich A und Schild D. Anisotropic diffusion in mitral cell dendrites revealed by fluorescence correlation spectroscopy. Biophys. J., 83:510-522, 2002.

- Gennerich A und Schild D. Fluorescence correlation spectroscopy in small cytosolic compartments depends critically on the diffusion model used. Biophys. J., 79:32943306, 2000 .

- Peters F, Gennerich A, Czesnik D, und Schild D. Low frequency voltage clamp: recording of voltage transients at constant average command voltage. J. Neurosci. Meth., 99:129-135, 2000.

- Schild D, Gennerich A, und Schultens HA. Microcontrollers as inexpensive pulse generators and parallel processors in electrophysiological experiments. Med. Biol. Eng. Comput., 34:305-307, 1996.

\section{Tagungsbeiträge}

- Czesnik D, Rössler W, Kirchner F, Gennerich A, und Schild D. Neuronal representation of odourants in the olfactory bulb of Xenopus laevis tadpoles. Proceedings of the 5th Meeting of the German Neuroscience Society 2003, 29th Göttingen Neurobiology Conference, Göttingen, 2003.

- Gennerich A und Schild D. Sub-microscopic mitochondria motility in mitral cell dendrites studied by single particle tracking. Proceedings of the 5th Meeting of the German Neuroscience Society 2003, 29th Göttingen Neurobiology Conference, Göttingen, 2003.

- Gennerich A und Schild D. Sizing up sub-microscopic organelle dynamics in vivo by image cross-correlation spectroscopy. Biophys. J., 84:2164 Part 2, 2003. 
- Gennerich A und Schild D. Fluorescence correlation spectroscopy in small cytosolic compartments depends critically on the diffusion model used. Proceedings of the 4th Meeting of the German Neuroscience Society 2001, 28th Göttingen Neurobiology Conference, Göttingen, 2001.

- Gennerich A und Schild D. Anomalous diffusion in dendrites of cultured neurons revealed by fluorescence correlation spectroscopy. Biophys. J., 80:655.29 Part 2, 2001. 


\section{Danksagung}

Professor Dr. Werner Lauterborn danke ich für die Betreuung meiner Arbeit seitens der Physikalischen Fakultät der Georg-August-Universität Göttingen.

Mein besonderer Dank gilt Professor Dr. Dr. Detlev Schild, dem Leiter der Abteilung Molekulare Neurophysiologie des Physiologischen Instituts der Universität Göttingen. Seine wissenschaftliche Betreuung und Zusammenarbeit haben meine Arbeit und meinen persönlichen Werdegang maßgeblich geprägt.

Dank an die „gute Fee“ Gudrun Federkeil und an Joško Kuduz für die mühsame „Produktion" der Zellkulturen.

Dr. Friedrich Kirchner danke ich für die Unterstützung beim „Kampf“ mit der PCIKarte.

Hans-Jürgen Werner möchte ich für die Herstellung der exzellenten Platinen, Siegfried Klugmann für die unermüdliche Suche nach „unkäuflichen“ ICs danken.

Dr. Bernd Beyerstedt danke für seine Freundschaft, die unzähligen Mensagänge und die Hilfe bei grundlegenden und „semantischen“ Problemen der Mathematik. Ist das noch eine „Nullmenge"?

Meinem Kommilitonen Oliver Natt danke ich für die Unterstützung beim Umgang mit der Programmiersprache IDL und den LaTeX-Macros.

Meinem Kommilitonen Christian Wald sei herzlich gedankt für das entgegengebrachte Interesse an meiner Arbeit und den Nachhilfeunterricht in Sachen Statistik. Ist es noch wahrscheinlich?

Hergen Schultze und Bernhard Wolfrum möchte ich für ihre Freundschaft, die mentale Unterstützung und Ihre stets vorhandene Diskussionsbereitschaft danken. 
Meinem langjährigen Labormitstreiter und Freund Christoph Eberius danke ich für das stete Erinnern an die wesentlichen Dinge des Lebens und daran, wie wichtig unversehrte Augen sind: Achtung Laserlicht.

Dr. Markus Missler danke ich für die Bereitstellung der Escherichia coli Bakterien.

Den Graduiertenkollegsmitgliedern Edward Lemke, Martin Wienisch, Dinah Loerke und Alexey Kochubey möchte ich für die vielen PDF-Dateien danken. Hast Du Zugang?

Meinen Laborfreunden und Kollegen Dr. Ivan Manzini, Dirk Czesnik, Dr. Andre Zeug, Bei-Jung Lin, Dr. Leonid Nezlin, Stephan Heermann, Daniel Governatori, Christoph Brase, Ilonka Bartoszek, Susanne Meyer und Stefanie Ludwig danke ich für das angenehme Arbeitsklima.

Besonderer Dank gilt Prof. Dr. Wolfgang Rössler, Dr. Fred Wouters und Dr. Gertrude Bunt für ihre Freundschaft, ihr stetes Intresse an meiner Arbeit und ihre Unterstützung besonders wenn „Mann in Not" war.

Dr. Dieter Klopfenstein danke ich für die „Wegbereitung “ an die UCSF.

Meinem Freund und „Mentor“ Dr. Heiner Wedemeyer danke ich für die „eingelaufenen" Organisten-, WG-, Chorleiter- und Laborschuhe. Wenn sie auch am Anfang etwas groß waren, passen sie jetzt schon besser. Was werden „unsere Damen“ nur ohne uns machen?

Vor allem danke ich meinen Eltern und meinem Bruder Carsten, durch deren vielfältige Unterstützung meine wissenschaftliche Laufbahn erst möglich geworden ist.

Nicht zuletzt danke ich meiner Anja für ihre unermüdliche Unterstützung und die geduldige Beantwortung grammatikalischer Fragen, ihre Nachsicht an den vielen arbeitsreichen Wochenenden und für das Leben außerhalb der Uni generell. „... bis zum Mond und wieder zurück." 


\section{Lebenslauf}

Name:

Geburtsdatum:

Geburtsort:

Staatsangehörigkeit:

Familienstand:

\section{Schulbildung:}

08/1976 - 07/1980

08/1980 - 07/1986

Berufsausbildung:

08/1986 - 01/1990

\section{Berufstätigkeit:}

01/1990 - 07/1990

Schulbildung:

08/1990 - 06/1991

\section{Zivildienst:}

07/1991 - 09/1992

\section{Erststudium:}

09/1992 - 09/1995

\section{Zweitstudium:}

09/1995 - 10/1999

Diplomarbeit:

02/1998 - 10/1999
Arne Gennerich

14. Juli 1970

Uslar

Deutsch

ledig

Grundschule, Gleichen-Bremke

Georg-Christoph-Lichtenberg Gesamtschule Göttingen, Erweiterter Sekundarstufe I Abschluss

Ausbildung zum Nachrichtengerätemechaniker und Feingeräteelektroniker am Max-Planck-Institut (MPI) für biophysikalische Chemie in Göttingen

Elektroniker am MPI für biophysikalische Chemie in Göttingen

Fachhochschulreife, Berufsbildende Schule II in Göttingen

Universitätsklinik Göttingen

Studium der Elektrotechnik, Fachrichtung Nachrichtentechnik mit Schwerpunkt Nachrichtenverarbeitung an der Fachhochschule Braunschweig/Wolfenbüttel

Studium der Physik an der Georg-August-Universität zu Göttingen

III. Physikalisches Institut und Physiologisches Institut der Universität Göttingen 


\section{Dissertation:}

11/1999 - 10/2003 Physiologisches Institut, Abteilung Molekulare Neurophysiologie, Universität Göttingen (Prof. Dr. Dr. Detlev Schild)

10/2001 - 10/2003 Stipendiat und Koordinator des Graduiertenkollegs GRK723

„Raumzeitliche Signalprozesse in Neuronen und zelluläre

Biophysik“(Direktor: Prof. Dr. Dr. D. Schild) 